\title{
Cellular mechanisms of acquired torsades de pointes in the hypertrophied canine heart : the substrate and the trigger
}

Citation for published version (APA):

Volders, P. G. (1999). Cellular mechanisms of acquired torsades de pointes in the hypertrophied canine heart : the substrate and the trigger. [Doctoral Thesis, Maastricht University]. Universiteit Maastricht. https://doi.org/10.26481/dis.19990702pv

Document status and date:

Published: 01/01/1999

DOI:

10.26481/dis.19990702pv

Document Version:

Publisher's PDF, also known as Version of record

Please check the document version of this publication:

- A submitted manuscript is the version of the article upon submission and before peer-review. There can be important differences between the submitted version and the official published version of record.

People interested in the research are advised to contact the author for the final version of the publication, or visit the DOI to the publisher's website.

- The final author version and the galley proof are versions of the publication after peer review.

- The final published version features the final layout of the paper including the volume, issue and page numbers.

Link to publication

\footnotetext{
General rights rights.

- You may freely distribute the URL identifying the publication in the public portal. please follow below link for the End User Agreement:

www.umlib.nl/taverne-license

Take down policy

If you believe that this document breaches copyright please contact us at:

repository@maastrichtuniversity.nl

providing details and we will investigate your claim.
}

Copyright and moral rights for the publications made accessible in the public portal are retained by the authors and/or other copyright owners and it is a condition of accessing publications that users recognise and abide by the legal requirements associated with these

- Users may download and print one copy of any publication from the public portal for the purpose of private study or research.

- You may not further distribute the material or use it for any profit-making activity or commercial gain

If the publication is distributed under the terms of Article $25 \mathrm{fa}$ of the Dutch Copyright Act, indicated by the "Taverne" license above, 
Cellular Mechanisms of Acquired Torsades

de Pointes in the Hypertrophied Canine Heart 
(C) Paul G.A. Volders, Mastricht 1999

ISBN 9052782490

Omslag illustratie: Claudia Volders (olieverfschiderij, $50 \times 40 \mathrm{~cm}, 1999$ )

Vormgeving en druk: Datawyse I Universitaire Pers Maastricht 


\title{
Cellular Mechanisms of Acquired Torsades de Pointes in the Hypertrophied Canine Heart The Substrate and the Trigger
}

\author{
PROEFSCHRIFT \\ ter verkrijging van de graad van doctor \\ aan de Universiteit Maastricht, \\ op gezag van de Rector Magnificus, \\ Prof. dr. A.C. Nieuwenhuijzen Kruseman, \\ volgens het besluit van het College van Decanen. \\ in het openbaar te verdedigen \\ op vrijdag 2 juli 1999 om 10.00 uur \\ door \\ Paul Gertrudis Alphonsus Volders \\ geboren te Heerlen
}


Promator:

Prof. dr. H.J.J. Wellens

Co-promotares:

Dr. M.A. Vos

Dr. K.R. Sipido (Katholieke Universiteir Leuven, Belgiè)

Bevordelingscommissie:

Prof. dr. M.].A.P. Daemen (voorzitter)

Prof. dr. M.A. Allessie

Prof. dr. C. Antzelevitch (Masonic Medical Research Laboratory, Utica, NY, USA)

Prof. dr. D.J. Beuckelmann (University of Cologne, Germany)

Prof. dr. M. Borgers

Financial support by the Netherlands Heart Foundation and the Stichting RESCAR Maastricht for the publication of this thesis is gratefully acknowledged.

Additional support was granted by: Astra Pharmaceutica B.V., Bakken Research Center B.V., BardBenelux N.V., Guidant B.V., Pfizer B.V., Roche Nederland B.V., Sanofi B.V., St. Jude Medical Nederland B.V., Synthélabo Pharma B.V., Tramedico B.V., Vitatron Medical B.V. 
Dankzif mijn vader en moeder Voor lija en? 



\section{Content}

CHAPTER 1

9 Introduction

CHAPTER 2

31 Repolarizing $\mathrm{K}^{*}$ Currents $\mathrm{I}_{\mathrm{TO}}$ and $\mathrm{I}_{\mathrm{K}_{\mathrm{s}}}$ Are Larger in Right than Left Canine Ventricular Midmyocardium - Paul G.A. Volders, MD; Karin R. Sipido, MD, PhD; Edward Carmeliet, MD, PhD; Roel L.H.M.G. Spätjens, BS; Hein I.J. Wellens, MD. PhD; Marc A. Vos, PhD-Published in Circulation. 1999;99:206-210.

\section{CHAPTER 3}

41 Cellular Basis of Biventricular Hypertrophy and Arrhythmogenesis in Dogs with Chronic Complete Atrioventricular Block and Acquired Torsade de Pointes - Paul G.A. Volders, MD; Karin R. Sipido, MD, PhD; Marc A. Vos, PhD; Attila Kulcsar, PhD; S. Cora Verduyn, PhD; Hein J.J. Wellens, MD, PhD-Published in Circulation. 1998:98:1136-1147.

\section{CHAPTER 4}

65 Downregulation of Delayed Rectifier K+ Current in Dogs with Chronic Complete Atrioventricular Block and Acquired Torsades de Pointes-Paul G.A. Volders, MD; Karin R. Sipido, MD, PhD; Marc A. Vos, PhD; Roel L. H.M.G. Spätjens, BS; Jet D.M. Leunissen-Beekman, BS; Edward Carmeliet, MD, PhD; Hein J.J. Wellens, MD, PhD-Accepted for Circulation. 1999.

\section{CHAPTER 5}

85 Functional Upregulation of $\mathrm{Na}^{+}-\mathrm{Ca}^{2+}$ Exchange in Cardiac Hypertrophy May Contribute to Contractile Adaptation, But Also to Arthythmogenesis - Karin R. Sipido, MD. PhD; Paul G.A. Volders, MD; S.H. Marieke de Groot, MD, PhD; Mirella M.C. Molenschot, MS; Frans J. Van de Werf, MD, PhD; Hein J.J. Wellens, MD, PhD; Marc A. Vos, PhD. Manuscript submitted. 1999.

\section{CHAPTER 6}

109 Similarities Between Early and Delayed Afterdepolarizations Induced by Isoproterenol in Canine Ventricular Myocytes - Paul G.A. Volders, MD; Attila Kulcsár, PhD; Marc A. Vos, PhD; Karin R. Sipido, MD, PhD; Hein I.J. Wellens, MD, PhD; Ralph Lazzara, MD; Bela Szabo, MD, PhD-Published in Cardiovasc Res. 1997:34:348-359. 
CHAPTEP?

133 General Discussion Part I: Altered Electrical Properties in the Dog with Chronic Complete Atrioventricular Block: The Substrate and the Trigger for Torsades de Pointes

CHAPTER 8

145 General Discussion Part 11: Progress in the Understanding of Cardiac Afterdepolarizations and Torsades de Pointes: Time to Revise Current Concepts

185 Summary

189 Samenvatting

193 Dankwoord

197 Curriculum Vitae

199 Publications 
Chapter 1

\section{Introduction}

\section{Content}

1.1 Sudden Cardiac Death and the Long-QT Syndromes

1.2 Historical Rematks on Torsades de Poimtes Congenital Versus Acquired Long-QT Syndromes

1.3 Cellular Basis of Ventricular Repolarization

1.4 Aims of This Thesis. The Substrate and the rigger

1.5 The Dog with Chronic Complete Atroventricular Block

1.6 Methods

1.7 References 


\subsection{Sudden Cardiac Death and the Long-QT Syndromes}

Despite significant breakthroughs in cardiovascular medicine in the last decades, diseases of the heart and wessels, including stroke, continue to clam a high morbidity and death toll in the Western world. In the United Stares they account for $42 \%$ of all deachs (45,5,000 men and 505,000 women in 1995), exceeding by far the mortalicy from any other disease. 1,2 Although the incidence of cononary artery disease as a primary cause of mortality has gradually declined since the 1960 s, a comparison of mortality data from 1973 and 1993 reveals that this decline is most apparent in the young and middle aged. Significant improvements in acute treatment and secondary prevention programs ate the main reasons that these patients live longer after a heart attack or stroke, or after being diagnosed with hypertension, but this has only postponed the cardiovascular mortality with a few years. ${ }^{2}$ The resultan growing number of patients with congestive heart failure puts a burden on health-care facilities in 1999 and has farreaching consequences for the aext century.

Often the first manifestation of cardiovascular disease is sudden death. Sudden cardiac death is responsible for 300,000 to 400,000 victims per year in the United States. ${ }^{3}$ In the Mastricht area, with approximately 182,000 inhabitants, the overall yearly incidence of out-of-hospital sudden cardiac arrest (death rate $93 \%$ ) in the age of 20 to 75 years is 1 per 1000 people. ${ }^{4}$ Over $90 \%$ of the fatalities occur in patients with known or previously un recognized coronary artery disease or cardiomyopathies. In the remaining 5 to $10 \%$ no evidence of structural heart disease can be found. 5

Cardiac arrhythmias are a frequent cause of sudden death. In a study of parients. who had died suddenly and in which the cause of death was arrhythmic (as evident from Holter-recordings), ventricular tachyarthythmias were the terminal event in $83 \%$ of the cases, whereas bradyarrhythmias occurred in $17 \% .6$ Three forms of rachyarrhythmias were distinguished: (1) primary ventricular fibrillation $(10 \%$ of the $83 \%)$; (2) ventricular tachycardia or hutter precipitating ventricular fibrillation (75\%); and (3) torsades de pointes (15\%). ${ }^{6}$ Fortunately, most often, ventricular arthythmias have less detrimental consequences. Depending on the type and nature of these rhythm perturbations, some patients have no symptoms at all, whereas others experience palpitations, dizziness, lightheadedness, presyncope or syncope.

This thesis deals with the basic electrophysiological mechanisms of a lifethreatening ventricular arthythmia called "torades de pointes" (Figure 1). On the electrocardiogram, torsades de pointes appears as a polymorphic tachycardia characterized by a distinctive partern of undulating peaks of sequential QRS complexes and $T$ waves (by definition $\geq 5$ bears) that twist around the baseline. ${ }^{7}$ The arthythmia varies in duration, lasting several scconds to minutes. It can srop spontaneously, change inio a more monomorphic tachycardia, or degenerate into ventricular fibrillation thus leading to sudden death. Patients suffering and surviving from torsades de pointes describe sensations that range from mild discomfort to loss of consciousness. Torsades de pointes typically occurs in hearts characterized electrocardiographically by excessive QT prolongation and 


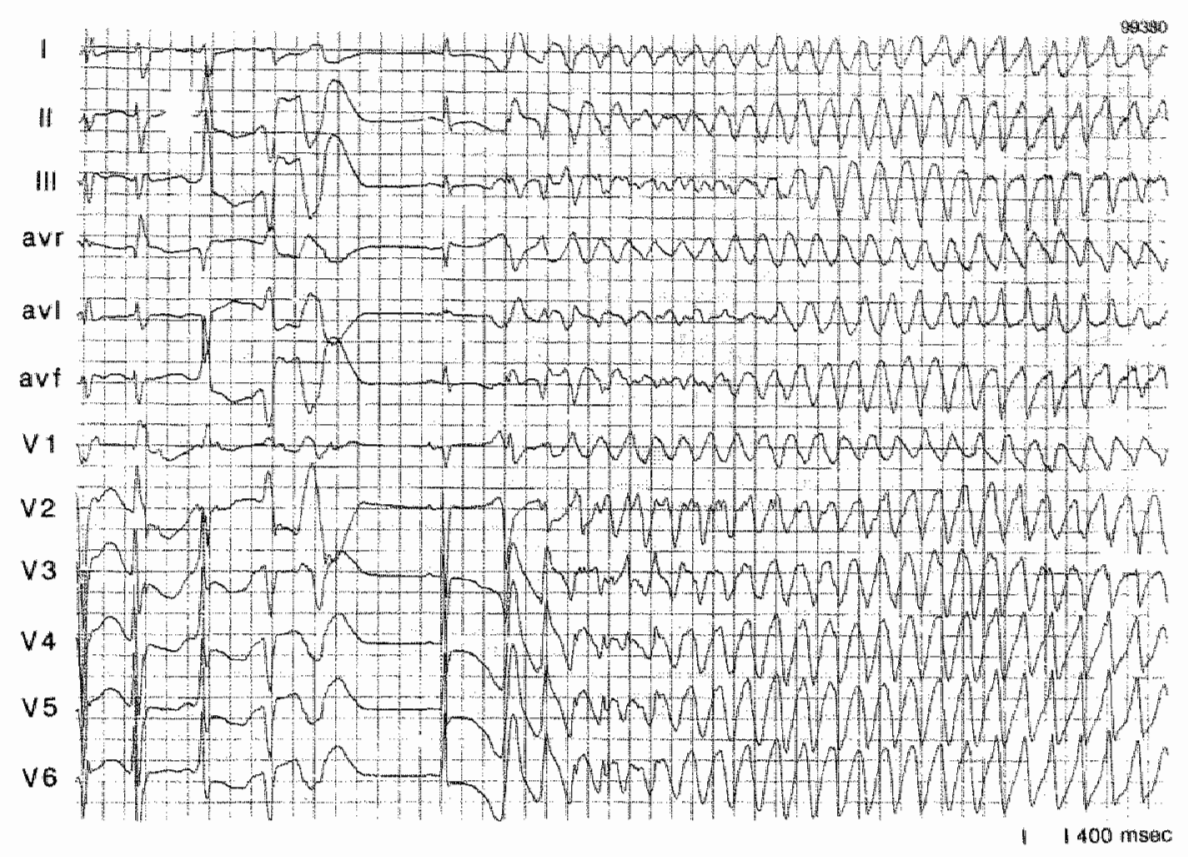

Figure 1. - Representative example of acquired torsades de pointes in a 66-year old female patient, who was given ibutilide intravenously to terminate an episode of atrial fibrillation. As shown, the arrhythmia develloped in the setting of sinus rhythm and a prolonged QT interval, and is preceded by a short-long-short RR interval. Courtesy of Dirk W. Donker, MD (Department of Cardiology. Academic Hospital Maastricht).

T-wave abnormalities, in the absence of changes of the QRS complex. Collectively, these states are called the "long-QT'syndromes'. The long-QT syndromes are congenital or acquired in nature.

The congenital long-QT syndromes are a unique group of functional cardiac repolarization disorders with the following common characteristics: (1) abnormal prolongation of the electrocardiographic QT interval due to the inherited malfunctioning of ion channels in the cardiac myocytes; plus (2) increased susceptibility to torsades de pointes.

The acquired long-QT syndromes can be broadly defined as a heterogeneous group of cardiac repolarization disorders with the following common characteristics: (1) the development of abnormal prolongation of the electrocardiographic QT interval after exposure to parhophysiological and/or pharmacological influences in previously normal myocardium; plus (2) increased susceptibility to polymorphic ventricular arrhythmias, notably torsades de pointes. A typical example of acquired torsades de pointes is shown in Figure 1.

The incidence of the congenital long-QT syndrome in the general population is low. In the International Long-QT Syndrome Registry, ${ }^{8-10}$ the number of enrolled 
symptomatic and asymptomatic family members with a confirmed diagnosis is approaching 10,000 worldwide. Most probably, the true incidence is much higher in various regions than suggested by this figure. Cases have been diagnosed in every continent and race. The overall male-to-female ratio of involvement is $31: 69$, indicating a clear female predominance. "The incidence of the acquired long-QT syndromes is much harder to estimate due to the multiple etiology. Undoubtedly, acquired forms of the long-QT syndrome are much more common than the congenital type. In the Department of Cardiology at the Academic Hospital Maastricht with 3300 clinical admissions per year, the number of admissions due to acquired rorsades de pointes is estimated at approximarely 10 per year (Dr. A.P.M. Gorgels, personal communication).

Several aspects make the long-QT syndrome a very interesting disease. First of all, the occurrence of syncope and sudden dearh are dramatic manifestations having a major impact on parient and families. Secondly, the syndrome is a Rosetta stone for the mechanisms by which modulation of the autonomic nervous system enhances or prevents ventricular tachyarrhythmias and sudden cardiac death. ${ }^{12}$ Thirdly, it is the prime example of how molecular biology, and ion-channel, cellular, and organ physiology can cooperate in unraveling a serious clinical problem.

\subsection{Historical Remarks on Torsades de Pointes: Congenital Versus Acquired Long-QT Syndromes}

\section{Congenital Long-QT Syndromes}

Probably the first report on torsades de pointes in the medical literature stems from 1856. Meissner ${ }^{13}$ described a congenitally deaf girl who collapsed and died while being rebuked in public. Two siblings of the girl had previously died suddenly during emotional stress. More than 100 years later congenital deaf-mutism combined with syncope or sudden death during exercise or emotion was linked to functional heart discase characterized by pronounced prolongation of the QT interval. ${ }^{14}$ In a landmark arricle, Drs. Jervell and Lange-Nielsen ${ }^{14}$ stated that 'The woustat clinical symptoms, the exceptional electrocardiographic findings, and the serious outcome of the illness, together, represent a characteristic syndrome ...' later to become known as the Jervell-LangeNiclsen long-QT syndrome. In 1963 and 1964, Romano er all5,16 and Ward ${ }^{17}$ reported independently that inherited QT prolongation and ventricular arrhythmias cam also exist without deafness. It is now known that this type is the most frequently encountered congenital long-QT syndrome with an autosomal dominant mode of inheritance, whereas the Jervell-Lange-Nielsen type inherits by autosomal recessive mode. ${ }^{10,18}$ In 1970, Garza et al ${ }^{19}$ described another case of the Romano-Ward syndrome. A comatose 3-year-old boy was admitted to the hospital with "a syndrome of prolonged Q-T internal, potentially fatal episodes of ventricular arthythmas, and nomal bearing'. A brother and the mother of this patient had previously experienced multiple syncopes themselves during moments of vigorous exercise. The authors endeavored to 
perform physiological investigations on the irreversibly brain-damaged boy in their search for an arrhythmia prophylaxis for the brother and mother. The responses to epinephrine, phenylephrine, isoproterenol and propanolol indicated a strong adrenergic dependence of the torsades de pointes in the young patient and led to a tailored, successful treatment of his relatives with propranolol. ${ }^{19}$ This concept was advanced for its time and was partly derived from the experimental studies by Yanowitz and associates, ${ }^{20}$ who had measured changes of the electrocardiogram and the ventricular refractory period following al terations of the sympathetic tone in dogs. Right-stellate ganglionectomy or left-stellate stimulation produced QT prolongation and increased T-wave amplitudes, whereas right-stellate stimulation or left-stellate ganglionectomy accentuated T-wave negativity without measurable changes of the QT interval. ${ }^{20}$ Soon thereafter, a case report in the New England Joumal of Medicine proved the clinical applicability of leftstellate ganglionectomy for the antiarrhythmic treatment of the congenital long-QT syndrome and it was hypothesized that an "endogenous sympathetic-nerve imbalance" could explain part of the etiology ("sympathetic-imbalance bypothesis"). ${ }^{21}$ Wellens et al ${ }^{22}$ deserve credit for proposing an additional, more intracardiac, mechanism of proarrhyrhmia. In 1972, they described a patient with syncopal attacks due to torsades de pointes on being awakened from sleep by auditory stimuli (thunderclap, alarm clock, falling bedpan, rock-and-roll music). In this famous case of, what was most likely, the Romano-Ward syndrome, the authors investigated whether increased asynchrony in refractoriness of different areas of the ventricles could predispose to the arrhythmic activity. Although no direct evidence for this could be found during electrical stimulation of the heart, the authors realized that '... this does not exchude the possibility that ... asynchrowy in refractoriness of ventricular muscle was present between subendacardial and subepicardial layers, nor that this occurred following neural stimulation or during the first beats following sudden changes in heart rate. ${ }^{22}$ Wellens et al also showed that the arrhythmia could be completely prevented by the $\beta$-blocking drug propanolol. ${ }^{22}$

Around the same time another cause for arrhythmias was reported when under experimental conditions afterdepolarizations were found to be responsibie for abnormal impulse generation in myocarclial tissue preparations. ${ }^{23,24} \mathrm{~A}$ putative proarthythmic role for afterdepolarizations in the congenital long- $Q T$ syndrome was investigated by Schechter et al. ${ }^{25}$ In a 23 -year-old female patient, they recorded electrograms from the ventricular endocarclium during emotional upser and epinephrine infusion. At various sites in the left and right ventricle, prominent diastolic humps on the electrogram, which occurred after the electrocardiographic $T$ wave, were observed at baseline and became more accentuated during adrenergic stimulation. Termination of the epinephrine infusion together with the administration of diazepam attenuated the potenthals. Based on these clinical observations and extrapolation from cellular electrophysiological events, adrenergic-induced afterdepolatizations were taken to be involved, at least partly, in the generation of ventricular ectopic beats and the initiation of torsades de pointes. ${ }^{25}$ Many subsequent studies with monophasic-action-potential recordings confirmed this hypothesis (eg, References 26 through 30). It was in 1975 
when Schwartz and Malliani ${ }^{31}$ identified alrernans of the T wave as a second electrocardiographic characteristic of the long-QT syndrome. They made this observation in a 9-year-old symptomatic girl and were able to reproduce it in anesthetized cats during umilateral left-stellaté-ganglion stimulation. ${ }^{31}$ In these years, the call for an international registry for the congenital long-QT syndrome intensified and in 1979 Drs. Moss, Crampton and Schwartz launched a prospective study to define (1) the natural history of the disease in asympromatic patients with prolonged $Q T$ intervals not receiving therapy, (2) the long-term efficacy of therapy in symptomatic patients, and (3) epidemiological and genetic characteristics. ${ }^{8}$ The registry, expected to last 25 years, enrolled more than 728 famillies thus far ${ }^{10}$ and served as the database for many important publications. A major breakthrough came in 1991, when Keating et a $\left.\right|^{32}$ demonstrated linkage of the long-QT" syndrome to the Harvey ras-1 gene on the short arm of chromosome 11 in a large family. In 1994, Towbin et a ${ }^{33}$ confirmed this for 15 of 23 families, whereas in 4 families linkage to the Harvey ras-1 gene was definitively excluded. Thus, conclusive evidence for genetic heterogeneity in the long-QT syndrome was found. These studies provided a second hypothesis on the pathogenesis of the syndrome: "the intracardiac-abnormality bypothesis', in which defecrive ionic currents in ventricular cells are the cause of a low repolarization reserve leading to QT prolongation and $\mathrm{T}$ wave alternans. Since the start of this $\mathrm{PhD}$ project in 1993, 5 loci have been associated with the Romano-Ward syndrome through generic studies worldwide and they are located on the chromosomes $3,4,7,11$, and 21.18 Four disease genes, each encoding an ion-channel protein, could be identified: KoLQTI encoding the $\alpha$ subunit of the $\mathrm{I}_{\mathrm{KS} \text { - }}$-channel protein (chromosome 11 ; LQT"1) ${ }^{34}$; HERG encoding the $\mathrm{I}_{\mathrm{Kr}}$-channel protein (chromosome 7; LQT 2) ${ }^{35}$; $S C N 5$ A encoding the cardiac $\mathrm{Na}^{+}$channel (chromosome $\left.3: \mathrm{LQT}^{3}\right)^{36}$, and $K C N E$ I encoding min $K$, the ancillary subunit of the $\mathrm{I}_{\mathrm{Ks}}$-channel complex (chromosome 21; LQT5) ${ }^{37}$. The gene at the chromosome-4 locus (LQT4) has not yer been identified. The reader is referred to Figures 2 and 3 for an outline of the funcrional relevance of these ionic currents for the ventricular action potential. Determination of the genotypes of 541 members of 38 families of the International Long-QT Syndrome Registry revealed that 12 had mutations at the LQT1 locus, 72 had mutations at the LQT 2 locus and 62 had mutations ar che LQT 3 locus, ${ }^{10}$ making LQT 1 the most frequently encountered form. The other 295 members were either not affected or their genorype could not be clarified. Reports on new mutations at these loci appear in the literature almost every month. A final aspect is that ventricular wall motion abnormaliries have been observed in parients with the congenital long-QT syndrome during echocardiography and these can be abolished with $\mathrm{Ca}^{2+}$-channel blockers. ${ }^{38}$ 


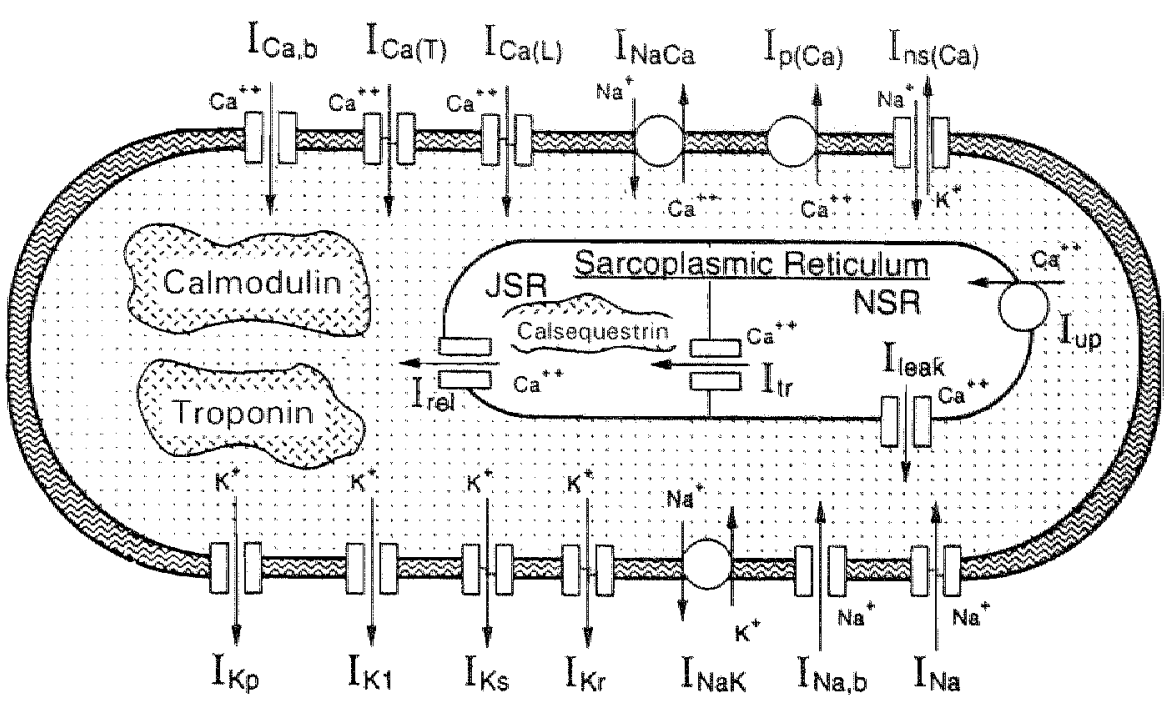

Figure 2. - Schematic diagram of the Luo-Rudy guinea-pig wentricular cell model, ${ }^{77}$ showing the sarcolemmal ionic currents and intracellular ionic fluxes that are relevant for the action potentiall.

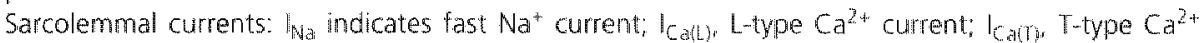
current; $\mathrm{K}_{\mathrm{K} \text { : }}$ rapidly activating component of the delayed rectifier $\mathrm{K}^{+}$current; $\mathrm{K}_{\mathrm{ks}}$ slowly activating component of the delayed rectifier $K^{+}$current; $l_{k \text {, }}$, inward rectifier $K^{+}$current: $l_{k p}$ " plateau $K^{*}$ current:

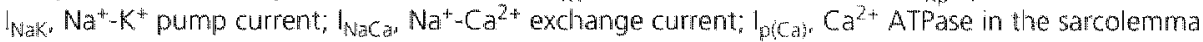

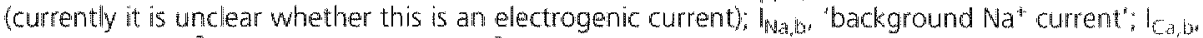

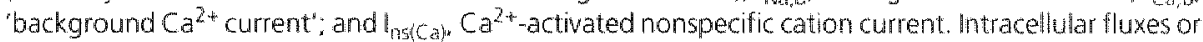
delays (these are not electrogenic currents): $l_{\text {up }}$ indicates $\mathrm{Ca}^{2+}$. ATPase for uptake of $\mathrm{Ca}^{2+}$ into the network sarcoplasmic reticulum (NSR): $I_{\text {rel }}, C^{2+}$ release from the junctional sarcoplasmic reticulum

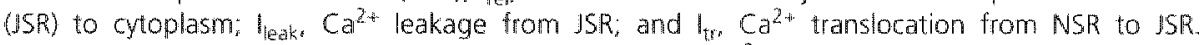
Calmodulin, troponin and calsequestrin are intracellular Ca ${ }^{2+}$ buffers. Not on this diagram, but

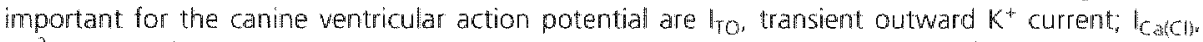
$\mathrm{Ca}^{2+}$-activated $\mathrm{Cl}$ current: $I_{\mathrm{K} \text { Ad h }}$ acetycholine-sensitive $\mathrm{K}^{+*}$ current. Courtesy of Yoram Rudy, PhD (Department of Biomedical Engineering. Case Westem Reserve University, Cleveland, Ohic, USA). Reproduced with permission of the American Heart Associationdid.

\section{Acquired Long-QT Syndromes}

Initial studies on acquired forms of the long-QT syndrome appeared in the literature in the 1920 s and $1930 \mathrm{~s} .{ }^{39-42}$ It is remarkable to find, and parricularly interesting for the scope of this thesis, that in almost every case these were reports on patients with atrioventricular block ('aturiculoventricular dissociation'). An active person in this field was Dr. Sidney P. Schwartz from the Montefiore Hospical in New York Ciry, who elaborated on the clinical and electrocardiographic characteristics of what was called "transient ventricular frbrillation" at that time. In 1934, Schwartz and Jezer ${ }^{43}$ criticized other specialists for their supposed therapeutical administration of quinine and quinidine to patients with atrioventricular block and transienr ventricular fibrillarion, because this was 'based on very meager clinical experience' and would be rather pro- than 


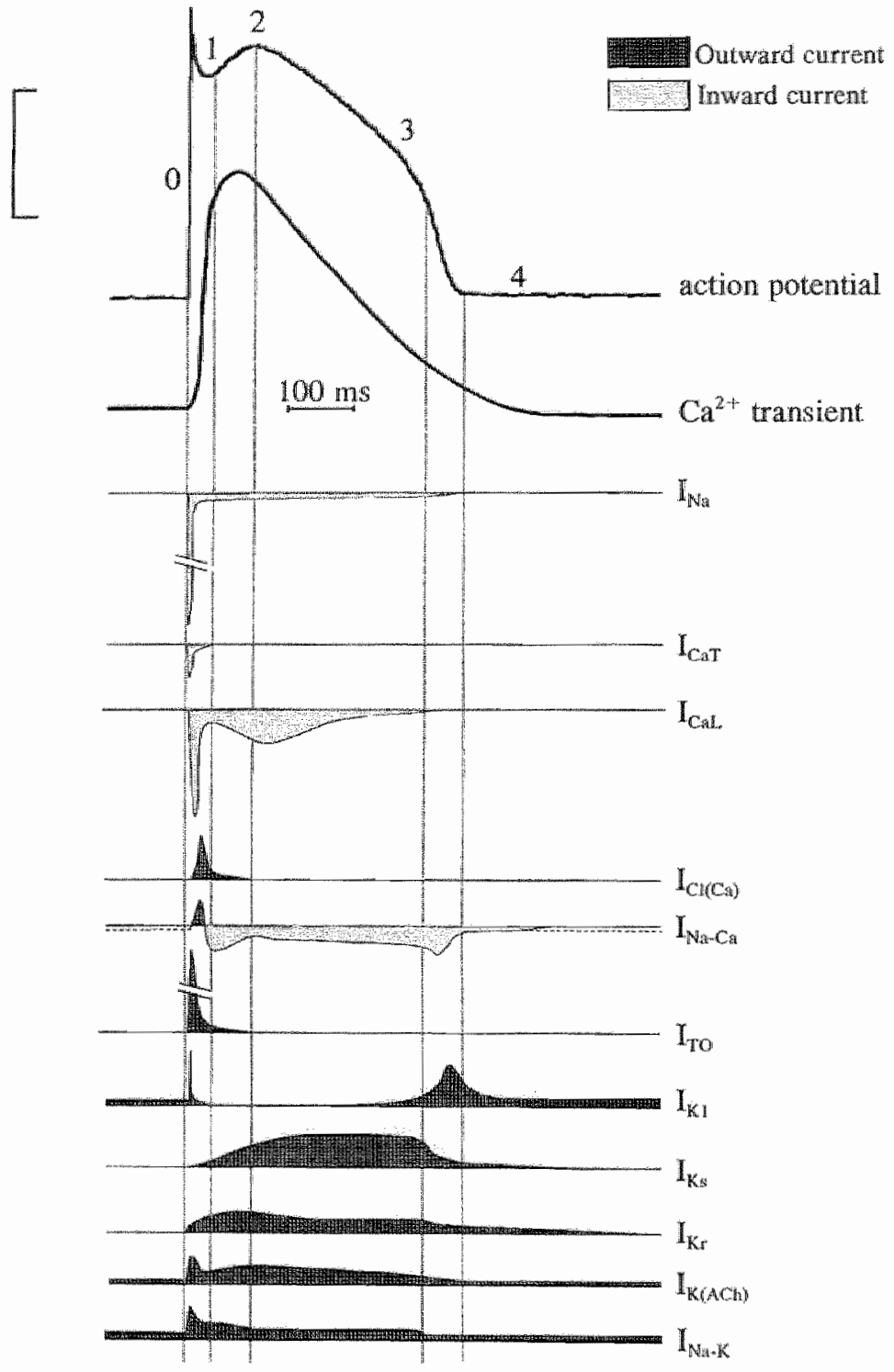

Figure 3. - Schematic representation of inward and outward ionic currents involved in the canine ventricular action potential, resting membrane potential and cytoplasmic $\mathrm{Ca}^{2+}$ transient under control conditions.

The numbers 0 through 4 indicate the different phases of the spike-and-dome action potential: 0 , upstroke; 1 , fast early repolarization phase with notch; 2 , plateau phase; 3 , repolarization phase; 4 , resting membrane potential. The relative contribution of each of the currents varies depending on the physiological conditions. The approximate time courses are shown symbolically. The current amplitudes are not to scale. For legends to the currents denotation see Figure 3. Vertical scale bar left to action potential indicates 0 to $-50 \mathrm{mV}$. Vertical thin dashed lines through whole figure refer to 4 time points in the action potential. Adapted from references 55,56, and 78 through 92 . 
antiarhythmic. To make their point, the authors injected quinine and quinidine into two pacients and, unfortuitously, both collapsed from torsades-like arrhythmias. It was judged that "the use of such dngs by this method is contraindicated in such parients". In a later paper, Schwartz ${ }^{2}$ described 6 patients with recurrent syncopal antacks due to torsades-like tachycardias, however now in the absence of drugs. These patients were admitted with second or third degree atrioventricular block of unrevealed cause, and had very low ventricular rates (the average bastic ventricular rate was 25 beats per wivute without the interposition of prematwe ventricular beats'), and long QT intervals. The term 'prefibrillatory mechanism' was used to denominate the alterations in heart thythm that preceded the arrhythmias in all 6 patients. "When the heart rate has thw been accelexated gradually to a certain level of speed, it then suddenly intermpted by at first single and then recurrent groups of ventricular oscillations of wide aberancy that berald the approach of a period of wentricular fibrillation'. 22 It was learned that 'exminsic nerves' had a major influence on the arrhyrhmia initiation and in 1950 Schwartz and de Sola Pool ${ }^{44}$ published on the effects of bodily rest, atropine and exercise on transient ventricular fibrillation. 'One patient ... had' experienced several seizures of mansient ventricular fibrillation following the type of exertion associated with "straining at stool" or when walking watly up an incline'. This was in line with a previous report by Dock, ${ }^{40}$ who observed such seizures in a patient after injection of epinephrine. In 1966 the term "transient ventricular fibrillation' was definirively replaced by "torsades de pointes'. Dr. Dessertenne of the Hôpital Lariboisière in Paris coined this expression after observing the 'electrocardiogramme en crise of an 80-year-old lady with heart failure, complete atrioventricular block and frequent syncopal attacks. Interestingly, when the patient was administered potassium chloride and put at rest, she was symptomless for three days. In the view of Dessertenne, torsades de pointes was the rwisting of two opposing foci of electrical activity in the ventricles and was distinguishable from ventricular fibrillation, although che torsades could end so. ${ }^{7}$ In the years that followed, and until this moment, a vast number of case reports and clinical studies on acquired torsades de pointes highlighted the notion that not only the condition of chronic atrioventricular block, but also various other parhophysiological and pharmacological influences, including antiarthythmic and non-candiovascular drugs, predispose to the arrhythmia. For excellent comprehensive reviews we refer to Jackman et al. $26,45,46$ The awareness of at poor basic electrophysiological understanding of torsades de pointes prompted the development of surrogate models of the long-QT syndromes. In 1983, Brachmann et all ${ }^{47}$ proposed the use of intravenous cesium chloride for the in-vivo and in-vitro study of 'bradycardia-dependent muliform ventricular tachycardia' in anesthetized dogs. These imvestigators invoked an important rolle for prolonged repolarization and afterdepolarization-dependent triggered activity in the initiation and maintenance of the tachycardia. Subsequently, in various other models, torsades de pointes was induced by class-Ia or class-III antiarrhythmic agents, or other substances with related actions. ${ }^{48} \mathrm{~A}$ great advantage of these animal models was the opportunity to study the cellular and ionic basis of in-wivo arthythmias in isolated cardiac tissues and myocytes. 
One additional matter deserves mentioning. Ventricular arrhythmias and sudden cardiac death are major concerns in the clinical management of cardiac hypertrophy and failure ${ }^{49,50}$ In contemporary discussions on the mechanisms of arrhythmias in these condirions, an important role is attributed to action-potential prolongation and increased regional dispersion of repolarization. ${ }^{51}$ The findings of QT-interval and repolarization labilities in parients with ischemic and nonischemic dilated cardiomyopathy, ${ }^{52,53}$ and other cardiac disorders with hypertrophy or failure, raises the question whether also here the substrate for arrhythmias is related, at least partly, to a lower repolarization reserve in the myocardial cells. Alterations in $\mathrm{K}^{*}$ currents have indeed been observed in such patients, ${ }^{54}$ and similar ionic changes occur in many experimental animal models with hypertrophy or failure of the heart. ${ }^{55}$ Although the long-QT syndromes and the cardiomyoparhies of overload are clearly distinctive clinical entities, mechanistic understanding of their common endpoints of excessive QT prolongation and $\mathrm{T}$-wave abnormalities warrants similar basic electrophysiological studies.

\subsection{Cellular Basis of Ventricular Repolarization}

The ionic mechanisms responsible for the repolarization of single ventricular cells are illustrared in Figures 2 and 3 . In the spike-and-dome acrion potential of the epiand midmyocardium of the dog, the experimental animal of this thesis, a large transient outward current thas been held responsible for the phase-1 repolarization (causing the typical notch; see Figure 3). This current is composed of a 4 -aminopyridine-sensitive component $\left(\mathrm{I}_{\mathrm{TO}}\right.$, also designated $\left.\mathrm{I}_{\mathrm{TO} 1}\right)$ and a $\mathrm{Ca}^{2+}$-activated $\mathrm{Cl}^{-}$current $\left(\mathrm{I}_{\mathrm{Ca}(\mathrm{Cl})}\right)$. During the plateau phase (phase 2), there is a delicate balance of inward and ourward currents. Inward currents can be carried through the $\mathrm{Na}^{+}$channel, the $\mathrm{Ca}^{2+}$ channels, and the $\mathrm{Na}^{+}-\mathrm{Ca}^{2+}$ exchanger. Outward currents during the plateau are carried by a number of $\mathrm{K}^{*}$ channels, a Cl channel, and the $\mathrm{Na}^{+}-\mathrm{K}^{+}$pump. For the initiation of phase 3 of the action potential, the contributions of rapidly and slowly activating delayed rectifier $\mathrm{K}^{*}$ currents are of key importance. Furthermore, the $\mathrm{Nat}^{+}-\mathrm{K}^{\prime \prime}$-pump current and the inward-rectifier $\mathrm{K}^{+}$curtent are important participants. An acetylcholine-sensitive $\mathrm{K}^{\text {* }}$ current is allso active. ${ }^{56}$ The stable resting membrane potential is maintained by the inward-rectifier $\mathrm{K}^{+}$current, $\mathrm{Na}^{+}-\mathrm{K}^{+}$-pump current, acetylcholine-sensitive $\mathrm{K}^{+}$current and possibly also $\mathrm{Na}^{+}-\mathrm{Ca}^{2+}$-exchange current (depending on the intracellular $\mathrm{Na}^{+}$and $\mathrm{Ca}^{2+}$ concentrations).

Electrophysiological studies on sliced myocardial-rissue preparations and arreriallyw perfused wedges indicate that voltage gradients in the ventricles, generated by the joint action of the myocytes, play an important role in the genesis of the electrocardiographic $T$ wave. ${ }^{57}$ Regional differences in baseline clectrical properties and in responses to pharmacological and pathophysiological influences characterize the ventricular myocardium. Such differences are found in the transmural and apico-basal ventricular myocardium, in Purkinje fiber-versus-working myocyte comparisons, in 
the cransseptal myocardium, and in left-versus-right ventricular comparisons. The transmural myocardium is known for its prominent disparity of action-potential configuration and duration berween epicardial, nidmyocardial and endocardial layers. These three layers differ principally with respect to phase-1 and phase-3 repolarization characteristics. Whereas a prominenr norch shapes the typical spike and-dome action potential of the epicardium and midmyocardium, this feature is absent in the endocatdium. Another electrophysiological distincrion among the three layers is their actionpotentional duration (APD) .58 .59 In isolated rissue and single-cell studies, action potentials appeared to be longest in the midmyocardium, and APD prolongarion in response to slow pacing rares, class $1 a^{60}$ and class 111 agents ${ }^{6}$ was more pronounced in this layer than in either the epi-or endocardium. The longer APD of midmyocardial cells, versus epi- and endocardial myocytes, has been explained on the basis of a lesser contribution of the slowly activating component of the delayed rectifier $K^{+}$current $^{61}$ and possibly also because of a larger background $\mathrm{Na}^{*}$ current in the midmyocardial cells. The rapidy activating componen to the delayed recrifier $K^{+}$currentand the inward rectifier $\mathrm{K}^{+}$current are not different in the three layers. As mentioned earlier (section 1.2), the attenuation of either component of the delayed rectifier $\mathrm{K}^{*}$ current by pharmacological inhibition or congenital or acquired downregulation has major action-potencialprolonging consequences and can be associated with the generation of early afterdepolarizations or plateau arrests.

In recent investigations, Yan and Antzelevirch ${ }^{62}$ used an experimental setup in which transmembrane action potentials recorded from epi-, mid-and endocardial sites, as well as from Purkinje fibers could be temporally correlated with a transmural 'electrocardiogram'. Under baseline conditions the early repolarization of the epicardial action potential coincided with the peak of the $T$ wave, whereas the late repolarization of the midmyocardial action potential was temporally aligned with the ending of the $T$ wave. In acquired QT prolongation by hypokalemia, dl-sotalol or both, these gradients were accentuated due to the more pronounced response of the midmyocardium and rhey caused a marked increase of the peak-to-end interval of the $T$ wave. Often the $T$ wave showed a widened and bifurcated aspect, suggesting the presence of a pathophysiological U wave, but this was more likely the second componene of an interrupted $T$ wave. ${ }^{62}$ Patterns of prolonged and bifurcated T waves have long been known for clinical acquired and congenital long-QT syndromes. 63,64

\subsection{Aims of This Thesis: The Substrate and the Trigger}

Previous in-vivo investigations on acquired torsades de pointes by our group indicated that electrical remodeling in the wentricular myocardium of dogs with chronic complere atrioventricular block causes an enhanced susceptibility to the arthythmia (The Substwat). The propensity to abnomal impulse formation in this substrate is likewise enhanced and is related to carly and delayed afterdepolarizations (The Trig- 
ger $\left.^{3}\right)$. It was the aim of this thesis to investigate the cellular basis of the substrate and the trigger in dogs with chronic complete atrioventricular block and acquired torsades de pointes.

\subsection{The Dog with Chronic Complete Atrioventricular Block}

The dog with complete atrioventricular block has been used by various members of the Department of Cardiology in Maastricht since the beginning of the 1980s and is very suitable for the investigation of ventricular arrhythmias. Early studies were directed to the understanding of ventricular impulse formation during digitalis intoxication. ${ }^{65}$ Subsequently, the role of programmed electrical stimulation and antiarrhythmic drugs for the identification and trealment of delayed-afterdepolarizationdependent ventricular arrhythmias were highlightred. ${ }^{66}$ The administration of class-III antiarthythmic agents, alone or in combination with programmed electrical stimulation, appeared a very suitable means to induce acquired torsades de pointes in a reproducible manner in this model. ${ }^{67}$ The relarive importance of action-potential prolongation, increased dispersion of repolarization, early afterdepolarizations and multiple ventricular ectopic beats for the initiation and perpetuation of torsades de pointes were appreciated. ${ }^{68}$ Recently, it became clear that electrophysiological and funcrional adaptations in the chronic, hypertrophic phase of complete atrioventricular block predisposed to triggered activity, and that electromechanical and mechanoelectrical interactions were of prime importance for the arrhythmogenesis under dynamic conditions. ${ }^{69}$ The results of these lines of investigation were published in a number of articles (eg, References 67,70 and 71) and led to the hypothesis that the process of electrical remodeling, causing increased arrhythmogenesis in a few weeks time, is determined by changes in ion-channel function. This was the start of the present work.

\subsection{Methods}

Isolation of Single Canine Ventricular Myocytes

The cell preparations used for this thesis are based on the isolation procedure originally described for rat heart by Powell and Twist in 1976,72 and modified by the same ${ }^{73}$ and orher ${ }^{74-76}$ investigators afterwards.

In our laboratory, the hearts of anesthetized dogs are quickly excised and washed with cold, cardioplegic solution. One or two coronary arteries are rapidly cannulated to perfuse the tissue with cardioplegic solution, nominally $\mathrm{Ca}^{27}$-free standard-buffer solution and collagenase solution at low $\left[\mathrm{Ca}^{2+}\right](50 \mu \mathrm{mol} / \mathrm{L})$. These steps take approximately 40 minutes. After washout with enzyme-free low- $\left[\mathrm{Ca}^{2+}\right]$ solution, the tissue is perfused with standard-buffer solution at $1.8 \mathrm{mmol} / \mathrm{L}\left[\mathrm{Ca}^{2+}\right]$. Finally, the tissue is minced into suspension, filtered and washed several rimes. $\mathrm{Ca}^{2+}$-tolerant and electro- 


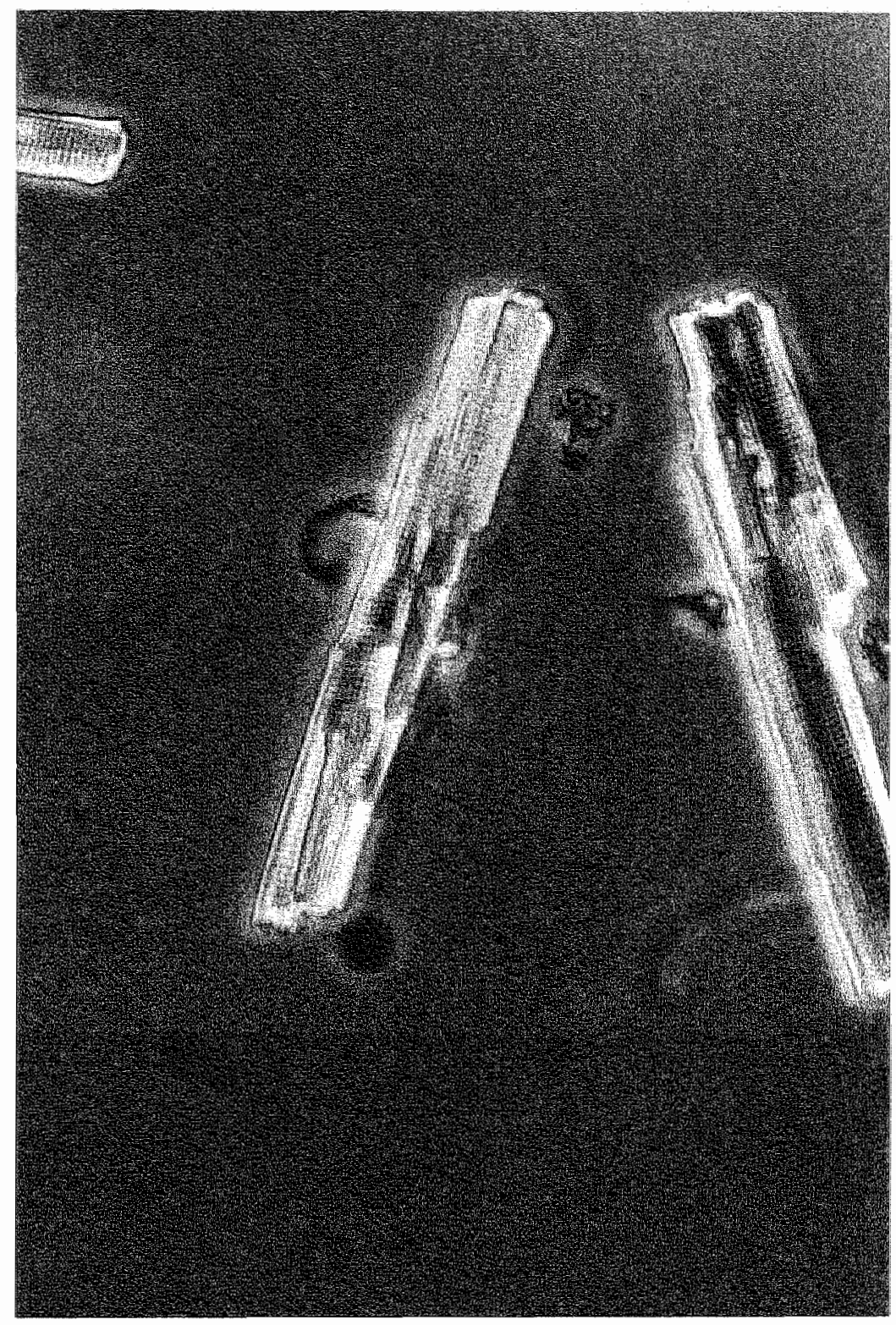

Figure 4. - Photomicrograph of enzymatically isolated myocytes from the left ventricle of a normal adult dog.

These are typical examples of the cells used for electrophysiological studies. They have clear rod-sheped contours, transparent cytoplasms, and marked striations. The myocyte in the center has a size of $170 \times 25 \mu \mathrm{m}$ (length $\times$ width). Magnification $\times 1000$. Courtesy of Jack P.M. Cleutjens, PhD and Mat I.A.P. Daemen, MO, PhD (Department of Pathology, Academic Hospital Madstricht). 


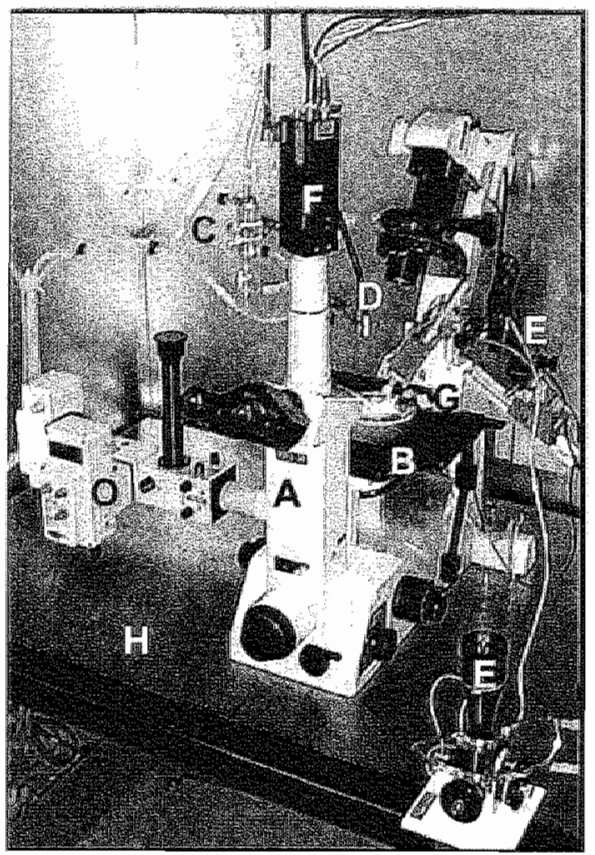

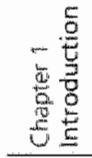

22

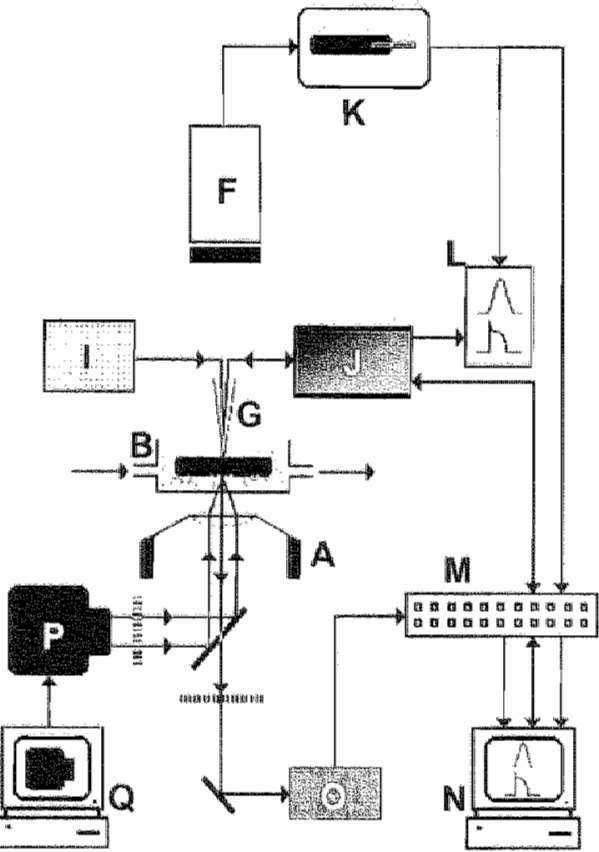

Figure 5. - Laboratory of cellular cardiac research in Maastricht.

The left panel is a schematic drawing of the assembly of the various components of the upper photographs. A indicates the inwerted fluorescence microscope; $B$, the microscope table with perfusion thamber for the myocytes: C. perfusion system with wateriacketed heat exchanger for inflow of superfusate to the chamber (B); $D$, fiber-optic light source: $E$. micromanipulators for coarse and frne positioning of the microelectrodes; $F$, video camera; $G$, heads tage (preamplifier) with holder and microelectrode; $H$, vibration-isolated work station: I stimulator: I, microelectrode amplifiers; $K$. wideo edgemotion detector: $L$. oscilloscope; $M$, analog-to-digital converter; $N$. computer with pCLAMPG sofware (Axon Instruments, inc for automated waveform control and data acquisition; 0 , photomutipliers; P, box with Kenonare lamp and monochromators; Q, computer with softwane for automated fillorescence wave-length control of monochromators. 


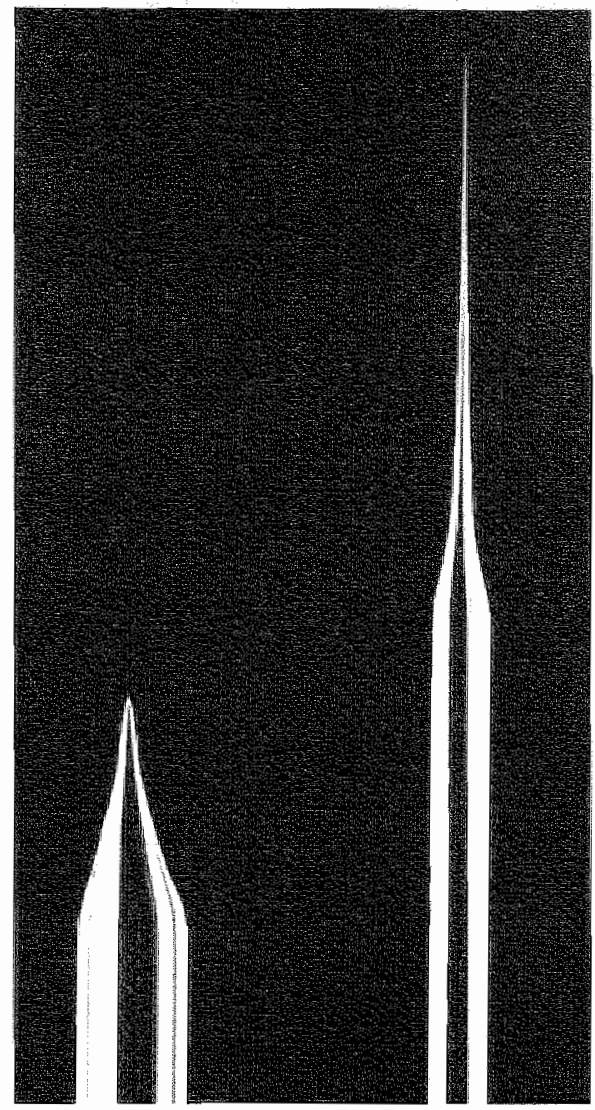

Figure 6. - Photomicrograph of glass micraelectrodes.

The "blunt" patch electrode (left ; borosilicalte glass" tip diameter $1-2 \mu \mathrm{m}$ ) is used for whole-cell voltage clamp and typically has a resistance of 1.0 to 3.0 $M \Omega$ when filled with internal solution. The 'sharp' microelectrode (right; standard glass; diameter $<1$ $\mu \mathrm{m})$ is used for membrane-potential recordings and typically has a resistance of 30 to $60 \mathrm{M} \Omega$ when filled with $3.0 \mathrm{~mol} / \mathrm{L} \mathrm{KCl}$.

physiologically useful single cells are obtained in a reproducible manner by this procedure (see Figure 4). For more detaled descriptions of the cell-isolation procedures, the reader is referred to the following chapters.

\section{Laboratory of Cellular Cardiac Research}

For the purpose of cellular electrophysiological, contraction and ion measurements a new experimental setup was built in 1995 (Figure 5). The setup is constructed around an inverted microscope and allows for the recording and analysis of action potentials, ionic currents (whole-cell voltage clamping) and cell contraction (video edgemorion detection) in single cardiac myocytes. The addition of an epifluorescence system has expanded the arsenal to detect and quantify intracellular ions $\left(\mathrm{Ca}^{2+}, \mathrm{Na}^{+}, \mathrm{K}^{+}\right.$, $\left.\mathbb{H}^{+}\right)$at high-time resolution. Currently, two different types of experiments can be conducted: (1) studies with (high-resistance, $3 \mathrm{~mol} / \mathrm{L} \mathrm{KCl}$ ) sharp microelectrodes (Figure 6) to record action potentials and contractions, in which the intracellular milieu is minimally altered, and (2) studies with patch electrodes (Figure 6) for the recording of 
ionic currents and $\left[\mathrm{Ca}^{2+}\right]_{i}$ (or other ions), in which the intracellular milieu is purposefully manipulared. Adetailed description of the actual experimental setup of the various studies is given in the different chapters.

\subsection{References}

1. Lenfant C. Task force on research in epidemiology and prevention of cardiovascular diseases. Circulation. 1994:90:2609-2617.

2. Fuster V. Epidernic of cardiovascular disease and stroke: the three main challenges. Cirsulation. 1999:99:1132-1137.

3. Zipes DP, Wellens HJJ. Sudden cardiac dearh. Circulation. 1998;98:2334-2351.

4. Widdershoven JWMG, de Vreede-Swagemakers JJM. Acute coronary syndromes in the Madstricht area: acute myocardial infarction, unstable angina pectoris, sudden cardiacarrest [PhD thesis]. Maastricht, Netherlands: Maastricht University; 1997.

5. Survivors of out-of-hospital cardiac arrest with apparently normal heart: need for definition and standardized clinical evaluation. Consensus Statement of the Joint Stecring Committees of the Unexplained Cardiac Arrest Registry of Europe and of the Idiopathic Ventricular Fibrillation Registry of the United States. Circulation. 1997;95:265-272.

6. Bayés de Luna A, Coumel P, Leclercq JF. Ambularory sudden cardiac death: mechanisms of production of fatal arrhychmia on the basis of data from 157 cases. Am Heart $\mathrm{y}$. 1989;117:151-159.

7. Desserrenne F. La tachycardie ventriculaire à deux foyers opposés variables. Arch Mal Cocur. 1966;59:263-272.

8. Schwartz PJ. The idiopathic long QT syndrome: the need for a prospective registry. Eut Heart J. 1983;4:529-531.

9. Moss AJ, Schwartz PJ, Crampron RS, Tzivoni D, Locati EH, MacCluer J, Hall WJ, Weirkamp L, Vincent GM, Garson A, Jr, Robinson IL, Benhorin J, Choi S. The long QT syndrome: prospective longirudinal study of 328 families. Circulation. 1991;84: $1136-1144$

10. Zareba W, Moss AJ, Schwartz PJ, Vincent GM, Robinson JL, Priori SG, Benhorin I, Locari EH, Towbin JA, Keating MT, Lehmann MH, Hall WJ. Influence of the genotype on the elinical course of the long-QT syndrome. International Long-QT Syndrome Registry Research Group. NEngl/ Med. 1998;339:960-965.

11. Schwartz PJ. Locari EH, Napolitano C, Priori SG. The long QT syndrome. In: Zipes DP, Jalife J, eds. Cardiac Electrophysiology: From Cell To Bedside. Philadelphia, PA: WB Saunders $\mathrm{Co}_{0}$ 1995:788-811.

12. Zipes DP. The longQT interval syndrome: a Rosetta stone for sympatheric related ventricular tachyarthythmias. Circulavion. 1991:84:1414-1419.

13. Meisner FL. Taubstummheit, Ohrw tund Gehörkrankhenten. Leipzig and Heidelberg, Germany: Winter; 1856:119-120. 
14. Jervell $A_{n}$ Lange-Nielsen $F$. Congenital deaf-mutism, functional hear disease with prolongation of the Q-T inceral, and sudden death. Am Fean 1. 1957:54:59.68.

15. Romano $\mathrm{C}$, Gemme $\mathrm{G}$, Pongiglione $\mathrm{R}$. Arimie cardiache rare dell'erà pediatrica. Cly Pediatr. 1963;45:656-683.

16. Romano C. Congenital cardiac arthythmia. Lanct. 1965;1:658-659.

17. Ward OC. A new familial cardiac syndrome in children. I hish Med Ass $1964 ; 54: 103-106$

18. Prion SG, Barhanin J, Hauer RNW, Haverkamp W, Jongsma HJ, Kleber AG, McKenna WJ, Roden DM, Rudy Y, Schwartz K, Schwartz PJ, Towbin JA, Wilde AM. Genetic and molecular basis of cardiac arrhythmias: impact on clinical management. Parts I and II. Circulation. 1999;99:518-528.

19. Garza LA, Vick RL, Nora JJ, McNamara DG. Heritable Q-T prolongation widhour deafness. Cimculation. 1970,41:39-48.

20. Yanowitz. F, Preston JB, Abildskov JA. Funcrional distriburion of right and left stellate innervation to the ventricles: produccion of neurogenic electrocardiographic changes by unilateral alteration of sympathetic tone. Cimc Res. 1966;18:41 16-428.

21. Moss AJ, McDonald J. Unilateral cervicothoracic sympatheric ganglionectomy for the treatment of long QT interval syndrome. N Engl J Med. 1971;285:903-904.

22. Wellens HJJ, Vermeulen A, Durrer D. Ventricular fibrillation occurring on arousal from sleep by auditory stimuli. Circulation. 1972;46:661-665.

23. Rosen MR, Gelband H, Merker C, Hoffman BF. Mechanisms of digitalis toxicity: effects of ouabain on phase four of canine Purkinje fiber transmembrane porentials. Circu lation. 1973; $47: 681-689$.

24. Ferrier GR, Saunders JH, Mendez C. A cellular mechanism for the generation of ventricular arrhythmias by acetylstrophanthidin. Circ Res. 1973;32:600-609.

25. Schechter E, Freeman CC, Lazzara R. Afterdepolarizations as a mechanism for the long QT syndrome: electophysiologic studies of a case. $J A m$ Coll Cardiol 1984;3: $1556-1561$.

26. Jackman WM, Szabo B, Friday KJ, Margolis PD, Moulton K, Wang X, Patterson lis, Lazzara R. Ventricular tachyarrhythmias related to early afeerdepolarizarions and triggered firing: relationship to QT interval prolongation and potential therapeutic role for callcium channel blocking agents. J Cardiovasc Electroplysiol. 1990;1:170-195.

27. Shimizu W, Ohe T, Kurita T, Takaki H, Aihara N, Kanakura S, Marsuhisa M, Shimomura K. Early afterdepolarizations induced by isoproterenol in patients with congenical long QT syndrome. Circulation. 1991;84:1915-1923.

28. Zhou JT, Zheng LR, Liu WY, Zhang GL, Zhao J, Shi JL, Wang ZY, Zhang YS. Early afterdepolarizations in the familial long QTU syndrome. / Cardiouac Electrophysiot. $1992: 3: 431-436$

29. Shimizu W, Ohe T, Kurica T, Tokuda T, Shimomura K. Epinephrine-induced ventricular premature complexes due to early afrerdepolarizations and effects of verapamil and propranolol in a patient with congenital long QT syndrome. J Cardiowasc Electrophysiol 1994:5:438-444. 
30. Shimizu W, Ohe T, Kurita T, Kawade M, Arakaki Y, Ahara N, Kamakura S, Kamiya T, Shimomura K. Effects of verapamil and propanolol on early afterdepolarizations and ventricular arrhythmias induced by epinephrine in congenital long QT syndrome. $\mathrm{Am}$ Coll Cardiol 1995:26:1299-1309.

31. Schwartz PJ, Malliani A. Electrical alternation of the $T$-wave: dinical and experimental evidence of its relationship with the sympatheric nervous system and with the long Q-T syndrome. Am Heart J. 1975;89:45-50.

32. Keating M. Arkinson D, Dunn C, Timothy K, Vincent GM, Leppert M. Linkage of a cardiac arthythmia, the long QT syndrome, and the Harvey ras-1 gene. Science. $1991: 252: 704-706$.

33. Towbin JA, LiH, Taggart RT, Lehmann MH, Schwartz PI, Satler CA, Ayyagari R, Robinson JIL, Moss A, Hejtmancik JF. Evidence of genetic heterogeneity in Romano-Ward long QT syndrome: analysis of 23 families. Circulation. 1994;90:2635-2644.

34. Wang Q, Curran ME, Splawski I, Burn TC, Millholland JM, VanRaay TJ, Shen J, Timothy KW, Vincent GM, de Jager T, Schwartz PJ, Towbin JA, Moss AJ, Ackinson DL, Landes GM, Connors TD, Kearing MT. Posirional doning of a novel potassium. channel gene: KVLQTI mutations cause cardiac arrhydumias. Nat Genet. $1996 ; 12: 17-23$

35. Curran ME, Splawski I, Timothy KW, Vincent GM, Green ED, Keating MT. A molecular basis for cardiac arrhythmia: $H E R G$ mutarions cause long QT syndrome. Cell. $1995: 80: 795-803$

36. Wang Q, Shen J, Splawski I, Atkinson D, Li Z, Robinson JL, Mass AJ, Towbin JA, Keating MT, SCNSA mutations associated with an inherited cardiac arthythmia, long QT syndrome. Cell. 1995;80:805-811.

37. Splawski I, Tristani-Firouzi M, Lehmann MH, Sanguinetti MC, Keating MT. Mutations in the hminK gene cause long QT syndrome and suppress $\mathbb{I}_{\mathrm{R} \text {, }}$ function. Nat $G_{e}$ met. $1997: 17: 338-340$.

38. De Ferrari GM, Nador F, Beria G, Sala S, Lorro A, Schwartz PJ. Effect of calcium channel block on the wall motion abnormality of the idliopathic long QT syndrome. Ciraulanion. 1994:89:2126-2132.

39. Kerr WJ, Bender WL. Paroxysmal ventricular fibrillation with cardiac recovery in a case of auricular fibrillarion and complete heart block while under quinidine sulphate therapy. Heart. 1921;9:269-281.

40. Dock W. Transitory ventricular fibrillation as a cause of syncope and its prevention by quinidine suiphate. With case report and discussion of diagnostic criceria for ventricular Abrillation. Am Heam / 1929;4:709-714.

41. Schwartz SP. Transient ventricular fibrillations a study of the electrocardiograms obtained from a parient with auriculoventricular dissociation and recurrent syncopal artacks. Aro lin Med 1932;49:282-302.

42. Schwartz SP. Studies on transient ventricular fibrillation: III the prefibrillatory mechanism during established auriculo-ventricular dissociation. Am / Med Sci. 1936;192: 1.53-163. 
43. Schwarz SP, Jezer A. The action of quinine and quindine on patents with mansient ventricular fibrillation. Am Hedrt J. 1934:97792-801.

44. Schwarz SP, de Sola Pool N. Transient wentricular fibrillation: III. the effects of bodily rest atropine sulfate, and exercise on parienrs with transient ventricular fibrillation during established auriculoventricular dissociation. A study of the influence of the extrinsic nerwes on the idioventricular pacemaker of the heart. Am Heart/. 1950;39:361-386.

45. Jackman WM, Clark M. Friday KJ. Aliot EM, Anderson J, Lazzara R. Ventricular tachyarrbychmias in the long QT syndromes. Med Clin North Am. 1984;68:1079-1109.

46. Jackman WM, Friday KJ. Anderson JL, Alior EM, Clark M, Lazzara R. The long QT syndromes: a critical review, new clinical observations and a unifying hypothesis, Prog Cardiovasc Dis 1988;31:115-172.

47. Brachmann J, Scherlag BJ, Rosenshtraukh LV, Lazzara R. Bradycardia-dependent triggered activiry: relevance to drug-induced multiform ventricular tachycardia. Cinculation. $1983 ; 68: 846-856$.

48. Eckandt L, Haverkarnp W, Borggrefe M, Breithardt G. Experimental models of rorsade de pointes. Cardiovas Res. 1998;39:178-193.

49. Bikkina M, Larson MG, Levy D. Asymptomaric ventricular arthythmias and morality risk in subjects with left ventricular hypertrophy. I Am Coll Cardiol. 1993;22: $1111-1116$.

50. Gorgels APM, Vos MA, Smeets JLRM, Wellens HJJ. Ventricular arrhythmias in heart failure. Am J Cardiol. 1992;70:37C-43C.

51. Tomaselli GF, Beuckelmann DI, Calkins HG, Berger RD, Kessler PD, Lawrence JH, Kass D, Feldman AM, Marban E. Sudden cardiac death in heart failure: the rolle of abnormal repolarization. Circulation. 1994;90:2534-2539.

52. Dinerman JL, Berger R, Haigney MCP, Lawrence JH, Tomaselli GF, Calkins H. Dispersion of ventricular activation and refractoriness in patients with idioparhic dilared cardiomyopathy. Am I Cardiol. 1997;79:970-974.

53. Berger RD, Kasper EK, Baughman KL, Maban E, Calkins H, Tomaselli GF. Beat-tobeat QT interval variability: novel evidence for repolarization lability in ischemic and nonischemic dilated cardionyopathy. Circulation. 1997;96:1557-1565.

54. Beuckelmann DJ, Nabauer M. Erdmann E. Alterations of K curents in isolated human ventricular myocytes from parients with terminal heart failure. Circ Res. 1993;73: 379-385.

55. Näbauer M, Käab S. Potassium channel down-regulation in heart failure. Cardiotasc" Res. 1998;37:324-334.

56. Yang ZK, Boyett MR, Janvier NC, McMorn SO, Sh wi Z, Karim Ji" Regional differences in the negative inotropic effect of acerylcholine within the canine ventricle $f$ pysiol. $1996,492789-806$

57. Antzelevitch C, Yan GX, Shimizu W, Burashnikov A. Elecrical heterogeneity, the ECG, and cardiac arrhythmias. In: Zipes DP, Jalife J, eds. Cardiac Electropbysiology: From Cell To Bedside. Philadelphia, PA. WB Saunders Co; 1999:in press. 
58. Sicouri $S$, Antzelevitch C. A subpopularion of cells with unique electrophysiological properties in the deep subepicardium of the canine ventricle: the $\mathrm{M}$ cell. Cir Res. $1991 ; 68: 1729-1741$.

59. Anyukhovsky ED, Sosunov EA, Rosen MR. Regional differences in electrophysiological properties of epicarditum, midmyocardium, and endocardium: in vitro and in vivo correlarions. Circulation 1996;94:1981-1988.

60. Sicouri $\$$, Antzelevitch C. Drug-induced afterdepolarizations and triggered activity occur in a discrete subpopulation of ventricular muscle cells ( $M$ cells) in the canine heart: quinidine and digitalis. / Cardiovasc Electrophysiol 1993;4:48-58.

61. Liu DW, Antzelevitch C. Characteristics of the delayed rectifier current $\left(I_{K_{s}}\right.$ and $\left.I_{K s}\right)$ in canine ventricular epicardial, midmyocardial, and endocardial myocytes: a weaker $1_{k}$ contributes to the longer action potencial of the M cell. Circ Res. 1995;76.351-365.

62. Yan $G X$. Antzelevitch $C$. Cellular basis for the normal $T$ wave and the electrocardiographic manifestations of the long-QT syndrome Cirulation. 1998;98:1928-1936.

63. Malfatto G, Beria G, Salla $S$, Bonazzi O, Schwartz PJ. Quantitative analysis of T wave abnomalities and their prognostic implications in the idiopathic long QT syndrome. JAm Coll Cardiol. 1994:23:296-301.

64. Houltz B, Darpö B, Edvardsson N, Blomström P, Brachmann J, Crijns HJGM, Jensen SM, Swernhage E, Vallin H, Swedberg K. Elecrrocardiographic and clinical predictors of torsades de pointes induced by almokalant infusion in patients with chronic atrial fibrillation or flutter: a prospective study. Pacing Clin Electrophysiol 1998:21:1044-1057.

65. Gorgels APM. Ventricular impulse formation and the influence of digitalis intoxication [PhD thesis]. Maastricht, Netherlands: Maastricht University; 1985.

66. Vos MA. New obserwations to identify abnormal impulse formation in the intact heart $[\mathrm{PhD}$ rhesis]. Maastricht, Netherlands; Maastricht Uniwersity; 1989.

67. Vos MA, Verduyn SC, Gorgels APM, Lipcsei GC, Wellens HJJ. Reproducible induction of early afterdepolarizations and torsade de pointes arrhythmias by $d$-sotalol and pacing in dogs with chronic atrioventricular block. Cimulation. 1995:91:864-872.

68. Verduyn SC. Acquived torade de pointes ambythwias: role of early afterdepolarizations and dispersion of repolarizanion [PhD thesis]. Maastricht, Netherlands: Maastricht University: 1996 .

69. de Groot SHMA. Triggered ventricula" ambythwias in the bypertrophied heart the role of electropbysiological and functional adaptarions [PhD thesis]. Maastricht, Netherlands: Maastricht University; 1998.

70. de Groot SHM, Vos MA, Gorgels APM, Leunissen JDM, van der Steld BJ, Wellens HJ]. Combining monophasic action potential recordings with pacing to demonstrate delayed afterde polarizations and triggered arrhythmias in the intact heart value of diastolic slope. Cinulation. 1995,92:2697-2704.

71. Vos MA de Groot SHM, Verduyn SC, van der Zande J, Leunissen HDM, Cleurjens JPM, van Bilsen M, Daemen MIAP, Schreuder J], Allessie MA, Wellens HIJ. Enhanced susceptibility for acquired torsade de pointes arthythmias in the dog wich chronic, com- 
plete AV block is related to cardiac hypertrophy and electrical remodeling. Cmatation 1998;98:1125-1135.

72. Powell T, Twist VW. A rapid technique for the isolation and purificacion of adult cardiac muscle cells having respiratory control and a tolerance ro calcium. Biochesn Biophys Res Commun. 1976;72:327-333.

73. Powell T. Methods for the preparacion and characterization of cardiac myocytes. In: Dhalla NS, ed. Metbods in Studying Cardiac Membrames Boca Raron, FL: CRC Press, Inc; $1984: 41-62$.

74. Hewett $\mathrm{K}$, Legato MJ, Danilo P, Jr, Robinson RB. Isolated myocytes from adult canine left ventricle: $\mathrm{Ca}^{2+}$ tolerance, electrophysiology, and ultrastmucture. Am I Plysiol 1983;245:H830-H839.

75. Lundgren E, Borg T, Mårdh S. Isolation, characterization and adhesion of calciumtolerant myocytes from the adult rat heart. J Mol Cell Cardiol 1984;16:355-362.

76. Mitra R. Morad M. A uniform enzymatic method for dissociation of myocytes from hearts and stomachs of vertebrates. An J Physiol. 1985:249:H1056-H1060.

77. Zeng J, Laurita IKR, Rosenbaum DS, Rudy Y. Two components of the delayed rectifier $\mathrm{K}^{*}$ current in ventricular myocytes of the guinea pig type: theoretical formulation and their role in repolarization. Cinc Res. 1995;77:140-152.

78. The Sicilian Gambit: a new approach to the classification of antiarthythmic drugs based on their actions on arrhyrhmogenic mechanisms. Task Force of the Working Group on Arrhythmias of the European Society of Cardiology. Circulation. 1991;84:1831-1851.

79. Arreola I, Dirksen RT, Shieh RC, Williford DJ, Sheu SS. Ca current and Cat transients under action potential clamp in guinea pig ventricular myocytes. Am $/ \mathrm{l} / \mathrm{gyiol}$ $1991 ; 261: \mathrm{C} 393-\mathrm{C} 397$.

80. Shimoni $Y$, Clark $R B$, Giles WR. Role of an inwardly recrifying potassium current in rabbit wentricular action porential. J Physiol. 1992;448:709-727.

81. Carmeliet E. Mechanisms and control of repolarization. Exr Heart J 1993;14 (suppl $\mathrm{H}): 3-13$.

82. Luo CH, Rudy Y. Adynamic model of the cardiac ventricular action porential: I. simulations of ionic currents and concentration changes. Cire Ros. 1994;74:1071-1096.

83. Luo CH, Rudy Y. Adynamic model of the cardiac wentricular action potential: II afterdepolarizations, triggered activity, and potentiation, Cir Res, 1994:74:1097-1113.

84. Sipido $\mathrm{KR}$, Callewaer $\mathrm{G}$, Carmeliet $\mathrm{E}$. Inhibition and rapid recowery of $\mathrm{Ca}^{2+}$ current during $\mathrm{Ca}^{2}$ release from sarcoplasmic reticultum in guinea pig ventricular myocytes. Cim Res. 1995,76:102-109.

85. Rosen MR. Cardiac arrhythmias and antiarthythmic drugs: tecent advances in our understanding of mechanism. / Cardionasc Electrophysiol. 1995;6868-879.

86. Grantham CJ, Cannell MB. Ca ${ }^{2 *}$ influx during the cardiac action potential in guinea pig ventricular myocytes. Circ Res. 1996:79:194-200.

87. Janvier $N C$, Boyert MR. The rolle of $\mathrm{Na}-\mathrm{Ca}$ exchange current in the cardiac action pom tental. Cardiovasc Res. 1996;32:69-84. 
88. Zygrnunt AC, Robitelle DC, Eddlestone GT. Im dictates behavior of $I_{C I C a}$ during early repolarization of canine ventricle. Am J Pbysiol 1997;273:H1096-H1106.

89. Sipido KR, Carmelier $E$, Van de Werf $\mathrm{F}^{2}$ T-type $\mathrm{Ca}^{2 *}$ current as a trigger for $\mathrm{Ca}{ }^{2 *}$ release from the sarcoplasmic reticulum in guinea-pig ventricular myocgres. I ptysiol. $1998: 508: 439-451$

90. Verkerk AO. Cellular mechanisms of arrbythmias: effects of noradrenaline, bypaxia and injury current on the electrophystology of isolated ventricular and Purkinje myocytes $\mathrm{PH} \mathrm{D}$ thesis. I. Amsterdam, Netherlands: University of Amsterdam; 1998.

91. Priebe $\mathbb{L}$, Beuckel mann DJ. Simulation study of cellular electric properties in heart failure. Cinc Res. 1998;82:1206-1223.

92. Zaza A, Rocchetri M, Brioschi A, Cancadori A, Ferroni A. Dynamic Ca ${ }^{2+}$-induced inward rectification of $K^{*}$ current during the ventricular action potential. Circ Res. $1998 ; 82: 947-956$. 


\section{Repolarizing $\mathrm{K}^{+}$Currents $\mathrm{I}_{\mathrm{TO} 1}$ and $\mathrm{I}_{\mathrm{KS}}$ Are Larger in Right Than Left Canine Ventricular Midmyocardium}

Paul G.A. Volders, Karin R. Sipido, Edward Carmeliet,

Roel L.H.M.G. Spätjens, Hein J.J. Wellens, Marc A. Vos

From the Department of Cardiology, Cardiovascular Research institute Maastricht (E.C.), Ma:astricht University, Netherlands; and the Laboratory of Experimental Cardiology, University of Leuven, Belgium (K.R.S.). 


\section{Abstract}

Background: The ventricular action potential exhibits regional heterogeneity in configuration and duration (APD). Across the left ventricular (LV) free wall this is explained by differences in repolarizing $K^{*}$ currents. However, the ionic basis of electrical nonuniformity in the right (RV) versus LV is poorly investigated. We examined transient outward (1,ol), delayed $\left(I_{K, 5}\right.$ and $\left.\|_{K,}\right)$, and inward rectifier $K^{+}$currents $\left(l_{K !}\right)$ in relation to action-potential characteristics of RV and LV midmyocardial (M) cells of the same adult canine hearts.

Method's and Results: Single RV and LV M cells were used for microelectrode recordings and whole-cell woltage clamping. Action potentials showed deeper notches, shorter durations at $50 \%$ and $95 \%$ of repolarization, and less prolonglation upon slowing of the pacing rate in RV than LV. Iro, density was significantly larger in RV than LV, while steady-state inactivation and rate of recovery were similar. $\left.\right|_{k s}$-tail currents, measured at $-25 \mathrm{mV}$ and in

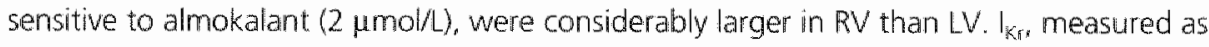
almokalant-sensitive tail currents at $-50 \mathrm{mV}$, and $\mathrm{I}_{k}$, were not different in the two ventricles. Conclusions: Differences in $\mathrm{K}^{*}$ currents may well explain the interventricular heterogeneity of action potentials in $\mathrm{M}$ layers of the canine heart. These results contribute to a further phenotyping of the ventricular action potential under physiological conditions. 


\section{Introduction}

Regional heterogeneiry of the acrion-potential configuration and duration (APD) characterizes the ventricular myocardium in large mammals, including humans. ${ }^{1-3}$ A prominent notch shapes the typical spike-and-dome action potential of the epicardium and midmyocardium ( $\mathrm{M}$ layer), but is absent in the endocardium. A relatively large transient outward current, containing a 4 -aminopyridine-sensirive component $\left(\mathrm{I}_{\mathrm{TO}}\right.$ ) and $\mathrm{Ca}^{2+}$-activated $\mathrm{Cl}^{-}$current, is mainly responsible for this notch. Another in-vitro electrophysiological distinction is the longer APD of midmyocardium and its pronounced increase in response to slow pacing rates, class la and class III agents. $1,4,5$ These repolarization characteristics have been explained on the basis of a lesser contribution of the slowly activating component $\left(I_{K s}\right)$ of the delayed rectifier $K^{+}$ current in $\mathrm{M}$ cells, ${ }^{4,6}$ while the rapidly activating component $\left(\mathrm{I}_{\mathrm{K}_{\mathrm{r}}}\right)$ and the inward recrifier current $\left(\mathrm{I}_{\mathrm{K} 1}\right)$ appear similar in the three transmural layers. ${ }^{7}$

Only limited information is available on action-potential and ionic differences in right (RV)-versus-left ventricular (LV) comparisons. A larger $\mathbb{I}_{\text {TOI }}$ in $R V$ versus $L V$ epicardial cells has been correlated with a larger notch in the former cell type. ${ }^{8}$ Since an interventricular comparison of $\mathrm{K}^{+}$currents in $\mathrm{M}$ cells is lacking, we examined action potentials and the $\mathrm{K}^{+}$currents $\mathrm{I}_{\mathrm{TO} 1}, \mathrm{I}_{\mathrm{Ks}}, \mathrm{I}_{\mathrm{Kr}}$, and $\mathrm{I}_{\mathrm{K} 1}$ in RV and LV M cells of the same adult canine hearts.

\section{Methods}

Sixteen mongrel dogs of either sex $(26 \pm 1 \mathrm{~kg})$ were anesthetized and received perioperative care as described. ${ }^{9}$ Thoracotomy was performed and hearts $(225 \pm 12 \mathrm{~g})$ were quickly excised. RV and LV M cells were obtained by simultaneously cannulating the left-anterior-descending and right coronary arteries. ${ }^{10}$ After $\approx 30$ minutes of collagenase perfusion, the epicardial surface layer was temoved from both wedges until a depth of $\geq 3 \mathrm{~mm}, 4,7$ and softened tissue samples were pipetted from the $M$ layer underneath, while contamination with the endocardium was avoided. Samples were gently agitated, filtered and washed. Isolated myocytes were stored at room temperature in standardbuffer solution.

The serup was built around an inverted microscope. ${ }^{10}$ Microelectrodes (standard glass) had resistances of 30 to $60 \mathrm{M} \Omega$ when filled wirh $3.0 \mathrm{~mol} / \mathrm{L} \mathrm{KCl}$. Intracellular pacing was done at various cycle lengths (CLs). For the recording of ionic currents, we used the whole-cell variant of the patch-clamp technique. Patch pipettes (borosilicate glass) had resistances of 1.0 to $3.0 \mathrm{M} \Omega$ when filled with internal solution. Experiments were performed at $37^{\circ} \mathrm{C}$. Cell capacitance, measured by hyperpolarizing steps from -60 $\mathrm{mV}$, was similar in RV $(\mathrm{n}=27)$ and LVM cells $(\mathrm{n}=25)$ being $226 \pm 12$ and $226 \pm 11 \mathrm{pF}$, respectively $(P=N S)$. L-type $C a^{2 *}$ current was blocked with nifedipine $(5 \mu \mathrm{mol} / \mathrm{L})$. Na* current was inactivated by $10-\mathrm{ms}$ prepulses to $-45 \mathrm{mV}$. The voltage-cla mp protocols are 
illustrated in Figures 1 and 2. I Tor amplitudes were measured as peak amplitudes minus steady-state walues at the end of the test pulses $\left(V_{\text {rest }}\right)$. For $\mathrm{I}_{\mathrm{Kr}}$, we measured the tail currents on repolarization to $-50 \mathrm{mV}$ sensitive to almokalant $\left(2 \mu \mathrm{mol} / \mathrm{L}\right.$; specific $\mathrm{I}_{\mathrm{Kr}}$ blocker). " For $\mathrm{I}_{\mathrm{K} \text { s }}$ we measured the almokalant-insensitive tail currents on repolarization to $-25 \mathrm{mV}$. For $l_{\mathrm{K}}$, we measured steady-state values at the end of $V_{\text {test }}$.

The standard-buffer solution used for the experiments was composed of (mmol/L): $\mathrm{NaCl} 145, \mathrm{KCl} 4.0, \mathrm{CaCl}_{2} 1.8, \mathrm{MgCl}_{2} 1.0, \mathrm{NaH}_{2} \mathrm{PO}_{4} 1.0$, glucose 11 , HEPES 10, $\mathrm{pH} 7.4$ with $\mathrm{NaOH}$ at $37^{\circ} \mathrm{C}$. The patch-pipette solution contained (in mmol/L): potassium aspartate $125, \mathrm{KCl} 20, \mathrm{MgCl}_{2} 1.0, \mathrm{MgATP} 5$, HEPES 5, EGTA 10, $\mathrm{pH} 7.2$ with $\mathrm{KOH}$.

The data are expressed as mean \pm SEM. Intergroup comparisons were made with the Student's test for unpaired and paired data groups, after testing for the normality of distribution. Differences were considered significant if $P<0.05$.

\section{Results}

\section{Action-Potential Characteristics}

Typical examples of RV and LV M action potentials are shown in Figure 1. Quantitarive data are given in the Table. RV M cells had a more pronounced spikeand-dome configuration than $\mathbb{L V} \mathrm{M}$ cells ar fast and slow pacing rates. ${ }^{I}$ Both the action-potential upstroke and plateau (phase- 0 and phase-2 amplitude) were larger in LV M cells, but only at fast rates. On average, action potentials were of shorter duration in RV than LV, and they displayed less prolongation (absolutely as well as relatively) upon increasing the CL from 500 to $4000 \mathrm{~ms}$.

\section{Properties of $I_{T 0}$}

$I_{T o v}$ actiwated at $V_{\text {tes }} \geq-20 \mathrm{mV}$ in both ventricles, but amplindes were signifcandly larger in RV than LV at all $V_{\text {eesr }}$ (Figures 1 and 2A). 4-Aminopyridine (5 mmol/L) nearly complecely suppressed $\mathrm{I}_{\mathrm{TO}}$ in both cell types. Inactivation during the $V_{\text {rest }}$ was best fitted with a single exponential function yielding similar time constants for RV and LV. The voltage dependence of $\mathrm{I}_{\mathrm{TO}}$ steady-state inactivation (Figure 2B) was well described by a Boltzmann fit with half points $\left(V_{0.5}\right)$ of $-52 \pm 0.6$ and $-50 \pm 0.5$ $\mathrm{mV}$, and slope factors of $6.8 \pm 0.6$ and $4.5 \pm 0.5 \mathrm{mV}$ in RV and $L V$, respectively $(P=\mathrm{NS})$. Time-dependent recovery from inacrivation was not different berween the ventricles. 


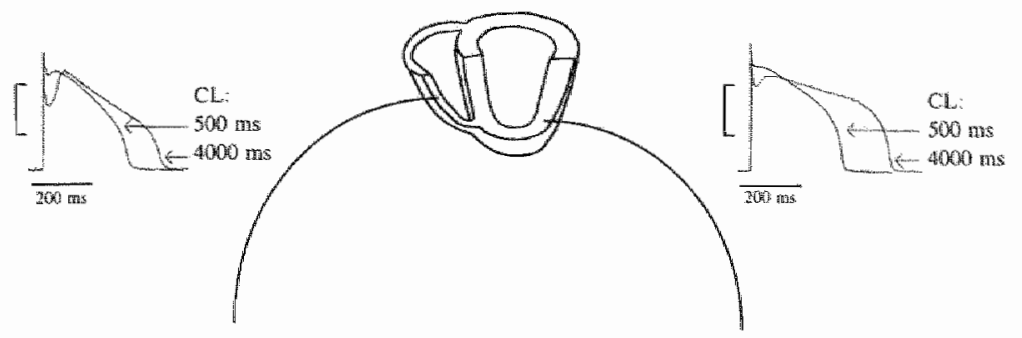

\section{Right ventricular $\mathbf{M}$ cells}

\section{Left ventricular $M$ cells}
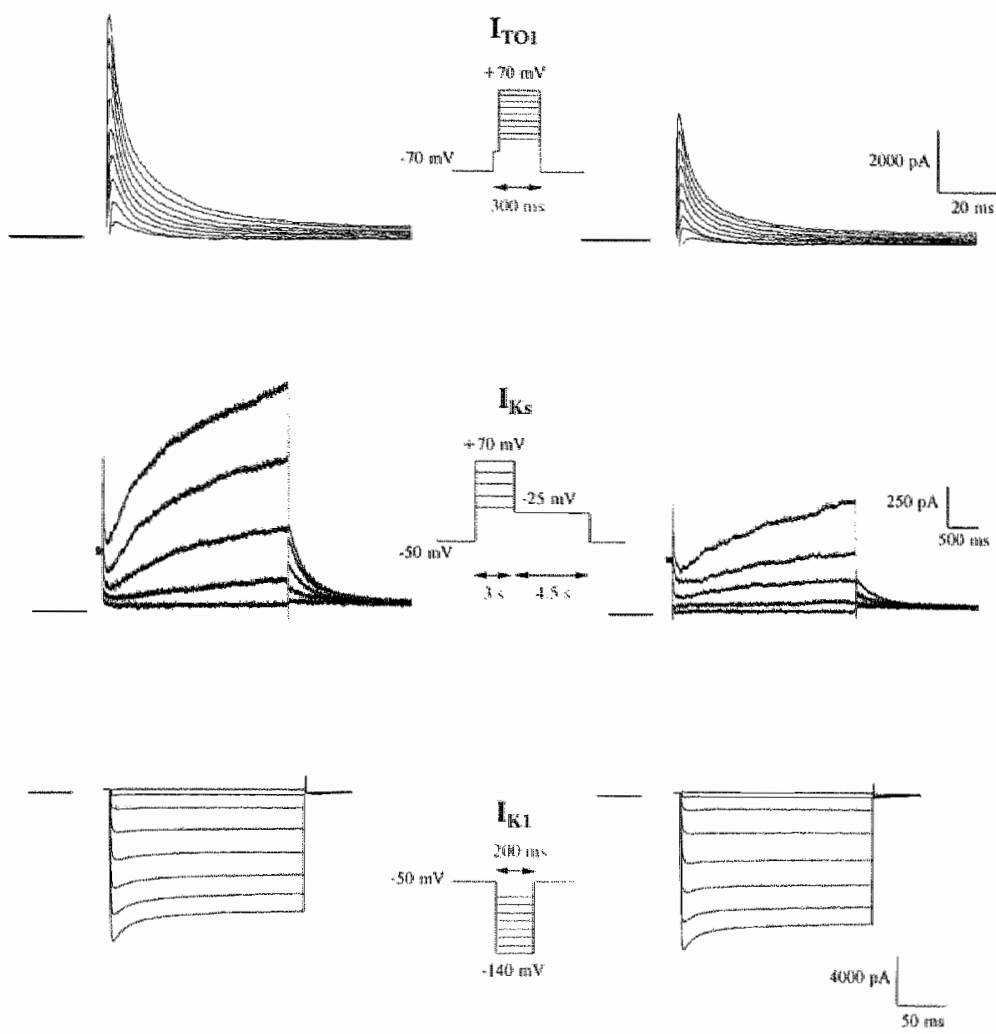

Figure 1. - $K^{*}$ currents $I_{\text {rol }}$ and $K_{K}$ are larger in RV than LV M cells isolated from the same normal dog heart, whereas $I_{K 1}$ is similar.

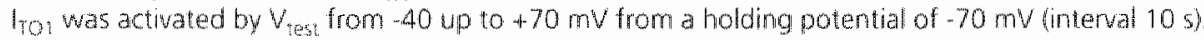
Shown are the traces of -10 to $+70 \mathrm{mV}$. K $_{k \text { s was }}$ wecorded in the presence of almokalant; we appled depolarizations from 20 up to $+70 \mathrm{mV}$ tollowed by repolarizations to $-25 \mathrm{mb}$. 5 hown are the traces of $-10,+10,+30,+50$, and $+70 \mathrm{~mW}$. Holding potential was $-50 \mathrm{mV}$ (interval 205 . $\mathrm{k}_{\mathrm{k}}$ was recorded during $V_{\text {iest }}$ of $-2010-140 \mathrm{~m}$. Shown are the traces of -70 to $-140 \mathrm{mV}$. Holding potential was $-50 \mathrm{mV}$ (interal 3 s). Left horizontal bars indicate 0.pA level Capacitances of the RV and LV M cells used for illustrations are smilar (1 9 : 247 and $226 \mathrm{pF}$; both $\mathrm{k}_{\mathrm{kg}}$ and $\mathrm{I}_{\mathrm{k}}: 249$ and $244 \mathrm{pF}$. Action potentias (microelectrode technique; vertical scale bars indicate 0 to -50 mv) were reconded at pacing cus of 500 and $4000 \mathrm{~ms}$, and illustrate that the difference of configuration and rate dependent prolongation between the ventricles is likely related to underlying $K^{*}$-current differences. 

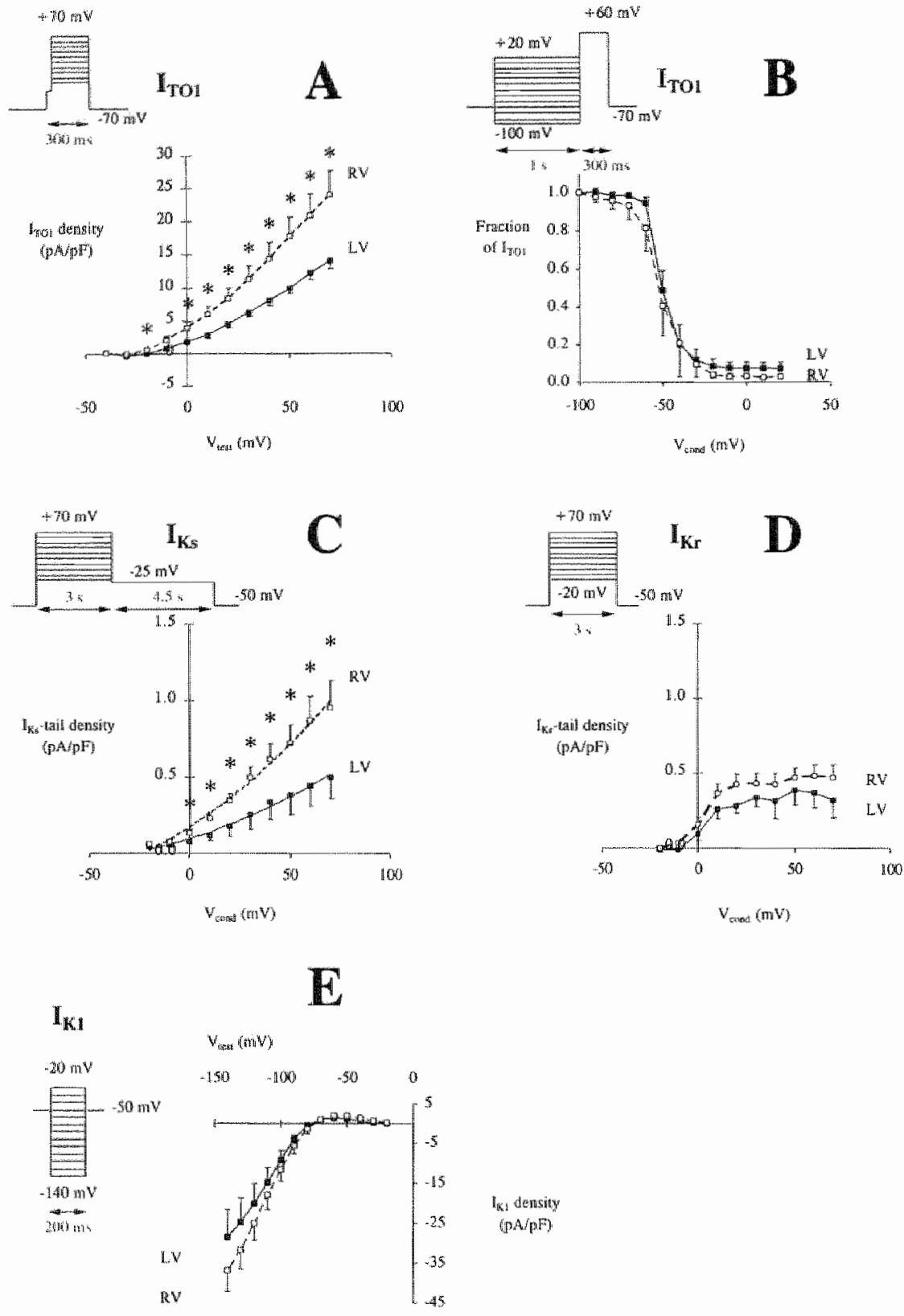

Figure 2. - Quantitative data for $I_{T o 1} I_{K_{S t}} I_{K_{r}}$ and $I_{K+1}$ in RV versus LV M cells from 9 dogs. Current density-voltage relation $\left(A ; n_{B V}=12, n_{L V}=10\right)$ and steady-state inactivation $\left(B ; n_{B V}=6, n_{L V}=9\right.$;

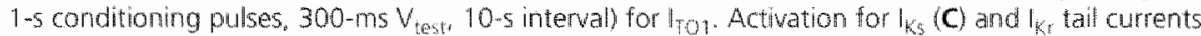
(D; $n_{R y}=18$ and $n_{L}=13$ ). Current density-voltage relation for $l_{K}$ steady-state activation $\left(E_{;} n_{R V}=8\right.$ and $\left.n_{L v}=5\right)$. Asterisks indicate statistically significant differences in $\|_{10}$ and $k_{k s}$ current densties between RV and $\mathrm{LV}(P<0.05)$. cond indicates conditioning voltage 
Table-Action-Potential Characteristics of Canine RV and LV M Cells

RVM cells $(n=1)$

LV M cels $n=15$ )

Pacing CL $500 \mathrm{~ms}$

Amplitude, mv

Phase 0

Phase 1

phase 2

Resting membrane potential, $\mathrm{mV}$

$A P D, 5, m s$

$\mathrm{APO} 5 \mathrm{~ms}$

Pacing Cl $4000 \mathrm{~ms}$

Amplitude, mv

Phase 0 :

Phase 1

Phase 2

Resting membrane potential mv

$A P D_{95}, \mathrm{~ms}$

$A P D_{50}$ ms

$$
\begin{aligned}
& 118+2^{*} \\
& 92 \pm 5^{*} \\
& 102 \pm 2^{*} \\
& -84 \pm 2 \\
& 272 \pm 8^{*} \\
& 206 \pm 7^{*}
\end{aligned}
$$

$113 \pm 2$
$71 \pm 6$
$102 \pm 2$
$-84 \pm 2$
$366 \pm 17(+35 \%)$
$297 \pm 13(+44 \%)^{*}$
$123 \pm 2$

$105 \pm 3$

$108 \pm 2$

$-84 \pm 1$

$294+1$

$236+6$

$118 \pm 2$

$87 \pm 4$

$105+2$

$-84+1$

$437+34(449 \%)$

$379+32(+61 \%)$

Microelectrode technique. Cells were obtained from 8 dogs Amplitudes were meastred as the voltage difference between resting membrane potential and pealk of upstroke (phase 0, deepest level of notch (phase 1), and dome (phase 2). Action-potential duration was measured at $95 \%$ $(\mathrm{APD}, 5)$ and $50 \%$ of repolarization (APD 50 ). Percentages im bracket indicate relatwe ncrease vs $\mathrm{CL}$ 500 ms $* P<0.05$ vs LV M cells.

Properties of $I_{k s}$ and $I_{k t}$

$\mathrm{I}_{\mathrm{Ks}}$-tail currents were evaluated on repolarization to $-25 \mathrm{mV}$ with $\mathbb{I}_{\mathrm{Kr}}$ blocked by almokalant. Examples of current traces are shown in Figure 1. Pooled data are given in Figure 2C. There was no saturation of tail-current amplitudes. Voltage dependence of $I_{K_{s}}$ acrivation was similar for both cell types, but density was significantly larger in $R V$ : $0.72 \pm 0.12 \mathrm{pA} / \mathrm{pF}$ than in $\mathrm{LV}: 0.38 \pm 0.13 \mathrm{pA} / \mathrm{pF}(P<0.05 ;$ depolarization to $+50 \mathrm{mV})$. This difference persisted after increasing $\mathbb{I}_{K^{\prime} s}$ in $K^{+}-$free solution $\left(0\left[\mathrm{~K}^{+}\right]_{\mathrm{O}}\right): 0.98 \pm 0.21$ $\mathrm{pA} / \mathrm{pF}$ in $\mathrm{RV}$ versus $0.58 \pm 0.17 \mathrm{pA} / \mathrm{pF}$ in $\mathrm{LV}$. Deactivation proved similar in RV and LV myocytes. Tail currents in $0\left[\mathrm{~K}^{+}\right]_{0}$ were best fitted by biexponential functions on repolarization to -10 to $-40 \mathrm{mV}$, and by monoexponential functions on more negative repolarizations $(-50$ to $-80 \mathrm{mV})$. At $-20 \mathrm{mV}$, time constants of the fast and slow components were $228 \pm 25$ and $1105 \pm 199 \mathrm{~ms}$ in $\mathrm{RV}(\mathrm{n}=7)$ and $278 \pm 35$ and $1486 \pm 269$ $\mathrm{ms}$ in $\mathrm{LV}(\mathrm{n}=6) ;$ at $-60 \mathrm{mV}$, monoexponential time constants were $99 \pm 16$ in RV and $94 \pm 11$ in LV ( $P=$ NS for all $)$.

$I_{K_{r}}$ was quantified as the almokalant-sensitive tail-current portion measured by digital subtraction at $-50 \mathrm{mV}$ in $4.0 \mathrm{mmol} / \mathrm{L}\left[\mathrm{K}^{+} \mathrm{l}_{\mathrm{O}}\right.$ (Figure 2D). Acrivation showed saturation at conditioning voltages $>+20 \mathrm{mV}$. Boltzmann fits to the data revealed $V_{0.5}$ of $2.9 \pm 1.0$ and $4.3 \pm 2.5 \mathrm{mV}$ in $R V$ and $L V$, respectively, while corresponding slope fac- 
tors were $6.2 \pm 2.1$ and $5.3 \pm 0.8 \mathrm{mV}(P=\mathrm{NS}) . \mathrm{I}_{\mathrm{KP}}$ density was not different berween RV and LV M cells. Voltage dependence and time course of $\mathrm{I}_{\mathrm{K}}$ deactivation were also not different.

\section{Properties of $t_{\text {w }}$}

Whole-cell recordings of $I_{K 1}$ are shown in Figure 1 . $I_{K} 1$ rapidly activated and showed inactivation at the more negative voltages. In all cases, this current was fully inhibited in $0\left[\mathrm{~K}+10\right.$. There were no differences in the magnitude of $\mathrm{I}_{\mathrm{K} 1}$ (initial minimal values as well as steady-state levels) berween $R V$ and $L V$ throughout the voltage range tested (Fugure 2E).

\section{Discussion}

For interventricular comparisons of action potentials and $\mathrm{K}^{+}$currents, we isolated myocytes from the deep subepicardial layers of the RV and LV free wall of the same canine hearts. In both ventricles, these myocytes have been designated $\mathrm{M}$ cells on the basis of discinctive electrophysiological characteristics. 1,3-6 Our results show that action potentials have a deeper notch, a shorter duration and less prolongation upon slowing of the pacing rate in RV compared to LV M cells. A longer APD in the LV versus $R V$ has already been recorded in dogs, both in vitro 1,8 and in vivo (in dogs with complete atrioventricular block). 9 In 6 dogs with sinus rhythm (CL: $507 \pm 32 \mathrm{~ms}$ ), we found endocardial monophasic APDs to be longer in $L V$ than $R V$ in all animals: $219 \pm 6$ versus $203 \pm 6 \mathrm{~ms}(P<0.05) .{ }^{12}$ Taken together, these data indicate that a larger $L V$ than $\mathbb{R V}$ APD exists at nomal heart rates and during bradycardia.

The presence of $\mathrm{I}_{\mathrm{Kr}}$ and $\mathrm{I}_{\mathrm{Ks}}$ was confirmed in $\mathrm{M}$ cells from the $\mathrm{LV}$ and demonstrated also in RVM cells. Densities of $I_{K r}$ were similar in borh ventricles. $I_{K S}$ density however, was significantly larger in $R V$ and this difference could explain, at least partly, why $\mathrm{APD}, 0$ and $\mathrm{APD}$ g5 were longer and why the $\mathrm{APD} / \mathrm{pacing}-\mathrm{CL}$ relationship was steper in $L$ V than in RV M cells. Heterogeneity of $\mathrm{KS}_{\mathrm{s}}$ across the transmural LV wall has been linked to dispersion of repolarizarion and the danger of torsades de pointes. 4,6 Our results on $\mathrm{I}_{\mathrm{K} \text { ( and }} \mathrm{I}_{\text {Tol }}$ ) suggest that arthythmogenic electromotive gradients could also arise at the septal junction of the $R V$ and $L V$.

In human ventricular nyocytes, the presence of $\mathbb{K}_{K}$ and $I_{K}$ has also been demonstrated. ${ }^{13}$ Interestingly, Li et al ${ }^{13}$ made their observations in apparenty undiseased RV myocytes of patients whth left-sided heart fallure. The finding of substantial amplitudes of $\mathrm{K}_{\mathrm{K}}$ and $\mathrm{I}_{\mathrm{K}}$, as well as the sensitivity of botis components to their blockers $\mathrm{E}-4031$ and indapanide, may underscore the importance of these currents for human ventricular repolarization, as expected from the clinical response to class La and class III agents in parients, and from molecular studies on $\mathrm{K}^{+}$channels in human myocardial tissue.

Our finding of a large $\mathbb{L}_{T O 1}$ in RV M cells is in keeping with the prominent spike-and-dome morphology of the action potentials. Yan and Antzelevitch ${ }^{14}$ pre- 
sened evidence that the distribution of 1 ro across the canine ventriculat wall is caus ally linked to the I wave of the ECG. The join results of this and anoher study indicate thar a large $\mathrm{I}_{\mathrm{TO}}$-mediated noch can be found chroughout mosr of the $\mathrm{RV}$ mass, which suggests that the contribution of the RV ro the formarion of the f wave on the $\mathrm{ECG}$ may be larger than previously assumed. Furthermore, this may have important consequences for our understanding of the Brugada syndrome. ST-segment elevation in the right precordial ECG leads of parients suffering from this disorder has ben linked to the concep of all-or-none repolarization in the $R V$ epicardium. "If If datareapplcable to patients, then the substrate predisposed to all-ot-none repolarization may cover most of the RV transmural wall.

\section{References}

1. Antzelevitch C, Sicouri S, Lukas A, Nesterenko VV, Liu DW, Di Diego JM. Regional differences in the electrophysiology of ventricular cells: physiological and clinical impl-

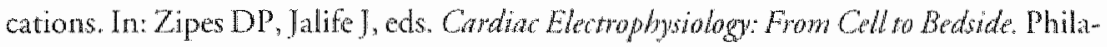
delphia, PA: WB Saunders Co: 1995:228-245.

2. Drouin E, Charpentier F, Gauthier C, Iaurent K, Le Marec H. Electrophysiologic characteristics of cells spanning the lef ventricular wall of human heart evidence bor presence of M cells. IAm Coll Cardiol. 1995:26:185-192.

3. Li GR, Feng ], Yue L, Carrier M. Transmumal hererogeneiry of action potentials and It in myocytes isolated from the human right ventricle. Am / Pbysiol 1998;275: $\mathrm{H} 369-\mathrm{H} 377$.

4. Liu DW. Antzelevtch C. Characteristics of the delayed recrifier current $\left(\mathbb{I}_{k, \text { and }} I_{k}\right)$ in canine ventricular epicardial, midmyocardial, and endocardial myocytes: a weaker $I_{\text {his }}$ contributes to the longer action porential of the M cell. Circ Res. 1995;76:351-365.

5. Anyukhovsky EP. Sosunov EA. Rosen MR. Regional differences in electrophysiological properties of epicardium, mid myocardium, andendocardium: in witroand in vivo correlations. Circulation. 1996:94:1981-1988.

6. Gincant GA. Regional differences in $I_{\mathrm{x}}$ density in canine left ventricle: role of $\int_{\text {R }}$ in electrical heterogeneity. Aw J Physiol 1995;268:H604-H613.

7. Liu DW, Gintant GA, Antzelevitch C. Ionic bases for electrophysiological distinctions among epicardial, midmyocardial. and endocardial myocyces from the free wall of the canine left ventricle. Cinc Res. 1993:72:671-687.

8. Di Diego JM, Sun Z-Q, Antzelevitch C. I and action porential notch are smaller in left vs. righe canine ventricular epicardium. Am J Plgsiol. 1996;271:H548-H561.

9. Vos MA, de Groot SHM, Verduyn SC, van der Zande J, Leunissen HDM. Cleurjens JPM, van Bilsen M, Daemen MJAP. Schreuder J]. Allessic MA, Wellens HIJ. Enhanced suscepribiliry for acquired corsade de pointes arrhythmias in the dog with chronic, complete A block is related to cardiac hyperrophy and electical remodeling. Cinculation. $1998 ; 98: 1125-1135$. 
10. Volders PGA, Sipido KR, Vos MA, Kulcsár A, Verduyn SC, Wellens HJJ. Cellular basis of biventricular bypertrophy and arrhythmogenesis in dogs whth chronic complete atrioventricular block and acquired rorsade de poinres. Circalation. 1998;98; $1136-1147$.

11. Carmeliet E. Use-dependent block and use-dependent unblock of the delayed rectifier $\mathrm{K}^{*}$ current by almokalant in rabbir ventricular myocytes. Cin Res. 1993;73:857-868.

12. de Groot SHMA. Triggered ventricular arrbythmias in the hypertrophied heart. the role of electrophysiological and functional adaptations [PhD thesis]. Maastricht, Netherlands: Maastricht University; 1998.

13. Li GR, Feng J, Yue L, Carrier M, Nartel S. Evidence for two components of delayed rectifier $K^{+}$current in human ventricular myocytes. Cire Res. 199678:689-696.

14. Yan $\mathrm{GX}$, Antzelevitch C. Cellular basis for the electrocardiographic J wave. Cincularion. 1996:93:372-379.

15. Artzelevitch C. The Brugada syndrome. J Cardiovasc Electroplysiol 1998;9:513-516. 


\section{Cellular Basis of Biventricular Hypertrophy and Arrhythmogenesis in Dogs with Chronic Complete Atrioventricular Block and Acquired Torsade de Pointes}

Paul G.A. Volders, Karin R. Sipido, Marc A. Vos, Attila Kulcsár, S. Cora Verduyn, Hein J.1. Wellens

From the Department of Cardiology, Cardiovascular Research Institute Maastricht, Maastrichit University. Netherlands; and the Laboratory of Experimental Cardiology, University of Leuven, Belgium (K.R.S.).

Published in: Circulation. 1998;98:1136-1147

Young Investigators Award of the Stichting Herman Snellen Fonds, Leiden. Netherlands, April 1999 
Abstract

Background: In the dog with chronic complete atrioventricular block (AVB) torsade-depointes arrhythmias (TdP) can be induced reproducibly by class-1ll antiarmythmic agents. In-vivo studies reveal important electrophysiological alterations of the heart at 5 weeks of AVB resulting in increased proarrhythmia. Autopsy studies indicate the presence of biventricular hypertrophy. In this study, the cellular basis of proarrhythmila and hypertrophy in chronic AVB was investigated.

Methods and Results: From chronic-AVB dogs with increased heart weights and TdP, left midmyocardial and right ventricular myocytes were isolated by enzymatic dispersion. These myocytes were significantly larger than sinus-rhytim (SR) controls. In chronic AVB the action-potential spike-and-dome configuration was preserved. However, the actionpotential duration (APD) at $95 \%$ and $50 \%$ of repolarization of the left midmyocardium was significantly larger in chronic AVB than in SR, with little change in the right ventricle, causing enhanced interventricular dispersion of repolarization at slow pracing rates. Treatment with the class-III agent almokalant increased the APD to a much larger extent in chroni-AVB than in SR myocytes and resulted in a higher incidence of early afterdepolarizations (EAD). EAD had their take-off potential between -35 and $0 \mathrm{mV}$. There was no evidence that spontaneous sarcoplasmic reticulum $C^{2}$ release underlies these EAD.

Conclusions: In the dog, chronic AVB leads to hypertrophy of both right and left ventricular myocytes. The repolarization abnormalities predisposing for dass-lll dependent ToP in wivo are the result of cellular electrophysiological remodeling. 


\section{Introduction}

The dog with chronic complete atrioventricular block (AVB) has been described as an animal model of acquired worsade-de-pointes arrhythmias (IdP). ${ }^{12}$ Clincally relevant doses of class-III antiarthythmic agents, either alone (spontaneous TdP) or in combination with programmed electrical srimularion, can evoke such a proarrhyrhmic response in a reproducible manner in the majority of anestherized dogs with chronic AVB. ${ }^{2,3}$ In-wivo studies show that the duration of AVB is an important determinan of the susceptibility to acquired TdP, because the latrer are rarely inducible ar 0 weeks of AVB (acute AVB) or at sinus thyth (SR), but are readily inducible at 5 weeks or later (chronic AVB) in most animals. ${ }^{4}$ The increased susceptibility to arrhythmias in chronic AVB has been related to an inhomogeneous prolongation of the monophasic ventricular action potential (in the left ventricle more than the right ventricle), leading to enhanced regional dispersion of repolarization. Furthermore, class-IIl dependent early afterdepolarizations (EAD) are prominent, which may explain the more frequent observation of ventricular ectopic beats 56 in chronic-AVB dogs. ${ }^{4}$

Structural adaptations accompany the altered hamodynamic load in the heart with AVB. Autopsy studies have demonstrated increased heart-weight to body-weight ratios with significant contributions of both the right-and left-ventricular mass. ${ }^{4}$ Morphologically, the biventricular hypertrophy is characterized by an eccentric expansion with increased right-and left-ventricular diameters, as seen during volume overload.

Therefore, proatrhythmia in dogs with chronic AVB seems to be based upon electrophysiological remodeling in the presence of bradycardia and cardiac hypertrophy. This study was designed to investigate the cellular basis of cardiac electrophysiological and structural changes in this animal model and to assess their contribution to the facilitarion of $\mathrm{TdP}$ induction.

\section{Methods}

The animal experiments were conducted in accordance with the guidelines of the American Physiological Society and under the regulations of the Commitee for Experiments on Animals of the Maastricht University, The Netherlands.

\section{In-Vivo Studies}

Adul mongrel dogs of either sex and weighing between 22 and $32 \mathrm{~kg}$ were used for the experiments. AVB was created according to the proced ure described by Steiner and Kovalik ${ }^{7}$ ( $n_{\text {dogs }}=9$ ). For a complete description of the perioperative care we refer to earlier publications. ${ }^{2-4}$

To document the inducrion of TdP, the class-III agent almokalant was administered incravenously ar a concentration of $0.12 \mathrm{mg} / \mathrm{kg} / 10 \mathrm{~min}$ infusion time in 7 of the 9 animals with chronic $\mathrm{AVB}{ }^{8}$ Almokalant is a known in hibitor of the rapidly-activating 
component $\left(\mathbb{I}_{\mathrm{Kr}}\right)$ of the delayed-rectifier $\mathrm{K}^{+}$current $\left(\mathrm{I}_{\mathrm{K}}\right)^{9}$ and increases regional dispersion of repolarization. ${ }^{810}$ Surface ECG leads and right- and left-ventricular monophasic-action-potential catheters were positioned for simultaneous on-line recording of the signals. TdP was defined as a polymorphic ventricular tachycardia consisting of $\geq 5$ beats rwisting around the baseline in a serting of prolonged QT(U) duration. These experiments were performed during anesthesia at the latest 1 week before the dogs were sacrificed for cell isolation. In subsequent cellular experiments almokalant was also used. Thus, the response to class-III treatment was rested both in wivo and in vitro in dogs with documented episodes of TdP and increased heart weights.

\section{Cell-isolation Procedure}

Anesthetized chronic-AVB ( $\mathrm{n}_{\text {dogs }}=9$ ) and $\mathrm{SR} \operatorname{dogs}\left(\mathrm{n}_{\mathrm{dogg}}=9\right.$; similar bodly weights) received 10,000 IU heparin IV on thoracotomy. In the former group AVB had been present for a duration of $6 \pm 1$ weeks (range, 5 to 9 weeks). The hearts were excised and washed in a cardioplegic solution at 5 to $10^{\circ} \mathrm{C}$. Single right and left ventricular myocytes were isolated simultaneously according to a procedure adapted from Powell. " Cannulas were quickly inserted in and surured to the left-anterior-descending and right coronary arteries under continuous perfusion with cardioplegic solution. Subsequent perfusion was done at $37^{\circ} \mathrm{C}$ with: (1) nominally $\mathrm{Ca}^{2+}$-free standard-buffer solution for $10 \mathrm{~min}$, (2) $\mathrm{Ca}^{2+}$-free solution with collagenase for $10 \mathrm{~min}$, and (3) $\mathrm{Ca}^{2+}$-free solurion with collagenase plus protease for 20 to $30 \mathrm{~min}$. The epicardial surface temperature and the $\mathrm{pH}$ of the cardiac effluent were regularly measured to check for an adequate perfusion of the tissues. Enzymes were washed out wirh $0.2 \mathrm{mmol} / \mathrm{L}\left[\mathrm{Ca}^{2+}\right]$ standard-buffer solution for $10 \mathrm{~min}$. Finally, the tissue was minced and the cell suspension filtered and washed. Left ventricular midmyocardial myocytes were isolated by careful harvesting of the middle third of the transmural wall of the perfused wedge, as described earlier. ${ }^{12}$ Right ventricular myocytes were harvested as a mixture from the transmural wall. Isolated myocytes were stored at room temperature in standard-buffer solution.

\section{Experimental Set-Up}

A sample of the cell suspension was transferred to a perfusion chamber $(0.5 \mathrm{~mL})$ and superfused with standard-buffer solution at a rate of $3 \mathrm{~mL} / \mathrm{min}$ and at $37 \pm 0.5^{\circ} \mathrm{C}$. Myocytes used for the experiments were selected on the basis of the following criteria: having shatp striations, clear contours, transparent cytoplasms withour granulations or blebs, and a resring membrane potential below $-75 \mathrm{mV}$.

Myocytes were imaged by a video camera connected to the inverted microscope (Diaphor 300, Nikon, Inc) of the set-up. The length and width of each cell were measured on a defined area of the monitor with a $\times 40$ microscopic objective. Although the width was not constant allong the length of many cells, we measured this dimension as the estimated average of the broadest and thinnest part of a cell near its middle. More than 600 left midmyocardial and more than 400 right ventricular cells per group were measured. 
For the experiments with microelectrodes, sharp standard glass electrodes filled with $3.0 \mathrm{~mol} / \mathrm{L} \mathrm{KCl}$ (resistance 30 to $60 \mathrm{M \Omega}$ ) were used. Action potentials were recorded with a microelectrode amplifier (Axoclamp-2B. Axon Instruments, Inc) ar cycle lengths (CL) of $300,400,500,1000,2000,3000$ and $4000 \mathrm{~ms}$. The values of accion. potential parameters at baseline and during treatment with almokalant presented throughout the text are the averaged measurements of fre beats during steadymstate pacing. Myocyte contractions were reconded with a video-edge-motion detector (Crescent Electronics) at 16-mus temporal resolution. ${ }^{13}$ The analog output signals were digitized and stored on computer hard disk. Cell shortening was expressed in percent: amplitude in micrometers relative to cell length.

For the measurements of intracellular Ca ${ }^{2+}$ transients and action potentials, the whole-cell variant of the parch-clamp technique was used. 4 Pipettes were pulled from borosilicate glass and had resistances of 1.0 to $3.0 \mathrm{M} \Omega$ when filled with $140 \mathrm{mmol} / \mathrm{L}$ $\mathrm{KCl}$. Membrane potentials were recorded in the current-clamp mode (Axopatch-1 D, Axon Instruments, Inc). The data were filtered at $5 \mathrm{kHz}$, read into a personal computer through an analog-to-digital converter $(2 \mathrm{kHz})$ and stored for later analysis. The data acquisition program also controlled the command potential and various components of the intracellular- $\mathrm{Ca}^{2+}\left(\left[\mathrm{Ca}^{2 *}\right]_{i}\right)$ measurement system (Fastlab Sofware, Indec Systems). The piperte solution contained Fluo-3 and Fura-ned (Molecular Probes). ${ }^{15}$ The combined use of these fluorescent indicators was validated in confocal microscopy. 16 Our experimental set-up for $\left[\mathrm{Ca}^{2}\right]_{\text {i }}$ measurements has been described elsewhere. ${ }^{15}$

\section{Solutions}

The standard-buffer solution contained (in mmol/L): $\mathrm{NaCl} 145, \mathrm{KCl} 4.0$, $\mathrm{CaCl}_{2} 1.8, \mathrm{MgCl}_{2} 1.0, \mathrm{Na}_{2} \mathrm{HPO}_{4} 1.0$, glucose 11, HEPES 10, pH 7.4 with $\mathrm{NaOH}$ at $37^{\circ} \mathrm{C}$ and bubbled with $\mathrm{O}_{2}$. In the cold cardioplegic solution, $\mathrm{KCl}$ was set to 8.0 mmol/L. For the cell isolation, collagenase (1.1 mg/mL; Type A, Boehringer Mannheim) and protease $(0.05 \mathrm{mg} / \mathrm{mL}$; Type XIV, Sigma Chemical Co) were used in the presence of bovine serum albumin $(1.0 \mathrm{mg} / \mathrm{m} \mathrm{L})$. The patch pipetre solution contained (in mmol/L): $\mathrm{K}^{+}$aspartare $120, \mathrm{KCl} 20, \mathrm{MgCl}_{2}$ 0.5, MgATP 5, NaCl 10, HEPES 10 , Fluo-30.03, Fura-red $0.07, \mathrm{pH} 7.2$ with $\mathrm{KOH}$. All of the chemicals were reagent grade and cell-culture tested (purchased from Sigma Chemical Co). Almokalant was kindly provided by Drs. L. Carlsson and G. Duker, Astra Hässle, Mölndal, Swoden.

\section{Statistical Analysis}

The data are expressed as means \pm SD. Intergroup comparisons were made by the Sudent's t test for unpaired (chronic AVB vs SR; right ws left ventricle) and paired (baseline vs treatment) data groups, respectively, after testing for the normality of distribution. The $\chi^{2}$ test was used when the data were presented as a proportion. Differences were considered significant if $P<0.05$. 


\section{Results}

\section{In-Vivo Studies}

In our companion study we report on the electrophysiological consequences of clinically relevant doses of $d$ sotalol in dogs with AVB. In preliminary cellular experiments of the present study, we chose to use almokalant because this agent exhibits a high specificity of $I_{\mathbb{K}}$ inhibition at nano-to micromolar concentrations, ${ }^{9}$ whereas d-sotalol may also exert other actions. ${ }^{17,18}$ Accordingly, the proarrhythmic potential of almokalant was tested in vivo ( $\mathrm{n}_{\text {dogs }}=7$ ). An example of the electrophysiological consequences of almokalant treament and subsequent spontaneous TdP induction is shown in Figure 1. At $4 \pm 2$ weeks of AVB, the class-III agent increased the QT interval from $415 \pm 90 \mathrm{~ms}$ to $545 \pm 105 \mathrm{~ms}(P<0.05)$ without significant change of the CL of the idioventricular thythm (from $1545 \pm 300 \mathrm{~ms}$ to $1655 \pm 295 \mathrm{~ms}_{*}^{*} P=\mathrm{NS}$ ). Almokalant caused an increase of the monophasic action-potential duration (APD) in the left ventricle from $380 \pm 55 \mathrm{~ms}$ to $525 \pm 115 \mathrm{~ms}(P<0.05)$ and in the right ventricle from $335 \pm 65 \mathrm{~ms}$ to $425 \pm 110 \mathrm{~ms}(P<0.05)$, contributing to an enhanced interventricular dispersion of repolarization of $45 \pm 15 \mathrm{~ms}$ ar baseline to $100 \pm 50 \mathrm{~ms}$ during treatment $(P<0.05)$. In 6 of the $7 \mathrm{dogs}$, TdP ensued spontaneously, while in the remaining animal TdP occurred neirher spontaneously nor with programmed electrical stimulation.

\section{Cellular Basis of Biventricular Hypertrophy}

When weighed directly after excision, the hearts of chronic-AVB dogs $\left(n_{\text {dogs }}=9\right.$; $6 \pm 1$ weeks of AVB) were significantly heavier than wose of SR controls $\left(\mathrm{n}_{\text {dogs }}=9\right)$ : $285 \pm 25 \mathrm{~g} v \mathrm{~s} 222 \pm 59 \mathrm{~g}$, respectively $(P<0.05)$. When corrected for body weight, the difference in heart weight remained significant: $10.3 \pm 1.3 \mathrm{~g} / \mathrm{kg}$ vs $8.5 \pm 1.5 \mathrm{~g} / \mathrm{kg}$, respecrively $(P<0.05)$. Myocytes were successfully isolated from the right ventricular free wall and the lef ventricular midmyocandium of all dogs. Representative photomicrographs of single lefr midmyocardial cells are shown in Figure 2. Right ventricular myocytes showed similar morphology, both in chronic AVB and in SR. All cells were quiescent during superfusion with the standard-buffer solucion containing $1.8 \mathrm{mmol} / \mathrm{L}\left[\mathrm{Ca} \mathrm{C}^{2+}\right]$. In the SR group, right ventricular myocytes were of equal length and wid th as compared to left midmyocardial myocytes: cell length was $140 \pm 10 \mu \mathrm{m}$ and $140 \pm 16 \mu \mathrm{m}(\mathrm{P}=\mathrm{NS})$, and cell wideh was $24 \pm 2 \mu \mathrm{m}$ and $25 \pm 2 \mu \mathrm{m}$, respectively (P=NS). In the chronic-AVB group, myocytes from both ventricles were significanty longer than $S R$ controls, being $172 \pm 8 \mu \mathrm{m}$ (right ventricle) and $158 \pm 7 \mu \mathrm{m}$ (left midmyocardium; both $P<0.05$, chronic $A V B$ vs $S R$ ). The difference in cell length of right vs left ventricle in chronic $A V B$ was statistically significant $(P<0.05)$. By contrast, the width of these cells was not different from SR controls: $26 \pm 1 \mu \mathrm{m}$ and $26 \pm 2 \mu \mathrm{m}$, right ws left ventricle, respeccively $(P=\mathrm{NS})$. Frequency distributions for cell length and width are shown in Figure 3. 
1 GONTAIOL

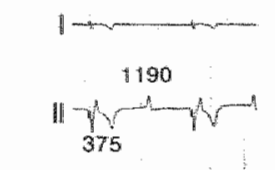

AVR A
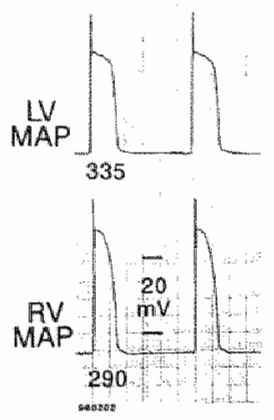

2

ALMOKALANT
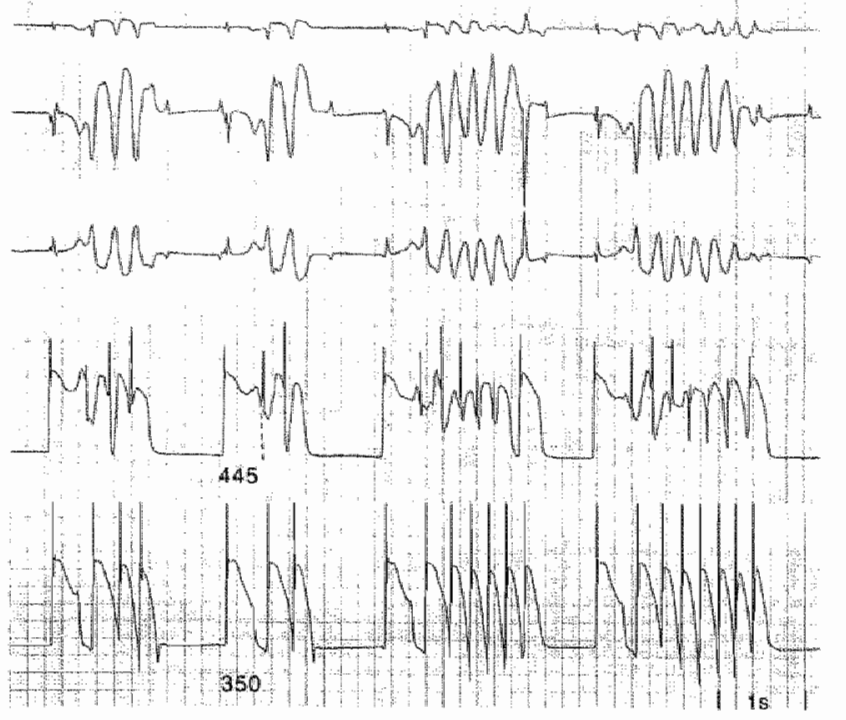

Figure 1. - Two runs of spontaneous TdP in a dog with 3 weeks AVB upon the administration of almokalant $(0.12 \mathrm{mg} / \mathrm{kg} / 10 \mathrm{~min}$ infusion time).

Shown are the electrocardiographic leads I, II and AVR, and the monophasic-action-potential recordings from the left (LV MAP) and right ventricular endocardium (RV MAP). At baseline (1) CONTROL there is an idioventricular mythrm with a CL of $1190 \mathrm{~ms}$ and a QT time of $375 \mathrm{~ms}$. At that moment the left ventricular APD is $335 \mathrm{~ms}$ vs $290 \mathrm{~ms}$ in the right ventricle. During almokalant treatment (2 ALMOKALANT) both the left and right ventricular action potentials prolong to approximately $445 \mathrm{~ms}$ and $350 \mathrm{~ms}$. This in homogeneous action-potential prolongation contributes to an enhancement of the interventricular dispersion of repolarization from $45 \mathrm{~ms}$ at baseline to approximately 95 ms during treatment. Short runs of spontaneous TdP were present until $>20 \mathrm{~min}$ after the end of the almokalant infusion. Characteristically, the initiating ventricular complexes occur before full termination of the T wawe of the ECG and simultaneously with EAD and triggered action potentials, as recorded by the monophasic-action-potential catheters in both the right and left ventricte. For an estimation of the left wentricular APD during almokalant treatment, the descent of the repolarization is drawn artificially.

\section{Action Potentials in Single Myocytes from Dogs with Chronic AVB}

Acrion potentials were recorded at various physiologically relevant pacing CL. with the microelectrode technique in a total of 51 myocytes (chronic $A V B: n_{d o g}=7$.

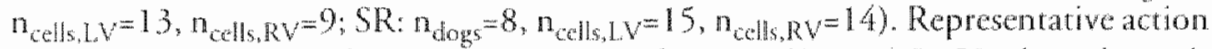
potentials of the four different cell groups are shown in Figure 4 . In SR, the spike-and dome configurarion was more pronounced in right-ventricular than lefemidmyocardial action potentials and more pronounced ar longer CL, as cxpected. In chronic AVB, this pattern was preserved or slighty accentuated (Figure 4). 

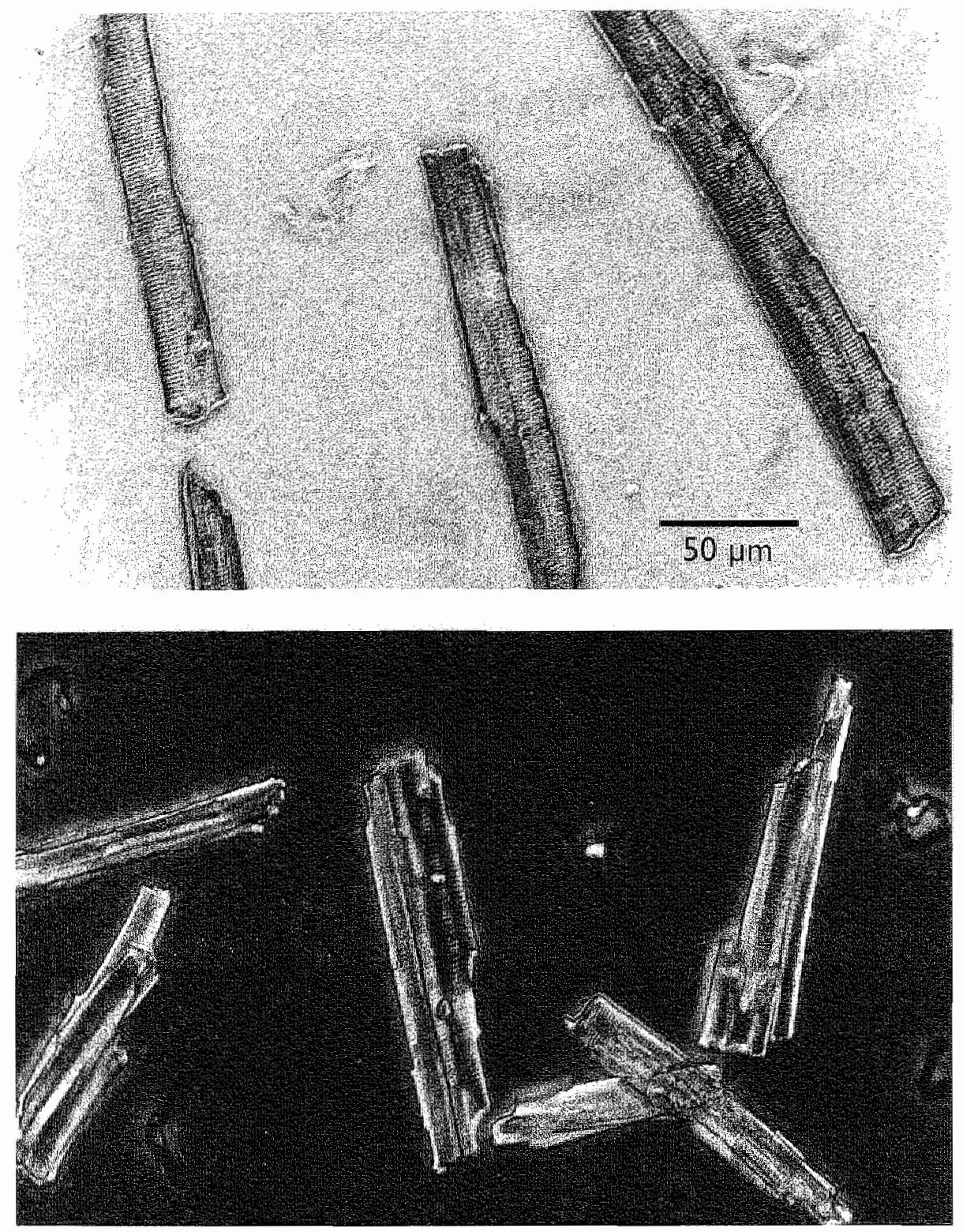

Figure 2. - Photomicrographs of single myocytes isolated from the left ventricular midmyocardium of a chronic-AVB (upper panel) and a SR dog (control; lower panel).

The chronic-AVB myocytes are larger than their SR controls with cell lengths of approwmately $230 \mu \mathrm{m}$ (upper panel, cell on the right) and 160 um (upper panel, cell on the left). Quantitative data for mean myocyte lengths and widths are presented in the Results section. The $50-\mu \mathrm{m}$ calibration bar applies to both panels. Magnification $\times 1000$. 

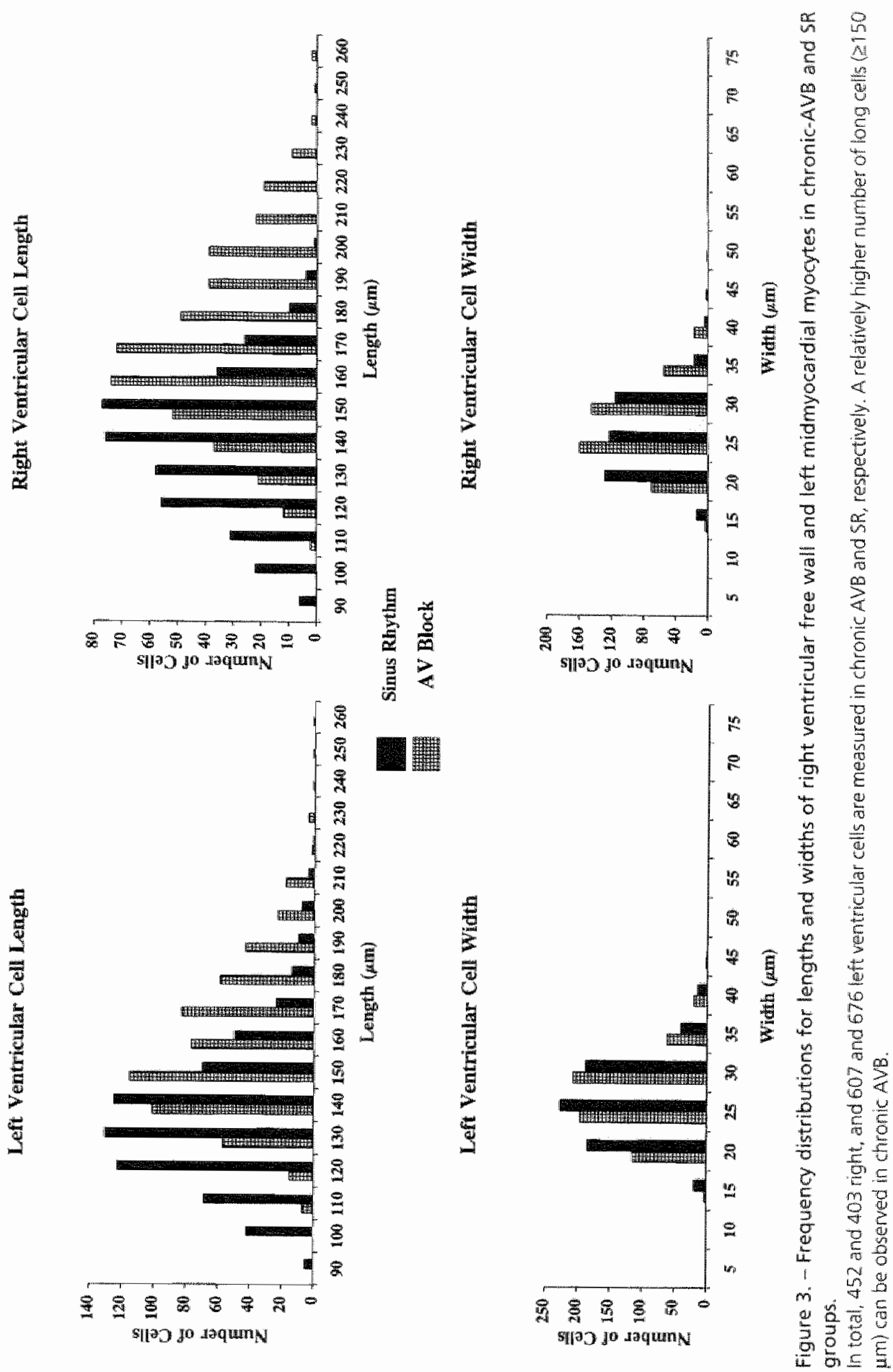


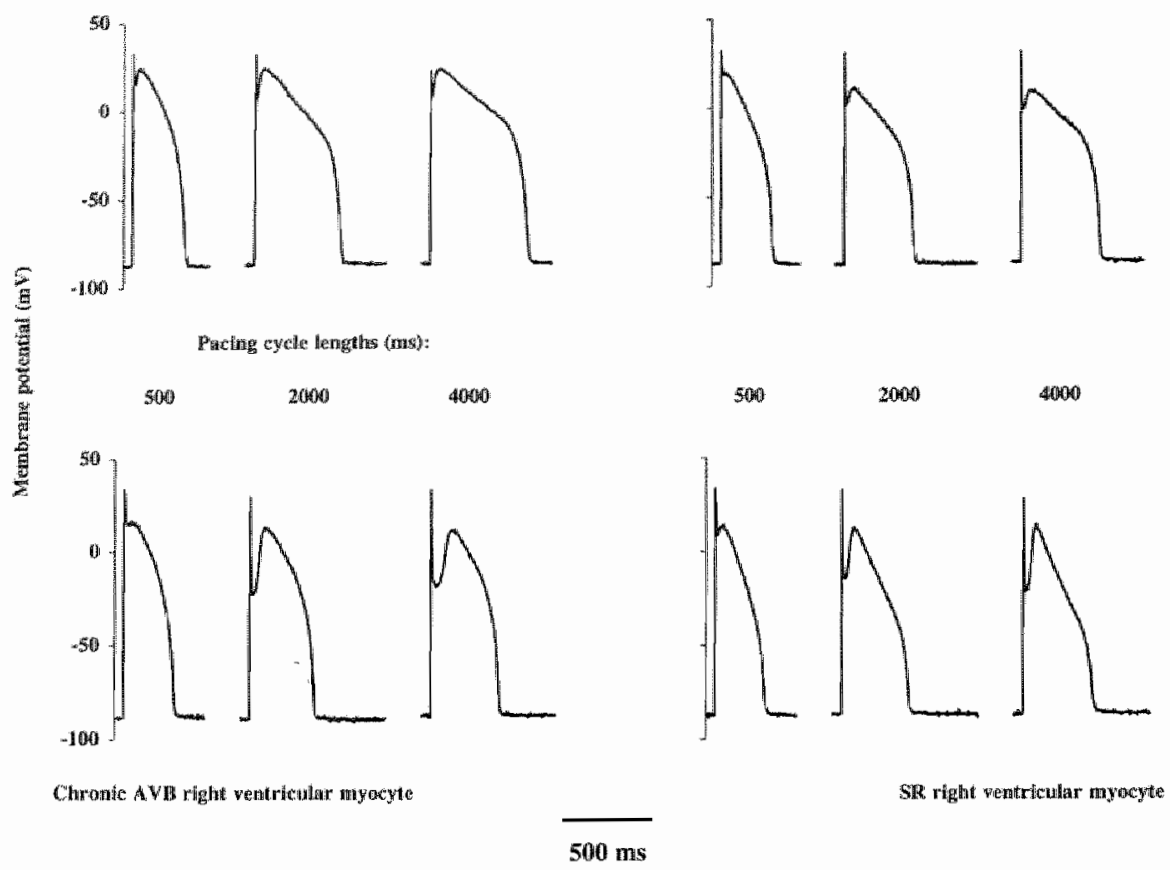

Figure 4. - Action potentials of single myocytes from dogs with chronic AVB as a function of pacing $\mathrm{CL}$.

in each panel, pacing CLS are 500,2000 and $4000 \mathrm{~ms}$, from left to right, respectively. Action potentials of left midmyocardial myocytes are more prolonged in chronic AVB than SR. The APD is larger in the left than the right ventricullar cells in both conditions, especially at long CL. Microelectrode technique.

In SR, the APD at $95 \%$ of repolarization $\left(\mathrm{APD}_{95}\right)$ increased on slowing of the pacing rate, as expected. Pooled data are shown in Figure 5. Chronic AVB significantly steepened this $A P D_{95} / C L$ relationship in the left midmyocardial myocytes $(P<0.05$, chronic $A V B$ ws $S R$ ), but not in the right ventricular cells ( $P=N S$, chronic $A V B$ vs $S R$ ). The interventricular difference of $A P D_{95}$ was therefore significant ar all CL (Figure 5 ). The same was found for the APD at $50 \%$ of repolarization (APD 50 ). This paramerer increased to the same extent as the $A P_{95}$ in chronic AVB, again with significant changes in the lef midmyocardial, but not the right venuicular cells. The maximal velocity of repolarization during phase 3 (measured as the most negative first derivative of the membrane potential in that phase) was not different berween chronic AVB and SR in both ventricles (data not shown).

In an addirional population of 32 myocytes of the same dogs we recorded action porentials during whole-cell patch clamp (chronic AVB: $n_{c e l l s, L}=7$, $n_{\text {cells, }}, y=8 ; S R$ : $\mathrm{n}_{c e l l s, L V}=10, \mathrm{n}_{w}$ lls.RV $=5$ ). We confirmed the differences berween APD of left ws right wenricle, and chronic AVB vs SR under orherwise similar conditions (data not shown). 


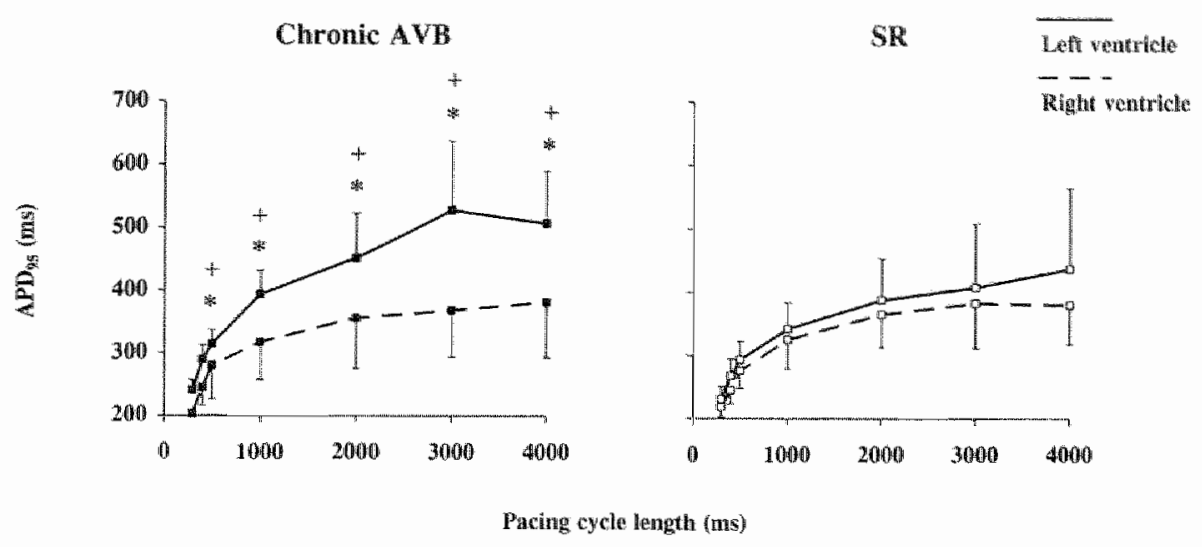

Figure 5. - Pooled data of $\mathrm{APD}_{95}$ as a function of pacing $\mathrm{CL}$ using the microelectrode technique.

In chronic AVB, action potentials of left midmyocardial myocytes are significantly longer than of right ventricular myocytes (left panel; *, P<0.05). Also, the average $\mathrm{APD}_{95}$ of chronic-AVB left midmyocardial cells is larger than of SR controls (lleft vs right panel;,$+ P<0.05$ )

We also examined the peak contraction amplitudes and $\left[\mathrm{Ca}^{2+}\right]_{\mathrm{i}}$ accompanying the action potentials. At the pacing CL of $1000 \mathrm{~ms}$ the peak contraction amplitude measured $4.3 \pm 1.9 \%$ vs $3.1 \pm 3.7 \%$ in right ventricular cells $(P=N S)$, and $7.2 \pm 2.2 \%$ vs $5.1 \pm 2.1 \%$ in left midmyocardial myocytes $(P<0.05$, chronic $A V B$ vs $S R$, respectively). Contraction durations were not different in these cell. groups. $\left[\mathrm{Ca}^{2+}\right]_{\mathrm{i}}$ peaked at $460 \pm 171 \mathrm{nmol} / \mathrm{L}$ vs $517 \pm 102 \mathrm{nmol} / \mathrm{L}$ in the right ventricular mixture $(P=\mathrm{NS}$, chronic AVB vs SR, respectively), and at $457 \pm 146 \mathrm{nmol} / \mathrm{L}$ vs $496 \pm 107 \mathrm{nmol} / \mathrm{L}$ in the left midmyocardium ( $P=$ NS).

Increased Sensitivity of Chronic-AVB Myocytes to Almokalant

We treated both SR and chronic-AVB myocyres with $1 \mu$ mol/L almokalant. A significant prolongation of the action potential was observed in all cells tested $(n=29$; microelectrode technique), which was most pronounced at long pacing CL. Representarive examples of action potentials of chronic-AVB myocytes during treatment with almokalant are shown in Figure 6 . In chronic-AVB cells the relative increase of the $\mathrm{APD}_{95}$ during almokalant (in the absence of EAD!) was much larger than in $\mathrm{SR}$, independent of the chamber. This is illustrated by the pooled data of APD $\mathrm{D}_{95}$ shown in Figure $7 \mathrm{~A}$. In all cells, the $A P D_{50}$ increased to the same extent as the $A P D_{95}$.

In the myocytes studied with patch electrodes $(n=32)$, we found comparable responses to al mokalant; likewise, the average increase of the APD was much larger in the chronic-AVB than the SR cells (Figure 7B).

Action-potential prolongation was often followed by the occurrence of EAD in chronic-AVB myocytes, but not in SR cells, with the microelectrode as well as the 


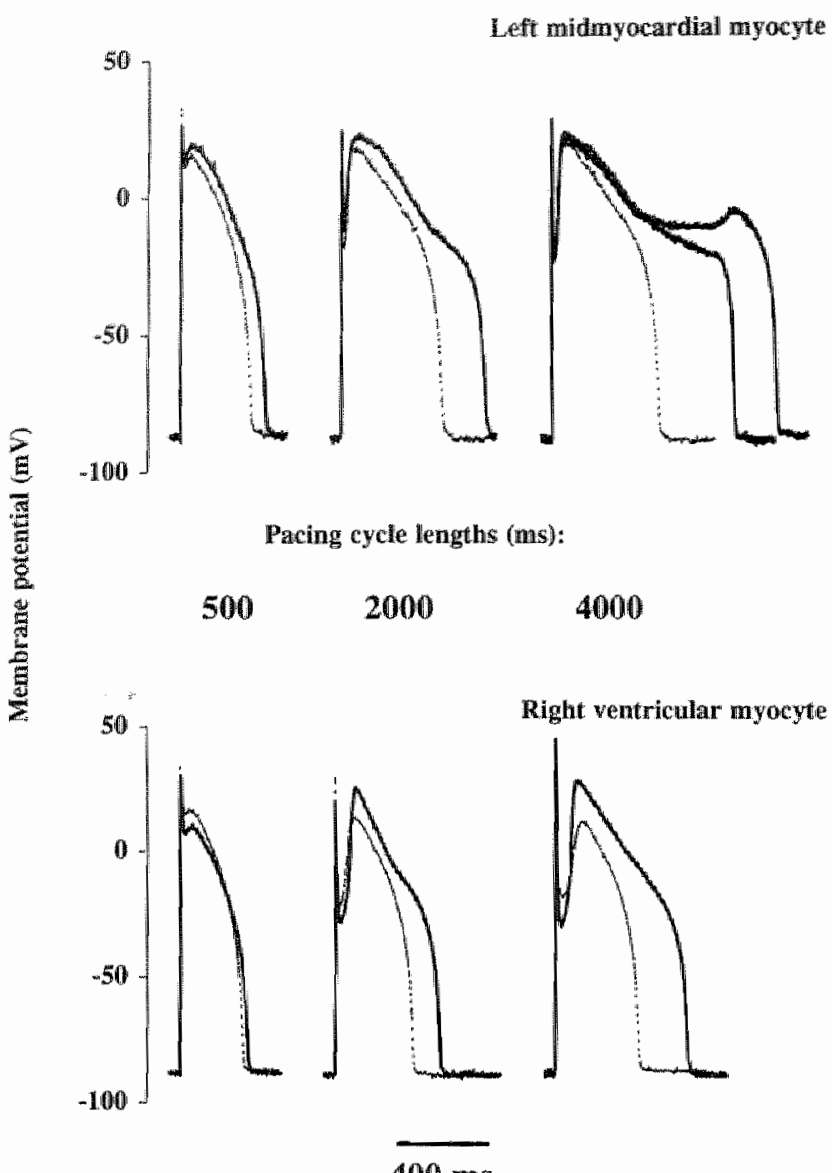

Figure 6. - Action-potential prolongation by almokalant in a left midmyocardial and a right ventricular myocyte during chronic AVB.

The thin dashed action potentials are from the myocytes under baseline conditions and the thick solid action potentials during treatment with the class-lll agent. Action-potential prolongation is most pronounced at long pacing $C L$ and, in this case, more in the left than the right ventricle. In the upper panel, an example of an EAD is shown.

patch-electrode technique. The Table expresses this increased sensitivity as a larger proportion of cells in which EAD were observed during trearment with almokalant. EAD were generared at the longer pacing CL of $\geq 2000 \mathrm{~ms}$. No EAD were observed at CL of $\leq 500 \mathrm{~ms}$. Whenever EAD appeared they caused a significant increase of the APD. In the most sensitiwe cells plateau arrests were often observed, ie, prolonged phases of de- 
polarization (sometimes lasting several seconds) that were followed by one or more EAD before a rapid repolarization. Large beat-to-bear variability of the APD often characterized the class-III action, as is shown in Figure 8.

\section{Characteristics of the Almokalant-Induced EAD in Chronic AVB}

The take-off potentials of almokalant-induced $E A D$ in chronic $A V B$ ranged between -35 and $0 \mathrm{mV}$. On average, EAD started at significantly more negarive levels in the right ventricle $\left(\mathrm{n}_{\mathrm{EAD}}=50\right)$ than the left midmyocardium $\left(\mathrm{n}_{\mathrm{EAD}}=100\right):-30 \pm 2 \mathrm{mV} \mathrm{vs}$ $-19 \pm 5 \mathrm{mV}$, respectively $(P<0.05)$, whereas the action potentials analyzed for this purpose had equal resting membrane potentials. EAD amplitudes were larger in right vs left ventricular myocytes: $21 \pm 6 \mathrm{mV}$ vs $10 \pm 5 \mathrm{mV}(P<0.05)$.

We addressed the question of whether spontaneous $\mathrm{Ca}^{2+}$ release from the sarcoplasmic reticulum could underlie these EAD, as described earlier for isoproterenolinduced EAD ${ }^{19}$ Figure 9 illustrates typical findings for two left midmyocardial myocytes. $\left[\mathrm{Ca}^{2+}\right]_{\text {i }}$ rose rapidly on depolarization, reflecting $\mathrm{Ca}^{2+}$ release from the sarcoplasmic reticulum. This release was followed by a rapid but incomplere decline of $\left[\mathrm{Ca}^{2+}\right]_{\mathrm{i}^{*}}$ and $\left[\mathrm{Ca}^{2+}\right]_{i}$ typically remained elevared at approximately $30 \%$ above baseline values as long as the membrane potential did not recover completely (Figure 9, left panel A). EAD during this phase, however, were not associated with distinct new $\left[\mathrm{Ca}^{2+}\right]_{i}$ transients. Small fluctuations of $\left[\mathrm{Ca}^{2+}\right]_{i}$ were sometimes observed, in amplitude always less than $5 \%$ of the initial $\left[\mathrm{Ca}^{2+}\right]_{i}$ transient. In the case of cell shortening the nomal witch contraction was followed by a relaxation phase during which cell length artained nearresting levels. However, as with the $\left[\mathrm{Ca}^{2+}\right]_{\mathrm{j}}$, full relaxation awaited full repolarization of the action potential (Figure 9, right panel B). In a few cells and only when largeamplitude EAD were generated, we could discern small early aftercontractions that followed the EAD upstroke with a delay of several tens of milliseconds (Figure $9 \mathrm{~B}$, arrow). Similar results on $\left[\mathrm{Ca}^{2+}\right]_{\mathrm{i}}$ and cell shortening during EAD were obtained in 30 cells rreated with almokalant.

\section{Discussion}

\section{Celiular Hypertrophy in Chronic AVB}

The present study confirms the earlier finding of increased heart-weight to body-weight ratios in adul $\mathrm{t}$ dogs with chronic $\mathrm{AVB}$. ${ }^{4}$ The hearts are enlarged consistent with eccentric hypertrophy, as described for volume overload. 20 The hypertrophy is telated to increased lengths of both right and left ventricular myocytes. Myocyte growth has been observed in most large animal models of cardiac hypertrophy reported in the literature (eg, References 21 through 23). We found that the biventricular hypertrophy of chronic AVB was not a homogenous process: growth responses were larger in the right than left ventricular myocytes $(+23 \% \mathrm{vs}+13 \%$ for cell length, respectively), sup porting the autopsy finding of a larger relative increase of the right-than the left- 


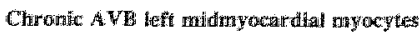

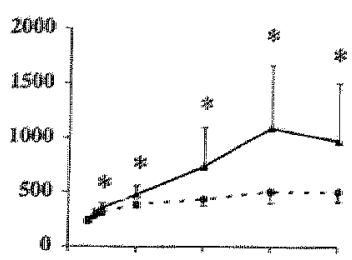

递

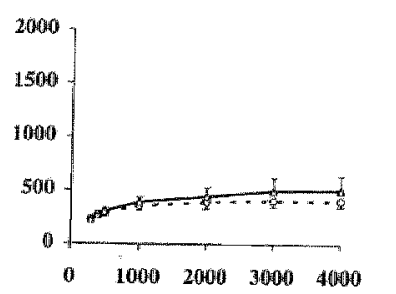

Chronic A VI nght newtricular myecrtes:

$\mathbf{A}$

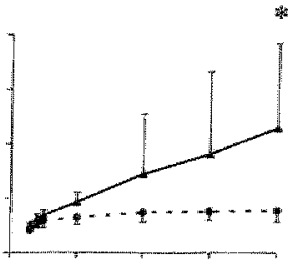

Almokalaut

Baseline

SR right ventricular myocytes

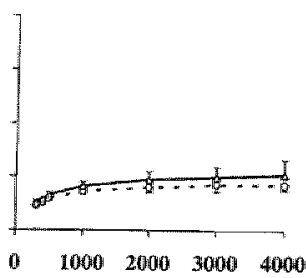

Pacing cycle length (ms)

Chronic AVB left midmyocardial myocytes

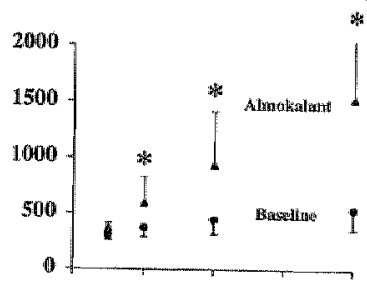

$\frac{1}{8}$
Chronic AVB right ventricular myocytes

B
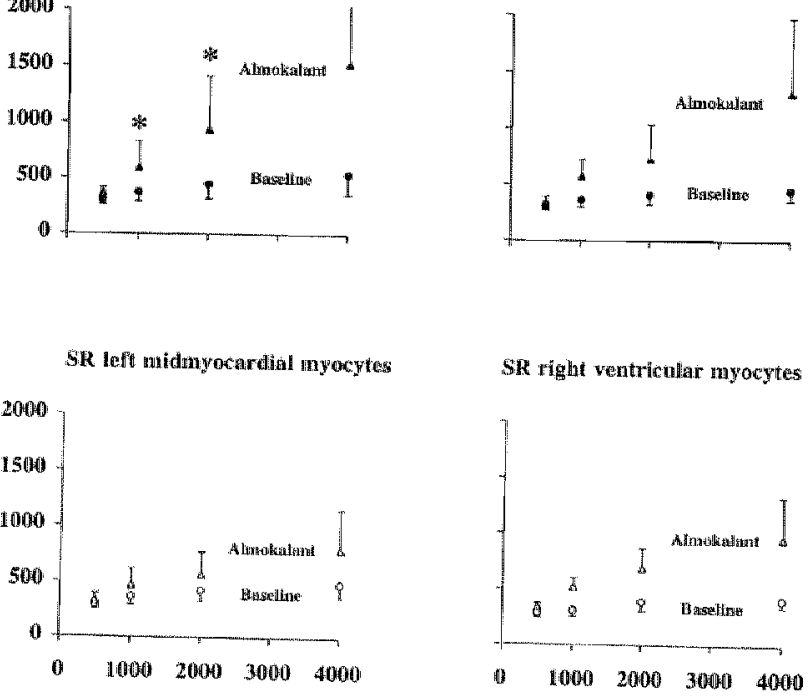

Pacing cycle length (ms)

Figure 7. - Pooled data of $A P D_{95}$ (in action potentials without $E A D$ ) as a function of pacing $C L$
duringl treatment with almokalant. A Dating almokant.

A Data obtained using the microelectrode technique. B. Patch-electrode technique. Almokalant caused a significant increase of the $A_{P D}$ gs in all cell groups, regardiess of the technique used. In absolute terms, this was much more pronounced and within a broader range during chronic $A V B$ than
in $S R$. $P<0.05$ between chronic $A V B$ and $S R$. 
Table _Proportion of Cells Generating EAD During Almokalant Treatinent:

Pacing $\mathrm{Cl}$

$2000 \mathrm{~ms}$

$4000 \mathrm{~ms}$

\section{Chronic AVB}

Left Midmyocardum

$10 / 18$ *

15118 *

Right Ventricular Free Wall

Control (Snus fhythm)

Left Midmyocardium

$7 / 14 *$

$9 / 4$ *

Right Ventricular Free Wall

$3 / 75$

$3 / 4$

414

Values are cell numbers. Almokalant, 1 mollL * P<0,05 between Chronic AVB and sinus fhythm at that $\mathrm{CL}$.



Figure 8. - EADs during treatment with allimokalant: beat-to-beat differences of the APD. Shown is a continuous recording of eight action potentials at a pacing $C L$ of $1000 \mathrm{~ms}$. In the first beat a plateau arrest can be observed that lasts for the full $\mathrm{CL}$ and is overcome only after the pacing stimulus of the next action potential. In consecutive beats, the $\mathrm{APD}_{95}$ varies from 500 to $900 \mathrm{~ms}$. This is an example of temporal dispersion of repolarization within a single cell.

ventricular weight. ${ }^{4}$ This differential ventricular growth response resembles the finding in another animal model of biventricular hypertrophy related to volume overload (aortocaval fistula). ${ }^{22}$ Also, in pigs with heart failure due to rapid pacing, myocytes were larger in the right than left ventricle. ${ }^{24}$ The preponderance of right ventricular cell growh in chronic AVB may reflect a greater impact of the altered hemodynamics on that chamber after the transition from SR to idioventricular rhythm.

As to the funcrional characteristics of chronic-AVB myocytes, we demonstrated that peak amplitudes of contraction and $\left[\mathrm{Ca}^{2+}\right]_{i}$ at $1000 \mathrm{~ms}$ pacing $\mathrm{CL}$ were nor different from SR cells (or, if anything, were slighrly increased). These data, which are the subject of further investigations, provide additional support for the notion, based on in-vivo hemodynamic measurements, ${ }^{4}$ of a compensated form of cardiac hypertrophy. 


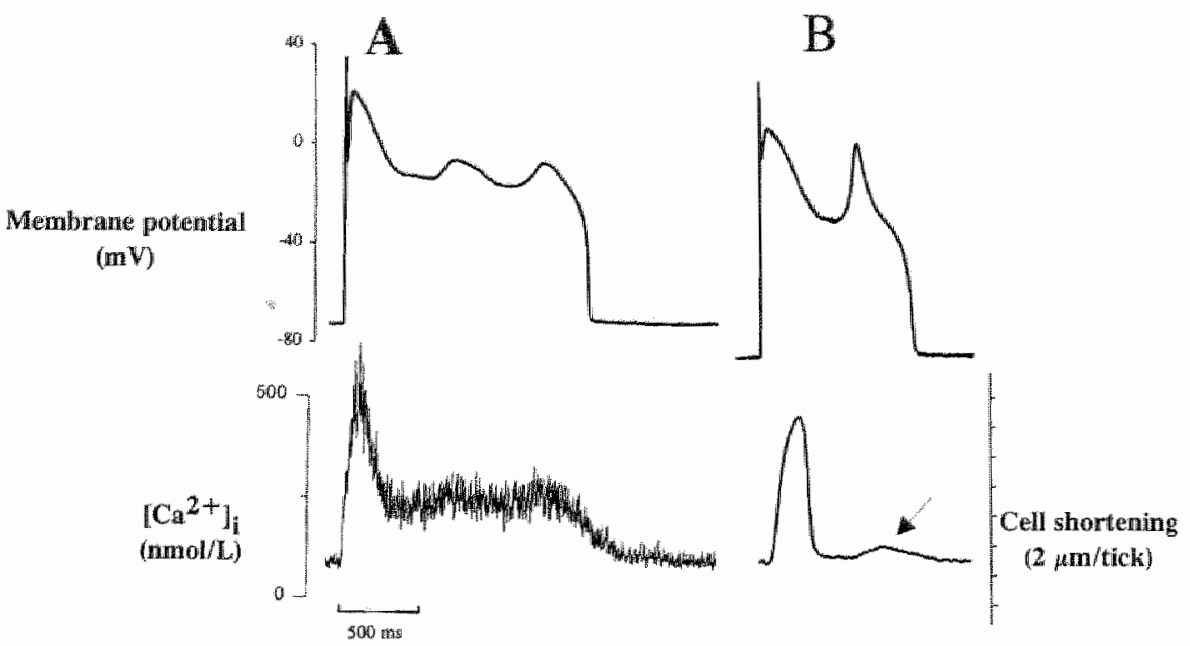

Figure 9. - Cellular handling of $\left[\mathrm{Ca}^{2+}\right]_{1}$ during class-ll dependent EADs in chronic AVB.

In the left half of this figure (panel A), the simultaneous recording of an action potential and $\left.\| C_{a}^{2+1}\right]_{i}$ is depicted using current clamping in the whole-cell variant of the patch-clamp technique and with the fluorescent indicators Fluo-3 and Fura-red in the internal pipette solution. In the right half (panel B), the action potential (microelectrode technique) is recorded simultaneously with cell shortening. In both panels, left ventricular midmyocardial cells were treated with almokalant at 1 umol/h during stimulation at a pacing $C L$ of $4000 \mathrm{~ms}$, leading to the generation of $E A D$. Full relaxation of the $\left[\mathrm{Ca}{ }^{2+}\right]$, and contraction, in $\mathbf{A}$ and $\mathbf{B}$, respectively, was delayed until full repolarization of the action potential. Distinct or high-amplitude peaks of $\left[\mathrm{Ca}^{2+}\right]_{j}$ (ie, $\mathrm{Ca}^{2+}$ aftertransients) were not observed during the EAD, as illustrated in $A$. Small aftercontractions following the upstroke of the EAD were rarely observed. An example is shown in B (arrow).

\section{Cellular Electrophysiological Remodeling in Chronic AVB}

Our data show that myocytes from dogs with chronic $A V B$ have: (1) an intrinsic disturbance of repolarization with prolonged action potentials at baseline, (2) interventricular differences of repolarization, and (3) an increased susceptibility to class-III antiarrhychtnic agents.

Intrinsic disturbance of repolarization. Prolongacion of the left-ventricular action potential is a consistent observation in myocardial hypertrophy of different causes in several species. ${ }^{25-27}$ Cellular electrophysiological data on right-ventricular hypertrophy are scarce. In pressure-overload induced right-ventricular hypertrophy, increases of the APD have been reported. ${ }^{28}$ Many of the sarcolemmal ion channels, exchangers and pumps, as well as intracellular ion transporters that shape the action potential under normal conditions can show functional defects leading to delayed repolarization in hypertrophy. 29,30 Other investigators have shown that this action-potential prolongation predisposes to an increased suscepribility to $\mathrm{EAD}^{31}$ and ventricular tachyarrhythmias. ${ }^{32,33}$ As yet, the ionic basis of action-potential changes in chronic AVB remains to 
be elucidared. The $\mathrm{APD}_{95}$ and $\mathrm{APD}_{50}$ increased to a similar extent, indicating that the delay in repolarization was likely due to a disturbance at the platea level. From the data in this study a prominent role for the ransient outward current ( $\mathrm{To}$ ) appars unlikely; the spike-and-dome configuration of the action potential was preserved or, if anything, accentuated. In this respect the dog with chronic AVB differs from the dog with pacing-induced heart failure. ${ }^{34}$ In thar model, downregulation of $\mathrm{I}_{\mathrm{TO}}$ is at least pardy responsible for an artenuation of the motch of the action potential and an increase of the $A \mathrm{PD}_{y}{ }^{34}$ which has been linked to the generation of lethal ventricular arthythmias. ${ }^{35}$ Additional insights into the ionic mechanisms of action-potential prolongation in chronic AVB come from the experiments with almokalant. Carmeliet ${ }^{9}$ demonstrated that in rabbit ventricular myocytes $\mathbb{I}_{K r}$ is fully blocked by $1 \mu$ mol/L of the agent and we have confirmed this in normal dog ventricular myocytes (data not shown). After block of $I_{K r}$ during almokalant treatment, we found that the APD was much larger in chronic-AVB left and right ventricular myocytes than in SR controls (Figure 7). This implies that ionic currents other than $\mathbb{l}_{K r}$ contribute to the abnormal repolarization of chronic AVB, even though we cannot exclude that $I_{K r}$ also plays a role.

Interventricular differences of repolarization. To the best of our knowledge this is the first sudy to compare action-potential characteristics of single hypertrophied myocytes isolated from both the right and left wentricle of the same dog. Interventricular differences of the action potential are known to exist in the nomal myocardium of dogs with $S R^{6,36}$ and this was confirmed by the present study. In chronic AVB, we found larger APD in left midmyocardial than right ventricular myocytes at baseline, in contrast to the larger degree of hypertrophy in the latter than the former cells. Yer, the administration of almokalant increased the APD to a similarly high level in both ventricles. Thus, the presence of intrinsic repolarization disturbances was unmasked in right ventricular myocytes. At least thee explanations could account for the interventricular differences of repolarization ar baseline: (1) there was a different electrophysiological remodeling in both ventricles. (2) the charge carriess involved were the same, but their functional alterations mounted to different amplitudes, or (3) a finer balance of currents existed during the plateau phase because of a decrease in outward curtent and/or an increase in inward current.

Increased susceptibility to almokalant. Chronic-AVB cells showed an increased susceptibility to action-potential prolongation and EAD generation during class-III reatment. These EAD were observed at long pacing CL and had take-off membrane potentials ranging between -35 and $0 \mathrm{mV}$. Very small changes in the balance of inward and outward currents during the high resistance plateau can determine the appearance or absence of EAD. At least two possibilities could explain the increased number of EAD found in this study: (1) they occurred because the APD was initially prolonged, and/or (2) the charge carrier(s) responsible for theirgeneration were more prominent in myocardial hypertrophy, eg, increased $\mathrm{L}$-rype $\mathrm{Ca}^{2+}$ current $\left(\mathrm{I}_{\mathrm{Cal}}\right)$ or more spontaneous sarcoplasmic reticulum $\mathrm{Ca}^{2+}$ release. If the former is true, it follows that any interwention causing the action potential to shorten, would lead to the diminished appeatance of 
EAD. Preliminary results with the agent levcromakalim, an $I_{K}$.ATP activator, support this hypothesis: we found that in consecurive action potentials with EAD leveromakitlim initially caused a decrease of the APD, followed by the disappearance of the EAD and further shortening of the action potential. The finding that DAD remained also absent during this action-potential shortening was argument against the possibility of spontaneous sarcoplasmic reticulum $\mathrm{Ca}^{2}+$ release to underlie the class-III dependent EAD of chronic AVB. Indeed, the characteristics of cytoplasmic $\mathrm{Ca}^{2+}$ during the $\mathrm{EAD}$ confirmed this notion. We did find that the relaxation of $\left[\mathrm{Ca}^{2+}\right]_{i}$ and cell shortening was slow during action potentials with EAD. The decline of $\left[\mathrm{Ca}^{2+}\right]_{i}$ al ways paralleled the repolariwation regardless of the $A P D$, which suggests that the volrage-dependence of cellular $\mathrm{Ca}^{2+}$ extrusion was maintained as under normal condicions. Our results in chronic-AVB myocyres resemble those of cesium-chloride-induced $\mathbb{E} A D$ in normal ferret ventricular muscle ${ }^{37}$ and class-1II-induced EAD in normal rabbit ventricular myocytes. ${ }^{38}$ Although our data support an important role for the initial actionpotential prolongation, we cannot exclude the possibility that intrinsic changes of $\mathrm{I}_{\mathrm{Cal}}$ may be involwed in the increased number of EAD.

Our finding that EAD amplitudes were larger in right than in left ventricular myocytes could be related to the lower take-off potentials in the former cells. If indeed $I_{\text {CaL }}$ is the major charge carrier of these EAD, its triggering at lower take-off potentials would likely lead to larger current amplicudes.

\section{Cellular Basis of In-Vivo Proarhythmia}

Our data show that the interventricular differences of APD were most pronounced at the longer pacing CL of $\geq 2000 \mathrm{~ms}$, measuring maximally $100 \mathrm{~ms}$ at baseline. Because in most cases the $\mathrm{CL}$ of the idioventricular rhythms of the dogs were $>1500 \mathrm{~ms}$, we consider the cellular findings relevant for the in-vivo siruation and find them consistent, at least qualitatively, with the monophasic-action-potential findings in the same dogs before they were sacrificed. We do nor believe that interventricular dispersion itself is the direct cause for the iniriation of torsade de pointes, but because it is always present during arthythmogenesis it probably reflects the existence of dispersion of more closely juxtaposed regions. When using almokalant in our experiments, we found that this agent promoted temporal heterogeneity of repolarization with varying APD and EAD chat appeared in an on-and-off fashion in consecutive beats during stcadywstate pacing. Dispersion could be enhanced even more if the heterogeneity of cell tular repolarization occurred out of phase in warious regions of the myocardium. We have demonstrated such spatial dispersion in vivo. ${ }^{3}$

Another important factor involved in the occurrence of T. $\mathrm{dP}$ is ventricular ectopy. In-vivo recordings in the dog with chronic AVB confirm the importance of ventricular ectopic beats (Figure 1),2,4 however until now their origin and mechanisms remain obscure. While others have demonstrated triggered activity upon EAD in Purkinje fibers during in-vitro conditions that mimic proarrhythmia in wivo, $39-41$ it can be concluded from the present study that in single cells from the working myocardium 
abnomal impulse generation is limited to EAD that do not rigger new action poten tials in these same cells. This conclusion is based on our findings that the ED always: (1) arose from a take-off membrane potential less negative than $-35 \mathrm{mV}$ (above the threshold for full activation of $\mathrm{Na}^{+}$current) and did not show a rapid upstroke as in normal action potentials; (2) had an amplitude $<30 \mathrm{mV}$; (3) prolonged the repolarizarion, bur did not take the shape of normal action potentials; (4) were incapable of inducing normal, if any, contractions; and (5) behaved differenty from the EAD observed in Purkinje fibers or in ventricular myocytes with take-offlevels closer to the resung membrane potential. Thus, the characteristics of these membrane responses do not match our definition of the ventricular action potential.

DAD-triggered action potentials or abnormal automaticity were also not observed in the chronic-AVB cells. This all may mean that the substrate for extrasystolic activity involved in the initiacion of TdP is multicellular (eg, phase-2 reentry) or includes the Purkinje newwork. In addition, the experimental setup chosen for this study lacks many of the components affecting arrinythmogenesis in vivo, such as adrenergic agonists, stretch and sudden rate changes. For this reason the absence of spontaneous action potentials in the single myocyte does not exclude their generation in vivo.

\section{Limitations of the Study}

One of the aspects of this study was to compare the action-potential chatracteristics of myocytes from the left midmyocardium with thase from the right transmural ventricular wall. One could argue that this comparison is not fully adequate given the findings made in tissue studies that the shape of the ventricular action porential and the CL dependence of its duration vary across the free wall of boch chambers. ${ }^{42}$ Because of the thinness of the right ventricular wall we found it difficult to isolate the cells according to their rransmural site of origin in that chamber. Nevertheless, at long pacing CL right ventricular myocytes consistently had a typical action-potential configuration that was different from that of the left midmyocardial cells. In addition, the range of APD measured in left and right ventricular cells, $\mathrm{cg}$, at a CL of $2000 \mathrm{~ms}$, showed an overlap of only $10 \%$ in chronic AVB and of $20 \%$ in SR. A bad pick of only epicardial or endocardial cells from the right ventricular muxture might explain this finding, but this is unlikely. A more plausible explanation is that the APD differences of midmyocardial vs epi-and endocardial myocytes are much less in the right than the left ventricle. The comparison of right transmural vs left transmutal ventriculat myocytes (instead of right mansmural vs left midmyocardial cells, as made now) would likely underestimate the interventricular dispersion of repolarization present in these hearts and was therefore not applied.

When we compared the action-potential characteristics of our right ventricular mixture with the data presented by Sicouri and Antzelevitch, ${ }^{42}$ we found that the majority of our cells ( $93 \%$ for $S \mathrm{R}$ and $67 \%$ for chronic AVB) had a steep APD/CL relationship, which would identify them as right ventricular midmyocardial cells. 


\section{Conclusions}

We conclude thar AVB of chronic duration leads to inhomogeneous hypertrophyof right and left ventricular myocyes. Cellular hypertrophy is associated with an intrinsic defect of tepolarization in the right and left ventricle. $\mathrm{APD}$ differences between left midmyocardial and right ventricular myocytes cause an enhanced interventricular dispersion of repolarization, which is most pronounced at the longer pacing CL. Almokalant increases the APD to a much larger extent in chronic $A V B$ than in $S R$, thus further unmasking the presence of intrinsic repolarization disturbances. In addition, chronic-AVB cells of both ventricles show an increased susceptibility to EAD generation. Although the present study does not elucidate the ionic basis of these actionpotential differences or the genesis of wentricular ectopic beats, it appears that phenotypic alterations of repolarization are involved in the ventricular arhychmias and sudden cardiac death of dogs with chronic AVB.

\section{Acknowledgements}

This study was supported by the Wynand M. Pon Foundation (Leusden, The Netherlands). Dr. Sipido is a postdoctoral researcher of the National Fund for Scientific Research Belgium. The European Society of Cardiology is acknowledged for providing a research fellowship to Dr. Kulcsár. Dr. Verduyn is a postdoctoral researcher of the Netherlands Heart Foundation, project number 94.010. The anthors wish to thank Jet D.M. Leunissen (Department of Cardiology) and Matthijs J.P. Killian, PhD (Department of Physiology) for expert technical assistance, and Jack P.M. Cleutjens, PhD and Mat J.A.P. Daemen, MD, PhD (Deparment of Pathology) for the photomicrography. Bela Szabo, MD, PhD (University of Okdahoma Health Sciences Center, USA) contributed with helpful comments to the manuscript.

\section{References}

1. Weissenburger J, Davy J-M, Chézal wiel F, Ertabischoffo, Poirier M, Engel F, Lainée P, Penin $\mathbb{E}$, Motté $G$, Cheymol G. Arrhythmogenic activities of antiarthydmic drugs in conscious hypokalemic dogs with atriowentricular block: comparison between quinidine, lidocaine, Alecainide, propanolol and sotalol. I Pharmacol Exp Ther. 1991; 259:871-883.

2. Vos MA, Verduyn SC, Gorgels APM, Lipcsei GC, Wellens HJ]. Reproducible inducrion of early afrerdepolarizations and torsade de pointes arrhythmias by $d$-sotalol and pacing in dogs with chronic atrioventricular block. Circulation. 1995;91:864-872.

3. Verduyn SC, Vos MA, van der Zande J, van der Hulst FF, Wellens HJ. Role of intervenrricular dispersion of repolarization in acquired torsade-de-poinres arrhythnias: reversal by magnesium. Cardiovasc Res. 1997;34:453-463. 
4. Vos MA, de Groot SHM, Verduyn SC, van der Zande I, Leunissen HDM, Cleurjens IPM, van Bilsen M, Daemen MJAP, Schreuder JJ. Allessie MA, Wellens HJ E. Enhanced susceptibility for acquired torsade de pointes in the dog with chronic, complete atrioven. tricular block is related to cardiac hypertrophy and electrical remodeling. Accompanying paper submitred to Cimculation.

5. El-Sherif N, Craelius W, Boucjdir M, Gough WB. Early afterdepolarizations and arrhythmogenesis. / Cardiousc Electrophysol. 1990;2:145-160.

6. Antzelevitch $\mathrm{C}$, Sicour $S$. Clinical relevance of cardiac arrhythmias generated by afterdepolarizations: role of $\mathrm{M}$ cells in the generation of $U$ waves, rriggered acriwiry and rorsade de pointes. I Am Coll Cardiol 1994;23:259-277.

7. Steiner C, Kovalik ATW. A simple technique for production of chronic complete heart block in dogs. J Appl 1'bysiol 1968:25:631-632.

8. Verduyn SC, Vos MA, van der ZandeJ, Kulcsà A, Wellens HJJ. Further observations to elucidate the role of interventricular dispersion of repolarization and early afterdepolatizations in the genesis of acquired torsade de pointes arrhythmias: a comparison benween almokalant and $d$-soralol using the dog as its own control. I Am Coll Cardiol. 1997;30: $1575-1584$.

9. Carmeliet $\mathrm{E}$. Use-dependent block and use-dependent unblock of the delayed ractifier K current by almokalant in rabbit ventricular myocytes. Cin Res. 1993;73:857-868.

10. Carlsson L, Abrahamsson C, Andersson B, Duker G, Schiller-Linhardt. G. Proarthythmic effects of the class $I I I$ agent almokalant: importance of infusion rare, QT dispersion, and early afterdepolarisations. Cardiotsts Res. 1993;27:2186-2193.

11. Powell T. Methods for the preparation and characterization of cardiac myocytes. In: Dhalla NS, ed. Methods in Studying Cardiac Membranes, Voll. Boca Rotan, FL: CRC Press; 1984:41-62.

12. Liu D-W, Antzelevitch $C$. Characterisrics of the delayed rectificr current $\left(I_{L_{r}}\right.$ and $\left.I_{\mathbb{K}}\right)$ in canine ventricular epicardial, midmyocardial, and endocardial myocytes: a weaker $I_{\text {kis }}$ contributes to the longer action potential of the M cell. Circ Res. 1995:76:351-365.

13. Steadman BW. Moore KB, Spitzer KW, Bridge JHB. A video system for measuring motron in contracting heart cells. IEEE Trans Biomed Eng. 1988:35:264-272.

14. Hamill OP, Marty A, Neher E, Sakmann B, Sigworth BJ. Improved parch-clamp techniques for high-resolution current recording from cell and cell-free membrane parches. Pflugers Arch. 1981;391:85-100.

15. Sipido KR, Maes M, Van de Werf F. Low efficiency of $\mathrm{Ca}^{2+}$ entry through the $\mathrm{Na}^{\prime}-\mathrm{Ca}^{2}$ " exchanger as trigger for $\mathrm{Ca}^{2 *}$ release from the sarcoplasmic reticulum: a comparison berween L-rype $\mathrm{Ca}^{2+}$ current and reverse-mode $\mathrm{Na}^{4}-\mathrm{Ca}^{2+}$ exchange. Circ Res. 1997:81:1034-1044.

16. Lipp P, Lüscher C, Niggli E. Photolysis of caged compounds characterized by rariometric confocal microscopy: a new approach to homogeneously control and measure the calcium concentration in cardiac myocytes. Cell Calciam. 1996;19:255-266.

17. Carmelier E. Electrophysiologic and voltage clamp analysis of the effeces of sotalol on isolated cardiac muscle and Purkinje fubers.J Phamorol Expt Ther. 1985;232:817-825. 
18. Holubarsch C, Schneider R, Pieske B, RufT, Hasenfuss G. Fraedrich G, Posival H, Just $H$. Positive and negarive inotropic effects of $D L$-sotalol and $D$-sotalol in failing and nonGailing humar myocardium under physiological experimental conditions. Circalation. $1995,92: 2904-2910$.

19. Volders PGA, Kulcsár A, Vos MA. Sipido KR, Wellens HIJ, Lazzara R, Szabo B. Similarities between early and delayed afterdepolarizations induced by isoproterenol in canine ventricular myocytes. Cardiowdsc Res. 1997,34:348-359.

20. Gerdes $A M$. The use of isolated myocytes ro evaluate myocardial remodeling. Trexds Cardiouar Med 1992;2:152-155.

21. Keiman RB, Houser SR. Electrophysiologic and mechanical properties of single feline RV and LV myocytes. J Mol Cell Cardiol 1988;20:973-982.

22. Liu Z, Hilbelink DR, Crocken WB, Gerdes AM. Regional changes in hemodynamics and cardiac myocye size in rats with aortocaval fisculas: 1. Developing and established hypertrophy. Cinc Res. 1991;69:52-58.

23. Urabe Y, Hamada Y, Spinale FG, Carabello BA, Kent RL, Cooper IV G, Mann DL. Cardiocyte contractile performance in experimental biventricular volume-overload hyperrophy. Am J Physiol 1993;264:H1615-H1623.

24. McMahon WS, Mukherjee R, Gillete PC, Crawford FA, Spinale FG. Right and left ventricular geometry and myocyte contractile processes with dilated cardiomyopathy: myocyte growth and $\beta$-adrenergic responsiveness. Cardiovasc Res. 1996;31:314-323.

25. Aronson RS. Character"stics of action potentials of hypertrophied myocardium from rats with renal hyperrension. Circ Res 1980;47:443-454.

26. Ryder KO. Bryant SM, Hart G. Membrane current changes in left ventricular myocytes isolated from guinea pigs after abdominal aorric coarctation. Cardiovas Res. $1993 ; 27: 1278-1287$.

27. Cerbai E, Barbieri M, Li Q, Mugelli A Ionic basis of action potential prolongation of hypertrophied cardiac myocytes isolated from hypertensive rats of different ages. Cardiowas Res. 1994:28:1180-1187.

28. Kleiman RB. Houser SR. Calcium curtents in normal and hypertrophied isolated feline ventricular myocytes. Am / Plysiol 1988:255:H1434-H1442.

29. Carré F, Rannou F, Sainte Beuve C. Chevalier B, Moalic JM, Swynghedauw B, Charlemagne D. Arrhyth mogenicity of the hypertrophied and senescent heart and relationship to membrane proteins involved in the altered calcium handling. Cardowarc Res. $1993: 27: 1784-1789$

30. Harr G. Cellular elecrophysiology in cardiac hyperephy and failure. Cardionas Res. 1994:28:933-946.

31. Aronson RS. Aferpotentials and riggered activity in bypertrophied myocardium from rats with renal hypercension. Circ Res. 1981;48:720-727.

32. Kowey PR. Friehling TD, Sewter J, Wu Y, Sokil A, Paul J, Nocella J. Electrophysiological effects oflef ventricular hypertrophy: effect of calcium and potassium channel blockade. Circulation 1991:83:2067-2075. 
33. Ben-David J, Zipes DP, Ayers GM, Pride HP. Canine lefe ventricular hypertrophy predisposes to ventricular tachycardia inducrion by phase 2 early afrerdepolarizations after administration of BAY K 8644. I Am Coll Cardol 199220:1576-1584.

34. Käab $S$, Nuss HB, Chiamvimonvat $N$, O'Rourke B, Pak J'H, Kass DA, Marban E. Tomaselli GF. Ionic mechanism of action potential prolongation in ventricular myocytes from dogs with pacing-induced heart failure. Cir Res. 1996:78:262-273.

35. Tomasell GF, Beuckelmann DJ, Calkins HG, Berger RD, Kessler PD, Lawrence JH, Kass D, Feldman AM, Marban E. Sudden cardiac death in heart failure: the role of abnormal repolarization. Circulation. 1994;90:2534-2539.

36. Di Diego JM, Sun Z-Q, Antzelevitch C. $\mathbb{I}_{\text {sio }}$ and action potencial notch are smaller in left vs. right canine ventricular epicardium. Am J Physol. 1996;271:H548-H561.

37. Marban E, Robinson SW, Wier WG. Mechanisms of arrhythmogenic delayed and carly afrerdepolarizarions in ferret ventricular muscle. / Clin Invest. 1986;78: 1185-1192.

38. Zhou Z, Sudenik C. January CT. Properties of E-4031-induced early afrerdepolarizations in rabbir ventricular myocytes: studies using a perforated patch method. Jn: Vereecke I, van Bogaert PP, Verdonck F, eds. Potassiwn Channels in Normal and Parhological Condrions. Leuven, Belgium: Leuven University Press; 1995:375-378.

39. Brachmann J, Scherlag BJ, Rosenshtraukh LV, Lazzara R. Bradycardiandependent triggered acrivity: relevance to drug-induced multiform ventricular tachycardia. Cinculafion. $1983 ; 68: 846-856$.

40. Damiano BP, Rosen MR. Effects of pacing on triggered activity induced by early afterde polarizations. Circulation. 1984;69:1013-1025.

41. Roden DM, Hoffman BF. Action potential prolongarion and induction of abnormal auromaticity by low quinidine concentrations in canine Purkinje fibers: relationship to potassium and cycle length. Cin Res. 1985;56:857-867.

42. Sicouri S, Antzellewitch C. A subpopulation of cells with unique electrophysiological properties in the deep subepicardium of the canine ventricle: the $M$ cell. Circ Res. $1991 ; 68: 1729 \times 1741$. 



\section{Downregulation of Delayed Rectifier $\mathrm{K}^{+}$Current in Dogs with Chronic Complete Atrioventricular Block and Acquired Torsades de Pointes}

Paul G.A. Volders, Karin R. Sipido, Marc A. Vos, Roel L. H.M. G. Spätjens, Jet D.M. Leunissen-Beekman. Edward Carmeliet, Hein J.J. Wellens.

From the Department of Cardiology, Cardiovascular Research Institute Maastricht (E.C.). Maastricht University, Netherlands; and the Laboratory of Experimental Cardiology, University of Leuven, Belgium (K.R.S.).

Young investigators Final at the 20th Annual Scientific Sessions of the North American Society of Pacing and Electrophysiology, Toronto, Canada, May 1999 


\section{Abstract}

Background: Acquired QT prolongation enhances the susceptibility to torsades de pointes (TdP). Clinical and experimental studies indicate ventricular action-potential prolongation. increased regional dispersion of repolarization and early afterdepolarizations as underlying factors. We examined whether $K^{*}$-current alterations contribute to these proarrhythmic responses in an animal model of TdP: the dog with chronic complete atrioventricular block (AVB).

Methods and Results: Whole-cell $K^{*}$ currents $I_{\text {ron }}, I_{k 1}, I_{k, r}$ and $I_{K S}$ were recorded in left (LV) and right wentricular (RV) midmyocardiai cells from dogs with $9 \pm 1$ weeks of AVB and controls with sinus rhythm. $\left.\right|_{10}$ density and kinetics, and $l_{\text {s }}$ outward current were not different between chronic AVB and control. $\left.\right|_{k r}$ measured as the almokalant-sensitive tail current on repolarization to $-50 \mathrm{mV}$, had a similar voltage dependence of activation and time course of deactivation in chronic AVB and control. $I_{\mathrm{K}}$, density was similar in LV myocytes, but smaller in RV myocytes (-45\%) of chronic AVB versus control. For $\mathrm{K}_{k_{5},}$ measured as the tall current on repolarization to $-25 \mathrm{mV}$ in o $\left[\mathrm{K}^{+}\right]_{0}$ and the presence of almokalant, voltage dependence of activation and time course of deactivation were similar in chronic AVB and control. However, $I_{K_{s}}$ densities of LV $(-50 \%)$ and RV cells $(-55 \%)$ were significantly lower in chronic AVB than control.

Conclusions: Significant downregulation of delayed rectifier $K^{*}$ current occurs in both ventricles of the dog with chronic AVB. The low functional expression of $I_{k s}$ predisposes to acquired TdP in vivo, and suggests that this animal model develops intrinsic repolarization defects as found in the human long-QT syndrome. 


\section{Introduction}

Acquired QT prolongation is a common electrocardiographic finding in heart disease, but can also be present as a primary derangement in the absence of structural abnormalities or drugs. ${ }^{1}$ It is regarded as one of the risk factors of ventricular arrhythmias and sudden cardiac death. ${ }^{1}$ Clinical and experimental studies on the acquired long-QT syndromes indicate an enhanced susceptibility to polymorphic ventricular tachycardias, notably torsades de pointes (TdP). ${ }^{2,3}$ Unlike for the congenital long-QT syndromes, in which distinctive defects of ion-channel function in myocardial cells are found to be responsible for delayed repolarization, ${ }^{4}$ the ionic basis of acquired QT prolongation, not related to drugs, is poorly understood.

In recent years we have used the dog with chronic complete atrioventricular block (AVB) as a model for the study of TdP. ${ }^{5}$ QT intervals and wentricular endocardial monophasic acrion-potential durations (APDs) are much longer than expected on the basis of the bradycardia alone in these animals and point towards a disturbed ventricular repolarization, ${ }^{6}$ corresponding with clinical findings on acquired $A V B .7,8$ Anesthetized dogs show an enhanced susceptibility to acquired $T d P$ after several weeks of $A V B$ duration, which is associated with the development of increased interventricular dispersion of repolarization and early afterdepolarizations. ${ }^{6}$ Electrical remodeling is accompanied by the development of biventricular hypertrophy, ${ }^{6.9}$ Approximately $15 \%$ of the dog population dies suddenly, often during circumstances of excitement ( $\mathrm{eg}$, dur-ing feeding or ambulation). Transmembrane action-potential recordings in isolared myocytes indicate that the prolonged ventricular repolarization of chronic AVB is an intrinsic abnormalicy, which is amplified by class III antiarrhythmic drugs. ${ }^{9}$ In addition, action-potential prolongation is more pronounced in left (LV) than right ventricular (RV) myocytes, supporting the in-vivo finding of increased regional dispersion of repolarization.

In our search for the ionic mechanisms of electrical remodeling and proarthythmia in dogs with chronic $A V B$, we investigated the possible contribution of $\mathrm{K}^{+}$-curtent alterations to ventricular acrion-potential prolongation and increased regional dispersion of repolarization. To this end, we measured whole-cell $\mathrm{K}^{+}$currents in midmyocardial cells of animals with documented $T d P$ and directly compared $L V$ and $R V$ myocytes in the same hearts.

\section{Methods}

Animal handling was in accordance with the 'Dutch Law on Animal. Experimentation' and the 'European Directive for the Protection of Vertebrate Animals Used For Experimental and Other Scientific Purposes (86/609/EU)'. The experiments were approved by the 'Committee for Experiments on Animals' of our university. 


\section{In-Vivo Studies}

Twenty four adult mongrel dogs of either sex and weighing between 22 and 37 $\mathrm{kg}$ were used for the experiments. For a complete description of the creation of AVB $\left(n_{\text {dogs }}=15\right)$ and perioperarive care we refer to a previous publication. ${ }^{6}$ To test the inducvion of TdP, the class IM agent almokalant $(0.12 \mathrm{mg} / \mathrm{kg} / 10$ minutes $\mathrm{W})$ was used, either alone (spontancous TdP) or in combination with programmed elecrical stimulation. $10 \mathrm{~T} d \mathrm{P}$ was defined as a polymorphic ventricular tachycardia consisting of $\geq 5$ beats twisting around the baseline in a setring of prolonged QT(U) duration. These experiments were performed during anesthesia $=1$ week prior to sacrifice of the dogs for cell isolation.

\section{Cellular Experiments}

Anestherized chronic-AVB $(9 \pm 1$ weeks) and control dogs (with sinus thythm; $\left.\mathrm{n}_{\text {dogs }}=9\right)$ received heparin IV upon thoracotomy. The hearts were quickly excised and washed in cold cardioplegic solution. Heart weights of chronic-AVB dogs were signifcantly larger than those of control dogs: $306 \pm 12$ versus $220 \pm 8 \mathrm{~g}$, respectively $(P<0.05)$. When corrected for body weight, this difference remained significant: $11.6 \pm 0.3$ versus $8.6 \pm 0.3 \mathrm{~g} / \mathrm{kg}(P<0.05)$.

To isolate single LV and RV midmyocardial cells simultaneously, the leftanterior-descending and right coronary artery were cannulated. The isolation proce-

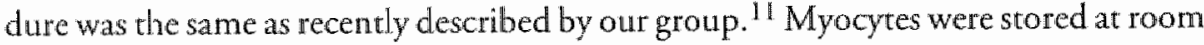
temperature in standard-buffer solution. Whole-cell currents were measured using patch pipettes (borosilicate glass) with resistances of 1.0 to $3.0 \mathrm{M} \Omega$ when filled with internal solution. Experiments were performed at $37 \pm 0.5^{\circ} \mathrm{C}$. Cell capacitance, measured by hyperpolarizing steps from a holding potential of $-60 \mathrm{mV}$, was similar in the four cell groups. In the $L V$ myocytes, average values were $216 \pm 9 \mathrm{pF}\left(\mathrm{n}_{\mathrm{Chroni}} \mathrm{AVB}=35\right.$ ) versus $227 \pm 11 \mathrm{pF}$ ( $\mathrm{n}_{\text {Control }}=27 ; \mathrm{P}=\mathrm{NS}$ ). In RV myocytes, capacitances were $221 \pm 12 \mathrm{pF}$ $\left(\mathrm{n}_{\text {Chronic }} \mathrm{AVB}=28\right)$ versus $228 \pm 11 \mathrm{pF}\left(\mathrm{n}_{\mathrm{Control}}=29 ; \mathrm{P}=\mathrm{NS}\right)$.

For the measurements of 1 rol, we used a holding potential of $-70 \mathrm{mV}$. Nat current was inactivated by a 10 -ms prepulse to $-40 \mathrm{mV}$. L-wype Cat ${ }^{2+}$ current was inhibited with nifedipine $(5 \mu \mathrm{mol} / \mathrm{L}$ ). The activation protocol consisted of 300 -ms rest pulses $\left(V_{\text {tess }}\right)$ to -20 up to $+70 \mathrm{mV}$ with $10-\mathrm{m} \mathrm{V}$ increments and 10 -s intervals. I Tol amplicudes were measured as peak amplitudes mimus steady-state values at the end of depolarizations. For the measurements of $I_{K l}, l_{K}$, and $I_{K s}$, the holding potential was set at -50 $\mathrm{mV} . \mathrm{I}_{\mathrm{K} \text { ! }}$ acrivation was tested during $200-\mathrm{ms}$ pulses from -20 to $-140 \mathrm{mV}$ with $10-\mathrm{mV}$ decrements every 3 s. Sustained outward currents were recorded during prolonged $(3-5)$ $V_{\text {tesi }}$ of -20 to $+70 \mathrm{mV}$ with $10-\mathrm{mV}$ increments and 20 -s intervalls. $\mathrm{I}_{\mathrm{Kr}}$ and $\mathrm{I}_{\mathrm{K} \text { sere }}$ measured as the peak tail currents upon repolarization. For $\mathrm{I}_{\mathrm{K}}$ we used the tai current sensitive to $2 \mu$ mol/L almokalant (specific $I_{K \mathrm{r}}$ blocker) upon repolarization to the holding

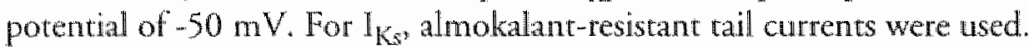

The standard-buffer solution used for the experiments was of the following composition (mmol/L): $\mathrm{NaCl} 145, \mathrm{KCl} 4.0, \mathrm{CaCl}_{2} 1.8, \mathrm{MgCl}_{2} 1.0, \mathrm{NaH}_{2} \mathrm{PO}_{4} 1.0$, 
glucose 11 . HEPES $10, \mathrm{pH} 7.4$ with $\mathrm{NaOH}$ at $37^{\circ} \mathrm{C}$. The patch-pipette solution conrained (in mmol/L): potassium aspartate $125, \mathrm{KCl} 20, \mathrm{MgCl}_{2} 1.0, \mathrm{MgATP} 5$, HEPES 5. EGTA 10, pH 7.2 with KOH.

The data are expressed as mean $\mathrm{SEM}$. Intergroup comparisons were made with the Student's test for unpaired and paired datagroups, after testing for the normality of distribution. Differences were considered significant if $P<0.05$.

\section{Results}

Acquired QT Prollongation and Susceptibility to TdP in the Study Group

In-viwo electrophysiological recordings during sinus rhythm, and during acute and chronic AVB revealed significant QT prolongations in all chronic-AVB $\operatorname{dogs}$. An example of these three states in the same animal is shown in Figure 1. On average, the QT time (measured in ECG lead II) increased from $241 \pm 9$ ms at sinus thyth to $316 \pm 14 \mathrm{~ms}$ upon creation of $\mathrm{AVB}(P<0.05)$, and to $374 \pm 15 \mathrm{~ms}$ ms in the chronic phase at $9 \pm 1$ weeks thereafter $(P<0.05$ versus acute $A V B)$. Corresponding $R$ R intervals measured $488 \pm 24 \mathrm{~ms}, 1479 \pm 142 \mathrm{~ms}(P<0.05)$, and $1381 \pm 80 \mathrm{~ms}$, respectively $(P=N \mathrm{~N}$ versus acute AVB). From acute to chronic AVB, QRS widths did not change significantly (see Figure 1). However, broad-based $T$ waves developed early after the QRS complex. In 13 of the 15 animals with chronic AVB, LV and RV endocardial monophasicaction potentials were recorded at the idioventricular cycle length. In all 13 the LV APD was longer than the RV APD: on average $419 \pm 25 \mathrm{~ms}$ versus $354 \pm 19 \mathrm{~ms}(P<0.05)$, yielding an interventricular difference of $65 \pm 12 \mathrm{~ms}$ (in line with previous results ${ }^{6,10}$ ). The susceptibility to TdP was tested in 7 animals using almokalant. In 6 of these dogs spontaneous TdP occurred, in the other dog TdP could not be induced.

In the sinus-rhythm control group used for comparisons in the cellular investigarions, the RR interval was $421 \pm 22 \mathrm{~ms}$ with a $Q T$ time of $231 \pm 6 \mathrm{~ms}$ (borh $P=\mathrm{NS}$ versus preoperative sinus rhythm in the chronic-AVB group).

\section{$I_{\text {Tol }}$ Is Not Altered in Chronic AVB}

The activation of $I_{T O}$ was tested during steps of -40 to $+70 \mathrm{mV}$. In all four cell types the current activated at $V_{\text {tcst }} \geq-20 \mathrm{mV}$ (Figure 2). There was no difference in $I_{\text {Tol }}$ density berween chronic $A V B$ and control in both ventricles. The difference in $I_{T o t}$ bewween LV and RV, recently described for normal canine hearts, " was maintained in chronic AVB. I TOl was nearly completely inhibited by $5 \mathrm{mmol} / \mathrm{L}$-aminopyridine in all four cell types. I TO inactivation during the $300-\mathrm{ms} \mathrm{V}_{\text {test }}$ was best fitted with a single exponential function yielding similar cime constants (range 7 to $14 \mathrm{~ms}$ ) in chronic AVB and control. As illustrated in Figures $3 A$ and $3 B$, voltage dependence of steady-state inactivation and time-dependent recovery from inactivation were not different between che cell types. 


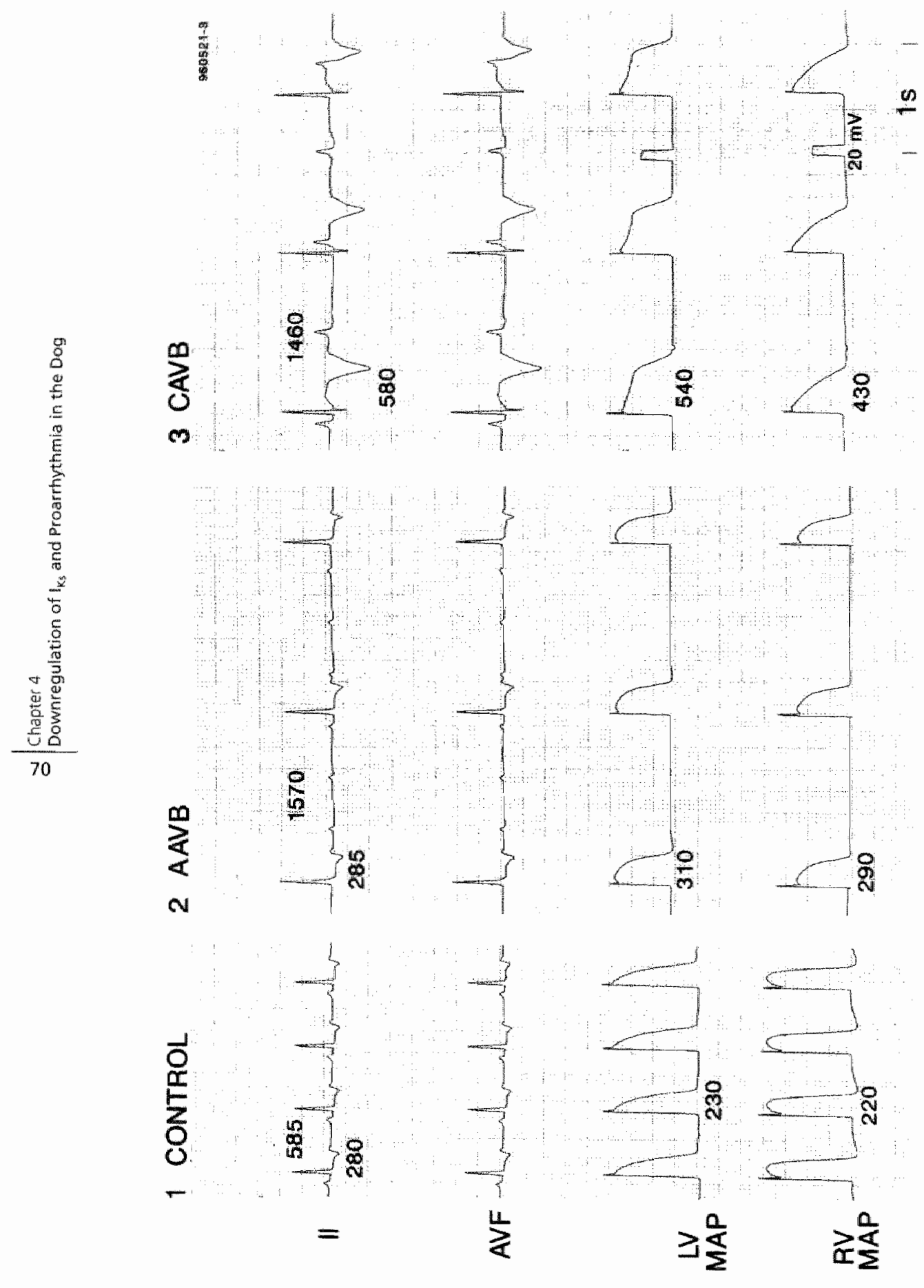


Figure 1 (left page) - Acquired QT prolongation in a dog with AVB.

Shown are the ECG leads II and AVF, and simultaneous monophasic-action-potential recordings from the LV (LV MAP) and RV endocardium (RV MAP) all a paper speed of $25 \mathrm{~mm} / \mathrm{s}$. During sinus rhythm (1 CONTROL) the cycle length is $585 \mathrm{~ms}$ and the QT time $280 \mathrm{~ms}$. LV and RV MAP duration measure 230 and 220 ms, respectively. When AV-nodal conduction is blocked with formaldehyde during the same session (2 AAVB), bradycardia ensues with an idioventricular cycle length of $1570 \mathrm{~ms}$. At this moment there is a minimal QT prolongation to 285 ms, while LV and RV MAP durations are 310 and $290 \mathrm{~ms}$. lin the right panel ( 3 CAVB), the effect of 6 weeks AVB on electrophysiological parameters is obvious: at a similarly slow idioventricular rhythm (cycle length $1460 \mathrm{~ms}$ ) the QT time has increased significantly to $580 \mathrm{~ms}$ with MAP prolongation to 540 and $430 \mathrm{~ms}$ in LV and RV, leading to an interventricular difference of 110 ms. Note the broad-based, high-amplitude Twaves in II and AVF. Note also that the QRS duration is unaltered in CAVB, compared to CONTROL and AAVB. TdP occurred spontaneously in this animal during administration of almokalant

\section{Properties of $t_{k 1}$}

Figure 4 shows rypical recordings of $\mathbb{I}_{K 1}$ in chronic-AVB and control myocytes, as well as current density-voltage relations at the end of $V_{\text {test }}$ of -140 to $-20 \mathrm{~m} \mathrm{~V}$ in both LV and RV. The current showed rapid activation and was fully inhibired in $\mathrm{K}^{+}-$free superfusate $\left(0\left[\mathrm{~K}^{+}\right]_{\mathrm{O}}\right.$; not shown). $\mathrm{I}_{\mathrm{K} 1}$ ourward currents (initial peak walues as well as steady-state levels) at $\mathrm{V}_{\text {rest }}$ positive to the $K^{*}$ reversal potential were similar in chronic AVB and control. Only at very hyperpolarizing pulses in RV cells, current densities were less negative in chronic AVB. There were no interventricular differences berween chronic AVB and control.

\section{Downregulation of $U_{k s}$ and $I_{k:}$}

To dissect the two components of the delayed recrifier $\mathrm{K}^{*}$ current ar baseline, we applied a protocol in which, afrer a depolarization to $+30 \mathrm{mV}$, repolarization was divided in wo steps: to $0 \mathrm{mV}$ for $4.5 \mathrm{~s}$ and then back to $-50 \mathrm{mV}$ (Figure 5 ). ${ }^{12}$ The hypothesis that tail currents at the first repolarizarion step were largely composed of deactivating $I_{K_{s}}$ and largely devoid of $I_{K r}$ was confirmed by the observation that they were insensitive to almokalant (Figure 5, first atrow in both pands). In contrast, tail currents at the second repolarization step decreased significantly on almokalant administation, indicating predomimately the presence of $I_{\mathrm{Kr}}$ (Figure 5 , second arrow in both panels). From these data it appeared that $I_{\mathrm{Ks}}$ (cail currents at first repolarization step) was smaller in chronic $\mathrm{AVB}$ than control myocytes: for $\mathrm{LV}, 0.19 \pm 0.02$ versus $0.40 \pm 0.09 \mathrm{pA} / \mathrm{pl}$. and for RV $0.21 \pm 0.03$ versus $0.51 \pm 0.08 \mathrm{pA} / \mathrm{pF}$, respectively (borh $P<0.05$ ). For the same comparison, $\mathbb{K}_{\mathrm{Kr}}$ (tail currents at second repolarization step) was similar in $\mathrm{LV}$, $0.34 \pm 0.03$ versus $0.42 \pm 0.05 \mathrm{pA} / \mathrm{pF}(P=\mathrm{NS})$, but smaller in $\mathrm{RV}$ myocytes, $0.34 \pm 0.02$ versus $0.48 \pm 0.02 \mathrm{pA} / \mathrm{pF}$ in chronic $\mathrm{AVB}$ versus control, respecively $(P<0.05)$. To elaborate further on the contriburion of $\mathbb{K}_{K s}$ to total delayed rectifier $K^{+}$current, we performed envelope-of-tails tests at baseline and in the presence of almokalant. These experiments revealed that $I_{k s}$ made up a sigmificant portion of the total curnent, even for depolarizations as short as $300 \mathrm{~ms}$. However, contributions were much smaller in chronic-AVB than control cells (data not shown). 


\section{$\mathbf{I}_{\mathrm{TO} 1}$}

Chronic AVB

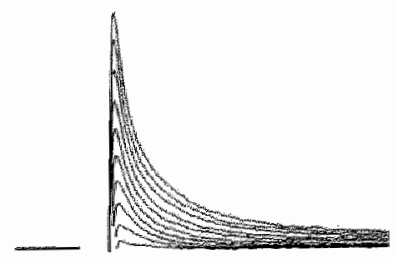

Control

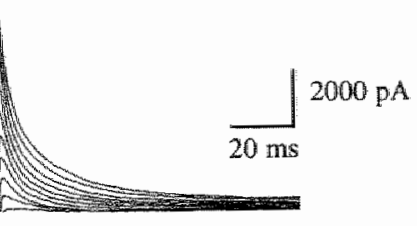

\section{Left ventricle}
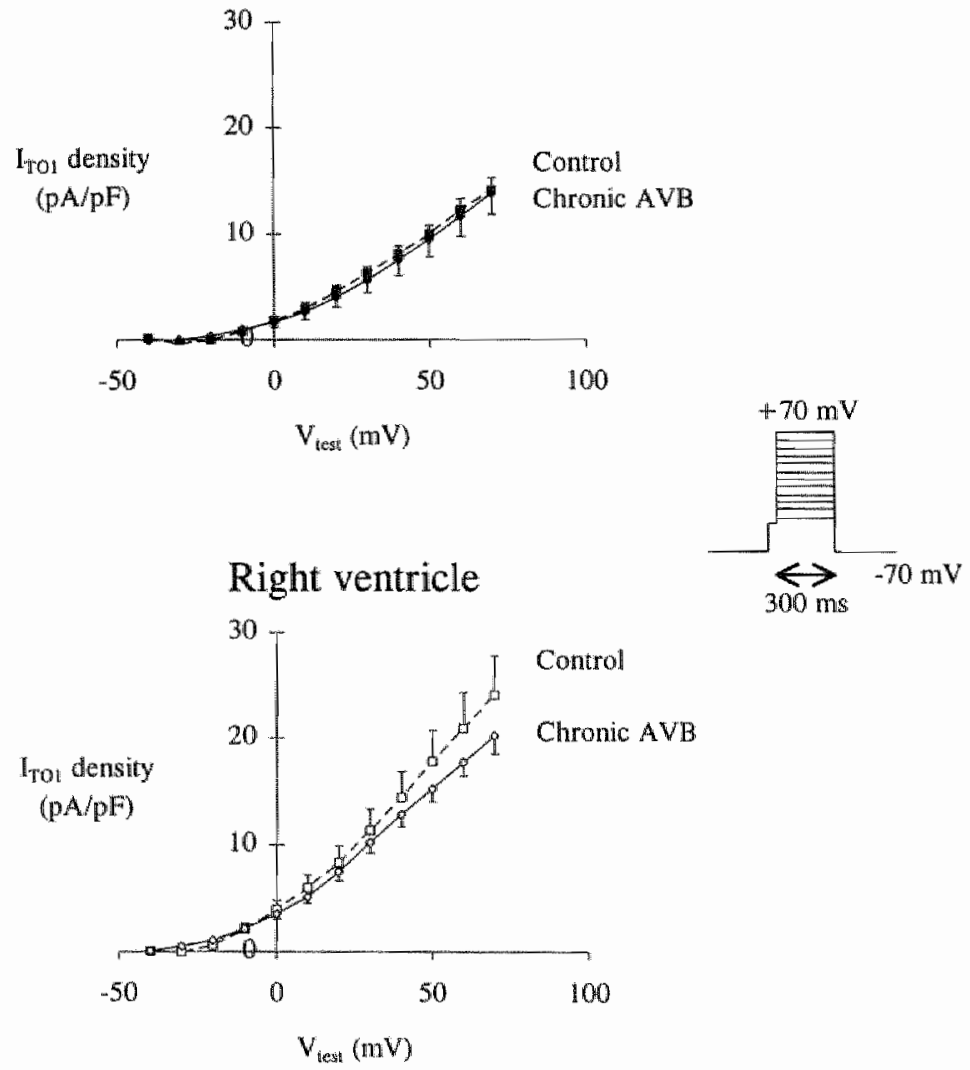

Figure 2. - To1 activation in chronic AVB.

Shown are families of current traces during $V_{\text {test }}$ of -20 to $+70 \mathrm{mV}$ (interval 10 s) in two RV myocytes (capacitances: 264 and $247 \mathrm{pF}$ in Chronic AVB and Control, respectively). Left horizontal bars indicate

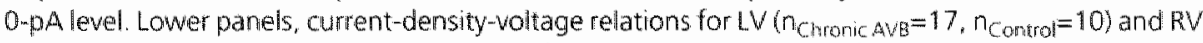
(nCronic $A V B=16$, ncontrol $=12$ ). Inset on the right, voltage-clamp protocol. 

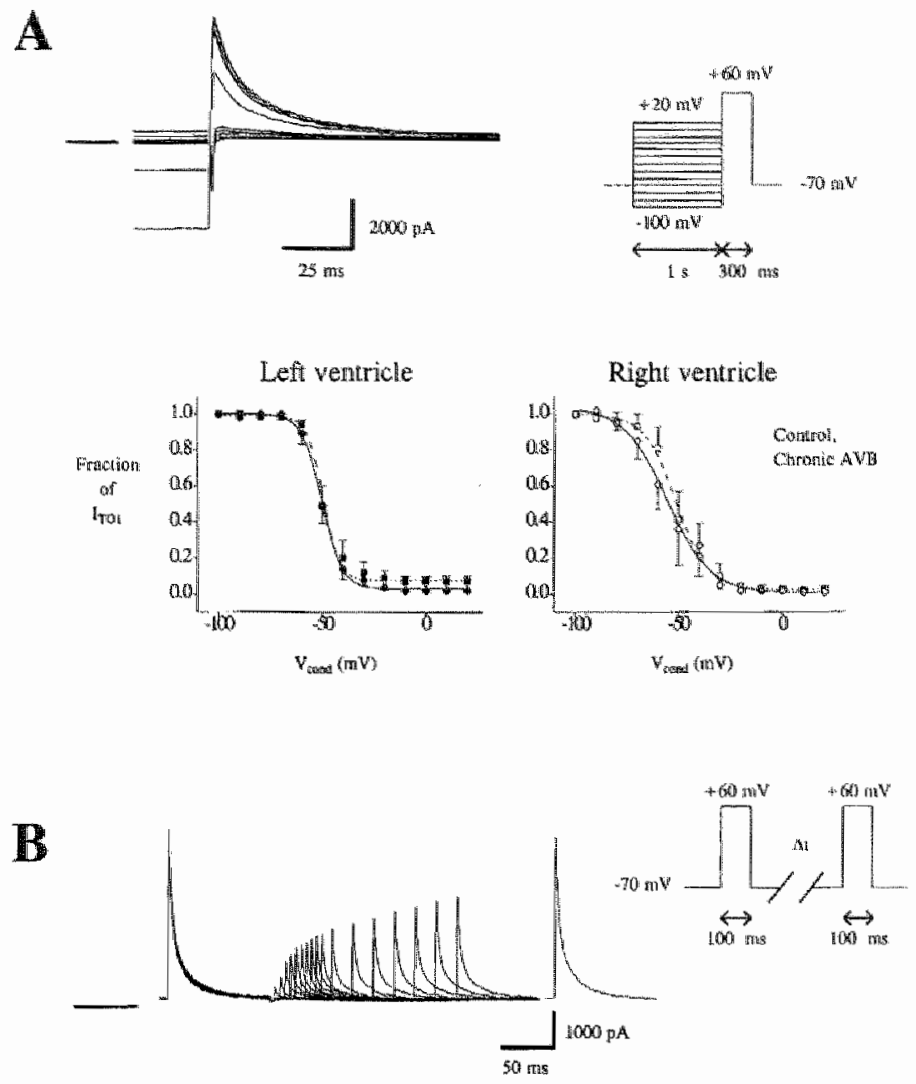

Left ventricle

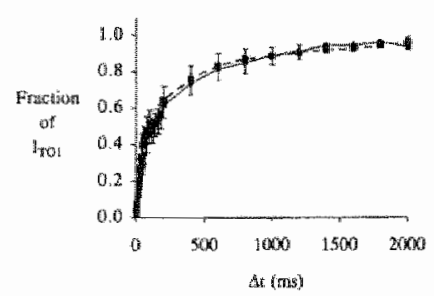

Right ventriclie

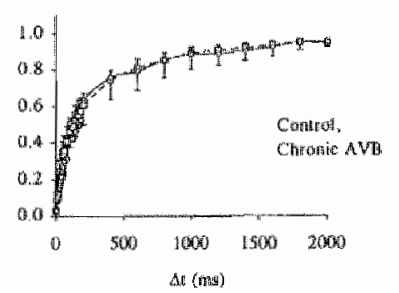

Figure 3. - A Voltage-dependence of steady-state inactivation of hos. Upper left panel family of traces in a chronic-AVB LV cell. Right inset, woltage-clamp protocol. Lower panels, fractions of $I_{T O}$ relative to amplitude at $V_{\text {test }}$ of $+60 \mathrm{mV}$ for a $V_{\text {cond }}$ of $-100 \mathrm{mV}$ in $L V\left(n_{\text {Chronic } A v B}=8\right.$, ncontrol $\left.=9\right)$ and $R V$ (nChonic $A \mathrm{AB}^{2}=4, \mathrm{n}_{\mathrm{Con}}=6$ ). Curves are Boltzmann fits to the data. Half points and slope factors are similar in the four groups. B, Time-dependent recovery from inactivation. Upper left panel, original traces with interpulse delays ( $\Delta t$ ) of 5 to $50 \mathrm{~ms}$ ( 5 -ms increments), 60 to $180 \mathrm{~ms}$ (20-ms increments), and 2000 ms in a chronic-AVB IV myocyte. Right inset, voltage-clamp protocol indicates prepulse to $+60 \mathrm{mV}$ followed by $V_{\text {esi }}$ to $+60 \mathrm{mV}$ at increasing $\Delta t$. Lower panels, fractions of tro relative to

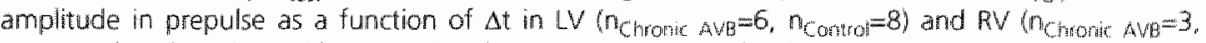
$n_{\text {Control }}=7$ ). Left horizontal bars in original traces indicate 0-pA levels. 


\section{$\mathbf{I}_{\mathrm{K} 1}$}

Chronic AVB

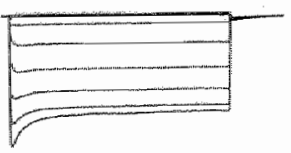

\section{Control}

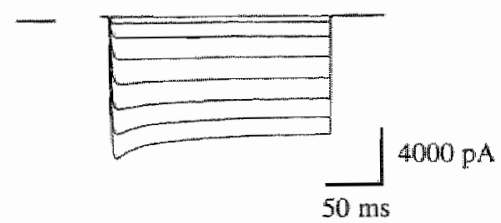

\section{Left ventricle}

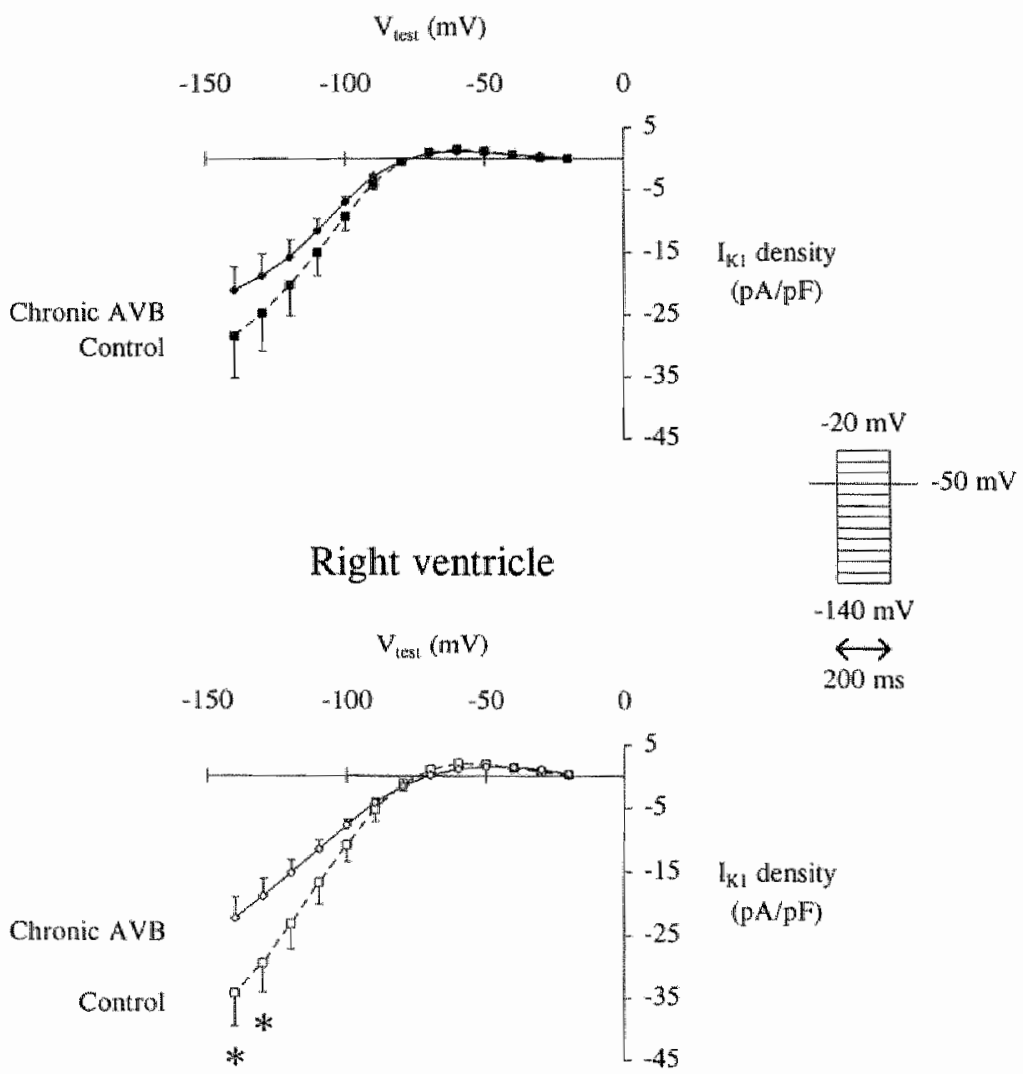

Figure 4. $\|_{K 1}$ in chronic AVB.

Examples are from LV myocytes and show currents during $V_{\text {es: }}$ of -70 to $-140 \mathrm{~m} V$ (intenal 3 s). Lower panels, current density-voltage relations for $I_{K,}$ steady-state activation in $L V\left(n_{C h r a i c} A V B=8\right.$; $n_{\text {Contol }}=5$ ) and PV (n Chronic $A V B=10$; $\left.n_{\text {Contral }}=9\right)$. In RV, * indicates significant difference $(P<0.05)$. 


\section{Chronic AVB}
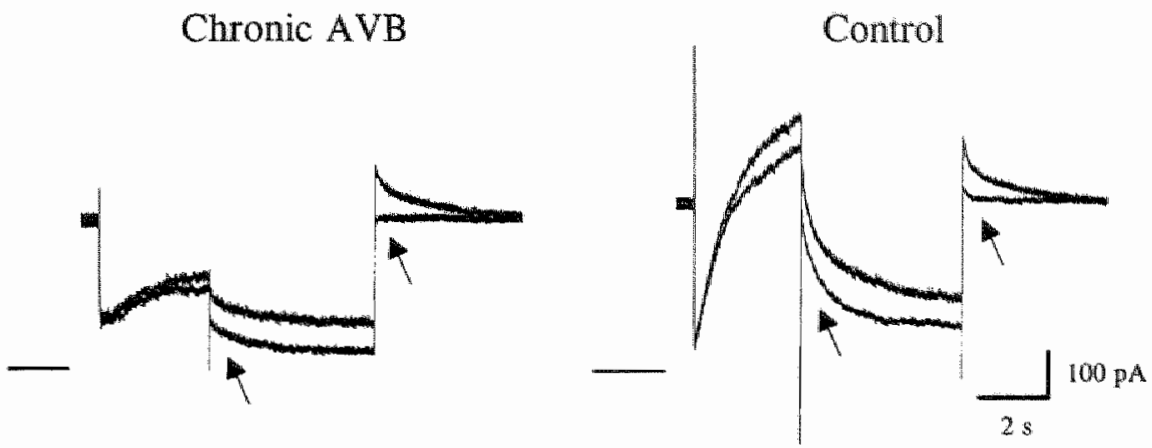

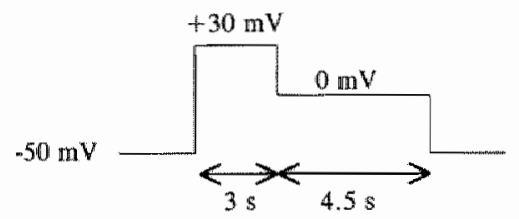

Figure 5. - Activation and deactivation of delayed rectifier $\mathrm{K}^{+*}$ current at baseline and during almokalant ( $2 \mu \mathrm{mol} / \mathrm{L}$ ) treatment in chronic AVB and control.

Shown is the activation in response to a $3-5$ depolarization to $+30 \mathrm{mV}$, followed by deactivation phases at $0 \mathrm{mV}$ for $4.5 \mathrm{~s}$ and at $-50 \mathrm{mV}$ in two LV cells (capacitances: Chronic AVB, $292 \mathrm{pF}$ and Control, $299 \mathrm{pF}$ ). In both panels, the upper of the two current traces is the baseline recording. whereas the lower trace is the current during almokalant a few intervals later (interval 20 s). Tail-current amplitudes at the first repolarization step (first arrow) are unaltered diuing almokalant, whereas tail currents at the second repolarization step (second arrow) are decreased significantly. In the comparison Chronic AVB versus Control, tail-current amplitudes at the first repolarization step are markedly lower in Chronic AVB, indicating a lower $\mathrm{k}_{\mathrm{ks}}$. Similar results. were obtained for LV in

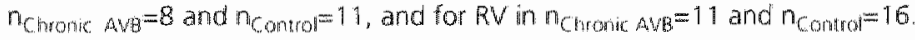

Voitage-dependent activation of $\mathrm{I}_{\mathrm{Ks}}$ was evaluated from tail currents on repolarization to $-25 \mathrm{mV}$ in $0\left[\mathrm{~K}^{*}\right]_{\mathrm{O}}$ in the presence of almokalant. Examples of families of current traces and pooled data are given in Figure 6 . There was no saturation of tailcurrent amplitudes. Voltage clependence of $\mathbb{I}_{K s}$ activation was similar in the four cell types. However, $\mathrm{I}_{\mathrm{Ks}}$ density was significantly smaller in chronic AVB than in control. Overall, tail currents were reduced by $50 \%$ in LV and by $55 \%$ in RV myocytes (Figure 6). Whereas interventricular differences of $\mathrm{I}_{\mathrm{Ks}}$ exist in normal canine hearts (Figure 6), ${ }^{11}$ due to the small current amplitudes in chronic AVB no differences could be discerned. Voltage dependence of $\mathrm{I}_{\mathrm{KS}}$ deactivation was not different between chronic $A V B$ and control. Likewise, the time course of deactivation proved simillarly fast in all four cell types. 


\section{$\mathbf{I}_{\mathrm{Ks}}$}

Chronic AVB
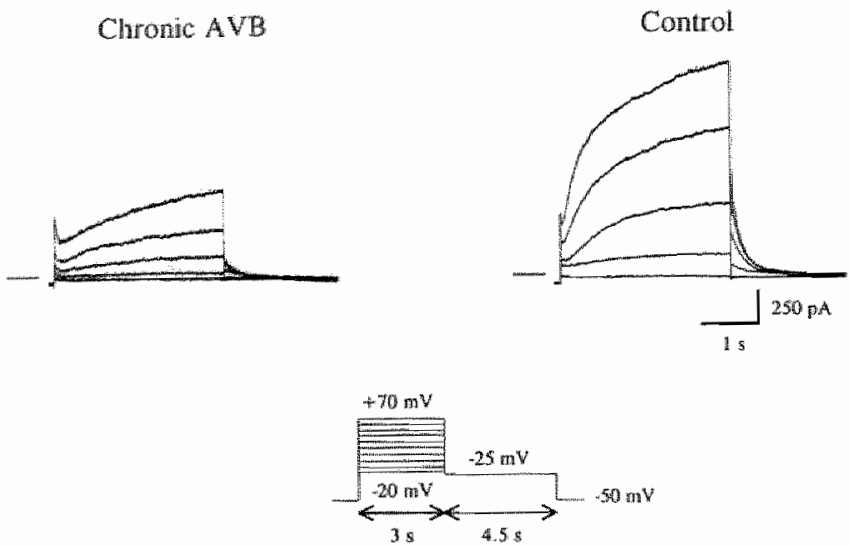

\section{Left wentricle}
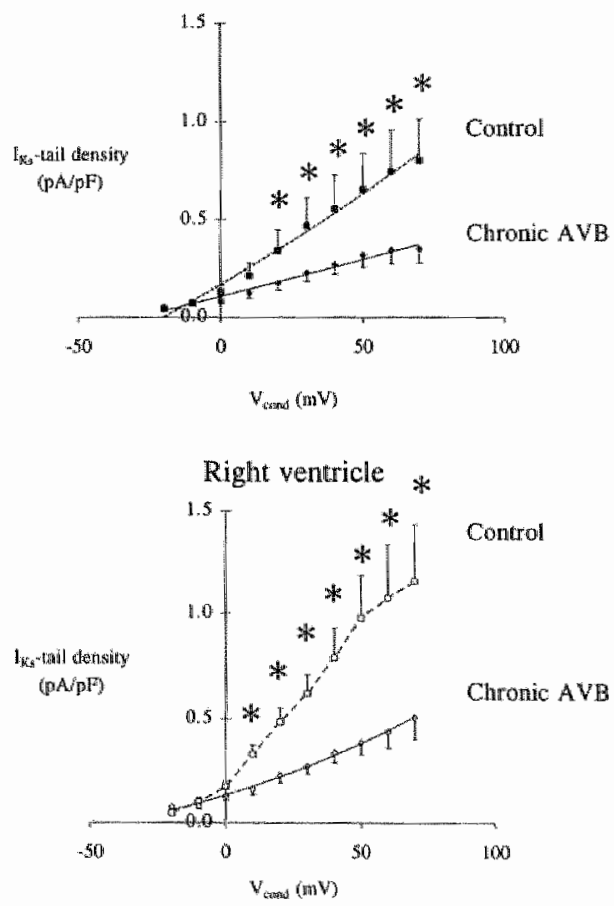

Figure $6 .-I_{k s}$ in chronic AVB.

Shown are currents for depolarizations to 20 to $+60 \mathrm{mV}(20$-mV increments; $20 \mathrm{~ms}$ interwals) followed by repolarizations to $-25 \mathrm{mV}$ in $0\left[\mathrm{~K}\right.$. $\mathrm{J}_{0}$ superfusate with $2 \mu \mathrm{mol} / \mathrm{L}$ almokalant in two LV myocytes (capacitances: 213 and $251 \mathrm{pF}$ in Chronic AVB and Control, respectively). Left horizontal bars indicate 0 -pA level. Lower panels, activation for $I_{K s}$ tail currents on repolarization to $-25 \mathrm{mV}$ in $\mathrm{LV}$

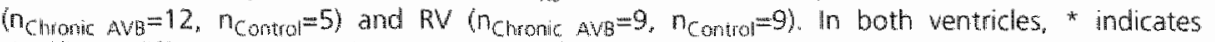
significant difference $(P<0.05)$. Inset, voltage-clamp protocol. 


\section{$\mathbf{I}_{\mathrm{Kr}}$}

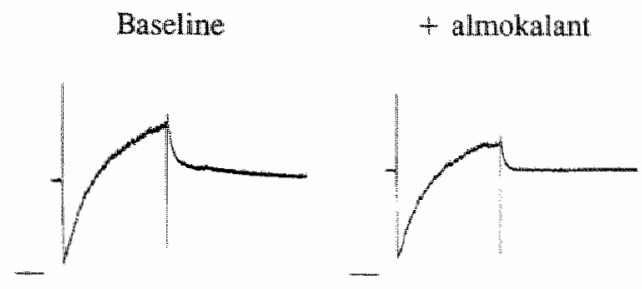

Almokalant-sensitive

difference current
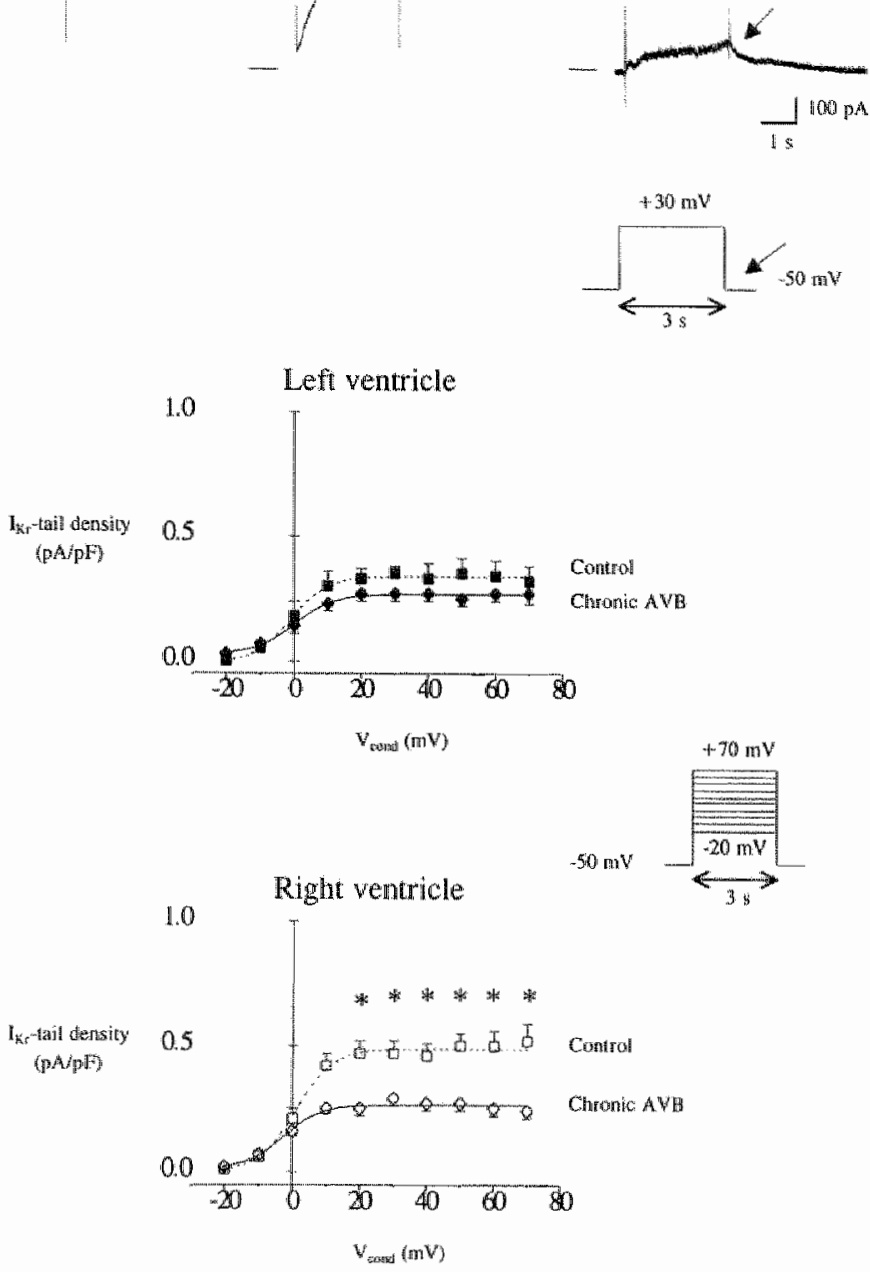

Figure 7. $-I_{K r}$ in chronic AVB.

Upper panels, $k_{k r}$ is evaluated as the almokalant-sensitive difference current after digital subtraction of the baseline current and the current remaining during subsequent treatment with $2 \mu$ mol/ almokatant. Tail currents are measured on repolarization to $-50 \mathrm{mV}$ (arrows) and are plotted as a

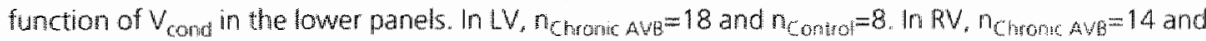
$n_{\text {Control }}=13$; * indicates significant difference $(P<0.05)$. Left horizontal bars, OpA level. Insets, voltage-dlamp protocols. 
$I_{K r}$ was quantified as the almokalant-sensitive tail-current portion measured by digital subtraction on single-srep repolarizations to - $50 \mathrm{mV}$ in $4.0 \mathrm{mmol} / \mathrm{L}\left[\mathrm{K}^{+}\right]_{\mathrm{O}}$ (Figure 7). Accivation occurred after depolarizations $\geq-1.0 \mathrm{mV}$, and showed saturation at conclitioning voltages $\left(V_{\text {cond }}\right)>+20 \mathrm{mV}$. Boltzmann fits to the data revealed half points of $0.3 \pm 1.1 \mathrm{mV}$ and $-1.1 \pm 3.1 \mathrm{mV}$ in $\mathrm{LV}$, and of $-2.5 \pm 2.1 \mathrm{mV}$ and $1.1 \pm 1.7 \mathrm{mV}$ in RV for chronic AVB and control, respectively (both $P=$ NS). In the same order, corresponding slope factors were $5.8 \pm 1.0 \mathrm{mV}$ and $5.7 \pm 2.8 \mathrm{mV}$ in $\mathrm{LV}$, and $5.5 \pm 1.7 \mathrm{mV}$ and $5.5 \pm 1.5$ $\mathrm{mV}$ in RV (both $P=N S$ ). $\mathrm{I}_{\mathrm{Kr}}$ density was similar in LV myocytes, but smaller in RV myocytes of chronic AVB versus control (reduction of $45 \%$; Figure 7 ). There were no interventricular differences. In both ventricles, voltage dependence and time course of $\mathbb{I}_{\mathrm{Ks}}$ deactivation were similar for chronic AVB and control.

\section{Discussion}

We have demonstrated that acquired QT prolongation in dogs with chronic $A V B$ and documented $T d P$ is associated with significant reductions of $I_{K s}$ in the $L V$ and $\mathrm{RV}$. In the RV of these animals, $\mathrm{I}_{\mathrm{Kr}}$ is also downregulated. Of the other $\mathrm{K}^{+}$currents, $I_{T O 1}$ and $I_{K 1}$ outward current are unaltered.

\section{Reproducible Induction of TdP in Chronic AVB}

The dog with chronic AVB is a very suitable large-animal model for the study of TdP. In the majority of anesthetized animals the arrhythmia can be evoked in a reproducible fashion with class III antiarrhythmic agents alone or combined with programmed electrical stimulation. ${ }^{5}$ In-vivo experiments indicate the critical importance of regional dispersion of repolarization, early afterdepolarizations and multiple ectopic beats for the initiation of TdP. ${ }^{10,13}$ Interventricular dispersion during arrhythmogenesis probably reflects the existence of significant repolarization gradients in closely adjacent areas, possibly the seprum. ${ }^{14}$ Our most recent results demonstrare that electrical remodeling of the myocardium is the substrate for the enhanced susceptibility to $\mathrm{TdP}^{6.9}$. The in-vivo part of the present study was not designed to reinvestigate the criteria for $T \mathrm{dP}$, but confirmed that the dogs used for cellular experiments were a representative population with significant QT prolongation and a low threshold for TdP.

\section{Contribution of Reduced $\mathrm{I}_{\mathrm{k}, \mathrm{s}}$ and $\mathrm{I}_{\mathrm{kr}}$ to Action-Potential Prolongation}

In a previous study, at serial testing in vivo, it was found that chronic (versus acute) AVB leads to increases of endocardial monophasic APDs of approximately $+30 \%$ in the LV, and $+20 \%$ in the RV. ${ }^{6}$ Based on our recent microelectrode study, ${ }^{9}$ the relative increase of the APD in chronic-AVB myocytes is $\rrbracket 0$ to $30 \%$ in the LV (depending on the pacing cycle length), and maximally $10 \%$ in the RV under baseline conditions. In these cells the class III agents almokalant and $d$-sotalol cause marked action-potential prolongation and the occurrence of early afterdepolarizations, which 
uncovers the importance of $I_{K}$ for ventricular repolarization in chronic $A$ VB. Whether a $50-55 \%$ reduction of $\mathbb{I}_{K s}$ can account for the action-potential characteristics in $L V$ and RV can only be answered indirectly. In a recent study on canine LV midmyocardial tissue, the $\mathrm{I}_{\mathrm{K} s}$ blocker chromanol $293 \mathrm{~B}$ at 30 umol/L increases the APD from $284 \pm 13$ to $357 \pm 25 \mathrm{~ms}$ at a pacing cycle length of $2000 \mathrm{~ms}(+25 \%))^{15}$ This concentration reduces (guinea-pig) $I_{\mathrm{Ks}}$ by approximately $80 \%,{ }^{16,17}$ In a theoretical model of the normal human ventricular action potential, ${ }^{18}$ adapted from the Luo-Rudy model, $1950 \%$ inhibition of $\mathrm{I}_{\mathrm{Ks}}$ increases the APD from 374 to approximately $425 \mathrm{~ms}(+15 \%$; their Figure 12). Thus, at rough approximation, the 50-55\% decrease of ${ }_{\text {Ks }}$ observed in our present study could account for a 10-30\% action-potential prolongation, at least in the $L$ V. The RV exhibits only minor action-potential alterations under baseline conditions, despite its additional downregulation of $\mathrm{I}_{\mathrm{Kr}}(-45 \%)$. "To explain why the alterations are less pronounced in the RV than LV we have ro consider that the basic determinants of repolarization are different between the two ventricles. Recendy, we have described that this is indeed the case in the normal canine heart: $I_{\mathrm{TO}}$ and $\mathrm{I}_{\mathrm{Ks}}$ are much larger in the RV, indicating a larger repolarization reserve. "In chronic AVB the difference in $\mathrm{I}_{\mathrm{TO} 1}$ is maintained, and it is likely that also orher membrane currents and/or their remodeling are responsible for the amplification of interventricular action-potencial inhomogeneities. We are currently investigating two candidates: the L-type Ca ${ }^{2}$ current and $\mathrm{Na}^{+}-\mathrm{Ca}^{2+}$ exchange. ${ }^{20}$

\section{lonic Remodeling in Chronic AVB}

Cardiac function of dogs with AVB of 9-weeks' duration is unimpaired. 6,20 Most animals have an enhanced contractile performance at the imposed bradycardia and lack signs of heart failure. At correspondingly slow pacing rates in single myocytes, $\mathrm{Ca}^{2+}$ release from the sarcoplasmic reticulum and contractions are larger than in control cells. ${ }^{20}$ Significant growth responses (merely of cell length) are observed in both RV $(+23 \%)$ and $L V(+13 \%)$ myocytes, ${ }^{9}$ while autopsy findings reveal increased $R V$ and LV tissue weights. ${ }^{6}$ These data strongly support the contention that dogs with long standing (weeks to months) AVB have a compensated form of biventricular hypertrophy. 21,22

In many other animal models and in humans with cardiac hypertrophy or failure, downregulation of $K^{+}$currents has been implicated in (inhomogeneous) ventricular action-potential prolongation, ${ }^{23}$ and the increased risk of ventricular arthythmias and sudden cardiac death chrough increased dispersion of repolarization. ${ }^{24}$ Reducrion of $\mathrm{I}_{\mathrm{TO}}$ is probably the most often observed in the spectrum of early compensated hypertrophy to terminal heart failure, ${ }^{25}$ and has been linked ro action-potential prolongavion. 26,27 However, it has been questioned wherher downregulation of this current alone can cause increased APDs in large mammals induding humans. ${ }^{18}$ Reduction of $I_{T O 1}$ is clearly absent in dogs with chronic $\mathrm{AVB}$, which corresponds to the finding of marked notch amplitudes in midmyocardial acrion potentials (RV $>$ LV). There have been only a few reports on the downregulation of delayed rectifier $\mathrm{K}^{+}$current in cardiac 
hypertrophy induced by pressure overload in cars ${ }^{28,29}$ In these studies, a role for the reduced total current in the increase of $A P D$ s was inferred, but the investigators did not discriminate between $I_{\mathrm{Kr}}$ and $\mathrm{I}_{\mathrm{K}}$. Our data do make this distinction for the hypertrophied cells of dogs with chronic AVB and indicate that changes of these relatively small currents can have major impact on the course of repolarization, as noted before. ${ }^{30}$

The Dog with Chronic AVB: A Model of the Human Long-QT Syndrome?

The combined findings of an enhanced susceptibility to acguired TdP, the (supposed) adrenergic dependence of spontaneous episodes of $T d P$, the typical $T$-wave patterns during prolonged QT intervals, and the reduction of $\mathrm{I}_{\mathrm{Ks}}$ in this animal model resemble the clinical characteristics of the LQT1 form of the human congeniral llongQT syndrome. Distinctive mutations in three ion channels (the slow and rapid delayed $\mathrm{K}^{+}$channels, and the $\mathrm{Na}^{+}$channel) have been identified in this syndrome, which could be linked to inherited arrhythmias. ${ }^{4}$ The LQT 1 form, with a reduced $\mathrm{I}_{\mathrm{K}_{s}}$, is the most often encountered in patients and carries the highest risk of cardiac events (syncope, aborted cardiac arrest, or sudden death) ${ }^{31}$ due to the generation of TdP. Experimental electrophysiological studies on the generation of TdP in the long-QT syndrome have often used models in which the phenorypes of reduced $\mathrm{I}_{\mathrm{Ks}}$ (LQT1 or LQTS) ${ }^{15}$ or $\mathrm{I}_{\mathrm{Kr}}$ (LQT2), ${ }_{0}^{32,33}$ or of prolonged late $\mathrm{Na}^{+}$current (LQT3) ${ }^{32-34}$ were mimicked by pharmacological interventions. The dog with chronic AVB may prove to be a valuable addition to these surrogates and could be favorable in experimental setups requiring a longitudinal design. Although the current reductions in this model are not the consequence of genetic mutations as in the congenital long-QT syndrome, the intrinsic nature of these functional alterations may constitute another advantage over the artificial inhibition with pharmacological agents.

\section{Conclusions}

Significant downregulation of delayed rectifier $\mathrm{K}^{+}$current contributes to the repolarization abnormalities in the LV and RV of dogs with chronic AVB. The low functional expressions of $\mathrm{I}_{\mathrm{Ks}}$ and $\mathrm{I}_{\mathrm{Kr}}$, in combination with the maintained interventricular difference in $\mathrm{I}_{\mathrm{TO}}$ and possibly other membrane currents, are responsible for the amplification of interventricular action-potential inhomogeneities at control. The resultant increased regional dispersion of repolarization constitutes the substrate for an enhanced susceptibility to acquired TdP. Thus, this animal model carries intrinsic repolarization defects and in-vivo proarrhythmia as in the human congenital long-QT syndrome.

\section{Acknowledgments}

Dr. Volders is supported by the Wynand M. Pon Foundation, Leusden, Netherlands. Dr. Sipido is supported by the National Fund for Sicientific Research, Bel- 
gium. The authors wish to thank Jêrome G.M. Jungschleger, MD and Ferenc F, van der Hulst, BS for helpful assistance.

\section{References}

1. Zipes DP, Wellens HIJ]. Sudden cardiac dearh. Crrolation. 1998;98:2334-2351.

2. Jackman WM, Friday KI, Anderson JL, Aliot EM, Clark M, Lazzara R. The long QT syndromes: a critical rewiew, new clinical observations and a unifying hypothesis. Prog Cardiovasc Dis. 1988;31:115-172.

3. Eckarde L, Haverkamp W, Borggrefe M, Breithard G. Experimental models of torsade de pointes. Cardiouss Res. 1998;39:178-193.

4. Roden DM, Lazzara R, Rosen M, Schwartz PI, Towbin J, Vincent GM. Multiple mechanisms in the long-QT syndromen current knowledge, gaps, and future directions. The SADS Foundation Task Force on LQTS. Cimulation. $1996 ; 94: 1996-2012$.

5. Vos MA, Verduyn SC, Gorgels APM, Lipesei GC, Wellens HJ]. Reproducible induction of early afterdepolarizations and torsade de pointes arrhythmias by $d$-sotalol and pacing in dogs with chronic atriowentricular block. Circulation. 1995;91:864-872.

6. Vos MA, de Groot SHM, Verduyn SC, van der Zande J, Leunisen HDM, Cleutiens JPM, van Bilsen M, Daemen MJAP, Schreuder J], Allessie MA, Wellens HJJ. Enhanced suscepribility for acquired torsade de pointes arrhythmias in the dog with chronic, complete AV block is related to cardiac hypertrophy and electrical remodeling. Cinculation. 1998;98:1125-1135.

7. Kurita T, Ohe T, Marui N, Aihara N, Takaki H, Kamakura S, Matsuhisa M, Shimomura K. Bradycardia-induced abnormal. QT prolongation in parients with complete atrioventricular block wich torsades de pointes. Am / Cardiol. 1992;69:628-633.

8. Kurita T, Ohe T, Shimizu W, Horra D, Shimomura K. Earlyafterdepolarization in a parient with complete atrioventricular block and torsades de pointes. Pang Clin Elentrophysiol 1993;16:33-38.

9. Volders PGA, Sipido KR, Vos MA, Kulcsár A, Verduyn SC, Wellens HJJ Cellular basis of biventricular hypertrophy and arthythmogenesis in dogs with chronic complete atrioventricular block and acquired torsade de pointes. Cinculation. 1998;98: $1136-1147$.

10. Verduyn SC, Vos MA, van der Zande J, Kulcsàr A, Wellens HJ]. Further obscrvations to elucidate the role of interventricular dispersion of repolarization and early afterdepolarizations in the genesis of acquired torsade de pointes arthythmias: a comparison between almokalant and d-sotalol using the $\operatorname{dog}$ as its own control. I Am Coll Cardiol. $1997: 30: 1575-1584$.

11. Volders PGA, Sipido KR, Carmelier E, Spätjens RLHMG, Wellens HJ], Vos MA. Ren polarizing $K^{*}$ currents $\mathbb{I}_{T 0}$ and $I_{K s}$ are larger in righe than left canine ventricular midmyocardium. Cinculation. 1999:99:206-210. 
12. Carmeliet $\mathbb{E}$. Voltage- and time-dependent block of the delayed $K^{*}$ current in cardiac myocytes by doferilide. J Phamacol Exp Ther. 1992;262:809-817.

13. Verduyn SC, Vos MA, van der Zande J, van der Hulst FE, Wellens HJ. Role of interventricular dispersion of repolarization in acquired torsade-de-pointes arhythmias: reversal by magnesium. Cardiovasc Res. 1997:34:453-463.

14. van der Hulsr FF, Vos MA, Leunissen HDM, Wellens H]J. Transseptal dispersion in the dog with chronic complere atrioventricular block: distriburion and frequency dependence. Eur Heart. 1998;19(suppl):72. Absuracr.

15. Shimizu W, Antzelevitch C. Cellular basis for the ECG features of the LQT1 form of the long-QT syndrome: effecrs of $\beta$-adrenergic agonists and antagonists and sodium channel blockers on transmural dispersion of repolarization and torsade de pointes. Circulavion 1998;98:2314-2322.

16. Busch AE, Suessbrich H, Waldegger S, Sailer E, Greger R, Lang HJ, Lang F, Gibson KJ, Maylie JG. Inhibition of $I_{K}$ in guinea pig cardiac myocytes and guinea pig $I_{5 K}$ channels by the chromanol 293B. Pfligers Arch. 1996:432:1094-1096.

17. Bosch RF, Gaspo R, Busch AE, Lang HJ, LI GR, Narrel S. Effects of the chromanol $293 \mathrm{~B}$, a selective blocker of the slow, component of the delayed rectifier $K^{*}$ current, on repolarization in human and guinea pig ventricular myocytes. Cardionas Res. $1998 ; 38: 441-450$.

18. Priebe L, Beuckelmann DJ. Simulation study of cellular electric properties in heart failure. Circ Res. 1998;82:1206-1223.

19. Luo CH, Rudy Y. A dynamic model of the cardiac ventricular action potential: I. simularions of ionic currents and concentration changes. Circ Res. 1994;74:1071-1096.

20. Sipido KR, Volders PGA, de Groot SHMA, Vos MA. Enhanced cardiac contractile performance and sarcoplasmic reticulum $\mathrm{Ca}^{2+}$ release in dogs with chronic complere atrioventricular block. Circulation. 1998;98(suppl 1):1-141-1-142. Abstract.

21. Turina M, Bussmann WD, Krayenbühl HP. Contractility of the hypertrophied canine heart in chronic volume overload. Cardowase Res. 1969;3:486-495.

22. Wusten B, Flameng W, Winkler B, Selraper W. Role of cardiac contractility in hypertrophy from chronic volume loading. Cardiovase Res. 1977;11:132-140.

23. Boyden PA, Jeck CD. Ion channel function in disease Cardiovas Res. 1995:29: $312-318$.

24. Tomaselli GE, Beuckelmann DJ, Calkins HG, Berger RD, Kessler PD. Lawrence JH, Kass D. Feldman AM, Marban E. Sudden cardiac death in heart failure: the role of abnormal repolarization. Circulation 1994,90:2534-2539.

25. Näbauer $M$, Kaab $S$. Potassium channel down-regulation in heart Galure. Cardionas Rer. 1998:37:324-334.

26. Beuckelmann DJ, Nabauer M, Erdmann E. Alteracions of $K^{*}$ currents in isolated human ventricular myocytes from patients with terminal heart failure. Cow Res. $1993: 73: 379-385$ 
27. Kääb S, Nuss HB, Chamwimonvat N, O'Rourke B. Pak PH, Kass DA, Marban E, Tomaselli GF. Ionic mechanism of action potental prolongation in ventricular myocytes from dogs with pacing-induced heart failure. Circ Res 1996;78:262-273.

28. Kleiman RB, Houser SR. Outward currents in normal and hypertrophied feline ventricular myocytes. Am / Physiol. 1989;256:H1450-H1461.

29. Furukawa T, Myerburg RJ, Furukawa N, Kimura S, Bassert AL. Metabolic inhibirion of $\mathrm{I}_{C_{a} \mathrm{~L}}$ and $\mathrm{I}_{\mathrm{K}}$ differs in feline lefe ventricular hypertrophy. Am J Pbysol. 1994:266: H1121-H1131.

30. Kass RS. Genetically induced reduction in small currents has major impact. Cimcratation. 1997;96:1720-1721.

31. Zareba W, Moss AJ. Schwartz PJ, Vincent GM, Robinson JL, PrioriSG, Benhorin J, Locati EH, Towbin JA, Keating MT, Lehmann MH, Hall WJ. Influence of the genotype on the clinical course of the long-QT syndrome. International Long-QT Syndrome Registry Research Group. N Engl J Med. 1998;339:960-965.

32. Shimizu W, Antzelevitch C. Sodium channel block with mexiletine is effective in reducing dispersion of repolarization and preventing torsade de pointes in LQT2 and LQT3 models of the long-QT syndrome. Circulation. 1997;96:2038-2047.

33. Priori SG, Napolitano C, Cantù F, Brown AM, Schwartz PJ. Differential response to $\mathrm{Na}^{+}$channel blockade, $\beta$-adrenergic stimulation, and rapid pacing in a cellular model mimicking the SCN5A and HERG defects present in the long-QT syndrome. Cir Res. $1996 ; 78: 1009-1015$.

34. El-Sherif $N$, Caref EB, Yin $H$, Restivo $M$. The electrophysiological mechanism of ventricular arrhythmias in the long QT syndrome: tridimensional mapping of activation and recovery patterns. Circ Res. 1996;79:474-492. 


\section{Functional Upregulation of $\mathrm{Na}^{+}-\mathrm{Ca}^{2+}$ Exchange in Cardiac Hypertrophy May Contribute to Contractile Adaptation, But Also to Arrhythmogenesis}

Karin R. Sipido, Paul G.A. Volders, 5.H. Marieke de Groot, Mirella M.C. Molenschot, Frans Van de Werf, Hein J.J. Wellens, Marc A. Vos.

From the Laboratory of Experimental Cardiology, University of Leuven, Belgium (K.R.5., F.V.d.W.); and the Department of Cardiology, Cardiovascular Research Institute Maastricht, Maastricht University, Netherlands. 


\section{Abstract}

Background: Triggered arrhythmias are a major cause of sudden death in patients with heart failure and hypertrophy. The dog with chronic complete atrioventricular block (AVB) has proarrhythmia and biventricular hypertrophy, and is a useful model to study cellular mechanisms of arrhythmias. We investigated whether contractile adaptation to chronic $A V B$ and changes in $C^{2 *}$ homeostasis might contribute to proarrhythmia.

Methods and Results: Contractile function in vivo was enhanced in chronic AvB, in particular at the (slow) idioventricular heart rate. In enzymatically isolated single cells, shortening and $\mathrm{Ca}^{2+}$ release from the sarcoplasmic reticulum (SR) were likewise enhanced at low stimulation frequencies. $\mathrm{Ca}^{2+}$ influx through L-type $\mathrm{Ca}^{2+}$ channels was unchanged, but $\mathrm{Ca}{ }^{2+}$ influx via the $\mathrm{Na}^{*}-\mathrm{Ca}^{2+}$ exchanger was significantly larger, and contributed to $\mathrm{Ca}{ }^{2+}$ loading of the SR. Inward $\mathrm{Na}^{+}-\mathrm{Ca}^{2}+$-exchange currents were larger in left ventricular cells from chronic AVB. In right ventricular cells of chronic AVB, changes in $\mathrm{Ca}^{2+}$ fluxes were less pronounced.

Condusions: Enhanced $\mathrm{Na}^{+} \times \mathrm{Ca}^{2+}$-exchange activity may improve contractile adaptation to chronic $A V B$, but may at the same time contribute to proarrhythmia, by (1) providing more inward current at the time of $\mathrm{Ca}^{2}$ release, leading to increased dispersion of repolarization at slow heart rates; (2) increasing the propensity to $\mathrm{Ca}^{2+}$ overload; and (3) enhancing (arrhythmogenic) currents during spontaneous $\mathrm{Ca}^{2+}$ release. 


\section{Introduction}

Enhanced susceptibility to arthythmias in hypertrophy and heart failure is due to structural and functional, including electrical, remodeling; disturbances in repolarization, with QT prolongation and enhanced dispersion of repolarization, provide the substrate for initiating and sustaining ventricular arhythmias. ${ }^{1-3}$ The underlyng cellular changes have been a major topic of investigarions in recent years. In myocyces isolated from human faling hearts, a regionally variable reduction in the transient outward $\mathrm{K}^{+}$current, $\mathbb{I}_{\mathrm{to}}$, was identified, 4,5 and similar changes were observed in animal models of heart failure and hyperrophy (eg, References 6 and 7 ). The role of a reduction of $I_{\text {ro }}$ in action-potential prolongation, however, is not yet resolved, and other membrane currents may be of najor importance. Changes in other $\mathbb{K}$ currents and in $\mathrm{Ca}^{2+}$ currents have been identifed in animal models of hypertrophy (reviewed in Reference 8). Another ionic current possibly involved in action-potential prolongation is the $\mathrm{Na}^{*}-\mathrm{Ca}^{2+}$ exchanger. This $\mathrm{Ca}^{2+}$ transporter exchanges $1 \mathrm{Ca}^{2+}$ for $3 \mathrm{Na}^{+}$ions, and generates an inward current during $\mathrm{Ca}^{2+}$ effux; $\mathrm{Ca}^{2+}$ influx via the $\mathrm{Na}{ }^{+}-\mathrm{Ca}^{2+}$ exchanger (reverse mode) will enhance $\mathrm{Ca}^{2+}$ loading of the cell. ${ }^{9}$ Its activity as a $\mathrm{Ca}^{2+}$-extrusion parhway, and thus the amplitude of the inward current, is closely linked to the amplitude and time course of the $\left[\mathrm{Ca}^{2+}\right]_{i}$ transient and contributes to the plateau of the action potential. ${ }^{10,11}$ Prolongation of the $\left[\mathrm{Ca}^{2+}\right]_{\mathrm{i}}$ transient due to a decrease in sarcoplasmic reticulum (SR) $\mathrm{Ca}^{2+}$ pumps, may lead to larger exchanger currents in heart failure, ${ }^{12}$ and contribute to action-potential prolongation in this condition. ${ }^{13}$ Studies of human failing hearts have found an increase in the level of expression of the $\mathrm{Na}^{*}-\mathrm{Ca}^{2+}$ exchanger. ${ }^{14.15}$ From studies of mice with overexpression of the $\mathrm{Na}^{+}-\mathrm{Ca}^{2+}$ exchanger, it has become clear that an increase in the level of $\mathrm{Na}^{+}-\mathrm{Ca}^{2+}$-exchanger proteins will affect $\mathrm{Ca}^{2+}$ homeostasis and membrane currents. ${ }^{16-18}$ Through it effects on membrane currents and $\left[\mathrm{Ca}^{2+}\right]_{\mathrm{i}}$, changes in $\mathrm{Na}^{+}-\mathrm{Ca}^{2+}$ exchange during ventricular hypertrophy and remodeling can shape the substrate as well as the rrigger for arrhythmias. However, the link berween arrhythmogenesis and changes in $\mathrm{Ca}^{2+}$ homeostasis, in particular the $\mathrm{Na}^{*}-\mathrm{Ca}^{2+}$ exchanger, is largely unexplored.

The dog wich chronic complete atrioventricular block (AVB) has proven to be an excellent model for the study of triggered arthych mias, linked to a prolongacion and increased dispersion of repolarization, and to the occurrence of afterdepolarizations. ${ }^{19}$ The proarhythmia rypically develops in parallel with biventricular bypertrophy and remodeling. Hypertrophy and action potential prolongation are intrinsic characteristics of the myocytes. 20 A decrease in delayed rectifier $K^{*}$ current was implicated in the action-potential prolongation, ${ }^{21}$ and confurms the presence of ionic remodeling. Therefore this model offers the unique opportunity to further chavacterize the culluat substrate of triggered arrhythmias in the setring of remodeling. In the present study we will explore alterations in cellular $\mathrm{Ca}^{2+}$ homeostasis, in particular changes in $\mathrm{Ca}$. release from the $\mathrm{SR}$ and in $\mathrm{Ca}^{2+}$ transport by the (electrogenic) $\mathrm{Na}^{+}-\mathrm{Ca}^{2 *}$ exchanger, which may contribute to proarrhythmia. 


\section{Methods}

\section{In-Wivo Studies}

The procedures for creating AVB and for anesthesia were as described before. ${ }^{22}$ All experiments were approved by the university 'Commitree for Experiments on Animals' (Leuven, Maastricht) and performed in accordance with the European Directive for the Protection of Vertebrate Animals and other Sciencific Purposes. In a total of 10 anestherized mongrel dogs of either sex lefrventricular (LV) pressure was recorded during LV epicardial pacing with a single micromanomerer pressure transducer catheter (Sentron, Roden, Netherlands), as previously described. ${ }^{22}$

\section{Celinsolation}

A total of $18 \mathrm{dogs}$ were studied after $8 \pm 1$ weeks of AVB. A group of $15 \mathrm{dogs}$ in sinus rhythm, with comparable body weight (BW) and age, served as control. The procedure for cell isolation has been described in detail before. ${ }^{20,23}$ Briefly, the heart was removed under deep anesthesia. Heart weight (HW) was immediately determined, and for all chronic-AVB dogs, hypertrophy was confirmed by a $H W / B W$ of $11.4 \pm 0.4 \mathrm{~g} / \mathrm{kg}$ versus $8.0 \pm 0.2 \mathrm{~g} / \mathrm{kg}$ for control dogs $(P<0.001)$. Both the left-anterior-descending coronary artery and the right coronary artery were cannulated and the rissue perfused with enzymes, ro obtain LV and right ventricular (RV) cells from the same hearts. ${ }^{23} \mathrm{Af}$ ter removal of the epicardial layer, midmyocardial cells were sampled with a pasteur pipette, avoiding contamination by the endocardium. Isolated myocytes were stored in a normal Tyrode's solution (see below) at room temperature.

\section{Recording of Cell Shortening, Membrane Currents, and $\left[\mathrm{Ca}^{2+}\right]$}

All experiments were performed at $36-37^{\circ} \mathrm{C}$. Cells were studied on an inverted microscope (Nikon Diaphot). Shortening of cells impaled with high-resistance microelectrodes was measured with a video-edge detector (Crescent Electronics).

Membrane currents were recorded in the whole-cell, ruptured patch-clamp mode with an Axoparch $1 \mathrm{D}$ amplifier, filtered at $1 \mathrm{kHz}$ and sampled and digitized at 4 $\mathrm{kHz}_{\mathrm{z}}$ (Fasulb45, Indec Systems). Cell capacitance, determined during short hyperpolarizing pulses from $-60 \mathrm{mV}$ to $-70 \mathrm{mV}$, was $155 \pm 6 \mathrm{pF}(\mathrm{n}=48)$ in chronic-AVB LV myocyres wersus $13549 \mathrm{pF}(\mathrm{n}=39)$ in control $\left(P_{<} 0.05\right)$, and capacitance of $\mathrm{RV}$ myocytes was $150 \pm 11 \mathrm{pF}^{\mathrm{F}}(\mathrm{n}=30)$ in chronic $\mathrm{AVB}$ versus $109 \pm 6 \mathrm{pF}(\mathrm{n}=39)$ in control $(P<0.05)$.

$\left[\mathrm{Ca}^{2+}\right]$. was monitored with fluo-3 $(50 \mu \mathrm{mol} / \mathrm{L})$ or a combinarion of fluo-3 $(30$ $\mu \mathrm{mol} / \mathrm{L})$ and futa-red $(70 \mu \mathrm{mol} / \mathrm{L})$. The setup and calibrarion were as described before. ${ }^{24}$ Wich fluo-3 alone, fluorescence values were background-corrected and normalized for baseline fluorescence (pseudo-ratio); $\left[\mathrm{Ca}^{2+}\right]_{i}$ was calculated assuming a $\mathrm{K}_{\mathrm{D}}$ of $400 \mathrm{nM}$ and a resting value of $100 \mathrm{nM} .{ }^{25}$ Previous studies have documented the use of fluo-3 and pseudo-ratios in comparing $\left[\mathrm{Ca}^{2+}\right]_{\text {i }}$ transients from normal cells to transients from hypertrophied cells. 26 Values obtained with this latter approach correlated well with the calibrated values obtained with the dual-dye method. 
Pooled data are shown as mean \pm SEM. Comparisons between groups were made with Student's unpaired $t$ test, or a $\chi^{2}$ test where appropriate. P values $<0.05$ were considered significant.

\section{Solutions and Experimental Protocols}

For measurement of $\left[\mathrm{Ca}^{2+}\right]_{\text {; }}$, the pipetre solution contained (in mmollL): $K$ aspartate $120, \mathrm{KCl} 20$, K-HEPES 10 , MgATP $5, \mathrm{MgCl}_{2} 0.5, \mathrm{NaCl} 10$ or 20 , fluo-3 0.05 (or fluo-30.03 and fura-red 0.07); $\mathrm{pH} 7.20$. In some experiments, K-aspartate and $\mathrm{KCl}$ were replaced with $\mathrm{Cs}$-aspartate and $\mathrm{CsCl}$ respectively. The external solution conrained (in mmol/L): $\mathrm{NaCl} 130, \mathrm{KCl} 5.4, \mathrm{Na}-\mathrm{HEPES} 11.8, \mathrm{MgCl}_{2} 0.5, \mathrm{CaCl}_{2} 1.8$, gucose $6 ; \mathrm{pH} 7.35$.

For measurement of the L-type $\mathrm{Ca}^{2+}$ current $\left(\mathrm{I}_{\mathrm{CaL}}\right)$, the pipetre solution contained (in mmol/L): NMDGC1 110, TEACl 20, HEPES 10, $\mathrm{MgCl}_{2} 0.5, \mathrm{MgATP} 5$, Cs-EGTA $10 ; \mathrm{pH} 7.20$ with TEAOH. The external solution contained (in mmol/L): NMDGCl 130 , HEPES 10 , glucose $10, \mathrm{MgCl}_{2} 0.5, \mathrm{CaCl}_{2} 1.8 ; \mathrm{pH} 7.40$ with TEAOH.

To block L-type Ca ${ }^{2+}$ channels we used $20 \mu$ mol/L nisoldipine (Bayer) or 20 H mol/L nifedipine (Sigma), boch prepared as a $20 \mathrm{mmol} / \mathrm{L}$ stock in DMSO. Ca ${ }^{2+}$ release from the SR was disabled with $10 \mu \mathrm{mol} / \mathrm{L}$ ryanodine (Sigma) prepared as a 10 mmol/L stock in water. In the presence of nisoldipine and ryanodine, $\mathrm{NiCl}_{2}$ (2.5 mmol/L) was used to block $\mathrm{Na}^{+}-\mathrm{Ca}^{2+}$ exchange. To minimize effects of $\mathrm{Ni}^{2+}$ on timedependent $\mathrm{K}^{+}$currents, we measured $\mathrm{Ni}^{2+}$-sensitrve currents at 30 ms into the depolarizing step. Current densities measured with all $\mathrm{K}^{+}$replaced with $\mathrm{Cs}^{+}$, were not different form those with $\mathrm{K}^{+}(1.25 \pm 0.62 \mathrm{pA} / \mathrm{pF}$ at $+70 \mathrm{mV}$ versus $1.23 \pm 0.65 \mathrm{pA} / \mathrm{pF}$, in each group 3 cells from the same heart), as we reported previously. 24

\section{Results}

\section{Contractile Function in Vivo and In Vitro}

Peak LV dP/dt was measured during LV epicardial pacing (Figure 1A). After the creation of $A V B$, an increase in pacing frequency resulted in an increase in $L \mathrm{~V} \mathrm{dP} / \mathrm{dt} . \mathrm{At}$ this time, $\mathrm{LV}$-end diastolic pressure ( $\mathrm{CV}$ EDP) was $15 \pm 2 \mathrm{~mm} \mathrm{Hg}$ at the lowest frequency (versus $11 \pm 1 \mathrm{~mm} \mathrm{Hg}$ at sinus thythm), and did not change significandly with pacing frequency. After 6 weeks of AVB, IL V P/dt at the lowest frequency was twice as large as at the time of acute $\mathrm{AVB}(P<0.01)$. LV dP/dt decreased with increasing frequency, but was still significantly larger than at acute AVB. LV EDP after 6 weeks of $\mathrm{AVB}$ was $11 \pm 2 \mathrm{~mm} \mathrm{Hg}$ at the low frequency and did not change significantly at the higher frequency.

In single LV cells from control dogs and impaled with high-resistance microelecrrodes, increasing the frequency of stimulation tended to increase the extent of shortening $(P=\mathrm{NS}$, Figure $1 \mathrm{~B})$. In cells from chronic-AVB dogs, the extent of shortening 
A

In vivo function

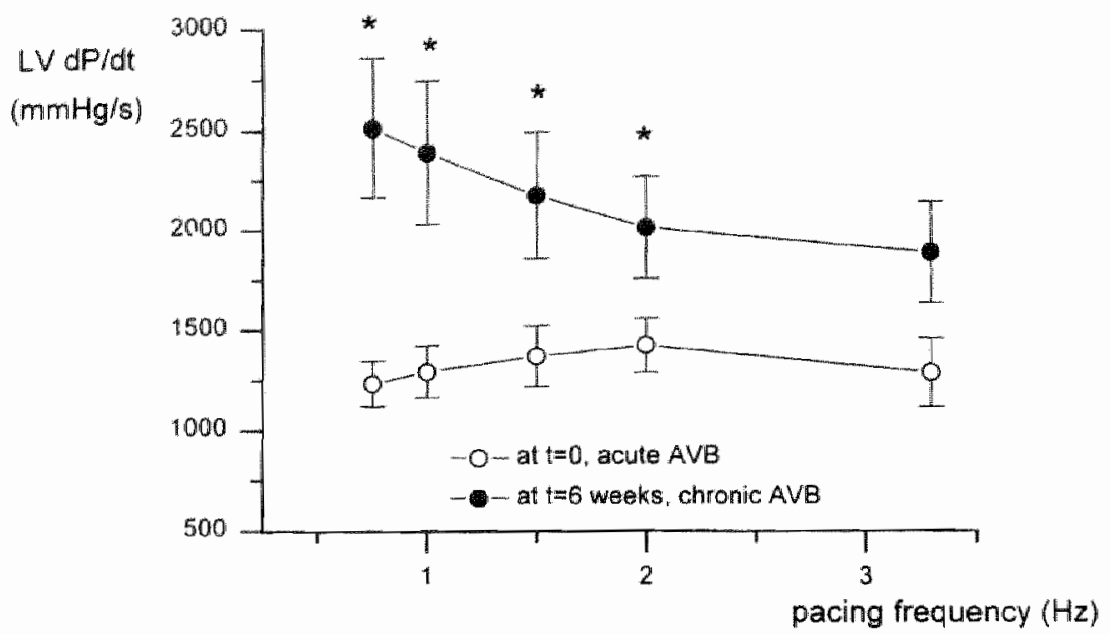

B

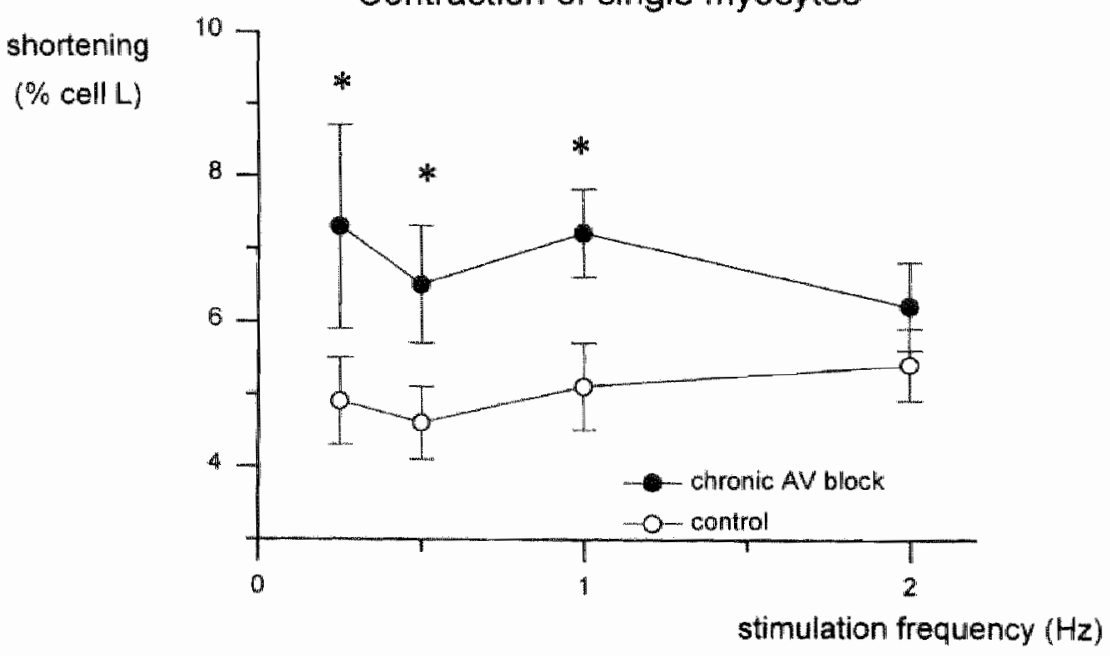

Figure 1. - Contractile function in chronic AVB.

A. In-wivo function was evaluated from the LV dP/dt. Control values (open circles) were obtained immediately after the creation of AVB (nogs $_{\text {cog }}=6$. Dogs were tested again after 6 weeks of AVB ichronic AVB, closed circles, $n_{\text {dogs }}=6$ ). B. Single cell shortening in myocytes isolated from dogs with chronic AVB (closed circles, $n_{\text {doggs }}=5, n_{\text {cells }}=15$ ), and in cells from control dogs (open circles, $n_{\text {dogs }}=5, n_{\text {eells }}=13$ ). 
was significantly larger than in control at frequencies less than $2 \mathrm{~Hz}(P<0.05)$, and tended to decrease with increasing frequencies.

\section{Characteristics of $\left[\mathrm{Ca}^{2+}\right]$ Transients}

Action potentials and $\left[\mathrm{Ca}^{2+}\right]_{\mathrm{i}}$ transients during whole-cell recording are illustrated in Figure 2. In cells from control dogs, a posicive staircase was mostly observed, while in most $\mathrm{AVB}$ cells the amplitude of the $\left[\mathrm{Ca}^{2+}\right]_{i}$ transient decreased with increasing frequency. This negative stair resulted from a significant increase in the amplitude of $\left[\mathrm{Ca}^{2+}\right]_{\mathrm{i}}$ transients at lower frequencies for cells from chronic $\mathrm{AVB}$, as illustrated by the pooled data in Figure $3 \mathrm{~A}$. The increase in peak amplitude at low frequencies was not dependent on a more pronounced increase in $\mathrm{APD}$ at the lower frequencies in chronic $\mathrm{AVB},{ }^{20}$ because it was maintained during stimulation at diferent frequencies in voltage-clamp made with a fixed pulse duration (results nor shown).

The slower rise following the rapid upstroke of $\left[\mathrm{Ca}^{2 *}\right]_{i}$ was more pronounced for AVB dog cells, and the time to peak of $\left[\mathrm{Ca}^{2+}\right]_{i}$ tended to be longer $(115 \pm 11 \mathrm{~ms}$ ar $0.25 \mathrm{~Hz}$ versus $93 \pm 15 \mathrm{~ms}$ in control, $P=\mathrm{NS})$. However, significant differences in $\left[\mathrm{Ca}^{2}{ }^{2}\right]$, were present already during the rapid upstroke (Figure $3 \mathrm{~B}$ ), indicating that early $\mathrm{Ca}^{2+}$ release from the SR was larger in AVB cells at the low frequencies. We nexr examined possible sources of increased $\mathrm{Ca}^{2+}$ influx that could provide either a larger trigget for $\mathrm{SR} \mathrm{Ca}^{2+}$ release and/or the necessary $\mathrm{Ca}^{2+}$ influx to increase $\mathrm{Ca}^{2+}$ content of the SR.

\section{Properties of the L-type $\mathrm{Ca}^{2+}$ Current}

$\mathrm{I}_{\mathrm{CaL}}$ was studied in a separate series of experiments. As illustrated in Figure $4 \mathrm{~A}$, the amplitude of the peak currents, measured during $300-\mathrm{ms}$ depolarizing steps, was similar for LV cells from control and from chronic-AVB dogs, and the I-V relations were not shifted. Steady-state inactivation properties, measured for a step to $0 \mathrm{mV}$, following 2.5-s condirioning pulses to various potentials, were unchanged (Figure 4B).

\section{Ca $a^{2+}$ influx wia the $\mathrm{Na}^{+}-\mathrm{Ca}^{2+}$ Exchanger}

$\mathrm{Ca}^{2+}$ influx via the exchanger in LV cells was measured with $l_{\text {Cil }}$ block and with $\mathrm{Ca}^{2+}$ release from the SR suppressed with $10 \mu$ mol/L ryanodine; pipette $\left[\mathrm{Na}^{+}\right]$was 20 mmol/L (Figure 5A). During depolarization, [Ca ${ }^{2+}$; rose slowly; on repolarization

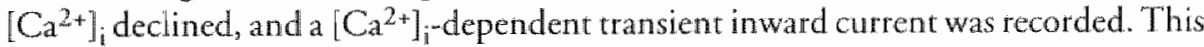
transient inward current was recorded at $-45 \mathrm{mV}$, close to $\mathrm{E}_{\mathrm{Cl}}(-39 \mathrm{mV})$, and was not sensitive to the $\mathrm{Cl}$-channel blocker niflumic acid $(100 \mu \mathrm{mol} / \mathrm{L})$, confirming it resulted from $\mathrm{Ca}^{2+}$ efflux through the exchanger. The increase in $\left[\mathrm{Ca}^{2+} \|_{i}\right.$ was significantly larger in cells from chronic AVB than in control cells (Figure 5 B). The rransient inward current, reflecting the previous increase in $\left[\mathrm{Ca}^{2}{ }^{*}\right]$, was also significantly larger in chronic AVB (Figure 5C). 


\section{chronic AVB}
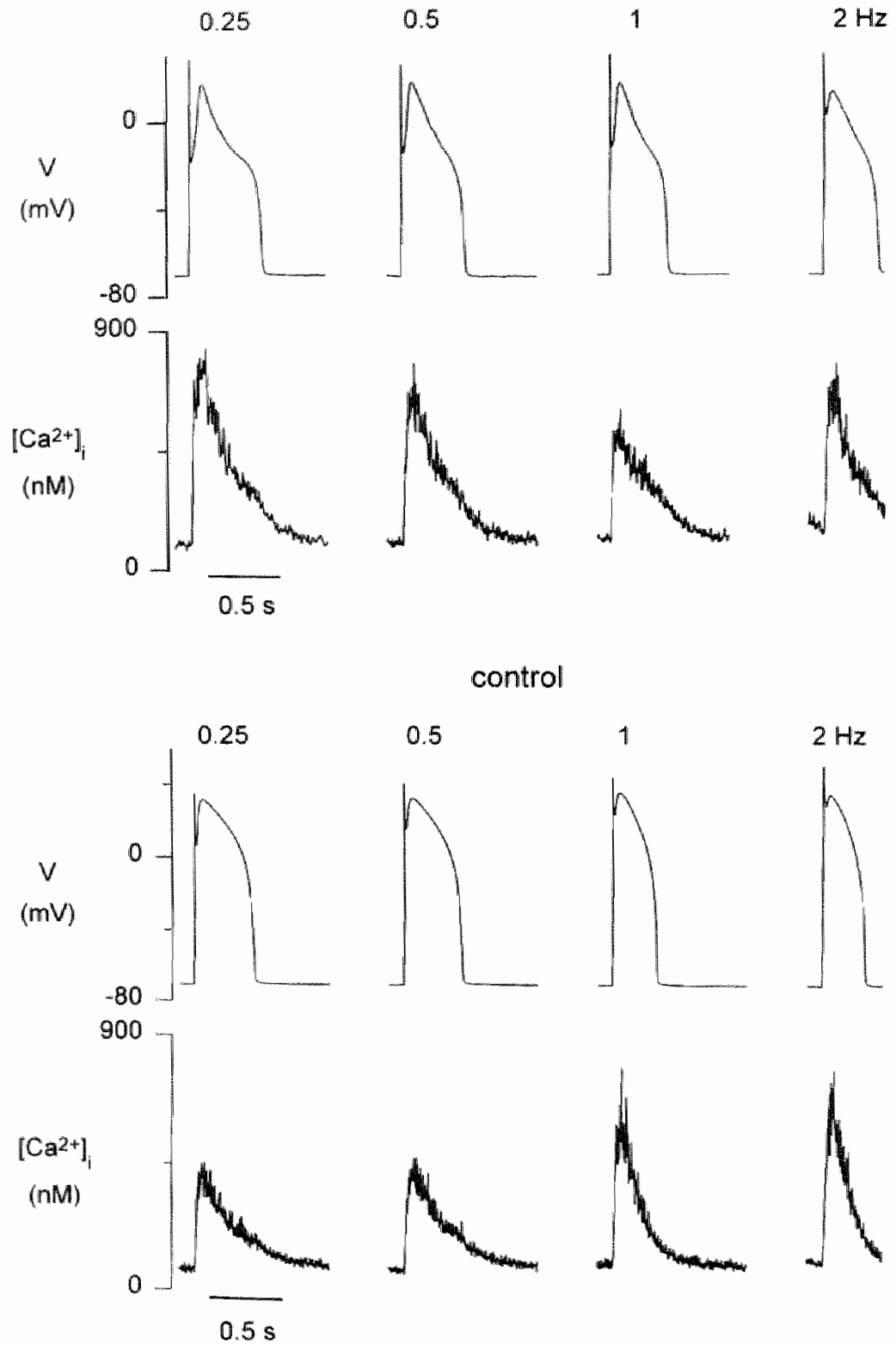

Figure 2. - Amplitude and time course of action potentials and $\left[\mathrm{Ca}^{2+}\right]_{\mathrm{i}}$ transients during whole-cell recording.

Cells were stmulated with 3 -ms depolarizing current pulses, at the indicated frequencies. Representative examples for LV cells from a dog with chronic AVB and a control dog. 

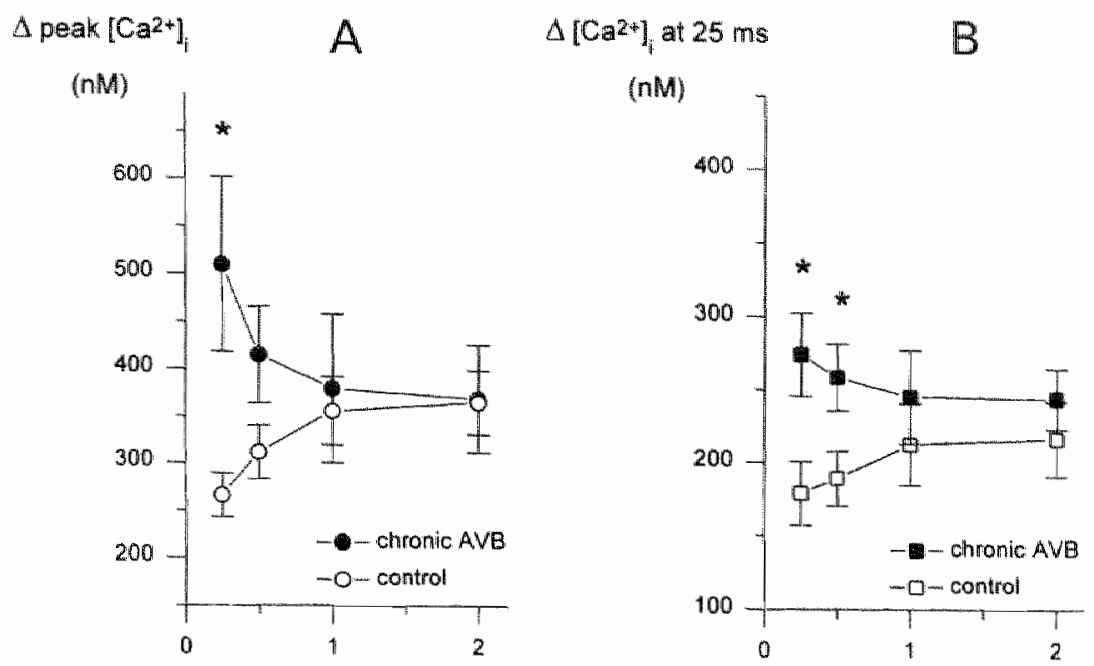

frequency $(\mathrm{Hz})$

Figure 3. - Characteristics of $\left[\mathrm{Ca}^{2+}\right]_{i}$ transients.

A, Frequency-dependence of the peak amplitude of $\left[\mathrm{Ca}^{2+}\right]$; average data of 11 cells from 5 control dogs (open symbols), and 13 cells from 5 AVB dogs (closed symbols). B. $\left[\mathrm{Ca}^{2+}\right]_{\mathrm{i}}$ measured at $25 \mathrm{~ms}$ following the 3 -ms depolarizing current pulse.

\section{Amplitude of $\mathrm{Na}^{+}-\mathrm{Ca}^{2+}$-Exchange Currents}

We next measured the outward $\mathrm{Na}^{+}-\mathrm{Ca}^{2+}$-exchange currents as the $\mathrm{Ni}^{2+}{ }^{2}$ sensitive currents, in the same experimental conditions (Figure 6). Consistent with the larger increase in $\left[\mathrm{Ca}^{2+}\right]_{\mathrm{i}}$, outward current densities of the exchanger were significantly larger for $\mathrm{AVB}$. In the negative potential range, effects of $\mathrm{Ni}^{2+}$ on $\mathrm{I}_{\mathrm{KI}}$ may pose a problem, and reversal potentials were hard to determine. We studied a number of cellswith $C s^{*}$ substitured for $K^{*}$, and found a clear inward exchanger current at the prepulse pocential of $-50 \mathrm{mV}$ in control cells $\left(-0.51 \pm 0.25 \mathrm{pA} / \mathrm{pF}, n_{\mathrm{cell}}=5\right)$, whereas we could hardly identify currents in cells from AVB $\left(0.02 \pm 0.15 \mathrm{pA} / \mathrm{pF}^{*}, \mathrm{n}_{\text {cells }}=5\right)$, suggesting $\mathrm{AVB}$ cells had a more negative reversal potential at resting values of $\left[\mathrm{Ca}^{2}+\right]_{\mathrm{i}}$. The current density of the transient inward current on repolarization as a function of the amplicude of the $\left[\mathrm{Ca}^{2+}\right]_{i}$ ransient evoked by the depolarizing step was larger for chronic AVB (Figure 6C).

\section{Changes in Ca ${ }^{2+}$ Homeostasis in the Right Ventricle}

Similar studies as described above were also performed in cells from the RV; results of the most pertinent protocols are shown in Figure 7. As for cells of the LV, the amplitude of $\left[\mathrm{Ca}^{2+}\right]_{i}$ transients was larger at low frequencies of scimulation (Figure $7 \mathrm{~A}$ ), but the increase was smaller than for the LV cells (compare to Figure 3). I Cal density of RV cells was unchanged with $A V B$, and comparable to values for the LV (Figure $7 \mathrm{~B}$, 
A
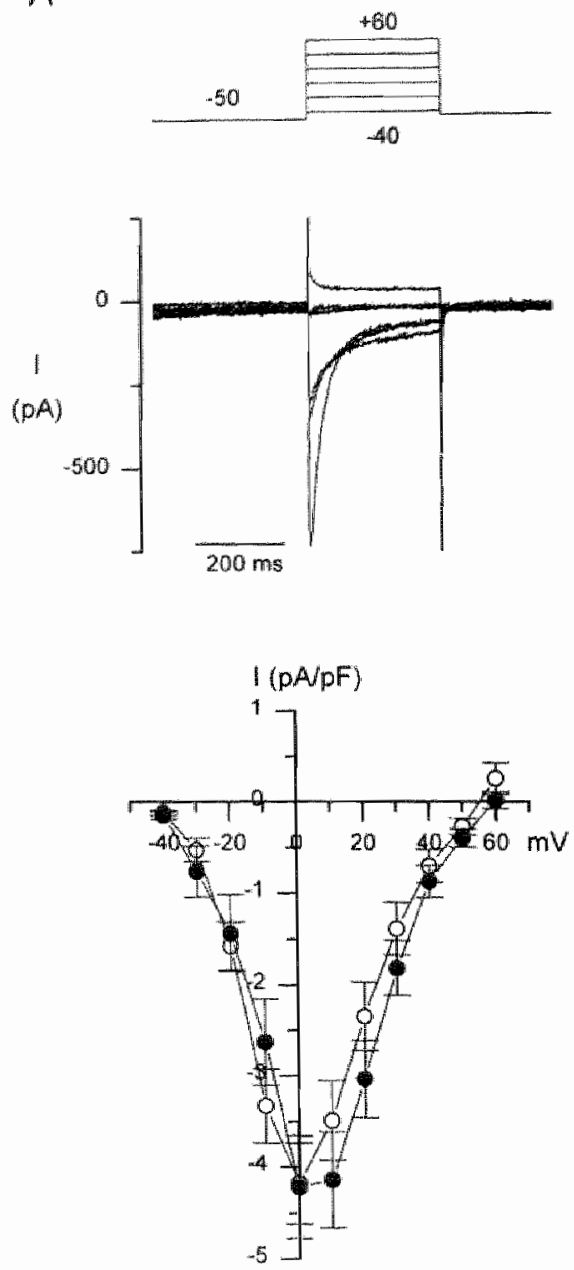

- chronic Áve

-... on control
B
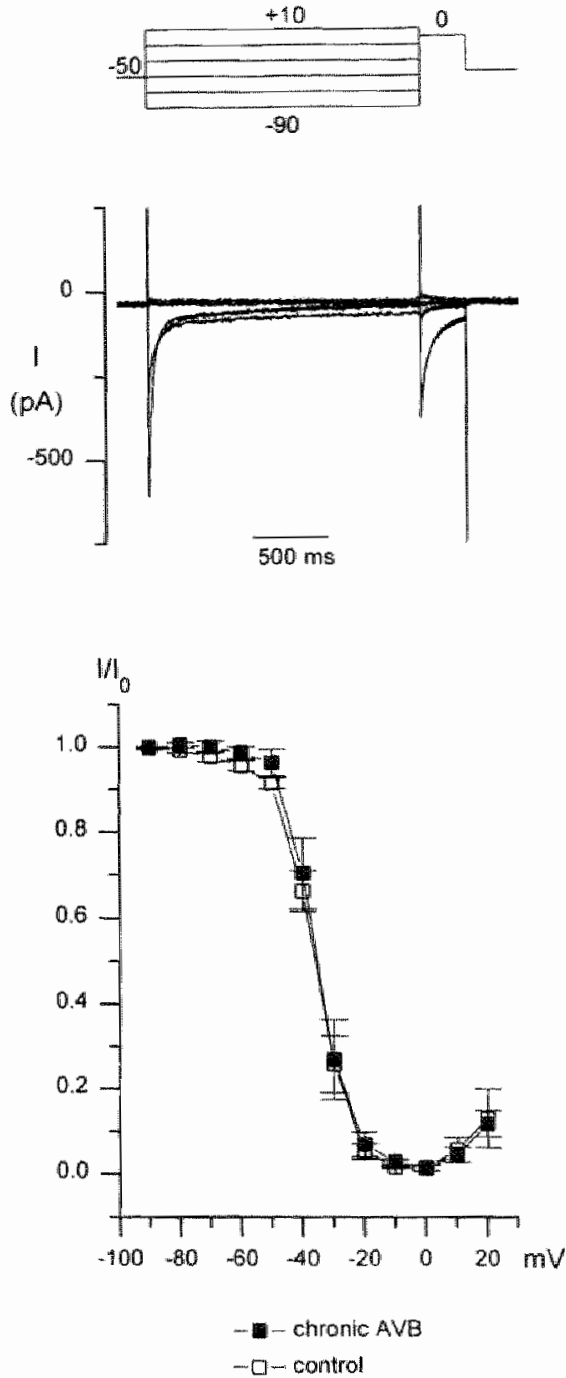

Fingure 4. - Properties of $\mathrm{I}_{\mathrm{Cal}}$.

A, Current densities and W relations were obtained during $300 \mathrm{~ms}$ depolarizing steps from a holding woltage of $-70 \mathrm{mV}$, with a prepulse $10.50 \mathrm{mV}$ (top panel); an example of current records from a cell of an $A V B$ dog is shown (middle panel), as well as pooled data (lower panel) for $A V B$ dogs $\left(n_{\text {cells }}=14\right.$, $\left.n_{\text {ogg }}=4\right)$, and control dogs $\left(n_{\text {cells }}=12, n_{\text {dog }}=3\right)$. B. Steady-state inactivation was studied for a pulse to $0 \mathrm{~m}$ following 2 -s steps to various potentials (top panel); an example of currents trom a cell of an AVB dog is shown (middle panel), as well as pooled data (lower panel) for AvB dogs $\left(n_{c e l l s}=7, n_{\text {dong }}=2\right.$ ), and control dogs $\left(n_{\text {cents }}=7, n_{\text {fogs }}=2\right)$ 
A

chronic AVB
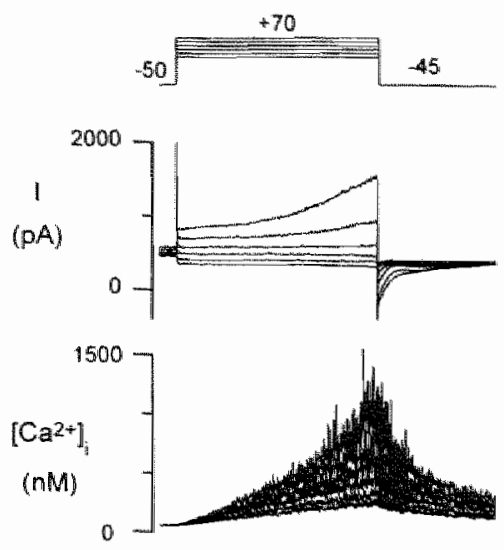

control
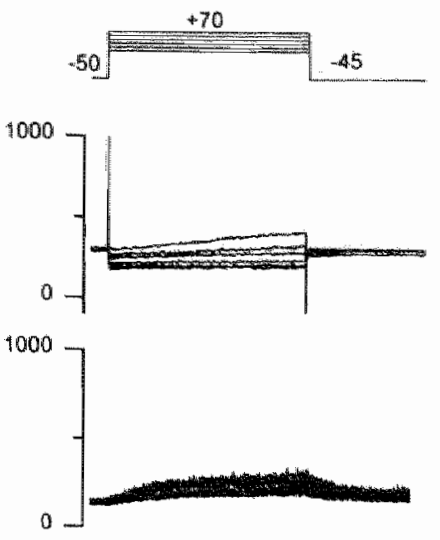

B

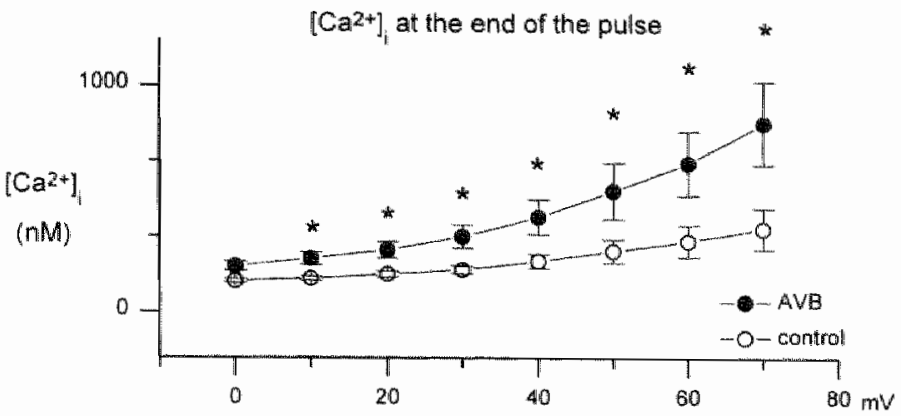

C

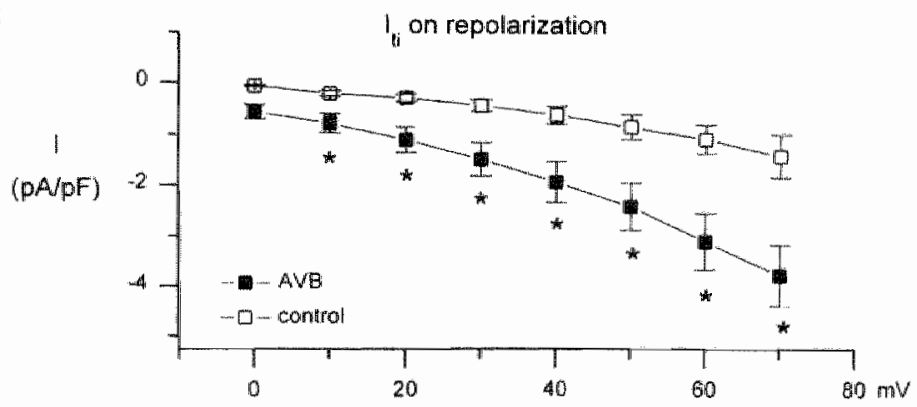

Figure 5. - $\mathrm{Ca}^{2+}$ influx via $\mathrm{Na}^{+}-\mathrm{Ca}^{2+}$ exchange.

A. Examples of current reconds and $\left[\mathrm{Ca}^{2+}\right]_{1}$ transients during long depolarizing pulses, control cell $110 \mathrm{pF}$, AVB cell $128 \mathrm{pF}$. The increasing outward current in the $A V B$ cell at $+70 \mathrm{mV}$ is most likely $\mathrm{Ca}^{2+}$-activated $\mathrm{Cl}$ current since this current was suppressed when the $\left[\mathrm{Ca}^{2+}\right]_{1}$ increase was biocked by $\mathrm{N}^{2+}$, and since this was also observed with all $\mathrm{K}^{+}$replaced by $\mathrm{CS}^{+}$. B. Average increase in $\left[\mathrm{Ca}^{2+}\right]_{1}$ at the end of the pulse of 15 control cells $\left(n_{\text {dog }}=7\right.$ ) and 14 cells from AVB $\left(n_{\text {dogis }}=6\right)$. C. Current density of the transient inward current on repolarization, reflecting the increase in [ $\mathrm{Ca}^{2+}{ }_{\text {lix }}$ of the sanie cells. 
A

B

C chronic $A v / 8$

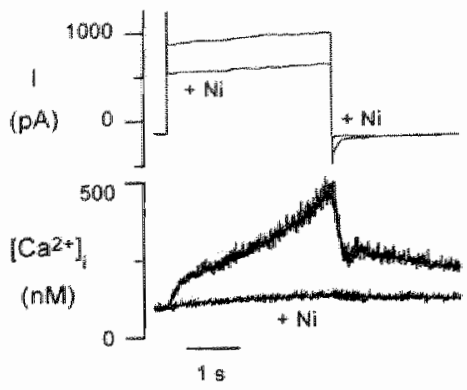

confingl:

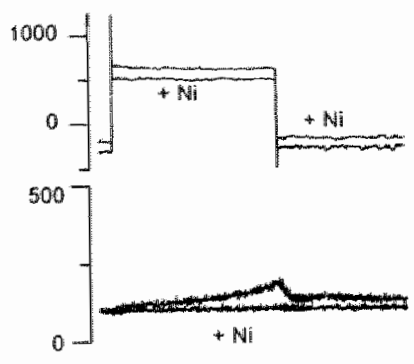

Density of the Wi-sensitive outward current

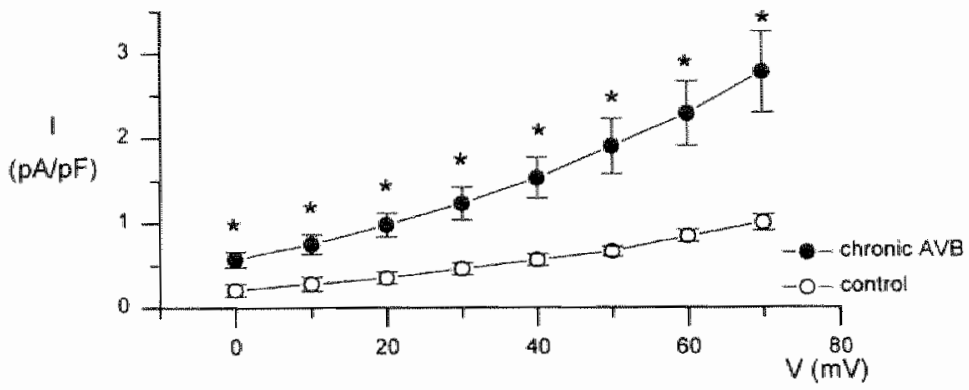

$I_{\text {if }}$ density as a function of $\left[\mathrm{Ca}^{2+}\right]_{i}$

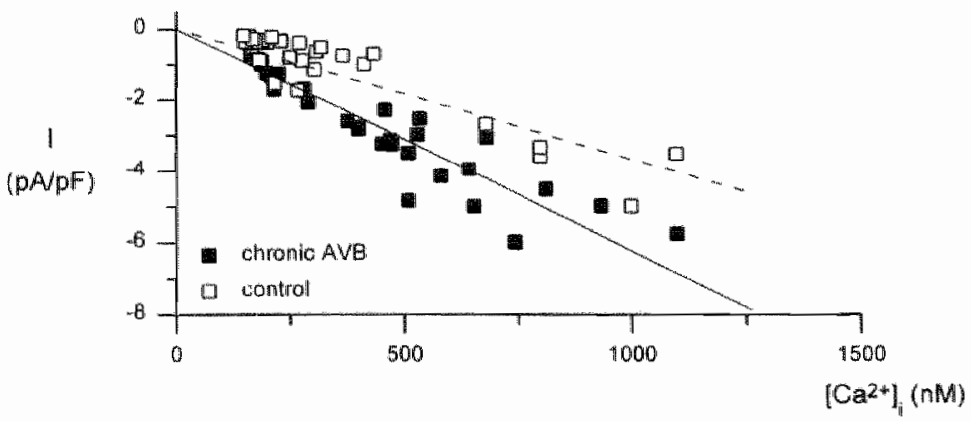

Figure 6. $-\mathrm{Na}^{+}-\mathrm{Ca}^{2+}$-exchange current densities are larger in chronic AVB.

A. Outwand currents were measured by subtraction of currents before and after addition of 2.5 mmol/ $\mathrm{NiCl}_{2}$; records obtained with all $\mathrm{K}^{+}$replaced with $\mathrm{Cs}^{+}$. Note that $\mathrm{Ni}^{2 *}$ suppressed the $\left[\mathrm{Ca}^{2+}\right]$ increase, and had no effect on holding current in the AVB cell (125 pF), but suppressed a snall inward current in the control cell (185 pF). B. Average density of the $\mathrm{Ni}^{2+-}$-sensitive outward current in control $\left(n_{\text {cefis }}=7, n_{\text {dogs }}=4\right)$, and in chronic $A V B\left(n_{\text {cehls }}=9 . n_{d o g r s}=5\right)$. In an additional 3 cells for each group, currents were measured at $\mathrm{O}_{\mathrm{r}}+40$ and $+70 \mathrm{mV}$ only; values were in the same range as shown for the N curve. C. Density of the transient inward current on repolarization to $-45 \mathrm{mV}$ as a function of the [C $\mathrm{C}^{2 *}$ li at that time. The full line is the fit to the chronic-AvB data points $\left(R^{2}=0.83\right)$, and the dashed line to the data points for control cells $\left(R^{2}=0.86\right)$. Statistical analysis separated the 2 groups with $P<0.001$. Data obtained from the experiments shown in Figure 5 , for depolarizing steps to 450,460 and +70 mv. 
A

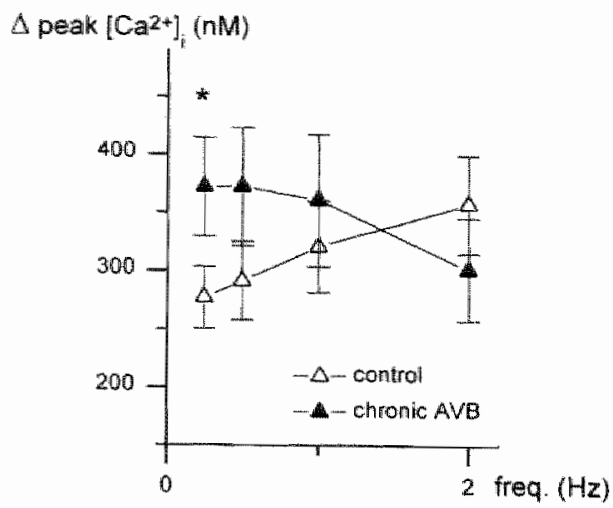

B

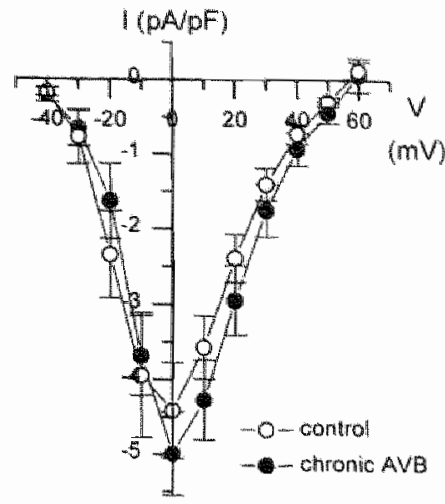

C

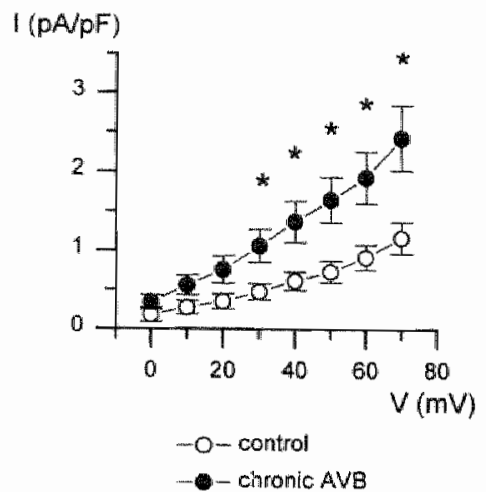

D

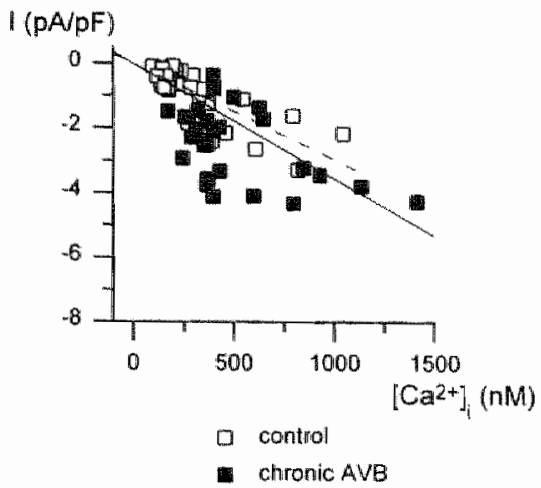

Figure 7. - RV cell properties in chronic AVB.

A, Average increase in peak $\left[\mathrm{Ca}^{2+}\right]_{i}$ during whole-cell recording in current-clamp mode at different

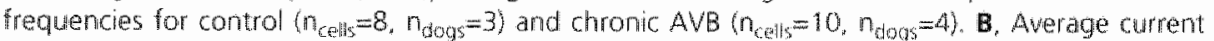

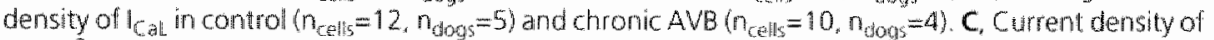

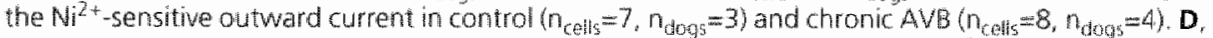
Density of the transient inward current on repolarization as a function of the $\left[\mathrm{Ca}^{2+}\right]_{1}$ at that time. The linear regression fits to the chronic-AvB data points and to the data points for control cells overlap. $\left(R^{2}=0.50\right.$ and 0.64 respectively; the groups could not be separated)

compare to Figure 4). Afrer block of SR release with ryanodinc, a significant increase in $\mathrm{Ca}^{2+}$ influx via the $\mathrm{Na}^{+}-\mathrm{Ca}^{2+}$ exchange was also observed for $\mathrm{RV}$ cells from chronicAVB dogs, compared to cells from control dogs (eg, for pulses $10+40 \mathrm{mV},\left[\mathrm{Ca}^{2}\right]_{\mathrm{i}}$ at the end of the pulse was $365 \pm 77 \mathrm{nM}$ for $\mathrm{AVB}\left(\mathrm{n}_{\mathrm{cell}}=11, \mathrm{n}_{\mathrm{dog}}=5\right)$, versus $234 \pm 46 \mathrm{nM}$ for control ( $\left.\mathrm{n}_{\text {cells }}=12, \mathrm{n}_{\mathrm{dogs}}=6\right)$, but this increase was slighty less than in L V cells $\left[\left[\mathrm{Ca}^{2+}\right]_{;}\right.$at $+40 \mathrm{mV}$ in LV AVB cells was $423 \pm 76 \mathrm{nM}$ ). $\mathrm{Ni}^{2+}$-sensitive ourward currents were sig- 
nificantly larger in $R V A V B$ than in control (Figure $7 C$ ), but again slightly less than in LV (at $+40 \mathrm{mV}, 1.37 \pm 0.26 \mathrm{pA} / \mathrm{pF}$ in RV AVB wersus $1.52 \pm 0.24 \mathrm{pA} / \mathrm{pF}$ in LV AVB). The transient inward exchanger current at $-45 \mathrm{mV}$ as a function of the amplitude of the $\left[\mathrm{Ca}^{2+}\right]_{i}$ transient during the depolarizing step was not significantly increased, and below the values for the LV AVB cells (Figure 7D, contrast with Figure 6C).

\section{Contribution of Reverse-mode $\mathrm{Na}^{+}-\mathrm{Ca}^{2+}$ Exchange to SR Ca2: Release}

We next examined whether $\mathrm{Na}^{+}-\mathrm{Ca}^{2+}$ exchange could act as a trigger for $S R$ $\mathrm{Ca}^{2+}$ release in chronic AVB. To facilitate the study, these experiments were performed with $20 \mathrm{mmol} / \mathrm{L} \mathrm{NaCl}$ in the pipette; a typical example is illustrated in Figure $8 \mathrm{~A}$. The peak amplitude of $\left[\mathrm{Ca}^{2+}\right]_{i}$ tended to be larger in LVAVB cells, and large $\left[\mathrm{Ca}^{2+}\right]_{i}$ transients were observed at positive potentials. However, as we previously observed in guinea-pig cells, ${ }^{24}$ the voltage dependence of the early increase in $\left[\mathrm{Ca}^{2+}\right]_{i}$ at $25 \mathrm{~ms}$ was srill bell-shaped, rellecting the voltage dependence of $I_{\mathrm{CaL}}$ (not shown). After block of $\mathrm{I}_{\mathrm{CaL}}$ the upstroke of $\left[\mathrm{Ca}^{2+}\right]_{i}$ was significantly delayed and slower (Figure 8A, traces marked by 'nis'). SR $\mathrm{Ca}^{2+}$ release triggered by reverse-mode $\mathrm{Na}^{+}-\mathrm{Ca}^{2+}$ exchange (ryanodine-sensitive, not shown) was observed more frequently in LVAVB cells, and the amplitude of $\left[\mathrm{Ca}^{2+}\right]_{\mathrm{i}}$ transients on average was larger (Figure $8 \mathrm{C}, \mathrm{D}$ ). In RV cells as well, SR release triggered by $\mathrm{Na}^{+}-\mathrm{Ca}^{2+}$ exchange was seen more frequently in $\mathrm{AVB}$, but again less than in LV cells (at $+10 \mathrm{mV}$ in $2 / 8 \mathrm{AVB}$ cells, versus $0 / 8$ control cells $(P=N S$ ), and at $+40 \mathrm{mV}$ in $5 / 8 \mathrm{AVB}$ cells, versus $2 / 8$ control cells $(P<0.05)$, compare to Figure $8 \mathrm{C})$.

We also tested whether the exchanger would contribute to $\mathrm{SR} \mathrm{Ca}^{2+}$ loading. With $10 \mathrm{mmol} / \mathrm{L} \mathrm{NaCl}$ in the pipette, and with $\mathrm{I}_{\mathrm{CaL}}$ blocked, we looked for $\mathrm{Ca}^{2+}$ release and oscillations indicative for $\mathrm{SR} \mathrm{Ca}{ }^{2+}$ overload, during long pulses to positive potentials (Figure 8E). Spontaneous release was observed more frequently in chronic-AVB cells, than in control cells (for steps to $+50 \mathrm{mV}$ in $10 / 12 \mathrm{AVB}$ cells, versus $1 / 8$ control

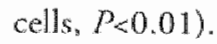

\section{Discussion}

Enhanced Contractile Function and SR C Ca' Release in the Dog with Chronic $A V B$

Measurements of $L V \mathrm{dP} / \mathrm{dt}$ in vivo indicated that contractile function after 6 weeks of $A V B$ is betrer than at baseline, and that this improvement is most pronounced at low stimulation frequencies. Whereas interpretation of in-vivo measurements may be complicated by changes in LV diameter ${ }^{19}$ or in autonomic drive, our measurements of cell shortening of the isolated myocytes confirm this finding. The "inversion" of the $\left[\mathrm{Ca}^{2+}\right]_{\mathrm{i}}$-frequency relation observed in the present study should be contrasted to the findings in human heart failure, where the inversion results from a loss of contraction at the higher rates, with (near) normal function at the low frequencies. 27,28 The enhanced 
A

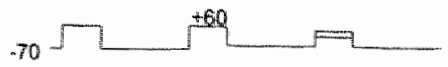

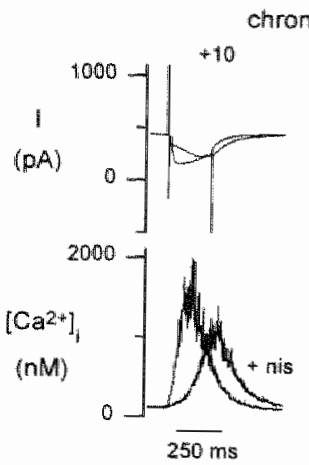

B

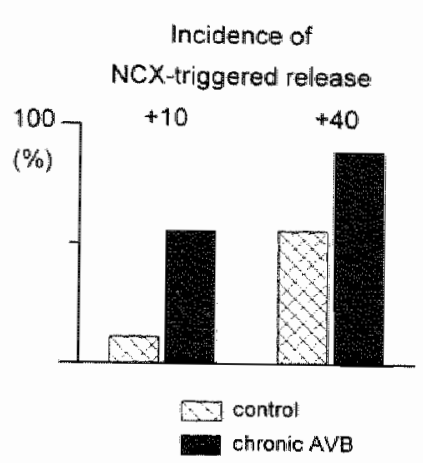

D

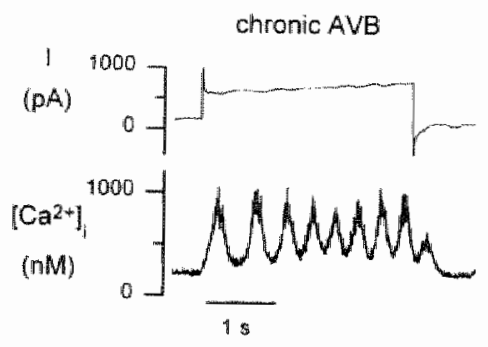

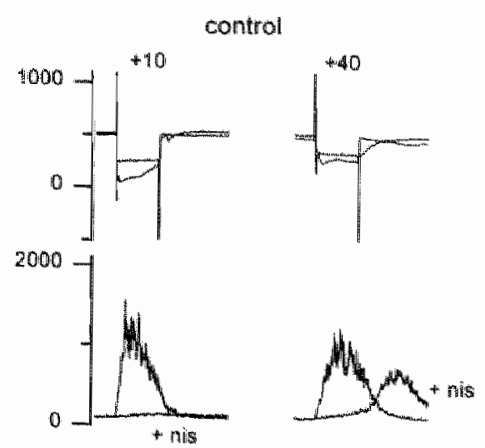

C

Peak [Ca't $]_{i}$ after block of ! ${ }_{\text {CaL }}$

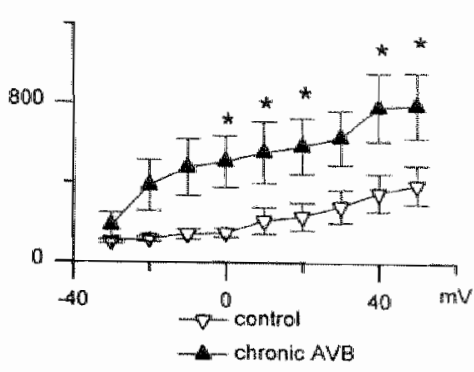

control

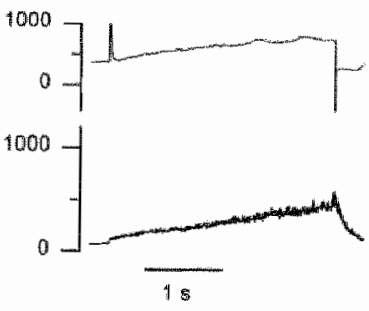

Figure 8. - Contribution of $\mathrm{Na}^{4}-\mathrm{Ca}^{2+}$ exchange to $\mathrm{Ca}{ }^{2+}$ release from the sarcoplasmic reticulum.

A, Membrane currents and $\left[\mathrm{Ca}^{2+}\right]_{1}$ transients were reconded during $300-\mathrm{ms}$ depolarizing steps to the indicated potentials (see inset), betore and after blocking bat. with nisoldipine, records marked + nis: The delayed but rapidly rising $\left[\mathrm{Ca}^{2+}\right]_{i}$ transient remaining in the presence of nisoldiphe was blocked by ryanodine (not shown). Records obtained in an LV cell from chronic AVB, 88 pF, and from a control dog, $110 \mathrm{pF}$. B. Incidence of $\mathrm{Ca}^{2+}$ release triggered by $\mathrm{Na}-\mathrm{Ca}{ }^{2 *}$ exchange at the indicated potentials. C. Average peak $\left[\mathrm{Ca}^{2+}\right]_{1}$ in the presence of nisoldipine for control $\left(\mathrm{n}_{\mathrm{cell}}=9{ }_{n} n_{\mathrm{dog}}=4\right)$ and chronic $\mathrm{AvB}$ tclosed circles, $n_{\text {cells }}=9$. $\left.n_{\text {elogs }}=4\right)$. D, Occurrence of spontaneous $\mathrm{Ca}^{2+}$ release during a long depolarizing pulse to $+50 \mathrm{mV}$, in the presence of nisoldipine, LV cell from chronic-AVB dog, $120 \mathrm{pF}$. and firom control dog, $95 \mathrm{pF}$. 


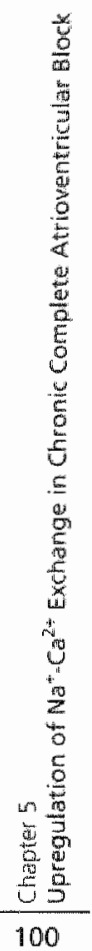
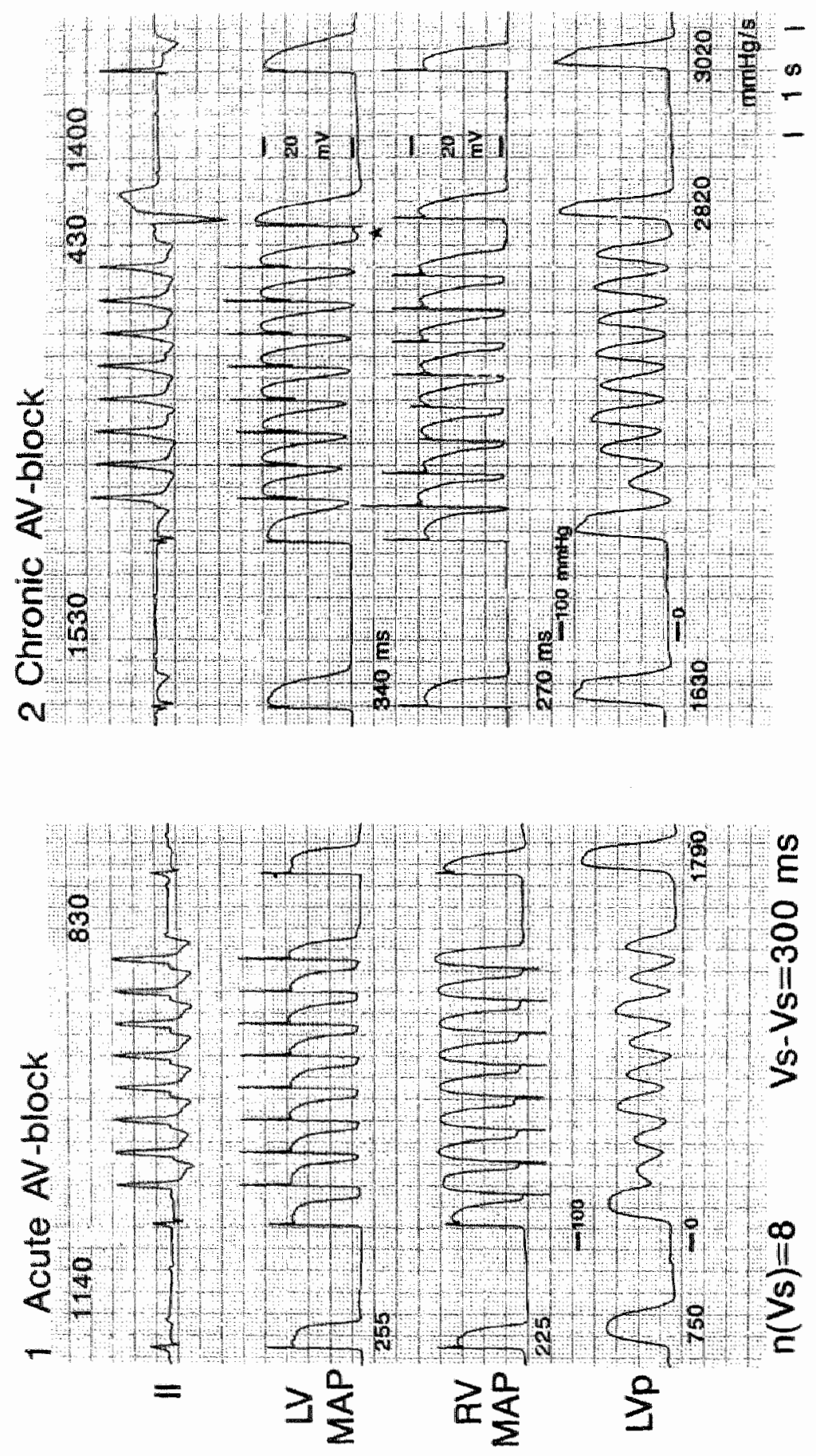
Figure 9 (left page). - Delayed afterdepolarizations and ectopic beats evoked by pacing. At 6 weeks of chronic AVB (right panel), monophasic-action-potential (MAP) duration is increased, and dispersion between LV and RV enhanced compared to the time of creation of AVA Ueft parelly. IV pressure is also higher at chronic AVB. A short pacing train now induces an afterdepolarizalion manifest in the LV MAP (marked by *), triggering an ectopic beat with a 430 -ms coupling intenal.

contractile function in chronic AVB maintains cardiac ourput at the slow idioventricular rate (S.H.M.d.G., PhD thesis). We have recently shown that the functional adaptation occur's in parallel with hypertrophy at the macroscopic and single cell level. ${ }^{20}$

In animal models of hypertrophy an increase in contraction or $\left[\mathrm{Ca}^{2+}\right]_{i}$ transients was reported for the spontaneously hypertensive rat, ${ }^{29}$ and no change in contractile function was seen in volume-dependent biventricular hypertrophy of the cat. ${ }^{30} \mathrm{How}$ ever, more often a depressed function or $\left[\mathrm{Ca}^{2+}\right]_{i}$ was found (eg, References 26 and 31 through 33). Some of these latter animal models may have a relatively early progression to heart failure, complicating the study of the stage of compensated hypertrophy (see also Reference 34). Indeed, a reduction in the amplitude of contraction or $\left[\mathrm{Ca}^{2+}\right]_{i}$ transients at the working heart rates was consistently observed in animal models of heart failure (eg, References 35 through 37). Our current findings are therefore of particular importance as they most likely represent a stage of compensated hypertrophy, before development of overt heart failure, a stage during which in patients, as in this animal model, there is an increased susceptibility to arrhythmias. ${ }^{2}$

\section{Mechanisms of Increase in Systolic [Ca $\left.{ }^{2+}\right]_{i}$ in Chronic AVB}

Analysis of the early phase of the $\left[\mathrm{Ca}^{2+*}\right]_{i}$ transients indicates that $S R \mathrm{Ca}^{2+}$ release is increased at the lower frequencies. This can be due to an increased $\mathrm{Ca}^{2+}$ influx triggering release, or a higher $\mathrm{SRCa}^{2+}$ content. $\mathrm{Ca}^{2+}$ influx through the $\mathrm{L}$-type $\mathrm{Ca}^{2+}$ channel is unchanged, and can therefore not be responsible for an increase in either trigger $\mathrm{Ca}^{2+}$ or $\mathrm{SR} \mathrm{Ca}^{2+}$ content. In contrast, $\mathrm{Ca}^{2+}$ influx through the exchanger is significantly enhanced in chronic AVB. Previous studies in other mammalian species have shown that $\mathrm{Ca}^{2+}$ influx through the $\mathrm{Na}^{+}-\mathrm{Ca}^{2+}$ exchanger is capable of triggering $\mathrm{Ca}^{2+}$ release albeit with low efficiency, and contribution of this mechanism in the presence of concomitant influx via $\mathrm{L}-t y p e \mathrm{Ca}^{2+}$ channels is probably limited (reviewed in Reference 38). Our data in dog myocytes indicate that in this species as well, $\mathrm{I}_{\mathrm{CaL}}$ is the predominant trigger, necessary to obtain rapidly rising $\left[\mathrm{Ca}^{2+}\right]_{i}$ transients, and the increased $\mathrm{Ca}^{2+}$ release in chronic $\mathrm{AVB}$ most likely results from an increase in $\mathrm{SR} \mathrm{Ca}{ }^{2+}$ content, with perhaps a small contribution of an increase in trigger $\mathrm{Ca}^{2+}$. In this respect it is of interest that the increase in the $\left[\mathrm{Ca}^{2+}\right]_{i}$ transient is restricted to the low frequencies of stimulation. In preliminary experiments we found that in $\mathrm{AVB}$ dogs the $\mathrm{SR} \mathrm{Ca} \mathrm{Ca}^{2+}$ content, as evaluated during caffeine-induced $\mathrm{Ca}^{2+}$ release, indeed tended to be larger at the lower than at the higher frequencies, whereas the reverse was true in control cells. Another hypothesis, which we intend to investigate, is that the local gain of release is increased, as recently proposed. 29 
Our data support the newly emerging idea that reverse-mode $\mathrm{Na}^{+}-\mathrm{Ca}^{2+}$ exchange may be important in cardiac remodeling. Increased $\mathrm{Ca}^{2+}$ influx wia the exchanger, contributing to $\mathrm{Ca}^{2+}$ loading of the $\mathrm{SR}$, was recently described in the rabbit heart post-myocardial infarction. ${ }^{39}$ In human heart failure, the $\mathrm{Na}^{+}-\mathrm{Ca}^{2+}$ exchanger also appears to be very important in determining the $\mathrm{SR} \mathrm{Ca}^{2}+10 a d,{ }^{40}$ a notion supported by the finding that increasing $\mathrm{Na}^{*}$ influx enhances contractile function to a larger extent in myocardium from heart failure patients than from controls. ${ }^{4}$.

\section{Increased Activity of the $\mathrm{Na}^{*}-\mathrm{Ca}^{2 *}$ Exchanger: Upregulation and/or Changes}

in Reversal Potential

When directly measured, $\mathrm{Ca}^{2+}$ influx via the exchanger was significantly increased in chronic $\mathrm{AVB}$, and ourward $\mathrm{Na}^{+}-\mathrm{Ca}^{2+}$-exchange currents were more than 3 fold larger in chronic AVB. Such an increase could result from an increase in the number of exchanger molecules, eg, due to higher expression levels, which is then expected to produce a nearly equal increase in inward currents. Although the inward $\mathrm{Na}^{+}-\mathrm{Ca}^{2+}$-exchange current for LV cells was larger, the increase was less than for the outward currents, especially in RV cells. One possible explanation is a concomitant negative shift of the reversal potential in chronic AVB, as supported by the presence of a net negative inward current at rest in control, but not in AVB cells. Such a shift could be relared to an increase in subsarcolemmal $\left[\mathrm{Na}^{+}\right]$. This hypothesis is attractive, because a small increase in cytoplasmic $\left[\mathrm{Na}^{+}\right]$has been associated with a preferential increase in $\mathrm{Ca}^{2+}$ release at low frequencies of stimulation, ${ }^{42,43}$ and because there is a wellestablished link between an increase in $\left[\mathrm{Na}^{+}\right]_{i}$ and the occurrence of spontaneous $\mathrm{Ca}^{2 *}$ release. ${ }^{44,45}$ We are currently investigating this hyporhesis by measuring $\left[\mathrm{Na}^{+}\right]$in these cells.

Whereas increased exchanger activity has been observed in certain animal models of hypertrophy ${ }^{46}$ and heart failure, ${ }^{12}$ thiss is not always so, ${ }^{32,36}$ suggesting that eventual changes, as in the dog with chronic AVB, represent a specific response, associated with a particular type of $\mathrm{Ca}^{2+}$ handling. Consistent with this idea, expression levels of $\mathrm{Na}^{4}-\mathrm{Ca}^{2+}$ exchange have recently been related to patterns of diastolic dysfunction in human heart failure. ${ }^{47}$

\section{A Link Between Enhanced $\mathrm{Ca}^{2+}$ Release, $\mathrm{Na}^{+}-\mathrm{Ca}^{2+}$ Exchange and Arrhythmogenesis?}

In the dog with chronic $A V B$, as in human ventricular remodeling, increased regional dispersion and prolongation of repolarization, are the substrate for arrhythmias, triggered by ecropic beats and related to afterdepolarizations or local reentry. 1,2,48 The increase in $\mathrm{Na}^{+}-\mathrm{Ca}^{2 *}$ exchange described in the present study is likely to be an important factor shaping the arrhythmia substrate. Enhanced $\mathrm{Ca}^{2+}$ release in steady-state conditions at low frequencies will lead to larger inward $\mathrm{Na}^{+}-\mathrm{Ca}^{2+}$-exchange currents during the plateau and the later phase of the action potential; this will be more pronounced in the $L V$, as $\left[\mathrm{Ca}^{2+}\right]_{i}$ and the inward exchanger current are larger, thus contrib- 
uting to regional dispersion. Our current findings may also shed new light on cellular events responsible for the initiation of arthythmias. Torsades de pointes in the dog with chronic AVB can be evoked in the presence of class III anciarthythmics, and early afterdepolarizations precede the onset of torsades de pointes. 49 Although in vitro these early afterdepolarizations are nor associated with spontaneous $\mathrm{Ca}^{2}+$ release, ${ }^{20}$ the $\mathrm{Na}^{+}-\mathrm{Ca}^{2}$ exchanger may provide the necessary inward current to facilitate depolarizing window $\mathrm{Ca}^{2+}$ currents. A more direct role for increased $\mathrm{Ca}^{2+}$ release and exchanger curtent can be inferred for arrhythmias evoked by pacing (in the absence of class III agents), which are dependent on the induction of an enhanced contracrile state. 50 The occurtence of delayed afterdepolarizations, and of ectopic beats, appears to be related to a critical increase in $L V d P / d t$, which can be obtained in chronic $A V B$, but not at acute $A V B$, following a well-defined short pacing rain of 8-10 beats, as illustrated in Figure 9 . This can be enhanced by oubain, and suppressed by ryanodine. As the amplitude of the $\mathrm{Na}^{*}-\mathrm{Ca}^{2+}$-exchange current will be directly related to the contraction and underlying $\left[\mathrm{Ca}^{2+}\right.$; transient, this current may provide the dynamic component for the condritional prolongation of the action potential, as well as for the initiation of the ectopic beats during spontaneous $\mathrm{Ca}^{2+}$ release. This latter event may be particularly relevant for the arrhythmias occurring during adrenergic stimulation, as previously suggested from in vitro studies. 51,52 A number of dogs with chronic AVB die suddenly, and preliminary data indicate that this event may be related to changes in autonomic drive. This link is currently being investigated.

\section{Conclusions}

An increase in $\mathrm{Na}^{+}-\mathrm{Ca}^{2+}$-exchange activity as part of a stimulus-specific ventricular remodeling process has potentially beneficial as well as negative consequences, for contractile as well as electrical function. Enhanced $\mathrm{Na}^{+}-\mathrm{Ca}^{2}$-exchange activity in the dog with chronic AVB may contribute to the adaptation of contractile function by increasing $\mathrm{Ca}^{2}{ }^{+}$release at the lowet heart rates. This adaptive mechanism may at the same time contribute to proarrhychmia, by increasing the propensity to $\mathrm{Ca}^{2+}$ overload. In addition, increased inward $\mathrm{Na}^{+}-\mathrm{Ca}^{2+}$-exchange curent at the time of $\mathrm{Ca} \mathrm{a}^{2-}$ release adds to prolongation and dispersion of the action-potential duration, and promotes arrhythmogenic currents during spontaneous $\mathrm{Ca}^{2+}$ release.

\section{Acknowledgments}

This sudy was supported by the National Fund for Scientific Research, Belgium (Dr. Sipido), by the Netherlands Organization for Sciencific Research (NWO 902-16-214, Dr. de Groot), and the Wynand M. Pon Foundation, Nerherlands (Dr. Volders). The authors wish to thank Jérome Jungschleger, Jer Leunissen, and Roel Spatjens for assistance, and Pim Dassen for help with statistical analysis. 


\section{References}

1. Tomalli GF, Beuckelmann DJ, Calkins HG, Berger RD, Kessler PD, Lawrence JH, Kass D, Feldman AM, Marban E. Sudden cardiac death in heart failure: the role of abnormal repolarization. Circulation. 1994;90:2534-2539.

2. Zipes DP, Wellens HJ], Sudden cardiac death. Circulation 1998;98:2334-2351.

3. Pak PH, Nuss HB, Tunin RS, Käab S, Tomaselli GF, Marban E, Kass DA. Repolarization abnormalities, arrhychmia and sudden death in canine tachycardia-induced cardiomyopathy. IAm Coll Cardiol 1997:30:576-584.

4. Wettwer E, Amos G), Posival H "Ravens U. Transient outward current in human venrricular myocyres of subepicardial and subendocardial origin. Ciw Res. 1994:75: $473-482$.

5. Näbauer M, Beuckelmann DJ, Überfuhr P, Steinbeck G. Regional differences in current density and rate-dependent properties of the rransient outward current in subepicardial and subendocardial myocytes of human left ventricle. Circulation. 1996;93:168-177.

6. Lue WM, Boyden PA. Abnormal electrical properties of myocytes from chronically infarcted canthe heart: alterations in $\mathrm{V}_{\max }$ and the transient outward current. Circulation. $1992 ; 85: 1175-1188$.

7. Kaab S, Nuss HB, Chiamvimonvat N, O'Rourke B, Pak PH, Kass DA, Marban E, Tomaselli GF. Ionic mechanism of action potential prolongation in ventricular myocytes from dogs with pacing-induced heart failure. Circ Res. 1996;78:262-273.

8. Hart G. Cellular electrophysiology in cardac hypertrophy and failure. Cardionasc Res. $1994 ; 28: 933-946$.

9. Kimura J, Noma $A$, Irisawa $\mathrm{H}$. Na-Ca exchange current in mammalian heart cells. Noture. $1986 ; 319: 596-597$.

10. Luo CH, Rudy Y.A dynamic modell of the cardiac ventricular action potentiall: I. simulations of ionic currents and concentration changes. Circ Res. 1994:74:1071-1096.

11. Janver NC, Boyett MR. The role of Na-Ca exchange current in the cardiac action porencial. Cardiowase Res. 1996;32:69-84.

12. O'Rourke B, Peng LF, Tomaselli GF, Marban E. Excitation-contraction coupling alterations in canine rachycardia-induced heart failure. Corculation. 1997;96(suppl 1): $1-238$. Abstract.

13. Priebe L, Beuckelmann DJ. Simulation sudy of cellular electric properties in heart failure. Cinc Res. 1998;82:1206-1223.

14. Studer R, Reinecke H, BilgerJ, Eschenhagen T, Bóhm M, Hasenfuss $G$, Just H, Holtz I, Drexler $\mathrm{H}$. Gene expression of the cardiac $\mathrm{Na}^{*}-\mathrm{Ca}^{2+}$ exchanger in end-stage human heart failure. Circ Res. 1994;75:443-453.

15. Flesch M, Purz F, Schwinger RHG, Böhm M. Functional relevance of an enhanced expression of the $\mathrm{Na}^{*}-\mathrm{Ca}^{2+}$ exchanger in the failing human heart. Ann NY Acad Sw: $1996,779.539-542$. 
16. Adachi-Akahane S, Lu L, Li Z, Frank IS, Philipson KD, Morad M. Calcium signaling in transgenic mice overexpressing cardiac $\mathrm{Na}^{2}-\mathrm{Ca}^{2}$ exchanger $/ \mathrm{Gew}$ Pbytol. $1997 ; 109: 717-729$.

17. Yao A, Su Z, Nonaka A, Zubair I, Lu L, Philipson KD, Bridge JHB, Barry WH. Effecrs of owerexpression of the $\mathrm{Na}^{*}+\mathrm{Ca}^{2 *}$ exchanger on $\left[\mathrm{Ca}^{2+}\right]_{1}$ transients in murine ventricular myocytes. Cinc Res. 1998;82:657-665.

18. Terracciano CMN, De Souza AI, Philipson KD, MacLeod KT. Sarcoplasmic reticulum (SR) $\mathrm{Ca}^{2+}$ handling in cardiac nyocytes isolated from transgenic mice overexpressing the $\mathrm{Na}^{*} / \mathrm{Ca}^{2}$ exchanger. Cinculation. 1998;98(suppl 1):I-188. Abstract.

19. Vos MA, de Groot SHM, Verduyn SC, van der Zande I, Leunissen HDM, Cleuriens JPM, van Bilsen M, Daemen MJAP, Schreuder J], Allessie MA, Wallens HIJ. Enhanced suscepribility for acquired torsade de pointes arrhythmias in the dog with chronic, conplete $A V$ block is relared to cardiac hypertrophy and electrical remodeling. Circulation. 1998:98:1125-1135.

20. Volders PGA, Sipido KR, Vos MA, Kulcsár A, Verduyn SC, Wellens HJJ. Cellular basis of biventricular hypertrophy and arrhythmogenesis in dogs with chronic complete atrioventricular block and acquired torsade de pointes. Cinculation. 1998:98: 1136-1147.

21. Volders PGA, Sipido KR, Vos MA, Spätjens RLHMG, Lemnissen-Beekman JDM, Carmeliet $\mathbb{E}_{\text {, Wellens }} \mathrm{H}$ J]. Downregularion of delayed rectifier $\mathrm{K}$. current in dogs with chronic complete arrioventricular block and acquired torsades de pointes. Circalation. 1999: in press.

22. Vos MA, Verduyn SC, Gorgels APM, Lipcsei GC, Wellens HJJ. Reproducible induction of early afterdepolarizanions and torsade de pointes arrhythmias by d-sotalol and pacing in dogs wich chronic atrioventricultar block. Circulation. 1995;91:864-872.

23. Volders PGA, Sipido KR, Carmeliet E, Spärjens RLHMG, Wellens HJJ, Vos MA. Re-

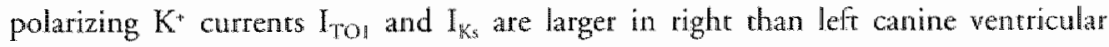
midmyocardiun. Circulation. 1999;99:206-210.

24. Sipido KR, Maes $\mathrm{M}$, Van de Werf F. Low efficiency of $\mathrm{Ca}^{2}{ }^{2}$ entry through the $\mathrm{Na}$ - $\mathrm{Ca}^{2}$ exchanger as trigger for $\mathrm{Ca}^{2+}$ release from the sarcoplasmic reticulum: a comparison between L-type $\mathrm{Ca}^{2 *}$ current and reversemode $\mathrm{Na}^{*}{ }^{2} \mathrm{Ca}^{2+}$ exchange Circ Res. $1997 ; 81: 1034-1044$.

25. Cheng H, Lederer WT, Cannell MB. Calcium sparks: elementary events underlying excitation-contraction coupling in heart muscle. Science. 1993;262:740-744.

26. Gomez AM, Valdivia HH, Cheng H, Lederer MR, Santana LF, Cannell MB, McCune SA, Altschuld RA, Lederer WJ. Defecrive excitation-contraction coupling in experimental cardiac hypertrophy and heart failure. Science. 1997:276:800-806.

27. Picke B, Kretschmann B, Meyer M, Holubarsch C, Weirich J, Posival H, Minami K, Just $\mathrm{H}$, Hasenfuss $\mathrm{G}$. Alterations in intracellular calcium handling associated with the inverse force-frequency relation in human dilated cardiomyopaty. Circulation. $1995,92: 1169-1178$ 
28. Sipido KR, Stankowicova T, Fameng W, Vanhacke J, Verdonck F. Frequency dependence of $\mathrm{Ca}^{2}$ release from the sarcoplasmic reviculum in human ventricular myocytes from end-stage heart failure. Cardionate Res. 1998;37:478 488.

29. Shorofsky $S R$, Aggarwal R, Corrert M, Baffa JM, Strum JM, Al-Seikhan BA, Kobayashi YM. Jones LR, Wier WG, Balke CW. Cellular ryechanisms of altered contractility in the hypertrophicd heart big hearts, big sparks. Circ Res. 1999;84:424-434.

30. Unabe Y, Hamada Y, Spinale FG, Carabello BA, Kent RL, Cooper G, IV, Mann DL. Cardiocyte contractile performance in experimental biventricular volume-overload hypertrophy. Am J Physiol. 1993:264:H1615-H1623.

31. Siri FM, Krueger J, Nordin C, Ming Z, Aronson RS. Depressed intracellular calcium transients and contraction in myocytes from hypertrophied and failing, guinea pig hearts. An f Pbysiol. $1991: 261:$ H514-H530.

32. McCall E, Ginsburg KS, Bassani RA, Shannon TR, Qi M, Samare AM, Bers DM. Ca Aux, contractility, and excitation-contraction coupling in hypertrophic rat ventricular myocytes. An J Proysiol 1998;274:H1348-H1360.

33. Bailey BA, Houser SR. Sarcoplasmic reticulum-selated changes in cytosolic calcium in pressure-overload-induced feline LV hyperrophy. Am J Physiol. 1993;265:H, 2009H2016.

34. Balke CW, Shorofsky SR. Alterations in calcium handling in cardiac hypertrophy and heart failure. Cardiovasc Res. 1998;37:290-299.

35. Ravens U, Davia K, Davies CH, O'Gara P, Drake Holland AJ, Hynd JW, Noble MI, Harding SE. Tachycardia-induced failure alters contractile propercies of canine ventricular myocytes. Cardiovasc Res. 1996;32:613-621.

36. Yao A, Su Z, Nonaka A, Zubair I, Spirzer KW. Bridge JHB, Muelheims G, Ross J, Jr, Barry WH. Abnormal myocyte $\mathrm{Ca}^{2}$ homeostasis in rabbits with pacing-induced heart Failure. Am J Physiol. 1998;274:H1441-H1448.

37. Spinale FG. Fulbright BM, Mukherjee R, Tanaka R, Hu J, Crawford FA, Zile MR. Relacion berween wentricular and myocyte function with tachycardia-induced cardiomyopaHy. Cim Ros. 1992;1:174-187.

38. Eisner DA, Tafford AW, Daz ME, Overend CL, ONeill SC. The control of Ca release from the caldiac sancoplasmic reticulum: regulation versus auroregulation. Cardiowasc Re. 1998:38:589-604.

39. Lirwin $\mathrm{SF}^{*}$ Bridge $\mathrm{JHB}$. Enhanced $\mathrm{Na}^{2}-\mathrm{Ca}^{2}$ exchange in the infarcted heart implications for excitation contraction coupling. Circ Res. 1997;81:1083-1093.

40. Matriello JA, Margulies KB Jeevanandam V, Houser SR. Contribution of reverse-mode sodium-calcium exchange to contractions in failing human left ventricular myocytes. Cardiovatic Res. 1998:37:424-431.

41. Flesch M. Schwinger RHG. Schiffer F, Frank K, Südkamp M, Kuhn-Regnier F, Arnold $G$, Böhm M. Evidence for funcrional relevance of an enhanced expression of the $\mathrm{Nat}^{4}-\mathrm{Ca}^{2+}$ exchanger in failing human myocardium. Circulation. 1996;4:992-1002. 
42. Bers DM, Christensen DM. Funccionat interconversion of rest decay and ryanodine effecrs in rabbit and rat vencricle depends on $\mathrm{Na} / \mathrm{Ca}$ exchange. I Mol Coll Cardol $1990 ; 22: 715-723$.

43. Mubagwa K, Lin W, Sipido KR, Bosteels S, Flameng W. Monensin-induced reversall of positive force-frequency relationship in cardiac muscle: role of incracellutar sodium in rest-dependent potentiation of contraction. J Mol Cell Cardiol 1997,29.977-989.

44. Díaz ME, Cook SJ, Chamunorwa JP, Trafford AW, Lancaster MK, S.C. ON, Eisner DA. Variability of spontaneous $\mathrm{Ca}^{27}$ release between different rat wentricular myocytes is correlared wich $\mathrm{Na}^{*}-\mathrm{Ca}^{2+}$ exchange and $\left[\mathrm{Na}^{+}\right]$. Circ Res. 1996:78:857-862.

45. Eisner DA, Lederer WI, Vaughan Jones RD. The quantitariwe relarionship between witch tension and intracellular sodium activity in sheep cardiac Parkinje fibres. $y$ Pbysiol. 1984:355:251-266.

46. Kent RL, Rozich JD, McCollam PL, McDermott DE, Thacker UF, Menick DR, McDermort PJ, Cooper G, IV. Rapid expression of the Na-Ca exchanger in response to cardiac pressure overload. Am J Physiol. 1993;265:H1024-H1029.

47. Hasenfuss G, Schillinger W, Lehnarr SE, Preuss M, Pieske B, Maier LS, Preste I, Minami $\mathrm{K}$, Jusit $\mathrm{H}$. Relationship between $\mathrm{Na}^{+}-\mathrm{Ca}^{2+}$-exchanger protein levells and diastolic function of failing human myocardium. Circulation. 1999;99:641-648.

48. Aronson RS, Ming Z. Cellular mechanisms of arrhythmias in bypertrophied and tailing myocardium. Circulation. 1993;87(suppl VII):VII-76-VII-83.

49. Verduyn SC, Vos MA, van der Zande J, Kulcsar. A, Wellens HIJ. Further observations to elucidate the role of interventricular dispersion of repolarization and early afterdepolarizations in the genesis of acquired torsade de pointes arrhythmias: a comparison berween almokalant and d-sotalol using the dog as its own control. I Am Coll Cardiol. $1997 ; 30: 1575-1584$.

50. de Groot SHM, Vos MA, Schoenmakers M, Leunissen JD, Wellens HJJ. Adaptations in contractile function at chronic $A V$-block (AVB) make the heart more susceptible to triggered arhythmias (TA). Cinculation. 1997:96(supp I):I-239-1-240. Absract.

51. Priori SG, Corr PB. Mechanisms underlyng early and delayed afterdepolarizations induced by catecholamines. Am J Plywal. 1990:258:H1796-H1805.

52. Volders PGA, Kulcsár A, Vos MA, Sipido KR, Wellens HJJ, Lazara R, Srabo B. Similariries beween early and delayed afterdepolatizations induced by isoproterenol in canine wentricular myocytes. Candiovase Res. 1997;34:348-359. 



\section{Similarities Between Early and Delayed Afterdepolarizations Induced by Isoproterenol in Canine Ventricular Myocytes}

Paul G.A. Volders Attila Kulcsár, Marc A. Vos Karin R. Sipido, Hein J.J. Wellens, Ralph Lazzara, Bella Szabo.

From the Department of Medicine, Cardiowascular Section, University of Oklahoma Health Sciences Center, and the Department of Veterans. Affairs Medical Center, Oklahoma City, USA (R.L., B.S.); Laboratory of Experimental Cardiology, University of Leuven, Belgium (K.R.S.); Department of Cardialogy, Cardiovascular Research Institute Maastricht, Maastricht University, Netherlands.

Published n. Cardiovasc Res. 1997;34:348-359 
Abstract

Objectives: This study aims at clarifying the role of cellular Ca ${ }^{2+}$ overload and spontaneous sarcoplasmic reticulum (SR) Ca ${ }^{2+}$ release in the generation of early afterdepolarizations (EAD) by isoproterenol. The involvement of a Catactwated membrane current in isoproterenol-induced EAD is investigated.

Methods: Membrane potential and contraction (an indicator of SR Ca2+ release) were recorded in canine left ventricular myocytes at pacing cycle lengths (CL) of $300-4000 \mathrm{~ms}$. Threshold concentration for EAD was $20-50 \mathrm{mmol} / \mathrm{L}$ isoproterenol. $\mathrm{Ni}{ }^{2+}(2.0-5.0 \mathrm{mmol} / \mathrm{L})$

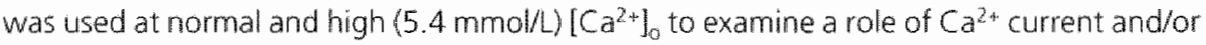
$\mathrm{Na}^{+}-\mathrm{Ca} \mathrm{a}^{\mathrm{z}+}$ exchange $\left(\mathrm{I}_{\mathrm{NaC}}\right)$ in EAD.

Results: In all cells delayed afterdepolarizations (DAD) appeared during isoproterenol. In most $(\approx 70 \%$ ) cells EAD were also generated, which were fast-pacing dependent, occurring only at CL of $400-1000$ ms. EAD were always initiated by a delay in repolarization. Early aftercontractions preceded the EAD upstrokes, often occurring without them. They coincided with the initial delays in repolarization. During treatment with isoproterenol, $\mathrm{N} i^{2+}$ and high $\left[\mathrm{Ca} \mathrm{a}^{2}\right]_{0}$, EAD and DAD were suppressed despite the continued presence of early and delayed aftercontractions.

Conclusions: Our data indicate that $\beta$-adrenergic EAD share a common ionic mechanism with DAD in terms of cellular $C a^{2 *}$ overload and spontaneous $S R \mathrm{Ca}^{2+}$ release. $\beta$-Adrenerglc EAD consist of two phases: (1) a conditional phase coinciding with the onset of an early aftercontraction, often followed by (2) an EAD upstroke. A Ca*-activated membrane current, likely $I_{\text {Natan }}$ is necessary at least for the initiation of these EAD. 


\section{Introduction}

Both early (EAD) and delayed afterdepolarizations (DAD) have been incrim:naved in the generation of cardiac arrhythmias in paricnts. ${ }^{1}$

$\mathrm{DAD}$ are generated under conditions that favor accumulacion of cytoplasmic $\mathrm{Ca}^{2+}\left(\left[\mathrm{Ca}^{2+}\right] \mathrm{cyt}\right)$, cellular $\mathrm{Ca}^{2+}$ overload and spontaneous $\mathrm{Ca}^{2+}$ release from the sarcoplasmic reticulum (SR). The DAD is caused by a $\mathrm{Ca}^{2+}$-acrivated inward current during spontaneous $S R \mathrm{Ca}^{2+}$ release: the $\mathrm{Na}^{+}-\mathrm{Ca}^{2+}$ exchange current $\left(\mathrm{I}_{\mathrm{Na}-\mathrm{Ca}}\right)^{2,3}$ and or nonselective cation current $\left(\mathbb{I}_{\mathrm{NS}}\right)$. Together with $\mathrm{DAD}$ also delayed aftercontractions are generated and one may assume that spontaneously released $\mathrm{Ca}^{2+}$ ions from the $\mathrm{SR}$ activate the sarcolemmal inward current and the contractile system simulaneously. 5

EAD are afterdepolatizations that occur as transient retardations or reversals of the repolarization of the action potential. ${ }^{6}$ Progress and agreenent on their ionic mechanism (s) have been meager in comparison with DAD. This relates partly to the variety of conditions during which EAD are generated, indicaring that there is not one type of EAD. In general, EAD are generated at slow pacing rates (drive cycle lengths (CL) longer than $1000 \mathrm{~ms}$ ) and after prolongation of the repolarization. $\mathrm{L}$-and $\mathrm{T}$-rype $\mathrm{Ca}^{2+}$ current $\left(\mathrm{I}_{\mathrm{CaT}}\right.$ and $\left.\mathrm{I}_{\mathrm{CaL}}\right)$ as well as $\mathrm{Na}^{*}$ current $\left(\mathrm{I}_{\mathrm{Na}}\right)$ have been implicated as the currents underlying these EAD' (i.e. sarcolemma-dependent mechanisms).

$\beta$-Adrenergic receptor stimulation can induce both DAD and EAD. We $e^{7,8}$ and other investigators 9,10 have suggested that cellular $\mathrm{Ca}^{2+}$ overload and spontaneous $\mathrm{SR}$ $\mathrm{Ca}^{2+}$ release are responsible for both afterdepolarizations in this condirion via activation of a $\mathrm{Ca}^{2+}$-dependent inward current (i.e a SR-dependent mechanism).

The present study aims primarily at clarifying the role of cellular $\mathrm{Ca}^{2+}$ overload and spontaneous $\mathrm{SR} \mathrm{Ca}^{2+}$ release in the generation of $\mathrm{EAD}$ by isoproterenol in canine left wentricular myocytes. It is hypothesized that if these EAD are generated by a SRdependent mechanism, early aftercontractions are generated simultaneousiy, ln contrast, if the EAD are generated by a sarcolemma-dependent mechanism, early aftercontractions will be present as a consequence of the EAD and will therefore occur after the EAD upstroke. In addition, block of the currents underlying the EAD will suppress carly aftercontractions that are the consequence of the $\mathbb{E A D}$ (sarcolemmadependent mechanism), but will not affect those that are the cause of EAD (SR-dependent mechanism).

\section{Methods}

This study was approved by the Animal Studies Subcommitree of the Departmen of Veterans Affairs, Oklahoma City, USA and the Commitee for Experiments on Animals, University of Maastricht, Maastricht, The Netherlands, and conformed with the Guide for the care and use of laboratory anmals published by the US National Institutes of Health. 


\section{Cell-1solation Procedure}

The hearts of adult mongrel dogs anaesthetized with pentobarbital (20-30 $\mathrm{mg} / \mathrm{kg}$ iv), were quickly excised, washed and a branch of the left-anterior-descending coronary artery was perfused with a cardioplegic solution at $10^{\circ} \mathrm{C}$ for 5 minutes. The perfusion was continued at $37^{\circ} \mathrm{C}$ with $100 \mathrm{~mL}$ of a nominally $\mathrm{Ca}^{2+}$-free standardbuffer solution and with collagenase at low $-\left[\mathrm{Ca}^{2+}\right](50 \mu \mathrm{mol} / \mathrm{L})$ for $30 \mathrm{~min}$. After washout with enzyme-free low- $\left[\mathrm{Ca}^{2+}\right]$ solution the tissue was perfused with the standardbuffer solution containing $1.8 \mathrm{mmol} / \mathrm{L}\left[\mathrm{Ca}^{2+}\right]$. Finally, the tissue was minced into suspension, filtered and washed five times. Isolated myocytes were stored at $15^{\circ} \mathrm{C}$ remperature in eicher minimum-essential medium or in standard-buffer solution. No electrophysiological differences were observed berween cells stored in either solution. The yield of rod-shaped myocytes from one dog heart was always between 60 and $80 \%$.

\section{Composition of Solutions:}

The standard-buffer solution contained (in mmol/L): $\mathrm{NaCl} 145, \mathrm{KCl} 4.0$, $\mathrm{CaCl}_{2} 1.8, \mathrm{MgCl}_{2} 1.0, \mathrm{NaH}_{2} \mathrm{PO}_{4} 1.0$, glucose 11,4 -(2-hydroxyethyl)-1-piperazine ethane sulfonic acid (HEPES) 1.0, $\mathrm{pH} 7.4$ with $\mathrm{NaOH}$ at $37^{\circ} \mathrm{C}$ and saturated with 100 $\% \mathrm{O}_{2} . \mathrm{KCl}$ was set to $8.0 \mathrm{mmol} / \mathrm{L}$ in the cold cardioplegic solution. For the disaggregation process, collagenase $(0.1 \% \mathrm{w} / \mathrm{v}$ Type 2, Worthington Biochemical Co., Freehold, NJ or $0.08 \%$ w/v Type A, Boehringer Mannheim, Germany) was used to which was added bowine serum albumin $(0.03 \% \mathrm{w} / \mathrm{v})$. The storage medium used in part of the cell isolations was minimum essential medium enriched with Hanks' salts (Gibco Laboratories $\$ 410-1600 \mathrm{EA}$, Life Technologies, Inc., Grand Island, NY) and with (in $\mathrm{mmol} / \mathrm{L}$ ): $\mathrm{NaHCO}_{3} 24$, glucose 11 , taurine 10 , pyruvic acid 2.0 , ribose 5.0 , allopurinol 0.1 , pH 7.4 equilibrated with $5 \% \mathrm{CO}_{2}$ and $95 \% \mathrm{O}_{2}$ at $15^{\circ} \mathrm{C}$. Isoproterenol was dissolved in distilled water containing $30 \mu \mathrm{mol} / \mathrm{L}$ ascorbic acid, kept at $5^{\circ} \mathrm{C}$ and in the dark. $\mathrm{NiCl}_{2}(2.0-5.0 \mathrm{mmol} / \mathrm{L})$ was added to the standard-buffer solution with or without isoproterenol at a $\left[\mathrm{Ca}^{2+}\right]$ of 1.8 or $5.4 \mathrm{mmol} / \mathrm{L}$ for inhibition of $\mathrm{I}_{\mathrm{Ca}}$ and $\mathrm{I}_{\mathrm{Na}-\mathrm{Ca}}$ (see Results). All of the chemicals used were reagent grade and cell-culture tested (purchased from Sigma Chemical Co., St. Louis, MO). Almokalant was kindly provided by ASTRA, Göreborg, Sweden.

\section{Electrophysiological and Contraction Recordings}

A sample of the cell suspension was transferred to a water-jacketed perfusion chamber $(0.5 \mathrm{~mL})$ and superfused with standard-buffer solution at a rate of $3 \mathrm{~mL} / \mathrm{min}$ and at $37 \pm 0.5^{\circ} \mathrm{C}$. Cells were allowed to stabilize at CL of $1000 \mathrm{~ms}$ for at least $10 \mathrm{~min}$ utes before the start of the recordings. Myocytes used for the experiments were selected on the basis of the following criteria: having sharp striations, clear contours, transparent cytoplasms without granulations and blebs, and behaving electrophysiologically normal upon impalement. Cells could be used for experiments until two days after isolation without electrophysiological deterioration. In this period the arrhythmogenic 
response of myocytes to isoproterenol was inwariably high and it was tully reverthe uporn washout of the agent.

Membrane-potential recordings and intracellular stimulation were performed with standard glass microelectrodes $(3.0 \mathrm{~mol} / \mathrm{L} \mathrm{KCl}, 30$ to $60 \mathrm{M \Omega})$ connected to a microelectrode amplifier (Axodamp-2A, Axon Instruments, Inc., Foster City, CA). Myocyte contractions were imaged by a video camera (Panasonic GP-CD60, Panasonic Industrial Co., Secaucus, NJ) connected to an inverted microscope (Nikon, Inc., Melwille, NY) and video edge morion detector (Crescent Electronics, Sandy, U'T) allowing for recording at 16-ms temporal resolution. 11 The analog output signals were digitized and stored on video tape or computer hard disk for off-line analysis. Membrane potencial and cell shortening were recorded simultaneously.

The presence of EAD, appearing as transient retardations and/or reversals of the membrane porential during repolarization, was always confirmed by the reversal of the negative first derivative of the membrane potential 12 towards less negarive and/or positive values, respectively. DAD were accepted if their amplitudes were $\geq 5 \mathrm{mV}$.

Contraction was recorded as an indicator of $\mathrm{Ca}^{2+}$-induced $\mathrm{Ca}^{2+}$ rellease and spontaneous $\mathrm{Ca}^{2+}$ release from the $\mathrm{SR}$. The amplitude of cell shortening was expressed in $\mu \mathrm{m}$. Relative changes of contraction amplitude within one cell (eg, by treatment) are indicated as \% of control values. In this manuscript the "vwitch contraction" is that linked to the normal rapid upstroke of the action porential. The 'aftercontraction" follows the twitch contraction either during or after repolarization of the acrion potential.

The cellular responses to $\beta$ adrenergic receptor stimulation were studied in 25 ventricular myocytes from 11 dogs under different conditions.

\section{Statistics}

The data are expressed as mean \pm SEM. Statistical comparisons were made with the Student's test and the paired trest for unpaired and paired data groups, respectiwely, after testing for the normality of distribution. Differences were considered significant if $P<0.05$.

\section{Results}

The Effect of Isoproterenol on the Ventricular Action Potential and

\section{Contraction}

In all myocytes a concentration of isoproterenol as low as $20 \mathrm{nmol} / \mathrm{L}$ consisrenty induced increased twitch contractions, followed by the appearance of DAD and delayed aftercontractions. For the generation of EAD, we used the same or sighty higher concentrations (up to $50 \mathrm{nmol} / \mathrm{L}$ ), inducing EAD in approximately $70 \%$ of all cells tested.

In 10 cells from 6 dogs treated with $20 \mathrm{nmol} / \mathrm{L}$ of isoproterenol and stimulated. at a CL of $1000 \mathrm{~ms}$, the dome amplitude of the action potential increased from $100 \pm 3$ 
ro $111 \pm 2 \mathrm{mV}(\mathrm{n}=10 ; P<0.05)$. No effect on the resting membrane potential was measured, which was on average $-84+3 \mathrm{~m} V$ at control. Twitch-contraction amplitudes increased to $683 \pm 157 \%$ of the control values. These observations are in line with earlier findings in single myocytes. 13,14

Figure I illustrates thar isoproterenol at low concentration $(20 \mathrm{mmol} / \mathrm{L})$ had divergent effects on the action potential duration at $95 \%$ of repolarization $\left(\mathrm{APD}_{95}\right.$ ) of the 10 myocytes: the $A P_{95}$ either decteased (by $47 \pm 14 \mathrm{~ms}$, from 274 to $227 \mathrm{~ms} ; \mathrm{n}=5$; $P<0.05$ ) or increased (by $13 \pm 5 \mathrm{~ms}$, from 242 to $255 \mathrm{~ms} ; \mathrm{n}=5 ; P<0.05$ ). Changes in the corresponding twitch-contraction durations tended ro follow the changes in $A \mathrm{PD}_{95}$. but were less pronounced. In all 5 myocytes initrally responding to isoproterenol with an increased $\mathrm{APD} \mathrm{D}_{25} \mathrm{EAD}$ (as well as DAD) were generated upon continued treatment with the agent (Figure 2). We did not see EAD in the absence of DAD. In the 5 myocytes with a decreased APD95, only DAD were observed.

After an initial phase with increasing contraction amplitudes, further treatment with isoproterenol rapidly led to an arrhythmogenic response characterized by the induction of EAD, DAD and aftercontractions (as illustrated in Figure 2). Subsequently, DAD-riggered action potentials could occur that could deteriorate into sustained triggered rhythms (data not shown). EAD observed in our experiments did not trigger action potencials nor resulted in sustained triggered athythms, as was observed earlier.?

The enhancement of conrraction observed in the initial phase of isoproterenol treatment continued in the presence of afterdepolarizations and aftercontractions (Figure 2 ; arrow). In all 10 cells larger twitch-contraction amplitudes were intermittently measured in this phase (Figure $2 ;^{*}$ ) to a maximum of $776 \pm 164 \%$ of control amplitudes. This difference between the maximal twitch-contraction amplitudes before vs. after the first appearance of afterdepolarizations and aftercontractions $(683 \pm 157 \%$ vs. $776 \pm 164 \%$ of control, respectively) was significant $(\mathrm{n}=10 ; P<0.05)$. Such large twitch-contraction amplitudes appeared as stimullated contractions (not as afterconractions: Figure 2).

\section{EAD and Early Aftercontractions Induced by Isoproterenol are Fast-pacing} Dependent: Comparison with Almokalant

Isoproterenol-induced EAD were always accompanied by early aftercontracrions. Early aftercontractions could occur without EAD upstrokes, but always before full repolarization of the action porential. Their gradual appearance after an inirial response with increasing contracrions and simulaneously with the appearance of DAD suggested a role for cellular $\mathrm{Ca}^{2+}$ overload. If so, these $\mathrm{EAD}$ and early aftercontractions would be exaggerated by fast pacing and tempered by slow pacing. We tested this in an additional series of 7 myocytes from 4 dogs. Threshold concentrations of isoproterenol used to induce EAD were $20 \mathrm{nmol} / \mathrm{L}(\mathrm{n}=2 \mathrm{cel} / \mathrm{s}), 40 \mathrm{mmol} / \mathrm{L}(\mathrm{n}=2)$ and $50 \mathrm{nmol} / \mathrm{L}(\mathrm{n}=$ 3). We compared this with the rate dependency of EAD induced by the agent almokalant at $3.0 \mu \mathrm{mol} / \mathrm{L}$ in 5 cells from the same 4 dogs. Almokalant is known to possess dass-III activity. Ar nano-to micromolar concentrations it is a specific blocker of the 
A
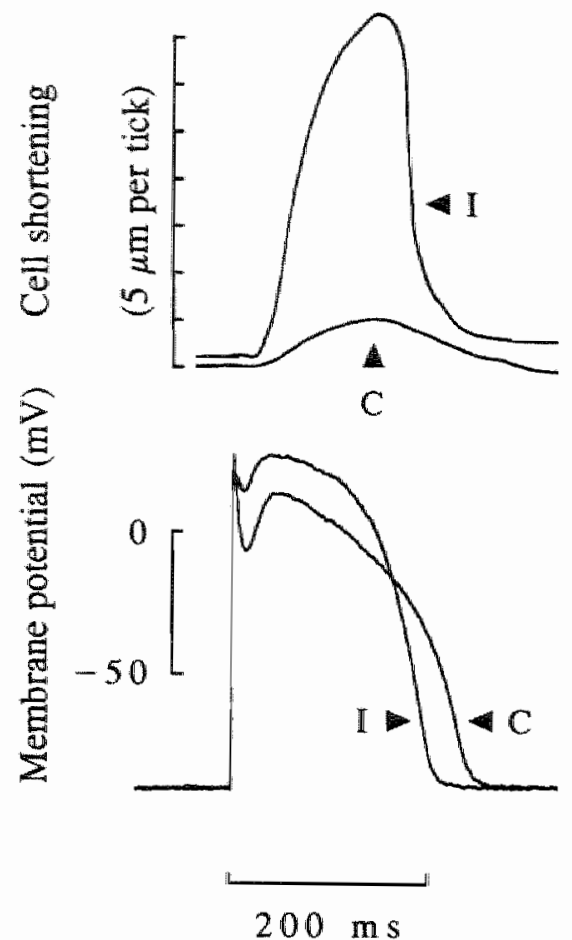

$\mathrm{B}$

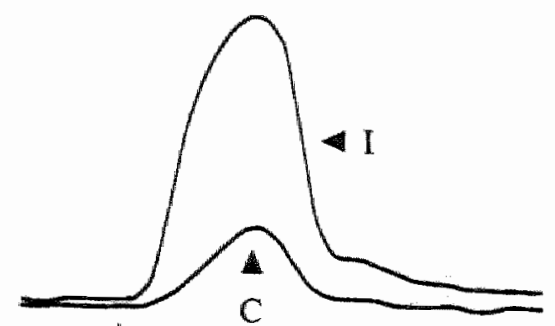

$\mathrm{C}$

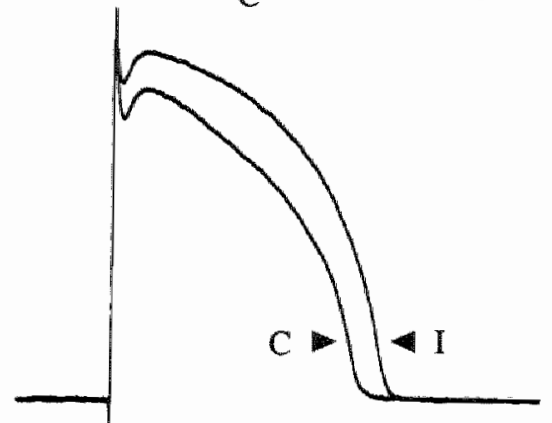

Figure 1. - The effect of isoproterenol on the action potential and contraction.

Action potentials (Iower panel) and contractions (upper panel) are recorded simultanecusly at steady-state pacing before $(C)$ and 1 minute after the start of isoproterenol treatment ( 20 nmol/L; i) and prior to the generation of EAD and/or DAD. There is a differential response of the $\mathrm{APD}_{35}$ to isoproterenol in myocyte $\mathrm{A}$, the $\mathrm{APD}, \mathrm{s}$ decreases from 251 to $210 \mathrm{~ms}$, while the contraction shortens trom 303 to $283 \mathrm{~ms}$. In contrast, in myocyte B, the APDgs increases from 251 to $279 \mathrm{~ms}$. The contraction prolongs from 204 to $209 \mathrm{~ms} . \mathrm{CL}=1000 \mathrm{~ms}$.

rapidly-activating component of delayed-rectifier $K^{+}$current $\left(I_{K}\right)$, ${ }^{15}$ like other pure $I_{K}$ blockers such as doferilide and $\mathrm{E}-4031 .{ }^{16}$ These agents delay repolarization and promote EAD induction at slow pacing rates. Pacing CL of $300,400,500,1000,2000$, 3000 , and $4000 \mathrm{~ms}$ were applied in all cells given eicher isoproterenol of almokalant. We calculated the number of EAD in 10 consecurive action potentials after $\geq 30 \mathrm{~s}$ of steady-stare pacing at a given CL.

In Figure 3 ir is shown that almokalant-induced EAD occurred only at $\mathrm{CL} \geq$ $2000 \mathrm{~ms}$, with an incidence increasing to $6 \mathrm{EAD}$ per 10 consecutive beats at $\mathrm{CL}=4000$ ms in these 5 cells. No early aftercontractions were observed with these EAD. The rate dependency of isoproterenol-induced EAD and afrercontractions was completely dif 


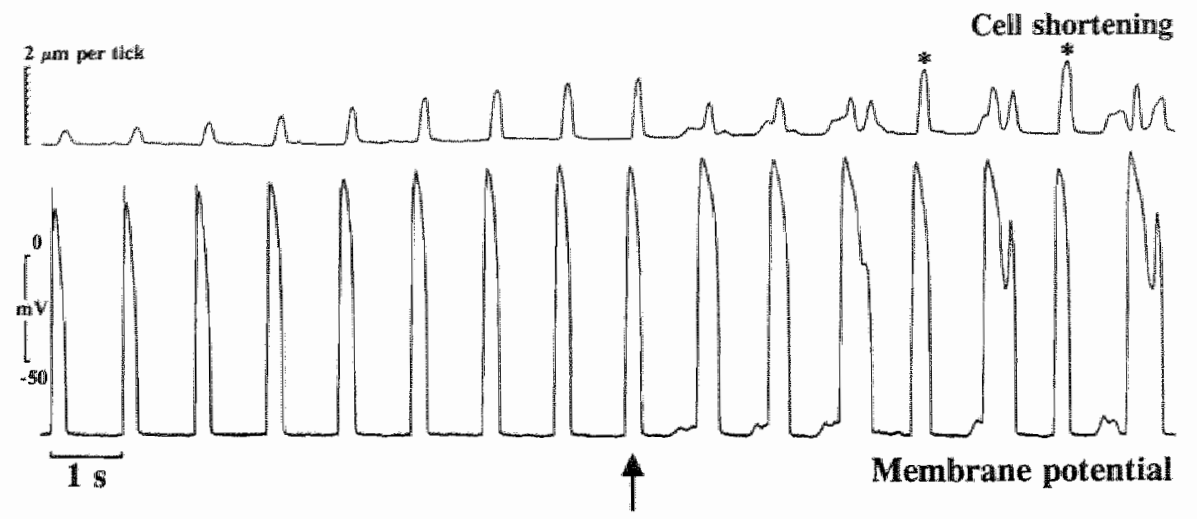

Figure 2. - Beat-to-beat induction of EADs and early aftercontractions by isoproterenol. In this myocyte, after the phase with increasing contraction amplitudes, DAD and aftercontractions appear (arrow indicates first action potential with a DAD). Thereafter $\mathbb{E} A D$ and early aftercontractions are also generated. Twitch amplitudes are intermittently obserwed during the phase with DAD and EAD that are larger (*) than the twitch amplitudes priof to the first appearance of DAD and EAD. Typically the increasing twitch amplitudes during systole arise from a stable (ie, non-increasing) diastolic baseline. In this phase there are no triggered action potentials. Isoproterenol: $20 \mathrm{nmol} / \mathrm{CL}=$ $1000 \mathrm{~ms}$.

ferent. Here, only at CL of 400 to $1000 \mathrm{~ms}$ EAD were observed with a peak incidence of $3 \mathrm{EAD}$ per 10 consecurive beats at $\mathrm{CL}=500 \mathrm{~ms}$ ( $\mathrm{n}=7$ cells; Figure 3 ). Representative action-potential and contracrion traces at $\mathrm{CL}=500$ and $4000 \mathrm{~ms}$ are shown in Figure 4 . The murual dependence between $A P D_{05}$ and EAD was different for almokalant and isoproterenol. In the case of almokalant, EAD were generated upon an already prolonged action potential. During isoproterenol the $\mathrm{APD}_{95}$ was increased whenever $\mathrm{EAD}$ were (to be) present in consecutive beats, but decreased between such beats (Figure 4, upper left panel).

In addition to a difference in rate dependency, there was also a difference in the average take-off membrane potentials of EAD upstrokes in the presence of isoproterenol vs. almokalant. It is shown in the Table that the upstrokes of isoproterenol-induced EAD developed at more negative levels and at broader range. These levels could vary from close to the resting membrane potential to sometimes slightly positive voltages. There was a significant difference between the ayerage take-off potentials of EAD generated at $\mathrm{CL}=400$ vs. $1000 \mathrm{~ms}$ during isoproterenol (Table).

In summary, (1) isoproterenol-induced EAD are fast-pacing dependent; (2) their charge carrier(s) can be acrivated over a broad range of membrane potentials; and (3) isoproterenol-induced EAD appear to be mechanistically different from almokalant-induced EAD. 


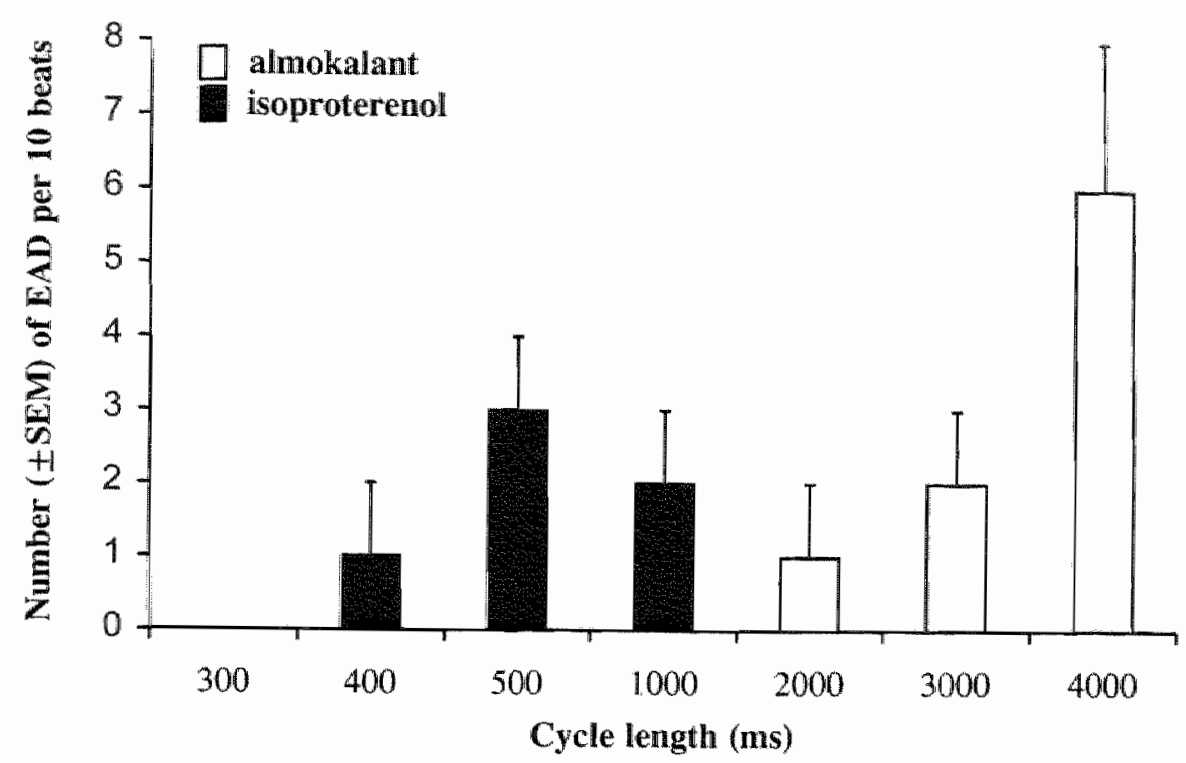

Figure 3. - Rate dependency of isoproterenol- vs almokalant-induced EAD in canine left ventricular myocytes.

Pacing CL of $300,400,500,1000,2000,3000$ and $4000 \mathrm{~ms}$ are applied in all cells. Isoproterenal is administered at 20,40 or 50 nmol/l (until EAD appear; $n=7$ cells); almokalant at 3.0 mmoi/h $h=5$ cells). Expressed is the mean number of EAD ( \pm SEM) per 10 consecutive beats during steady-state pacing for at least $30 \mathrm{~s}$. Almokalant indures $E A D$ only at $C L=2000,3000$ and $4000 \mathrm{~ms}$; isoproterenol only at $\mathrm{CL}=400,500$ and $1000 \mathrm{~ms}$. There is no overlap of the $\mathrm{Cl}$ at which $E A D$ are induced by these agents.

\section{Early Aftercontractions Precede EAD Upstrokes}

To determine the onser of EAD accurately, ie, the time and voltage of the start of the delay in repolarization, we used the first derivative ( $\mathrm{dV} / \mathrm{dt}$ rep) of the membrane potential. ${ }^{12}$ This is shown in Figure 5 for beats in which a delay in the repolarization was eirher followed (Figure 5A) or nor followed (Figure 5B) by a frank EAD upstroke.

We examined the temporal relationship between EAD and early aftercontractions in 100 action potentials, as illustrated in the example of Figure 5. The arrows in Figs. $5 \mathrm{~A}$ and $\mathrm{B}$ indicate the moment of the reversal of $\mathrm{dV} / \mathrm{dt}$ sep and the same time points on the action potential and concraction. A summary of this temporal comparison is shown in Figure 6. The initial delay in repolarization occurred at $228 \pm 22 \mathrm{~ms}$ after the upstroke of the action potential at a membrane potential of $1 \pm 3 \mathrm{mV}$. The take off of the upstroke of the EAD came after $271 \pm 16 \mathrm{~ms}$ at $-17 \pm 2 \mathrm{mV}$. The start of the early aftercontraction came at $238 \pm 17 \mathrm{~ms}$. This was sigmificantly earlier than the start of the upstroke of the $\operatorname{EAD}(271 \pm 16 \mathrm{~ms} ; P<0.05)$, but not different from the initial delay in repolarization ( $228 \pm 22 \mathrm{~ms} ; P^{p}=\mathrm{NS}$ ). Early aftercontractions occurred often in the absence of EAD upstrokes (Figure 5 B), but never without the initial delay in repolariza- 
Hsoproteremst

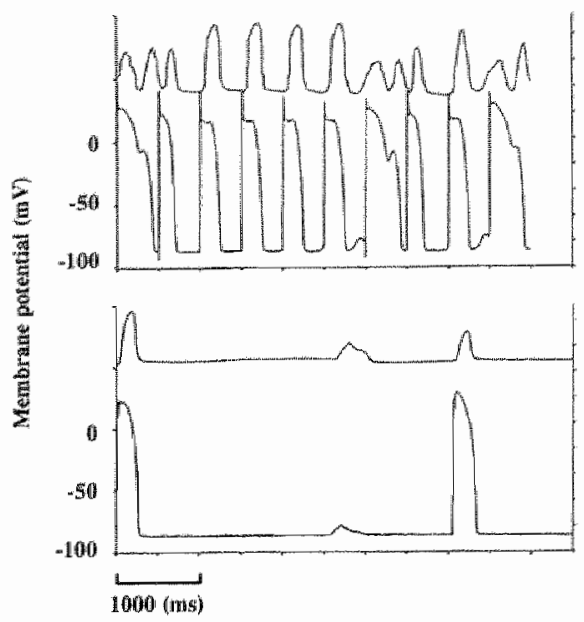

Aimokglan:
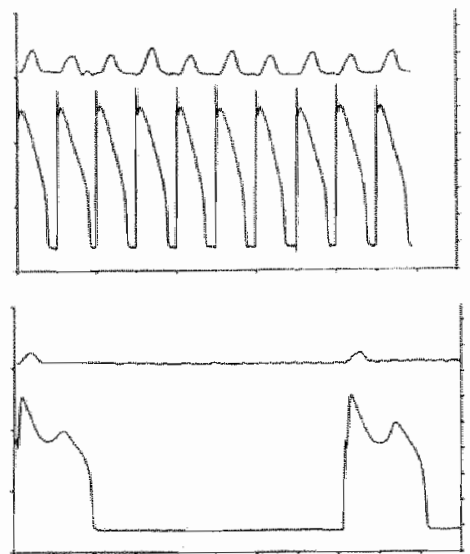

1000 (ms)

Figure 4. - Representative tracings showing generation of EADs at fast pacing rate by isoproterenol and at slow pacing rate by almokalant.

In the presence of isoproterenol ( 40 nmol/L; left panels) or almokallant ( $3.0 \mu$ mol/l; right panels) myocyles are stimulated at $\mathrm{Cl}=500 \mathrm{~ms}$ (upper panels) and $\mathrm{CL}=4000 \mathrm{~ms}$ (lower panelsh. Note the generation of $\mathrm{EAD}$ at $\mathrm{CL}=500 \mathrm{~ms}$ during isoproterenol and at $\mathrm{CL}=4000 \mathrm{~ms}$ during almokalant, but not uncer opposite conditions. Isoproterenol-induced EAD are accompanied by early aftercontractions, almokalant-induced EAO are not. Left $Y$ axes denote membrane potential (mV) in the four panels; right $Y$ axes: cell shortening $(\mu \mathrm{m})$; $X$ axes: time (ms). Upper traces denote contraction: lower traces: arction potentials.

tion. Generally, their amplitude was larger in the presence than the absence of EAD upstrokes, as illustrated in Figure $5 \mathrm{~A}$ and $\mathrm{B}$.

For comparison we evaluated the temporal linking berween DAD and delayed aftercontractions measured in 100 acrion porencials. It was found that the onset of DAD coincided with the onset of delayed aftercontractions in the same way as was found for the start of the delay in repolarization and the onset of early aftercontractions during EAD (Figure 6).

Thus, the time course of isoproterenol-induced EAD is characterized by two phases: (1) a conditional phase ${ }^{17}$ (i.e. the initial delay in repolarization); (2) an EAD upstroke. The onset of the early aftercontraction coincides with the conditional phase of the EAD, i.e. significandly earlier than the EAD upstroke.

Generation of early and delayed aftercontractions during inhibition of EAD and DAD by $\mathrm{Ni}^{2 *}$

To clarify the relarionship berween isoproterenol-induced EAD and early aftercontractions we used the cation $\mathrm{Ni}^{2+}$, which in the millimolar range is a non-specific in- 

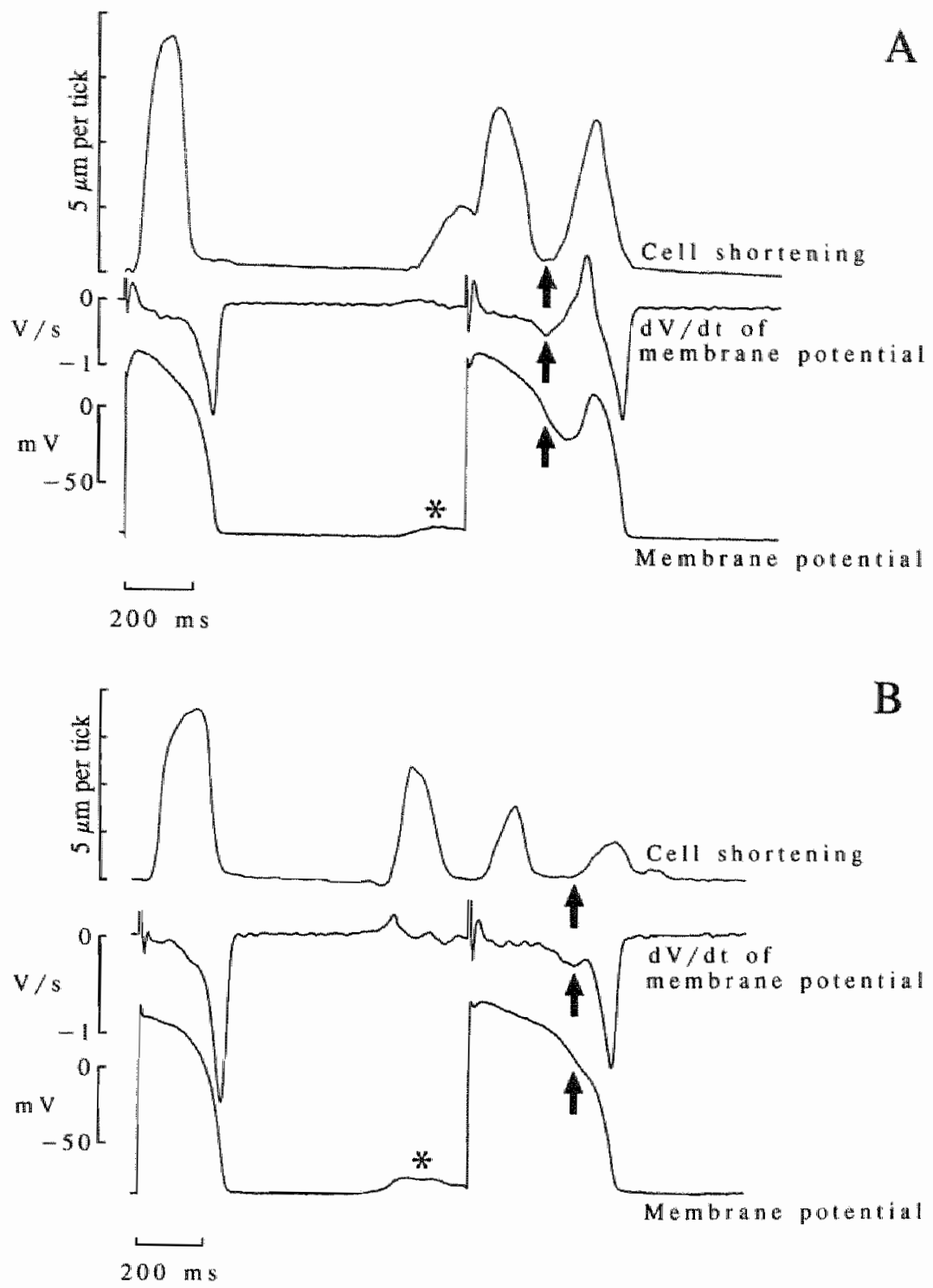

Figure 5. - Temporal relationship between EAD and early aftercontraction.

Contracion (upper irace), first derivative of the membrane potential (middle trace) and action potential (lower trace) is shown for a cycle with an EAD exhibiting a frank upstroke (A) and one without an $\mathrm{EAD}$ upstroke (B). In $\mathrm{A}$, a delay in repolarization precedes the upstroke of the $E A D$, as evidenced by the reversal towands positive levels of d $/ \mathrm{dt}_{\mathrm{reo}}$ (arrow). This delay is initiated at $240 \mathrm{~ms}$ after the upstroke of the action potential and is followed by the EAD upstroke at 310 ms. The start of an early aftercontraction is at $245 \mathrm{~ms}$, at the same moment as the initial delay in repolarization. In $\mathbf{B}$. an early aftercontraction appears even without a frank EAD upstroke. The retardation of repolarization, as evidenced by the reversal of $d \mathrm{Vdt}_{\mathrm{tg}}$ (arrow), is initiated at $313 \mathrm{~ms}$; the start of the early aftercontraction at $309 \mathrm{~ms}$. Note the presence of late-coupled DAD (*) and corresponding aftercontractions in $\mathbf{A}$ and $\mathbf{B}$. The first derivatives of the action-potential upstrokes are artificially truncated. 
Table - The take-off membrane potential of EAD upstrokes durng isoproterenol and almokalant in relation 10 pacing $C L$

Take-of membrane ootential (mM)

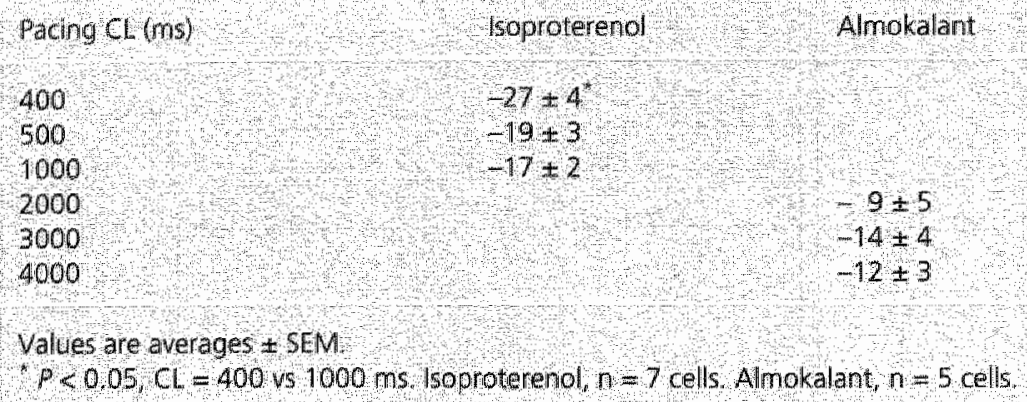

hibitor of the $\mathrm{Na}^{+}-\mathrm{Ca}^{2+}$ exchanger ${ }^{3,18}$ and a blocker of $\mathrm{I}_{\mathrm{CaL}}$ and $\mathrm{I}_{\mathrm{CaT}} \cdot{ }^{19}$ We reasoned that if the ionic current responsible for the EAD also induces the early aftercontraction, that is if the aftercontraction was secondary to the $\mathrm{EAD}$, ${ }^{20}$ elimination of the EAD must also eliminate the aftercontraction. On the other hand, if the early aftercontraction is induced by an intracellular mechanism, i.e. spontaneous release of $\mathrm{Ca}^{2+}$ from the $\mathrm{SR}$, which also induces the ionic current $(s)$ that produce $E A D$ as we hypothesize, the aftercontraction may occur even when the sarcolemmal currents causing the EAD are blocked and the EAD eliminated. However, aftercontractions due to spontaneous SR $\mathrm{Ca}^{2+}$ release would not occur in the presence of a complete block of $\mathrm{I}_{\mathrm{CaL}}$ because the primary contracion due to $\mathrm{Ca}^{2+}$-induced $\mathrm{Ca}^{2+}$ rellease would also be attenuared. Therefore, we took advantage of the fact that a rise in $\left[\mathrm{Ca}^{2+}\right]_{0}$ can partially overcome the block of $\mathrm{I}_{\mathrm{CaL}}$ by $\mathrm{Ni}^{2+}$ because the blocking effect of $\mathrm{Ni}^{2+}$ results from competitive binding to the divalent cation-binding side of the channel. ${ }^{19}$ In separate voltage-clamp experiments in 3 myocyres, we confirmed the relief of $\mathrm{Ni}^{2+}$-induced inhibition of $\mathrm{I}_{\mathrm{CaL}}$ by high $\left[\mathrm{Ca}^{2+}\right]_{0}$ (dara not shown).

$\mathrm{Ni}^{2+}$ was applied in 5 myocytes from 3 dogs at a concentration of 2.0 or 5.0 $\mathrm{mmol} / \mathrm{L}$. As shown for the cell in Figure $7 \mathrm{~A}$, following the induction of EAD and DAD by isoproterenol (left panel), $\mathrm{Ni}^{2+}$ at normal $\left[\mathrm{Ca}^{2+}\right]_{0}(1.8 \mathrm{mmol} / \mathrm{L})$ greatly attenuated the action potential and abolished all rwitch contractions, aftercontractions and afterdepolarizations (second from left panel). Thus, $\mathrm{Ni}^{2 *}$ acted as a $\mathrm{Ca}^{2+}$-channel inhibitor, preventing both $\mathrm{Ca}^{2+}$-induced $\mathrm{Ca}^{2+}$ release and spontaneous $\mathrm{Ca}^{2+}$ release from the $\mathrm{SR}$ not loaded with $\mathrm{Ca}^{2+}$. To offser this effect of $\mathrm{Ni}^{2 *}$ at least partly, the $\left[\mathrm{Ca}^{2+}\right]_{0}$ was increased to $5.4 \mathrm{mmol} / \mathrm{L}$. Under these conditions there was sufficient $\mathrm{I}_{\mathrm{CaL}}$ to induce a primary contraction and early and delayed aftercontractions occurred in the absence of $\mathrm{EAD}$ and $\mathrm{DAD}$ respectively (Figure $7 \mathrm{~A}$, right two panels). The spike-and-dome con- 


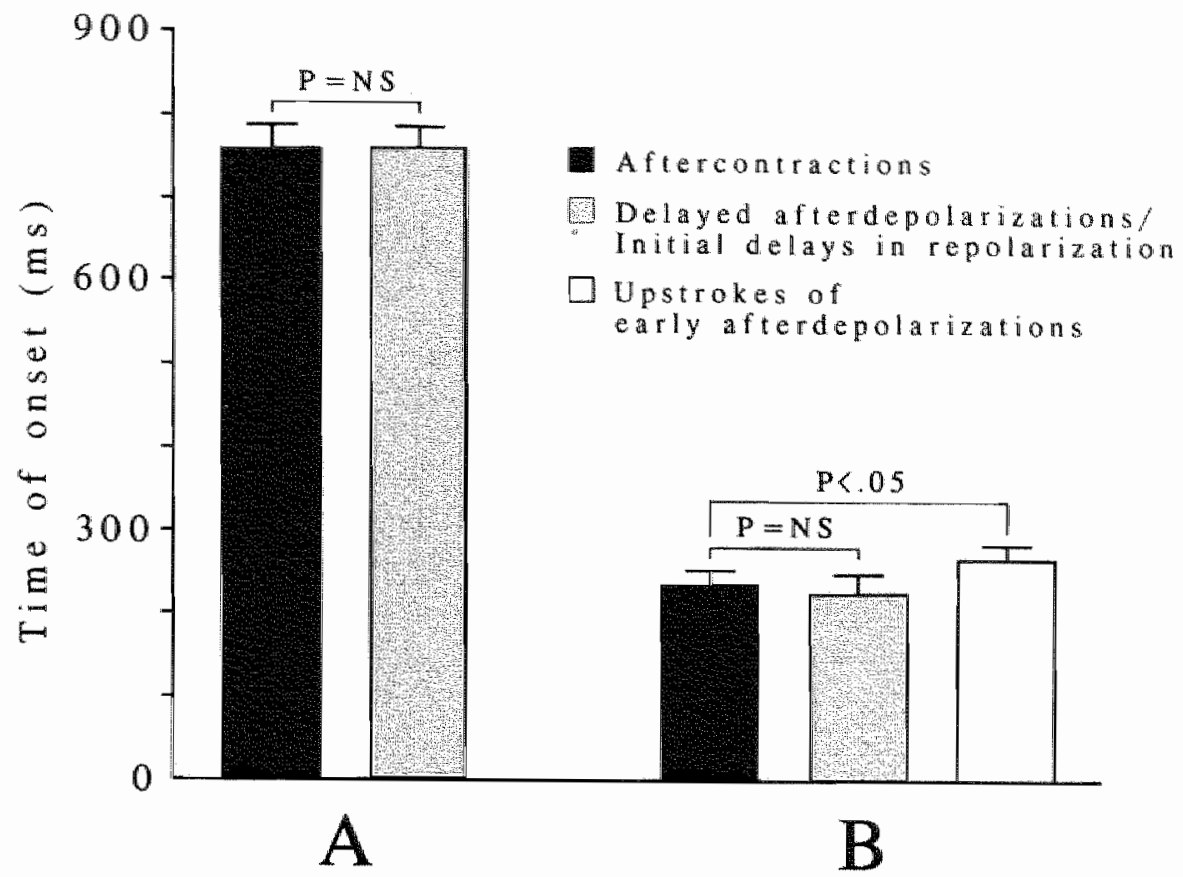

Figure 6. - Bar graph showing temporal comparison between aftercontractions and afterdepolarizations induced by isoproterenol $(20 \mathrm{nmol} / \mathrm{L})$.

$A_{v}$ Onset of aftercontractions vs onset of DAD that are chosen from the recordings in 10 ventricular myocytes. No significant difference in timing is found. B, Onset of early aftercontractions ws the initial delays in repolarization (change in $\mathrm{dV} / \mathrm{dt} \mathrm{t}_{\mathrm{F}}$ ) in action potentials with $\mathrm{EAD}$, and vs the upstrokes of these EAD. The early aftercontractions coincide with the initial delays, but come significantly earlier than the EAD upstrokes. The data are averages \pm SEM for $100 \mathrm{DAD}$, EAD and their aftercontractions.

figuration was still attenuated at this $\left[\mathrm{Ni}^{2+}\right]_{0}$. We confirmed these observations in three additional myocytes.

In the other cell showing only DAD, $2.0 \mathrm{mmol} / \mathrm{L}\left[\mathrm{Ni}^{2+}\right]_{0}$ and high $\left[\mathrm{Ca}^{2+}\right]_{0}$ attenuated DAD, but not delayed aftercontractions (Figure $7 \mathrm{~B}$, right panel). The spikeand-dome configuration of the action potential remained at this $\left[\mathrm{Ni}^{2+}\right]_{6}$. The washout of $\mathrm{Ni}^{2+}$ and high $\left[\mathrm{Ca}^{2+}\right]_{0}$ rapidly reversed their actions and afterdepolarizations returned within minutes.

In these $\mathrm{Ni}^{2 *}$ experiments, early and delayed aftercontractions behaved clearly the same as before. The presence of isoproterenol was essential for their generation: withour isoproterenol no aftercontractions.

The step from 1.8 to $5.4 \mathrm{mmol} / \mathrm{L}\left[\mathrm{Ca}^{2+}\right]_{0}$ during $\mathrm{Ni}^{2+}$ and isoproterenol was also essential to generate early and delayed aftercontractions during inhibition of EAD and DAD. Such step in the absence of $\mathrm{Ni}^{2 *}$ resulted in contracture of the cells within seconds and therefore could not be used as control. 

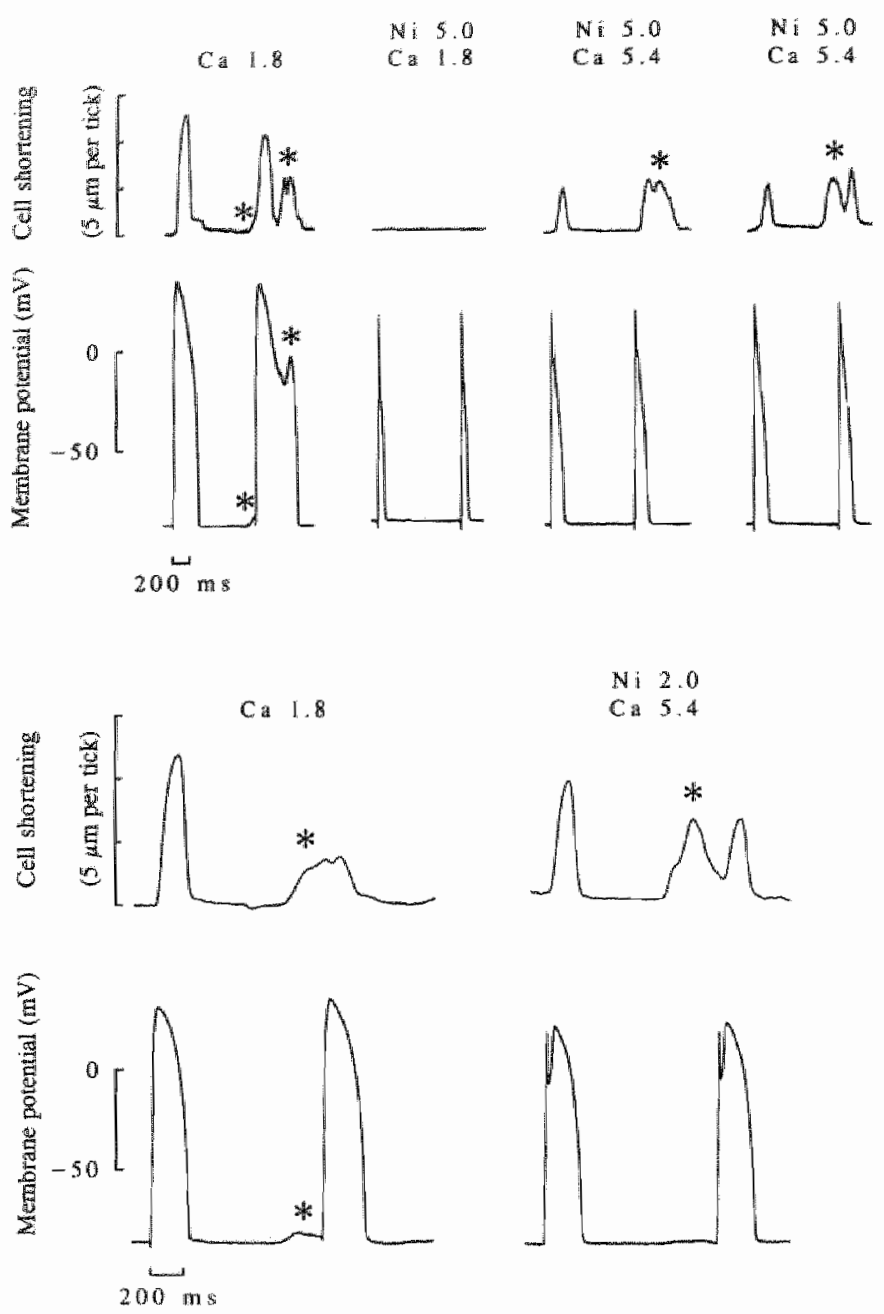

Figure 7.- Generation of aftercontractions without afterdepalarizations in the presence of isoproterenol, $\mathrm{Ni}^{2++}$ and high $\left[\mathrm{Ca}^{2+}\right]_{0}$.

Action potentials (lower traces) and contractions (upper traces) are shown during treatment with isoproterenol $20 \mathrm{mmol} / \mathrm{L}$ ) at $\mathrm{Cl}=1000 \mathrm{~ms}$. $\mathrm{A}$. Generation of DAD, EAD and aftercontractions (left panel). The subsequent addition of 5.0 mmoll $\left[\mathrm{Ni}^{2+} \mathrm{I}_{0}\right.$ (second from left panel) abolishes all contractions, aftercontractions and afterdepolarizations. However, an increase of [C. $\left.{ }^{2}{ }^{2 *}\right]_{0}$ to 5.4 mmoll (in the continued presence of isoproterenol and $\mathrm{Ni}^{2+}$ ) partially restores this effect, as evidenced by the reappearance of twitch contractions and aftercontractions. Note the early aftercontraction without a companion EAD (second from right panel) and the delayed aftercontraction without a DAD (right panel). Similar results were obtained in replicate experiments on 3 cells B, DAD and delayed aftercontraction (onset at $796 \mathrm{~ms}$ and $792 \mathrm{~ms}$ after the upstroke of the action potential, respectively) are generated (lett panel). With the subsequent addition of $2.0 \mathrm{mmol}$. $\left[\mathrm{Ni}^{2+}\right]_{0}$ and $5.4 \mathrm{mmol} / \mathrm{L}\left[\mathrm{Ca}{ }^{2+}\right]_{0}$ (right panell), the DAD is inhibited, while the aftercontraction remains present starting at $701 \mathrm{~ms}$. in panels $\mathrm{A}$ and $\mathrm{B}$, Ca indicates $\left[\mathrm{Ca}^{2+}\right]_{0}$ and $\mathrm{Ni},\left[\mathrm{Ni}{ }^{2+}\right]_{0}$ both in mmolit. in all panels $D A D, E A D$ and aftercontractions are marked with * 
In summary, (1) early and delayed aftercontracrions can accur independendy from $E A D$ and DAD, indicating that spontaneous $S R \mathrm{Ca}^{2+}$ telease is the primary event; (2) a $\mathrm{Ni}^{2+}$-sensitive inward current, is necessary for both EAD and DAD.

\section{Discussion}

Changes in the APD 95 and Contraction by lsoproterenol

In this study we observed that the $A \mathrm{PD}_{95}$ of canine left ventricular myocytes either increased or decreased during treatment with $20 \mathrm{mmol} / \mathrm{L}$ isoproterenol. Divergent effects of $\beta$-adrenergic agonists on the $A P D_{95}$ have been reported carlier to occur through direct or indirect modulation of many components that derermine the net repolarizing curtent, ${ }^{21,22}$ however not at the same concentration of the agonist. This dualiry of isoproterenol responses was ofren found in myocytes from the sane dog heart, which makes it unlikely that our cell-isolacion procedure per se was responsible for increases of $A P_{95}$ and EAD generation. In addition, these effects disappeared fully upon wash out of isoproterenol.

We did not isolate the cells according to their transmural sice of origin. It is known from the work of Antzelevitch et al ${ }^{23}$ that epicardial and endocardial myocytes respond differenty to $\beta$-adrenergic receptor agonists, i.e. both show action-potential shortening but this is more pronounced in apicardium than endocardium. These investigators have also described a unique population of midmyocardial (M) cells with pharmacological responsiveness different from epicardial and endocardial cells. A weaker $L_{K}$ contributes to a longer accion potential in $\mathrm{M}$ cells, especially at slow pacing rates. ${ }^{24}$ Preliminary data from their laboratory show that isoproterenol at $20 \mathrm{nmol} / \mathrm{L}$ causes prolongation of the action potential in $\mathrm{M}$ cells, but not in epicardial and enclocardial myocytes (Dr. C. Antzelevitch, personal communication). This prolongation is greater ar more rapid pacing rates, consistent with the possibility that a $\mathrm{Ca}^{2}$-activated inward current counteracts the weaker outward current to delay repolarization. Isoproterenol was shown to produce even more prolongation and EAD generation in canine left ventricular $M$ cells, bur not in epicardial or endocardial cells, when the contribution of $I_{k}$ was further reduced by $\mathbb{E}-4031$. ${ }^{25}$ Therefore, one possible explanation for the dualicy of isoproterenol responses in our study could a heterogeneiry of the cell population with M cells having an $\mathrm{APD}_{95}$ increase, and epicardial and endocardial myocytes having an APDig decrease.

During $\beta$-adrenergic recepror stimulation of ventricular myocytes, increasing twitch contraction amplitudes arose from a stable diastolic baseline, stuggesting a beacto-bear accumulation of $\mathrm{Ca}^{2}$ in the $\mathrm{SR}$ without an increment of diastolic $\left[\left.\mathrm{Ca}^{2+}\right|_{c y}\right.$ (as shown earlier ${ }^{26}$ ) and attributed to enhanced uptake of $\mathrm{Ca}^{2 *}$ by the SR. ${ }^{27}$ In contrast to the study of Capogrossi et al. ${ }^{28}$ the amplitude of witch contractions of our myocytes was not maximal at the time of the first manifestation of DAD and aftercontractions as in all cells significantly larger amplitudes were intermitrenty measured during the ar- 
rhythmogenic phase of treatment. Our data may indicate that in canine ventricular myocytes the amount of $\mathrm{Ca}^{2+}$ loading of the $\mathrm{SR}$ necessary for spontaneous $\mathrm{Ca}^{2+}$ release is lower than that for maximal inotropy, in line with the computations by Luo and Rudy. ${ }^{29}$ Species-related differences in intracellular $\mathrm{Ca}^{2+}$ handling ${ }^{30}$ may explain these different findings: in rat myocytes ${ }^{28}$ the SR is known to work near its capacity for $\mathrm{Ca}^{2+}$ sequestration.

\section{Role of Cellular $\mathrm{Ca}^{2+}$ Overload in Isoproterenol-Induced EAD}

In the present study, EAD and early aftercontractions were generated just after the first appearance of DAD and delayed aftercontractions, often in conjunction with the same action potential. EAD were never observed without DAD. The occurrence of EAD and early aftercontracrions was increased by rapid pacing, an experimental condition known to promote cellular $\mathrm{Ca}^{2+}$ loading. While the 'optimal' $\mathrm{CL}$ for these EAD was around $500 \mathrm{~ms}$, they disappeared at slow pacing $(\mathrm{CL} \geq 2000 \mathrm{~ms}$ ) and as such behaved completely different from the EAD induced by almokalant. These links between the appearance of $\mathrm{EAD}$ and $\mathrm{DAD}$, and between $\mathrm{EAD}$ and fast pacing strongly support out hypothesis that isoproterenol-induced EAD are related to cellular $\mathrm{Ca}^{2+}$ overload.

Earlier, we have demonstrated the simultaneous generation of EAD and DAD in ventricular myocytes under different conditions of $\mathrm{Ca}^{2+}$ loading. ${ }^{31}$ In a recent preliminary study ${ }^{32}$ the development of EAD in ventricular cells and Purkinje fibers exposed to E-4031, was shown to be promoted by the acceleration of stimulation from initially slow rates, indicating that increased $\left[\mathrm{Ca}^{2+}\right]_{c y}$ could also be involved in the generation of those EAD.

Role of Spontaneous SR C $a^{2+}$ Release in Isoproterenol-Induced EAD

In this study, we recorded contraction as a physiological marker of $\mathrm{Ca}^{2+}-\mathrm{i}-$ nduced and spontaneous $\mathrm{Ca}^{{ }^{2+}}$ release from the $\mathrm{SR}$ at relatively high temporal resolution ( $16 \mathrm{~ms}$ ). The onset of early aftercontractions coincided with the initial delays in repolarization during $\mathrm{EAD}$, on average more than $30 \mathrm{~ms}$ before the $\mathrm{EAD}$ upstrokes. It is recognized that contraction can lag behind $\left[\mathrm{Ca}^{2+}\right]_{\text {cy }}$ in a complex manner ${ }^{3.3}$ As but one example, Berlin et al. ${ }^{34}$ showed thar during DAD in rat ventricular myocytes, the $\mathrm{Ca}^{2+}$ aftertransient coincided with $\mathrm{I}_{\mathrm{TI}}$ and both preceded the aftercontraction by 60 to 90 ms. ${ }^{34}$ If we apply such delay to our recordings, it implies that the underlying $\mathrm{Ca}^{2+}$ aftertransients occurred 60 to 90 ms earlier than the early aftercontractions and even more early than the EAD upstrokes.

Ir has been proposed that early afrercontractions are the result of $\mathrm{Ca}^{2+}$-induced $\mathrm{Ca}^{2+}$ release and that sarcolemmal 'window' $\mathrm{I}_{\mathrm{CaL}}$ (underlying the EAD) triggers this $\mathrm{Ca}^{2+}$-induced $\mathrm{Ca}^{2+}$ release. ${ }^{20,35}$ However, our observation of the temporal coincidence between the onset of early aftercontractions and the condirional phase of EAD (but not the EAD upstroke) suggests the opposite, namely that spontaneous $\mathrm{SR} \mathrm{Ca}{ }^{2+}$ release activates $\mathrm{I}_{\mathrm{TI}}$ counteracting the repolarizing currents. This hypothesis predicts that aftercontractions based on spontaneous $\mathrm{SR} \mathrm{Ca}^{2+}$ release can occur wichout $\mathrm{EAD}$. 
Our experiments with $\mathrm{N}^{2}$ " show that $\mathrm{EAD}$ can be eliminated completely without suppression of the early aftercontractions, demonstrating conclusively that the af tercontractions cannot all be secondary to the currents that induce EAD. Under these conditions, the aftercontractions cannot be due to $\mathrm{Ca}^{2+}$-induced $\mathrm{Ca}^{2+}$ release from a surge of $\mathrm{I}_{\mathrm{CaL}}$ that simulaneously also generates the EAD, as hypothesized by oth ers. $20,29,35$ Since the aftercontractions must be due to $\mathrm{Ca}^{2}+$ release from the $S \mathrm{R}$ that is not induced by transsarcolemmal $\mathrm{Ca}^{2+}$ current, the $\mathrm{Ca}^{2+}$ release responsible for the ar tercontractions must be by definition spontaneous. Spontaneous $\mathrm{C}^{2+}$ release has been accepted as the basis for DAD and delayed afrercontractions. However, the precise medhanisms for spontaneous $\mathrm{Ca}^{2}$ release are unclear. Although our observations do not exclude the possibility that some EAD with take-off membrane potentials more posivive than $-35 \mathrm{mV}$ are generated by reactivation of $\mathrm{C}_{\mathrm{CaL}}$, they establish that some af tercontractions and their associated $\mathrm{EAD}$ are independent of $I_{\mathrm{Cal}}$. With respect to the specific identity of the current carrier for the EAD associated with spontaneous $\mathrm{Ca}^{2+}$ release, our experiments are not as conclusive because unknown effects of $\mathrm{Ni}^{2+}$ may exist on other currents which may be candidates for generating EAD. The $\mathrm{Ni}^{2+}$ experiments demonstrate that aftercontractions are primary and not secondary and thus support the inference of a $\mathrm{Ca}^{2+}$-activated inward curtent in EAD.

With the use of fluorescent $\mathrm{Ca}^{2+}$ indicators, $\mathrm{Ca}^{2+}$ aftertransients of relatively large amplitude have been observed during isoproterenol-induced EAD. 10,35 Yamada and Corr described these cransients as multiple peaks of $\left[\mathrm{Ca}^{2+}\right]_{C t}$ following the actionpotential upstroke. ${ }^{10}$ The temporal relationship between $\mathrm{EAD}$ and $\mathrm{Ca}^{2}+$ aftertransients could not be determined in these experiments, due to the low time resolution (40 ms) of the techniques used. ${ }^{35} \mathrm{Ca}^{2+}$ aftertransients were inhibited by ryanodine, thus identifying the SR as the source of $\mathrm{Ca}^{2+} .{ }^{10}$ However, whether these transients were the result of $\mathrm{Ca}^{2+}$-induced $\mathrm{Ca}^{2+}$ release or spontaneous $\mathrm{Ca}^{2+}$ release from the $\mathrm{SR}$ could nor be distinguished with the use of ryanodine.

The trigger for "spontaneous" $\mathrm{Ca}^{2+}$ release during EAD and DAD is unknown. $\beta$-Adrenergic receptor stimulation has been shown to augment the removal of $\mathrm{Ca}^{2}$. from the cytoplasm both into the extracellular space and into the SR. This suggests that the triggering of "spontaneous" $\mathrm{Ca}^{2}$ release may be linked to a high level of $\mathrm{Ca}^{2+}$ in the SR. Recently, Ca ${ }^{2+}$ sparks have been observed, which have been presented as the elementary phenomenon of $\mathrm{Ca}^{2+}$-induced $\mathrm{Ca}^{2}$ release. ${ }^{36}$ It has been demonstrated that the fractional release of $\mathrm{Ca}^{2}$ from the $S \mathrm{R}$ is increased with an increase of the SR $\mathrm{Ca}^{2}$. content. ${ }^{37}$ Therefore, it could be possible that in the presence of isoproterenol Cat ${ }^{2}+$ sparks are augmented borh in amplitude and in number and that they trigger a general SR Ca ${ }^{2+}$ release as the result of their spatial and temporal summation, which has been shown to occur in myocytes loaded with $\mathrm{Ca}^{2}+$ by high $\left[\mathrm{Ca}^{24}\right]_{0}{ }^{38}$ In addition, the spontaneous $\mathrm{Ca}^{2+}$ release inducing early aftercontractions could be triggered by $\mathrm{Ca}^{2+}$ being removed from the myoflament space after the rwich contraction and encountering a suprachreshold gradient of $\mathrm{Ca}^{2+}$ over the $5 \mathrm{R}$ membrane. 
Isoproterenol-induced EAD Are Initiated by itacia

Based on the results of our study we conclude that cellular $\mathrm{Ca}^{2}$ overload and spontaneous $\$ \mathrm{RCa}^{2}$ release are responsible for isoproterenol-induced $\mathrm{EAD}$ via activarion of a $\mathrm{Ca}^{2+}$-dependent inward curent. This current appeared to be $\mathrm{Ni}^{2+}$ sensitive. $\mathrm{Ni}^{2+}$ is a blocker of $\mathrm{I}_{\mathrm{Cal}}, \mathrm{I}_{\mathrm{CaT}}$ and $\mathrm{I}_{\mathrm{Wa}-\mathrm{Ca}}$. It has already been discussed that $\mathrm{I}_{\mathrm{Ca}}$ or $\mathrm{I}_{\mathrm{CaT}}$ are unlikely to be involved in the wituation of $\mathrm{EAD}$ and $\mathrm{DAD}$, leaving $\mathrm{I}_{\mathrm{Na}-\mathrm{Ca}}$ as a serious candidate.

A role for $\mathrm{I}_{\mathrm{Na} \text { Ca }}$ is also supported by our observation that $\mathrm{EAD}$ could be activated over broad range of membrane potentials. Schouren er al. ${ }^{39}$ demonstrated that $I_{\mathrm{Na}-\mathrm{Ca}}$ is present throughout repolarization. They indicated that an increase in the $\mathrm{Ca}^{2+}$ transient would enhance inward $\mathrm{I}_{\mathrm{Na}} \mathrm{Ca}$ during the action potential and delay repolarization, a point confirmed in the comprehensive mathemarical model of the electrical activity of the ventricular myocyte by Luo and Rudy. ${ }^{29}$ These mechanisms could explain why a modest action-potential prolongation was the initial response in myocyntes ultimately generating EAD during isoproterenol.

At least one orher candidate for the $\mathrm{Ca}^{2+}$-activated imward current has to be considered, namely $\mathrm{I}_{\mathrm{NS}}{ }^{4}$ However, the presence of $\mathrm{Ca}^{2+}$-activated non-selective cation channels has not been demonstrated in canime ventricular myocytes, while the contribution of $\mathrm{I}_{\mathrm{NS}}$ to $\mathrm{I}_{\mathrm{TI}}$ in orher species is not consistent (eg, Reference 40). Moreover, on the basis of experiments with the cation $\mathrm{Sr}^{2+}$, Niggli ${ }^{2}$ found that $\mathrm{Ni}^{2+}$ inhibited $\mathrm{I}_{\mathrm{TH}}$ gencrated by the $\mathrm{Na}^{+}-\mathrm{Ca}^{2+}$ exchanger, whereas it did not block current through the $\mathrm{Ca}^{2+}$-activated non-selective carton channel. Our observation that $\mathrm{Ni}^{2}$ complerely suppressed both DAD and EAD suggests that $I_{N S}$ was not involved. It remains possible however that $\mathrm{Ni}^{2+}$ blocks some yet-unidentified $\mathrm{Ca}^{2+}$-activated inward current that could contribute to EAD.

Thus, our present results indicate that $\mathbb{I}_{\mathrm{Nat}} \mathrm{Ca}$ plays an important role at least in the iniriation of isoproterenol-induced EAD. The initial delay in repolarization characrerizing the conditional phase of these EAD may set the stage for other inward currents to become activated. In this way, $I_{\text {CaL }}$ could also be activated, not as the original cause of the EAD, but rather as the consequence of the depolarization initiared by $\mathrm{I}_{\mathrm{Na}-\mathrm{Ca}}$.

\section{Possible Clinical Implications}

Our results in isolated myocytes suggest that $\beta$-adrenergic receptor stimulation of the working myocardium could be arrhythmogenic by wo discinct mechanisms. With intracellular $\mathrm{Ca}^{2+}$ overload, DAD appear that can induce triggered action potentials and sustained riggered rhythms. The EAD do not trigger new action potentials simply because at rhe membrane potential of their occurence peak $I_{N a}$ cannor be activated. However, the EAD could induce electrical heterogeneiry by causing a variable prolongation of repolarization. Regional differences of repolarization (ie, dispersion) favor reentry 42,43 .

The present study supports a role for $\beta$-adrenergic receptor stimulation in facilitating the onset of ventricular tachyarhythmias on the basis of EAD generation and electrical heterogeneity in the idiopathic long QT syndrome. ${ }^{44,45}$ In addition, the con- 
traction abnormalities that accompany EAD generation could provide the cellular basis for the wall motion abnomalities of patients suffering from this syndrome. 46 The alleviation of both the electrical and mechanical abnormalities of patients wirh the long QT syndrome by $\mathrm{Ca}^{2 *}$ channel blocking agents suggests that abnormal cellular $\mathrm{Ca}^{2 *}$ handling is the common denominator. $\mathrm{Ca}^{2+}$ channel blockade would prevent or diminish the accumulation of intracellular $\mathrm{Ca}^{2+}$ and thus inhibir the generation of EAD and aftercontractions by preventing spontaneous $\mathrm{Ca}^{2+}$ release from the $\mathrm{SR}$.

\section{Conclusions}

It is concluded that afterdepolarizations and aftercontractions induced by isoproterenol can occur during systole and diastole. Their simultaneous occurrence indicates a common underlying mechanism, likely spontaneous SR Ca ${ }^{2+}$ release. The observation that the onset of early aftercontractions precedes the upstroke of EAD also supports the role of spontaneous $\mathrm{SR} \mathrm{Ca}{ }^{2+}$ release and indicates the involvement of at $\mathrm{Ca}^{2+}$-activated current, most likely $\mathrm{I}_{\mathrm{Na}-\mathrm{Ca}}$. The inhibitory effect of $\mathrm{Ni}^{2+}$ on both EA.D and DAD, but not on their simultaneous aftercontractions, provides turther support for the involvement of spontaneous $\mathrm{Ca}^{2+}$ release and $\mathrm{I}_{\mathrm{Na}-\mathrm{Ca}}$ in afrerdepolarizarions induced by $\beta$-adrenergic receptor stimulation.

\section{Acknowledgements}

The study was supported by grant HL-35047 from the National Institutes of Health, by the Presbyterian Health Foundation, and by the Wynand M. Pon Foundation, Leusden, The Netherlands. This material is based upon work supported by the Office of Research and Development, Medical Research Service, Department of Veterans Affairs. The "Stichting VSB Fonds", Utrecht, The Netherlands is greatly acknowledged for providing a stipend to P.G.A.V.. The authors wish to thank Eva Szabo for her expert technical assistance, Benjanin J. Scherlag, PhD, University of Oklahoma Health Sciences Center for helpful comments in his review of the manuscript, and Charles Antzelevitch, PhD, Masonic Medical Research Laboratory, Urica, NY for providing information on transmural differences in isoproterenol responses.

\section{References}

1 Wir AL, Rosen MR. Afterdepolarizations and triggered activity: distincrion from aturo maciciry as an arbythmogenic mechanism. In: Fozzard HA, Haber E, Jen nings RB, Kat? AM, Morgan HE, eds. The Heart and Cardiownolar System. New York. NY: Raven Press, 1992;2113-2163.

2 Lipp P. Potr $\mathbb{L}$. Transient inwat current in gunea-pig atral myocytes retlects a change of sodium-calcium exchange currenc. / Pbyriol 1988;403:355-366. 
3 Bendorf $K$, Biskup $C$, friedrich $M$. Voltage-dependent kinetics of $\mathrm{Na}$-Ca exchange current in $\mathrm{Ca}^{2}$-loaded guinea pig heart cells. Am J Pbyiol 1993;265:C1258-C1265.

4 Ehara T. Moma A, Ono K. Calcium-acrivared non-selective cation channel in ventricular cells isolated from adult guinea-pig hearts. J Pbysiol. 1988;403: 117-133.

5 Lakatta EQ. Functional implications of spontaneous sarcoplasmic reticulum $\mathrm{Ca}^{2 *} \mathrm{re}-$ llease in the heart. Cardiovasc Res. 1992;26:193-214.

6 Cranefeld PF. Action porentials, afterpotentials, and arrhythnias. Circ Res. 1977;41: $415-423$.

7 Sweidan R, Gesztelyi I, Fugate R, Szabo B, Lazzara. R. Adrenergic receptor stimulation, intracellular $\mathrm{Ca}^{2+}$ transients and afrerdepolarizations in canine ventricular myocyres. Circulation. 1990;82(suppl II):[1]-523 Abstract.

8. Szabo B, Banyasz T, Fugate R, Lazzara $\mathbb{R}$. Adrenergic $\alpha$, receptor activation modulates the effects of $\beta$, activation on the action potential and intracellular $\mathrm{Ca}^{2}$ transients in canine ventricular myocytes. Eur Heart J. 1991:12(suppl):46 Abstract.

9 Priori $\mathrm{SG}, \mathrm{Corr} \mathrm{PB}$. Mechanisms underlying early and delayed afterdepolarizations induced by catecholamines. Am J Plysiol 1990;258:H1796-H1805.

10 Yamada KA, Corr PB. Effects of $\beta$-adrenergic receptor acrivation on intracellular callcium and membrane potential in adult cardiac myocytes. / Cardiovas Electrophysiol. $1992 ; 3: 209-224$.

11 Steadman BW, Moore KB, Spitzer KW, Bridge JHB. A wideo system for measuring motion in contracting heart cells. IEEE Trans Biomed Eng. 1988;35:264-272.

12 Szabo B, Sweidan R, Rajagopalan $\mathrm{CV}$, Lazzara $\mathrm{R}$. Role of $\mathrm{Na}^{2}: \mathrm{Ca}^{2}$ exchange current in $\mathrm{Cs}^{*}$-induced early afterdepolarizations in Purkinje fibers. J Cardiovasc Electrophysiol. $1994 ; 5: 933-944$.

13 Belardinelli $L$, Isenberg $G$. Actions of adenosine and isoproterenol on isolated mammalian ventricular myocytes. Circ Res. 1983;53:287-297.

14 Marchis, Szabo B, Lazzara R. Adrenergic induction of delayed afterdepolarizations in ventriculat myocardial cells: Binduction and $\alpha$ modulation. / Cardiouas Electrophysiol. $1991 ; 2: 476-491$.

15 Cameliet E. Use-dependent block and use-dependent unblock of the delayed rectifier $K^{*}$ current by almokalant in rabbit wentricular myocytes. Circ Res. 1993;33:857-868.

16 Abrahamsson C, Duker G, Lundberg C, Carlsson L. Elecrophysiological and inotropic effecrs of $\mathrm{H} 234 / 09$ (almokatant) in vitro: a comparison with two orher novel $\mathbb{K}_{k}$ blocking drugs, UK-68,798 (doferilide) and E-4031. Cardiowac Res. 1993:27: 861-867.

17 Zeng. I, Rudy Y. Early afterdepolarizations in cardiac myocytes: mechanism and rate dependence. Biophys J. 1995:68:949-964.

18 Sheu S-S, Blaustein MP. Sodium/calcium exchange and control of cell calcium and contractility in cardiac and vascular smooth muscles. In: Fozzard HA, Haber E, Jennings RB. Karz AM, Morgan HE, eds. The Hart and Cardiowalar Sytem. New York. NY: Raven Press, 1992;903-943. 
19 Pelzer D, Pelzer $\$$, McDonaldTF. Calciumchannels in heart. In: Fozzard HA Haber E,

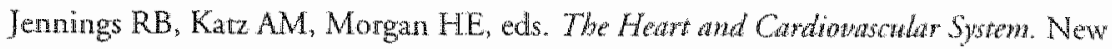
York, NY: Raven Press, 1992:1049-1089.

20 January CT, Shorofsky S. Early afterdepolarizations: newer insights into cellulat medhanisms. J Cardiovac Electrophysiol. 1990;1:161-169.

21 Kass RS, Wiegers SE. The ionic basis of concentration-related effects of notadrenaline on the action potential of calf cardiac Purkinje fibers. / Physiol 1982,322:541-558.

22 Gadsby DC. Effects of $\beta$ adrenergic catecholamines on membrane currents in cardiac cells. In: Rosen MR. Janse MI, Wit AL, eds. Cardac Electrophysialogy Textbook. Molint Kisco, NY: Futura Publishing Co, 1990;857-876.

23 Antzelevitch C, Sicouri S, Lukas A, et al. Clinical implications of electrical heterogeneity in the heart: the electrophysiology and pharmacology of epicardial, $M$, and endocardial cells. In: Podrid PJ, Kowey PR, eds. Cardiac Arrbythmia: Medhanism, Diagnosis, and Management. Baltimore, MD: Williams and Wilkins, 1995;88-107.

24 Liu D-W, Antzelevitch C. Characreristics of the delayed rectifier current $\left(I_{k}\right.$ and $\left.I_{k s}\right)$ in canine ventricular epicardial, midmyocardial, and endocardial myocytes. A weaker $I_{k}$ : contributes to the longer acrion potential of the M cell. Cinc Res. 1995;76-351-365.

25 Burashnikov A. Anzelevitch C. $\beta$ Adrenergic stimulation produces transient action potential prolongation in canine ventricular $M$ cells but not in Purkinje epicardial, or endocardial cells when the contribution of $\mathbb{I}_{k,}$ is reduced. Paxing Clin Electropisytol. 1996;19:639 Abstract.

26 Tatsulkawa Y, Arita M, Kiyosue T, Mikuriya Y, Nasu M. A comparative study of effects of isoproterenol and dihydroouabain on calcium transients and contraction in cultured rat ventricular cells. J Mol Cell Cardiol 1993;25:707-720.

27 Callewaer $\mathrm{G}$, Cleemann L, Morad M. Epinephrine enhances Ca ${ }^{2+}$ carrent-regulated $\mathrm{Ca}^{2+}$ release and $\mathrm{Ca}^{2+}$ reuptake in rat ventricular myocytes. Proc Natl Acad Sci USA. 1988;85:2009-2013.

28 Capogrossi MC, Stern MD, Spurgeon HA, Lakara EG. Spontaneour Cat release from the sarcoplasmic reticulum limits $\mathrm{Ca}^{2}$-dependent witch porentiation in individual cardiac myocytes. Amechanism for maximum inotropy in the myocardium. / Gen Dhyiol. $1988.91: 133+155$.

29 Luo C-H, Rudy Y. Adynamic model of the cardiac ventricular action potential. Il. Afterdepolarizations, triggered acrivity, and potentiation. Circ Res. 1994:74:1097-1113.

30 Bers DM. Ca influx and sarcoplasmic rericul um Ca release in cardiac muscle activarion during postrest recowery. Am / Pbyiol. 1985:248:H366-H381.

31 Szabo B, Marchi S, Scherlag BJ. Lazzara R. Simultaneous demonstrantion of early-and delayed afterdepolarizanions in Ca" loaded cardiac cells. I Am Coll Cardiol. 1989:13:185A Abstrace.

32 Burashnikov A, Anzelevitch C. Acceleration-induced early afterdepolarizations and triggered acriviry. Circulation. 1995;92:1-434 Abstract.

33 Spurgeon HA, Stern MD, Baarz G, et al. Simultaneous measurement of Ca" , contraction, and potential in cardiac myocytes. An / Physol 1990:258:H574-H586. 
34 Berlin JR. Cannell MB. Lederer WI. Cellular orgins of the transient inward current in cardiac myocytes. Role of fuctuations and waves of elevated intracellular calcium. Con Res. 1989;65:115-126.

35 De Ferari GM, Vala MC, D'Amaro E, Antolin R, Forri S. Distinct patcens of calcium transicnts duringearly and delayed afterdepolariations induced by isoproterenol in ventricular myocytes. Circulation. 1995;91:2510-2515.

36 López-López JR, Shacklock PS, Balke CW, Wier WG. Local calcium transients triggered by single L-type calcium channel currents in cardiac cells. Schence. 1995:268:1042-1045.

37 BassaniJWM, Yuan W, Bers DM. Fractional SR Carelease is regulated by trigger Caand SR Ca content in cardiac myocytes. Am J Physiol 1995;268:C1313-C1319.

38 Cheng $H_{2}$ Lederer MR, Lederer W], Cannell MB. Calcium sparks and [Ca $\left.{ }^{3 *}\right]_{4}$ waves in cardiac myocyres. An f Plbyiol 1996;270:C148-C159.

39) Schouten VIA, ter Keurs HEDJ, Quaegebeur IM. Influence of electrogenic Na/Ca exchange on the acrion potential in human heart muscle. Cardovase Res. $1990 ; 24: 758-767$.

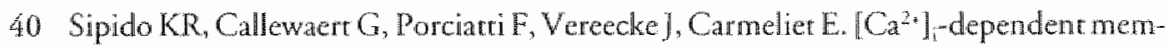
brane currents in guinea-pig ventricular cells in the absence of $\mathrm{Na} / \mathrm{Ca}$ exchange. pfliggers Arol. 1995;430:871-878.

41 Niggli E. Strontium-induced creep currents associated with tonic contractions in cardiac myocytes isolated from guinea pig. J Pbysiol. 1989;414:549-568.

42 Brugada P, Wellens HJI. Early afterdepolarizations: role in conduction block, "prolonged repolarization-dependent reexcitation," and tachyarhythmias in the human heart. Pacing Clin Electrophyirol 1985:8:889-896.

43 Di Diego JM, Antzelevich C. High $\left[\mathrm{Ca}^{23}\right]_{1}$-induced elecrical heterogeneity and extrasystolic acrivicy in isolated canine ventricular epicardium. Phase 2 reencry. Cinculation. $1994 ; 89: 1839-1850$

44 Jackman WM. Szabo B. Friday KJ, et all. Ventricular tachyarthythmias related to early afrerdepolariations and riggered fring: relationship to QT interwal prolongation and potenrial therapentic role for calcium channel blocking agents. J Cardiovas Electrophystol. 1990;2:170-195.

45 Shimizu W. Ohe T, Kurita T, er al Early afterdepolatizations induced by isoproterenol in patients with congeniral long QT syndrome. Circulation. 1991:84:1915-1923.

46 De Ferrari GM, Nador F, Beria G, Sala S, Lotto A, Schwarz PJ. Effect of calcium channelblock on the wall motion abnormality of the diopatic long $\mathrm{QT}$ syndrome. Ciratat tion. 1994:89:2126-2132. 


\section{General Discussion}

Part I of the General Discussion (Chapter 7) will deal with the specific electrical alterations in the dog with chronic complete atrioventricular block and how these could lead to arrhythmias in the animal model.

In Part II of the General Discussion, (Chapter 8) the new information from this thesis is put into a broader perspective, from cell to clinic, and a new view is formulated on $\mathrm{Ca}^{2+}$-dependent mechanisms of early afterdepolarizations and their significance for the initiation and treatment of torsades de pointes. 



\section{Altered Electrical Properties in the Dog With Chronic Complete Atrioventricular Block: The Substrate and the Trigger for Torsades de Pointes}

\section{Content}

1. Introduction

2. The Substrate

3. The Trigger

4. Possible Stimuli for Electrical Remodeling

5. Where to Go rom Here?

6 References 


\section{1.}

Forllong, it has been recognized that the mammalian ventricular myocardium is characterized by regional differences in electical properties. Experimental studies in the 1950 s and 1960 s demonstrated nonuniformity in the recovery from excitation in the endo-versu epicardium, ${ }^{12}$ and on the epicardial surface (anterior wall), ${ }^{3}$ van Dam and Durrer ${ }^{4}$ considered that the differences in refractoriness between the endo-and epicardial layers would not necessarily reflect the temporal sequence of repolarization across the transmural ventricular wall. They employed needle electrodes to determine the time course of excitability within the ventricular wall of the intact dog heart ("nidanterolateral portion of the left ventricle) and showed that the recovery from excitation was not uniform for all layers, but was shorter in the "middle layers than in the subendocardial and wher wall. 4 Mendez al al $^{5}$ were among the first to report on electrical differences berween Purkinje fibers and muscle tissue, on the basis of which reentrant activity in the Purkinje fiber-muscle junction could later be explained. 6 Since that time, the complex geometry and high degree of heterogeneicy of the action-potential duration (APD) of the Purkinje fiber-muscle junctional region have often been implicated in cardiac arthythmogenesis under various conditions. $7-11$ With the advent of the microelecrode technique and whole-cell voltage clamp, it became possible to study the electrical properties of the myocardium at the level of the action potential and its underlying membrane currents. These studies indicated a cellular, ionic basis for the previously-found differences in refractoriness between the epicardium and endocardium. ${ }^{12-16}$ In 1991, Sicouri and Antzelevitch ${ }^{17}$ described a unique population of cells (cermed M-cells) in the deep subepicardium of the canine ventricles with electrophysiological features remarkably different from those of epi- and endocardium. Microelectrode recordings in isolated tissue preparations revealed an increased maximal rate of rise of the action-potential upstroke, a longer APD, and a more pronounced actionpotential prolongation upon slowing of the pacing rate of the $M$-cells. ${ }^{17}$ Likewise, the responses of M-cells to class $I^{18}$ and class III agents were more pronounced. $M$-cells appeared to be widely distributed (base to apex) in the intramural left (LV) and right ventricle (RV), and also in the interventricular septum. 17.19,20 Subsequent isolatedrissue 211 and single-cell work 22.23 confirmed the presence of $M$-cells in the human ventricular wall. To explain the longer APD of M-cells compared to endo- and epicardial cells, the contribution of a weaker slowly activating delayed rectifier $\mathbb{K}^{+}$current $\left(\mathrm{I}_{\mathrm{K}_{3}}\right)^{24,25}$ and a larger late $\mathrm{Na}{ }^{*}$ current $\left(\mathrm{I}_{\mathrm{Na}}\right)^{26}$ were inferred. The three layers exhibited no differences in the rapidly activating delayed rectifer $K^{+}$current $\left(\mathrm{C}_{\mathrm{K}}\right)$ and the inward rectifier $\mathrm{K}^{+}$current $\left(\mathrm{I}_{\mathrm{KI}}\right) .2527$ Recent resuls show that the transmural differences in. $A P D$ are maintained in arterially-perfused wedge preparations (with a higher integrity and coupling of the myocardial cells), but they are quantitatively smaller due to electrotonic interaction. ${ }^{28}$ Similar experiments provided evidence that the voltage gradients between the $M$ region and the epi- and endocardium contribute prominently to the inscription of the electrocardiographic $T$ wave under normal conditions and to the 
arthythmogenic transmural dispersion of repolarization involved in rorsades-like polymorphic tachyarrhythmias during perfusion with class 111 agents. ${ }^{20}$ The results of this ${ }^{29}$ and other srudies ${ }^{30-33}$ implicate an important role for $\mathrm{M}$-cells in ventricular tachyarrhythmias, notably torsades de pointes. Because of these explicit features, we chose ro isolate cells from the midmyocardium in most of the studies of this thesis.

A controversy currently discussed in the licerature is if and to what exrent M-cell acrivity can be recorded in the intact, beating heart under normal and pathophysiological circamstances, and whether there is an inhomogeneous transmural gradient for ventricular repolarization, ${ }^{34,35}$

It is of great importance to identify the regional, electrical characteristics of the ventricular myocardium under normal conditions, as these may show variable responses during patho(physio)logical conditions. In ventricular hypertrophy and failure of different origin, action-potential prolongation is a very consistent electrophysiological alteration, ${ }^{36-38}$ which can often occur at different degrees in different regions. ${ }^{39-42}$ The resultant increased dispersion of repolarization can predispose to ventricular arrhythmias and sudden cardiac death. ${ }^{43}$

Biventricular hypertrophy and electrical remodeling are prominent fearures of myocardial adaptation in the dog with chronic complete atrioventricular block (AVB), and they are associated with an enhanced susceptibility to acquired torsades de pointes. ${ }^{44}$ The cellular results of this thesis indicate that the electrophysiological substrate for proarrhythmia is characterized by: (1) intrinsic disturbances of repolarization with prolonged action potentials at baseline; (2) pronounced regional dispersion of repolarization; and (3) increased susceptibility to action-potential prolongation and generation of early afterdepolarizations during administration of class III antiarrhythmic agents. In addition, the data indicate that alterations in cellular $\mathrm{Ca}^{2+}$ homeoscasis cause an increased propensiry to $\mathrm{Ca}^{2+}$ overload and spontaneous $\mathrm{Ca}^{2+}$ release from the sarcoplasmic reticulum. These events could trigger ventricular ectopic beats via carly and delayed afterdepolarizations.

\section{The Substrate}

We have demonstrated that, in the normal dog heart, differences in actionpotential configuration and APD are present between the LV and RV free wall. This was established in vivo with monophasic-action-potential catheters applied to the endocardium and in vitro with microelectrodes in midmyocardial cells (Chapter 2). The ionic basis of these action-potential characteristics is related to a different functional expression of the $\mathrm{K}^{*}$ currents $\mathrm{I}_{\mathrm{TO}}$ and $\mathrm{I}_{\mathrm{Ks}}$ between the ventricles (Chapter 2), and it is likely that also other membrane currents are involved. In the state of chronic AVB, the pronounced interventricular dispersion of repolarization appears to be based, ar least partly, on an exaggeration of the action-porential differences at control: the spikeand-dome configuration is maintained and the difference in APD berween LV and RV 
myocytes has significantly increased (Chaprer 3). Administration of the class III agent almokalant increases the APD to a similarly high level in both ventricles, thus unmasking the presence of intrinsic repolarization disturbances in boch myocyte populations. In contrast to the APD pattern, the cellular growth response is larger in the RV $(+23 \%$ versus control) than in the LV $(+13 \%)$, which may reflect a greater impact of the altered hemodynamics on that chamber after the rransition from SR to idioventricular rhythm and also indicates that there is no simple relation berween cell size and APD.

To explain the altered electrical properties in the chronic, hypertrophic state of $A V B$, we hypothesized three scenarios: (1) the ionic currents contributing to electrical remodeling were similar in both ventricles, but because the substrates were different at control (electrical nonuniformity between RV and LV), the impact of these contributions would be different; (2) the ionic currents to remodeling were similar in both ventricles, but their functional alterations occurred at different degrees; (3) the ionic currents contributing to remodeling were different in the two ventricles.

To learn more about the actual scenario, we performed whole-cell voltage clamp and $\left[\mathrm{Ca}^{2+}\right]_{i}$ measurements. In the RV there was a prominent decrease of both $I_{\mathrm{Ks}}$ $(-55 \%)$ and $\mathrm{I}_{\mathrm{Kr}}(-45 \%$; Chapter 4$)$, and yet the action-potential prolongation was minimal at baseline. Only after administering almokalant to the RV myocytes, a pronounced, pathological prolongation was observed and this suggested that the residual fracrion of $I_{\mathrm{Kr}}$ played a major role in their repolarization. In the $L V$ there was a prominent prolongation of only $I_{K s}(-50 \%)$ and here the action-potential prolongation was already prominent at baseline. Next to $\mathrm{I}_{\mathrm{Ks}}$ and $\mathrm{I}_{\mathrm{Kr}}$, the magnitude of $\mathrm{I}_{\mathrm{K} 1}$ was unaltered and so was the interventricular difference of $\mathrm{I}_{\mathrm{TO}}$. These paradoxical findings led to the following conclusions: (1) at control, the repolarization reserve of $\mathrm{RV}$ midmyocardial cells (ie, their intrinsic, ionic capacity to maintain a fast repolarization) was larger than of LV companions; and (2) the altered acrion-potential properties in chronic AVB, were based on the downregulation of $\mathrm{K}^{+}$currents, but most likely also on the alteration(s) of other membrane currents involved in the repolarization.

Important new insights were also provided by the studies on $\left[\mathrm{Ca}^{2+}\right]_{i}$ transients and $\mathrm{Ca}^{2+}$-dependent ionic currents (Chapter 5). The $\left[\mathrm{Ca}^{2+}\right]_{i}$ transients of chronic-AVB myocytes appeared significantly larger than those of control cells at low stimulation rates relevant for the in-vivo idioventricular thythm, and this was more pronounced in the $\mathrm{LV}$ than $\mathrm{RV}$. Inward $\mathrm{I}_{\mathrm{Na}-\mathrm{Ca}}$ was also larger and was due to the larger $\left[\mathrm{Ca}^{2+}\right]_{i}$ transients as well as larger current densities per given $\left[\mathrm{Ca}^{2}+\right]_{\mathrm{i}}$. The latter was again more pronounced in the LV than $R V$. The activation and inactivation characteristics of $\mathrm{I}_{\mathrm{CaL}}$ were nor modified. Thus, altered $\mathrm{Ca}^{2+}$ homeostasis in chronic $\mathrm{AVB}$ accentuated the interventricular dispersion of repolarization by the differential upregulation of inward $\mathrm{I}_{\mathrm{Na}-\mathrm{Ca}}$, causing more pronounced action-potential prolongation in the LV than in the RV.

If we consider the ensemble of ionic currents responsible for the repolarizarion of ventricular cells at control (see Figure 3 in Chapter 1) and their alterations in chronic AVB, none of the three scenarios hypothesized holds true exclusiwely. Rather, the three 
occur in concert. Furthermore, it is very well possible that other ionic currents than presenty investigated contribute to the pronounced regional dispersion of repolariza tion. Here we can think of the late $\mathbb{I}_{\mathrm{N}_{\mathrm{a}}}$, the $\mathrm{I}_{\mathrm{Na}-\mathrm{K}}$ and additional ionic currents known to be present under normal or pathophysiological circumstances.

What is the significance of increased interventricular dispersion of repolarization for the genesis of torsades de pointes? We believe that the observed differences in action-potential configuration and APD between the ventricles reflect the existence of dispersion in more closely juxtaposed regions, such as the transmural ventricular wal and/or the interventricular septum. Preliminary in-vivo data from our laboratory indicate that the transmural interventricular septum is a region of particular interest in this regard, because relatively large repolarization gradients are present in chronic AVB. ${ }^{45,46}$ Arrhythmogenic voltage gradients can arise in such areas of myocardium when the differences in refractoriness are sufficiently large to cause reexcitation, $47-49$ The resultant extrasystolic activity can initiate torsades de pointes. ${ }^{30}$ Under these circumstances the generation of early afterdepolarizations may facilitate proarrhythmia by an acute exaggeracion of the spatial and temporal electrical heterogeneity faworing reentry.

\section{The Trigger}

Ventricular ecropic beats are important for the initiation of torsades de pointes. We have just discussed that phase- 2 reentry can be a mechanism of extrasystolic activity in the myocardium of dogs with chronic AVB on the basis of increased regional dispersion of repolarizacion and/or early afterdepolarizations. For abnormal impulse generation of this kind to occur, a critical number of integrated myocytes is necessary. The present studies bring forward that other forms of abnormal impulse generation, which arise in the single cell, must also be considered. Chronic-AVB myocytes exhibit an increased propensity to $\mathrm{Ca}^{2}$ overload and spontaneous $\mathrm{Ca}^{2+}$ release from the sarcoplasmic reticulum. Together with the enhanced $\mathrm{Na}^{+4}-\mathrm{Ca}^{2 *}$-exchange activity these events facilitate the generation of afterdepolarizations and triggered action potentials. In-vivo experiments in chronic-AVB dogs confurm this notion: significant increases in the LV-pressure rise during short pacing trains are coupled to a steepening of the diastolic slope on the monophasic-action-potential signal and to the induction of ectopic beats, both of which are less pronounced or absent in acute AVB (Chapter 5 ), 50 The in-vivo relevance of afrerdepolarizations is further suggested by the observation that increased adrenergic stimulation is frequently involved in the initiation of torsades de pointes. ${ }^{51-55} \mathrm{As}$ discussed in Chapters 6 and 8 , intense $\beta$-adrenergic receptor stimuLarion causes spontaneous $\mathrm{Ca}^{2+}$ release from the sarcoplasmic reticul um that can occur during systole and diastole, thus giving rise to both early and delayed afterdepolarizations. The simultaneous occurrence of both membrane responses in relation to the same action potential often precedes a run of torsades de pointes. 
Finally, within the context of abnormal impulse generation, abnormal automaticity should not be overlooked as a possible arrhythmogenic mechanism in the dog with chronic $A V^{B}$, although this was nor investigated. In aged hypertensive rats, the expression of the hyperpolarization-activared pacemaker current $I_{\text {f }}$ is linearly related to the severity of myocardial hypertrophy, and its upregulation was implicated as a cellular mechanism for ventricular arrhythmias in this species. ${ }^{56}$ In trabeculae from failing human hearts, automaticity was observed under experimental conditions that mimicked the altered extracellular environment in vivo. ${ }^{57}$

\section{Possible Stimuli for Electrical Remodeling}

In the diagram, possible stimuli for the altered electrical properties of the dog with chronic AVB are highlighted. If we consider the cascade of events induced by the creation of AVB, then critical factors are bradycardia, increased myocardial stretch and altered ventricular activation. In addirion, neurohumoral activation and possibly myocardial ischemia will involve. Bradycardia is associated with an increased APD and prolonged diastolic intervals. Both affect the kinetics of $I_{K s}$ and $I_{K r}$ (and all other currents), and may cause definite current changes at chronic duration. Myocardial stretch is the trigger of numerous intracellular signaling pathways that eventually lead to cellular hypertrophy. ${ }^{58}$ Of the second messengers activated, protein kinases $A$ and $C$ have a direct effect on $\mathrm{I}_{\mathrm{Ks}}{ }^{99}$ and may alter channel function during long-term modulation. In addition, cell growth could be disproportionate to channel upregulation leading to decreases in current density. Altered ventricular activation is known to cause altered transmural gradients of repolarization and typical $T$-wave changes in experiments with dogs designed to study long-term cardiac memory. ${ }^{60}$ Rosen et a ${ }^{60,61}$ discussed that $I_{\mathrm{Ks}}$ and $\mathrm{I}_{\mathrm{Kr}}$ could play an important role under these circumstances. It is conceivable that the idioventricular rhyrhm in chronic $A V B$ mimics the siruation in long-term memory to some degree. Finally, we cannot rule out that a relative ischemia occurs during bradycardia and the development of hypertrophy. Subendocardial hypoperfusion during exercise has been described in dogs with volume-overload hypertrophy due to aortocaval fistulas. ${ }^{62}$ It was shown that ischemia reduces $I_{\mathrm{Ks}}{ }^{63}$ and also $\mathrm{I}_{\mathrm{K} ; \mathrm{in}}$

The altered $\mathrm{Ca}^{2+}$ dynamics can be explained, at least partly, by the upregulation of $\mathrm{Na}^{+}{ }^{+} \mathrm{Ca}^{2+}$-exchange activity. Outward $\mathrm{Na}^{+}-\mathrm{Ca}^{2+}$-exchangecurrents were severalfold larger in chronic AVB and this was the cause of an increased $\left[\mathrm{Ca}^{2+}\right]_{i}$ loading and release from the sarcoplasmic reticulum. The increased exchanger function could result from an increase in the number of exchanger molecules, eg, due to higher expression levels. Another explanation could be a negative shift of the reversal potential. Such a shift could be related to an increase in subsarcolemmal $\left[\mathrm{Na}^{*}\right]$, possibly due to an altered function of the $\mathrm{Nat}^{+}-\mathrm{K}^{+}$pump. These hypotheses are currently being investigated in close collaboration with Prof. Dr. F. Verdonck, University of Leuven at Kortrijk, Belgium. 
Induction of complete atrioventricular block $(A V B)$ :

Hypotheses on the stimuli for electrical remodeling

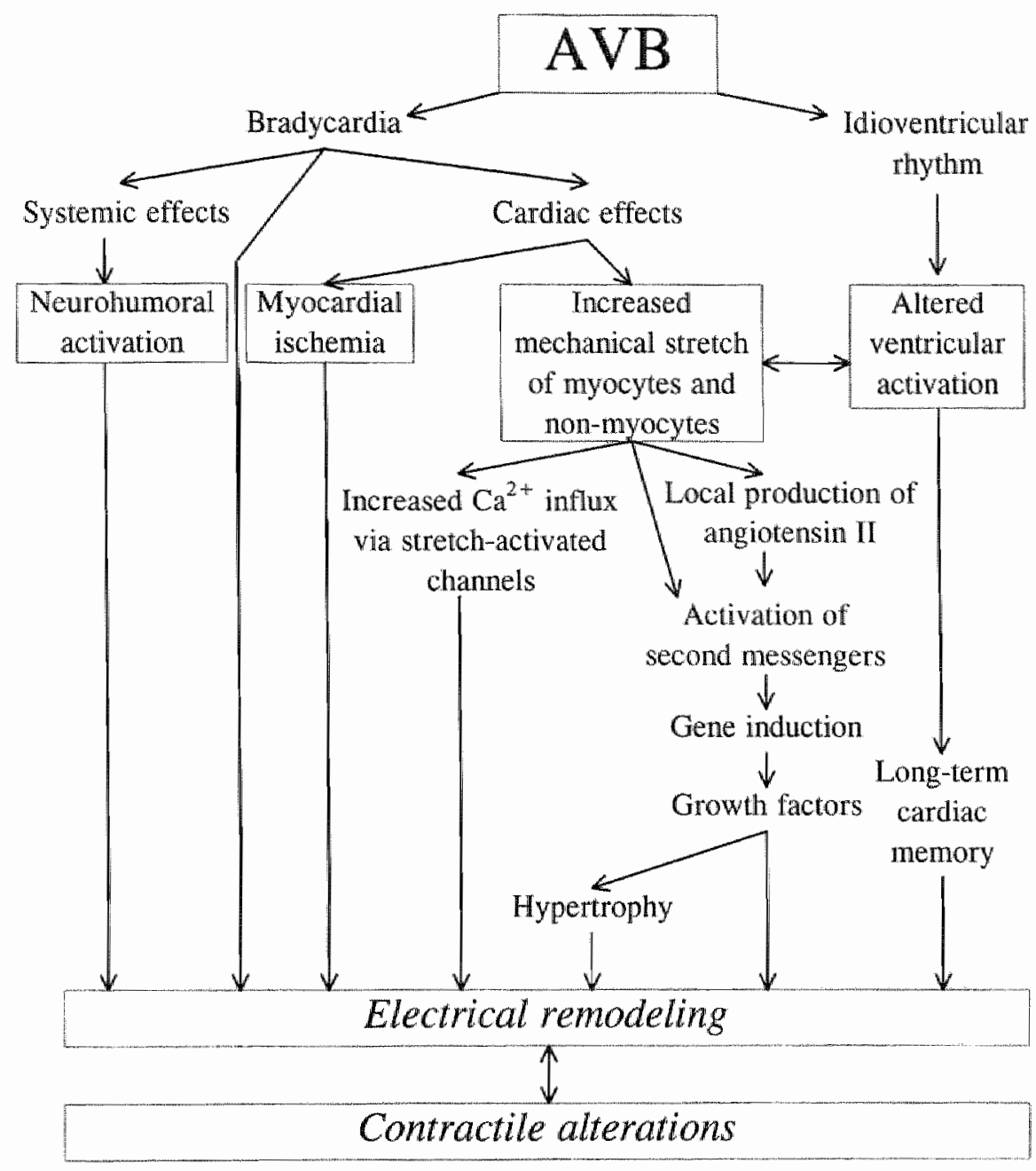

Figure. - Schematic diagram of the possible stimuli for electrical remodeling in the dog with chronic complete atrioventricular block. 


\section{Where to Go from Here?}

The dog with chronic AVB is an excellent model for the study of ventricular arthythmias in cardiac hypertrophy. Now that we have established that the process of electrical remodeling is determined by intrinsic changes in membrane currents, it is particularly relevant to know their time dependency and reversibility. The longitudinal design of such studies is a prerequisite to obtain the most consistent information on time-dependent alterations that generate proarthythmia and to identify the responsible pathogenetic factors. Molecular studies (in-situ hybridization, histochemical studies, analyses of $\mathrm{mRNA}$ and protein levels) on myocardial biopsies can contribute importantly to this identification. It is not that we have an exclusive interest for the dog with chronic AVB. Rather, the aim is to compare insights from this model with those from other models of heart disease and to implement all in to a framework of common pathophysiologic parhways. Ultimately, this may facilitate the understanding and treament of proarthythmic responses in the hypertrophied human heart.

The combined findings of an enhanced susceptibility to acquired torsades de pointes, the (supposed) adrenergic dependence of spontaneous episodes of torsades de pointes, the typical $T$-wave patterns during prolonged $Q T$ intervals, and the reduction of $\mathrm{I}_{\mathrm{K} s}$ in this animal model closely resemble the clinical characteristics of the LQT 1 form of the human congenital long-QT syndrome. In the $\operatorname{dog}$ with chronic AVB, this provides a unique opportunity to investigate the adrenergic dependence of torsades de pointes and sudden cardiac death under controlled conditions.

\section{References}

1. Pipberger H, Schwarz L, Massumi RA, Prinzmetal M. Studies on the nature of the repolarizarion process. Ann N Y Acad Sci. 1957:65:924-931.

2. Reynolds EW, Vander Ark CR. An experimental seudy on the origin of T-waves based on dereminations of effective refractory period from epicardial and endocardial aspects of the ventricle. Cisc Res. 1959:79943-949.

3. Han J, Moc GK. Nonuniform recovery of excitability in ventricular muscle. Circ Res. 1964:14:44-60.

4. wan Dam RT. Durrer D. Experimental study on the intramural distribution of the excitability cycle and on the form of the epicardial $\mathrm{T}$ wave in the dog heart in sicu. An Hearty. $1961 ; 61: 537-542$.

5. Mendez C. Mueller WJ, Urguiaga X. Propagation of impulses across the Purkinje fibermuscle junctions in the dog heart. Circ Res. 1970;26:135-150.

6. Sasyniuk BI, Mendex C. A mechanism for reentry in canine ventricular tissue. Cipc Res. $1971 ; 28: 3-15$. 
7. El-SherifN, Zeiler RH, Crelius W, Gough WB, Henkin R. QTU prolongationand polymorphic ventricular tachyartyythmias due to bradycardia-dependent early afrerdepolarizations: afterdepolarizarions and wentricular arthythmas. Cin Rer 1988:63: 286-305.

8. Li ZY, Maldonado C, Zee-Cheng C, Hiromasa 5, Kupersmith I. Purkinje fibrepapillary muscle interaction in the genesis of erriggered activity in a guinea pig model. Cardiovaric Res. 1992;26:543-548.

9. Carlsson L, Abrahamsson C, Andersson B, Duker G, Schiller-Linhardr G. Proarrhythmic effects of the class III agent almokalant: importance of infusion rate, QT dispersion, and early afrerdepolarisations. Cardiovasc Res. 1993;27:2186-2193.

10. Gilmour RF, Jr, Watanabe M. Dynamics of circus movement re-entry across canine Purkinje fibre-muscle juncrions. $/$ Physiol $1994 ; 476: 473-485$.

11. Berenfeld 0 , Jalife I. Purkinje-muscle reenry as a mechanism of polymorphic ventricular arthythmias in a 3-dimensional model of the ventrides. Circ Res. 1998;82: 1063-1077.

12. Litovsky $\mathrm{SH}$, Antzelevitch $\mathrm{C}$. Transient outward current prominent in canine ventricular epicardium but not endocardium. Cim Res. 1988;62:116-126.

13. Furukawa T, Myerburg RJ, Furukawa N, Bassert Al, Kimura S. Differences in transient ourward currents of feline endocardial and epicardial myocytes. Ciri Res. $1990 ; 67: 1287-1291$.

14. Wettwer E, Amos GJ, Posival H, Ravens U. Transient outward current in human wentricular myocyes of subepicardial and subendocardial origin. Cir Res. 1994;75: $473-482$.

15. Näbauer M, Beuckelmann DJ, Uberfuhr P. Sreinbeck G. Regional differences in current density and rate-dependent properties of the transient outward current in subepicardial and subendocardial myocyces of human left ventricle. Circulation. 1996:93:168-177.

16. Bryant SM, Wan X, Shipsey SJ, Hart G. Regional differences in the delayed rectifier current $\left(I_{K}\right.$ and $\left.I_{k}\right)$ contribute to the differences in action porential duration in basal left ventricular myocytes in guinea-pig. Cardionar Res. 1998;40:322-331.

17. Sicouri S, Anczelevitch C. A subpopulation of cells with unique electrophysiological properves in the deep subepicandium of the canine wentricle: the M cell. Cinc Res. $1991 ; 68: 1729-1741$.

18. Sicouri $\mathrm{S}$, Antzelevitch $\mathrm{C}$. Drug-induced afterdepolarizations and rriggered activity occur in a discrete subpopulation of ventricular muscle cells (M cells) in the canine heart: quinidine and digitalis. / Cardiovas Electropbysiol 1993;4:48-58.

19. Sicouri S, Fish $\mathrm{J}$, Antzelevitch C.. Distribution of $\mathrm{M}$ cells in the canine ventricle f Cardiowasc Electrophysiol. 1994;5:824-837.

20. Sicouri $S$, Antzelevitch $C$. Electrophysiologic characteristics of $M$ cells in the canine left ventricular free wall. / Cardiowasc Electroplyssiol. 1955;6:591-603.

21. Drouin E, Charpentier F, Gauthier C, Laurent K, Le Marec H. Electrophysiologic dharacteristics of cells spanning the left ventricular wall of human heart: evidence for presence of M cells. I Am Coll Cardiol 1995;26:185-192. 
22. LiGR, Feng), Yue L, Carrier M. Transmural heterogeneity of action potentials and $I_{\text {rol }}$ in myocytes isolated from the human righ ventride. Am / Physiol. 1998:275: H369- H377.

23. Drouin $E$. Lande $G$, Charpentic $F$. Amiodarone reduces transmural heterogeneity of repolatization in the human heart. $\mathrm{f}$ Am Coll Cardiol. 1998;32;1063-1067.

24. Girtant GA. Regional differences in $I_{K}$ density in canine left wentricle: role of $I_{K}$ in electrical heterogeneity. Am / Pbysiol. 1995;268:H604-H613.

25. Liu DW. Antzelevitch $C$. Characteristics of the delayed rectifier current $\left(\mathbb{I}_{K_{r}}\right.$ and $\left.I_{K s}\right)$ in canine ventricular epicardial, midmyocardial, and endocardial myocytes: a weaker $I_{k s}$ contributes to the longer action potential of the M cell. Circ Res. 1995;76:351-365.

26. Eddlestone $G T$, Zygmunt AC, Antzelevitch $C$. Larger late sodium current contributes to the longer action potential of the $\mathrm{M}$ cell in canine ventricular myocardium. Pacing Cin Electroplyysiol. 1996;19:569. Abstract.

27. Liu DW, Gintant GA, Antzelevitch C. Ionic bases for electrophysiological distinctions among epicardial, midmyocardial, and endocardial myocytes from the free wall of the canine left ventricle. Cinc Res. 1993;72:671-687.

28. Yan GX, Shimizu W. Antzelevitch C. Characteristics and distribution of M cells in arterially perfused canine left ventricular wedge preparations. Cinculation. 1998;98: $1921-1927$

29. Yan GX, Antzelevirch $\mathrm{C}$. Cellular basis for the normal $T$ wave and the electrocardiographic manifestations of the long. QT syndrome. Circulation. 1998;98:1928-1936.

30. Antzelcvitch $C$, Sicouri $S$. Clinical relevance of cardiac arrhythmias generated by afterdepolarizations: role of $\mathrm{M}$ cells in the generation of $\mathrm{U}$ waves, triggered activity and torsade de pointes. J Am Coll Cardiol. 1994:23:259-277.

31. Antzelevitch $C$, Sun ZQ, Zhang ZQ, Yan GX. Cellular and ionic mechanisms underlying erythromycin-induced long QT intervals and torsade de pointes. I Am Coll Caxdiot 1996:28:1836-1848.

32. Shimiza W. Anzelevitch C. Sodium channel block with mexiletine is effective in reducing dispersion of repolarization and preventing torsade de pointes in LQT2 and LQT3 models of the long-QT syndrome. Circulation. 1997;96:2038-2047.

33. Shimizu W, Antzelevith C. Cellular basis for the ECG Features of the LQT"1 form of the long.QT syndrome; effects of B-adrenergic agonists and antagonists and sodium channel blockers on transmural dispersion of repolarization and torsade de pointes. Cirwation. 1998;98:2314-2322.

34. Anyukhowsky EP. Sosunov EA, Rosen MR. Regional differences in electrophysiological properties of epicardium, nidmyocardium, and endocardium: in vitro and in wiwo correlations. Cinchation 1996;94:1981-1988.

35. Anyukhovsky EP, Sosunov EA, Gainullin RZ, Rosen MR. The controversial M cell. I Cardiounc Elactroplysiol. 1999;10:244-260.

36. Hart $G$. Cellular electrophysiology in cardiac hypertrophy and failure. Cardiovac Res. $1994: 28: 933-346$

37. Boyden PA. Jeck CD. Ion channel function in disease Cardiovat Res 1995;29:312-318. 
38. Näbauer M, Käab S. Potassium channell down-regulation in heart tailure. Condowas Res. 1998:37:324-334.

39. Keung ECH, Aronson RS. Non-uniform electrophysiological properties and electrotonic interaction in hyperrophied rar myocardium. Ciw Res. 1981:49:150-158.

40. Bryant SM, Shipsey SJ, Hart G. Regional differences in electrical and medanical propercies of myocytes from guinea-pig hearts with mild lefe ventricular hypertrophy. Cardiowase Res. 1997:35:315-323.

41. Gómez AM, Bénirah JP, Henzel D, Vinet A, Lorente P, Delgado C. Modulation of alectrical heterogeneity by compensated hypertrophy in rat left ventricle. Am $/ \mathrm{P} / \mathrm{ysiol}$. 1997:272:H1078-H1086.

42. Bailly P, Bénitah IP, Mouchonière M, Vassort $G$, Lorente P. Regional alteration of the transient outward current in human left ventricular sepum during compensated hypertrophy. Circulation. 1997:96:1266-1274.

43. Tomaselli GF, Beuckelmann DJ, Calkins HG, Berger RD, Kessler PD, Lawrence JH, Kass D, Feldman AM, Marban E. Sudden cardiac dearin in heart failure: the role of abnormal repolarization. Cinulation 1994,90:2534-2539.

44. Vos MA, de Groot SHM, Verduyn SC, van der Zande J, Leunissen HDM, Cleutjens JPM, van Bilsen M, Daemen MJAP. Schreuder JJ. Allessie MA, Wellens HJJ. Enhanced suscepribility for acquired torsade de pointes arrhythmias in the dog wirh chronic, complete AV block is related to cardiac hypertrophy and elecrical remodeling. Cimow rion. $1998 ; 98: 1125-1135$.

45. van der Hulst FF, Vos MA, Leunissen HDM, wellens HIJ. Transsepral dispersion in the dog with chronic complete atrioventricular block: distribucion and frequency dependence Evr Heart) 1998;19(suppl):72. Abstract.

46. wan der Hulst FF, Vos MA, Leunissen HDM, Volders PGA, Wellens HJ]. Regional hererogeneity of action-potential duration in the intacr hypertrophied canine heart: difference between the seprum and the lefi ventricular free wall. Bioplys $\mathrm{y}$. 1999:76:A365. Abstract.

47. Brugada P, Wellens HJJ. Early afrerdepolarizations: role in conduction block. "prolonged repolarization-dependent reexciation," and tachyarhythmias in the human heart. Pacing Clin Electrophysiol 1985:8:889-896.

48. Di Diego JM, Antzelevirch C. High $\left[\mathrm{Ca}^{2}{ }^{2}\right]_{n}$-induced electrical hererogensity and exerasystolic acriviry in isolated canine ventricular epicardium: phatse 2 rentry. Crotalion. $1994: 89: 1839-1850$

49. Uchida T, Yashima M, Gotoh M, QuZ, Garfinkel A, Weiss JN, Fishbein MC. Mandel WI. Chen PS, Karagueuzian HS. Mechanism of acceleration of functional reencry in the ventricle: effecs of ATP-sensitive ponssium channel opener. Circulation $1999 \% 99: 704-712$.

50. de Groo: SHM, Vos MA, Schoenmakers M, Leunissen JD, Wellens HJJ. Adaptations in contractile function at chronic AV-block (AVB) make the hear more susceprible to trigygered arrhythmias (TA). Circhlation. 1997:96(suppl 1):1-239-1 240. Abstract. 
51. Jackman WM, Szabo B. Friday KJ, Margolis PD, Moulon K. Wang X, Parterson E, Lazara $R$ Ventricular tachyarhychmias related to early afrerdepolarizarions and triggered fring relationship to QT intervat prolongarion and potential thetapeutic role for calcum channel blocking agents. / Cardiovasc Electrophysiol. 1990;1:170-195.

52. Shimizu W, Ohe $T$, Kurita $T$, Takaki $H$, Aihara $N$, Kamakura $S$, Matsuhisa $M$, Shimomura K. Early afterdepolarizations induced by isoproterenol in patients with congenital long QT syndrome. Croulation. 1991;84:1915-1923.

53. Locati EH, Maison-Blanche P, Dejode P, Cauchemez B, Coumell P. Spontaneous sequences of onset of torsade de pointes in patients with acquired prolonged repolarization: quantitarive analysis of Holter recordings. I Am Coll Cardiol. 1995:25:1564-1575.

54. Shmizu W, Ohe T, Kurita T;, Kawade M, ArakakiY, Ahara N, Kamakura S, Kamiya T. Shimomura $K$. Effecrs of verapamil and propanolol on early afterdepolarizations and ventricular arthythmias induced by epinephrine in congenital long QT syndrome. $/ \mathrm{Am}$ Call Cardiol 1995:26:1299-1309.

55. Viskin S, Alla SR, Barron HV, Heller K, Saxon L, Kitzis I, van Hare GF, Wong MI, Lesh MD, Scheinman MM.. Mode of onset of torsade de pointes in congenital long QT syndrome. J Am Coll Cardiol 1996:28:1262-1268.

56. Cerbai E, Barbieri M, Mugelli A. Occurrence and properties of the hyperpolarizationactivated current $I_{f}$ in ventricular myocytes from nomotensive and hypertensive rats during ageing. Circulation. 1996:94:1674-1681.

57. Vermeulen JT, McGuire MA, Opthof T, Coronel R, de BakkerJMT, Klöpping C, Janse MJ. Triggered activity and automaticity in ventricular trabeculae of failing human and rabbir hearts. Cardioudsc Res. 1994;28:1547-1554.

58. Sadoshima J, lzumo $S$. The cellular and molecular response of cardiac myocytes to mechanical stress. Ammu Rev Pyssiol 1997;59:551-571.

59. Lo CF, Numann R. Independent and exclusive modulation of cardiac delayed recrifying K. current by protein kinase C and protein kinase A. Circ Res. 1998:83:995-1002.

60. Shvilkin A, Danilo PJ, Wang J, Burkhoff D, Anyukhovsky EP, Sosunov EA, Hara M, Rosen MR. Evolution and resolution of long-term cardiac memory. Circulation. 1998;97:1810-1817.

61. Rosen MR, Cohen 1S, Danilo P, Jr, Steinberg SF. The heart remembers. Cardiowas Res. $1998 ; 40: 469-482$

62. Badke FR, Whire FC, Le Winter M, Covell J, Andres J, Bloor C. Effects of experimental volume-oveload hypertrophy on myocardial blood flow and cardiac function. Am J Phywol 1981:241:H564-1570.

63. Shaw RM, Rudy X. Electrophysiologic effects of acure myocardial ischemia: a theoretical study of altered cell excitability and action potential duration. Cardiovasc Res. 1997:35:256-272.

64. Jiang M. Ya JA. Wymore RS, Boyden PA. Tseng GN. Suppressed transcription and function of delayed rectifer $\mathrm{K}$ channels in post-myocardial infarction canine ventricle. Circulation. 1998;98(suppl 1):1-818. Abstract. 


\section{Progress in the Understanding of Cardiac Afterdepolarizations and Torsades de Pointes: Time to Revise Current Concepts}

This chapter is at the basis of a review article in preparation by:

Paul G.A. Volders, Marc A. Vos, Bela Szabo, Karin R. Sipido,

S.H. Marieke de Groot, Anton P.M. Gorgels, Hein J.J. Wellens, Ralph Lazzara.

From the Department of Cardiology, Cardiovascular Research Institute Maastricht, Maastricht University, Netherlands; Department of Medicine, Cardiovascular Section, University of Oklahoma Heaith Sciences Center, and the Department of Veterans Affairs Medical Center, Oklahoma City, USA (B.S., R.L.), Laboratory of Experimental Cardiology, University of Leuven, Bielgium (K.R.S.).

\section{Content}

1. Introduction

2. Cellular mechanisms of $\mathrm{Ca}^{2}$ homeostasis and their relation to delayed and early afterdepolarizations

$2.1 \mathrm{Ca}^{2}$ homeostasis in nomal cardiac cells

22 Differences of [Ca $\left.\mathrm{C}^{2}\right]$ between the bulk cytoplas mand the subsarcolemmal space

23 Cellular $\mathrm{Ca}^{2}$ foverload and spontaneous $\mathrm{Ca}$ r release from the SR

24 lonic mechanisms of DADS

25 lonic mechanisms of EADs

2.6 Evidence for $\left[\mathrm{Ca}^{2}\right]$, dependent mechanisms of EADs

3. Atterdepolarizations and arhythmogenesis in myocardial tis sue and the intact animal heart

3. EADs in multicelular preparations conseguences tor ambythmogenesis

3.2 Simultaneous appearance of DADs and EADs in the intact heat

3.3 EADs occurting in conditions associated with myocardial $\mathrm{Ca}^{2}$ overload

4. Clinical management of arthythmias in the congental and acguired long-QT symdromes

5. Conclusions

6. References 


\section{Introduction}

Afredepolarizations are oscillarions of the membrane potentral that depend on the preceding action potential for their generation. Within single cardiaccells, afterdepolarizations can give rise to new action potentials when they reach a critical threshold membrane potential for activation of a major depolarizing cation current. This form of abnormal impulse generation is called 'triggered activity'. ${ }^{2}$ Afterdepolarizations can also augment electrical heterogeneiry in regions of neighboring celis, which can lead to the formation of new action potentials via electrotonic interaction between regions that have recovered from refractoriness and those that are sull inexcitable. ${ }^{3}$ Alchough, by definition, the latter mechanism is not a form of abnormal impulse generation, the occurnence of afterdepolarizations appears to be of pivotal importance for arrhythmogenesis under many of these circumstances. "Thus, afterdepolarizations are of importance for the generation of arhythmias. Experimental or clinical interventions aimed at preventing or attenuating their occurence are therefore powerfulantiarhy thmic tools.

Two rypes of afterdepolarizations can be distinguished: delayed (DADs) and earlyaficrdepolarizations (EADs). DADs have been defined as oscillations in membrane potenthat that occur afer repolarization of an action potential and that are caused by that action potential. EADs appear cluring the action potential and have been defned as "oscillations at the platean level of membrane potential or later during phose 3 of repolarizanion' 4

The occurrence of DADs in the myocardium has been related to changes in contraction and $\mathrm{Ca}^{2+}$ handling, ${ }^{5-17}$ and it is generally accepted that DADs are caused by transient inward currents $\left(I_{1}\right)$ evoked by spontaneous $\mathrm{Ca}^{2}$ releases from the sarcoplasmic reticulum (SR) under conditions that favor accumulation of cytoplasmic $\mathrm{Ca}^{2+}$ ([Cat $\left.\mathrm{Car}^{2+}\right)$ and cellular $\mathrm{Ca}^{2+}$ overload. ${ }^{4,18}$

Progress and agreement on the mechanisms of EADs have been meager in comparison wirk DADs. With respect to the upstroke phase of EADs there is general consensus that $L_{-}$and $T$-rype $\mathrm{Ca}^{2+}$ current $\left(\mathrm{I}_{\mathrm{CaL}}\right.$ and $\left.\mathrm{I}_{\mathrm{Ca}} \mathrm{T}\right)$, and $\mathrm{Na}^{+}$current $\left(\mathbb{I}_{\mathrm{N}}\right)$ can be major charge cartiers (ic, sarolemwa-dependent medowisms for EADs). ${ }^{19,20}$ Less agreement has been reached on the ionic basis of the so-called 'condivonatphase. "This is the transient perturbation of the nomal course of repolarization that precedes the upstroke of most types of EADs. Slowed inacrivation and/or reactivation of $I_{C a}$ and $I_{\mathrm{Na}}$ are contributors to this phase, but it is now becoming clear that the $\left[\mathrm{Ca}^{2+}\right]_{\text {cym }}$ activated $\mathrm{Na}^{+}-\mathrm{Cat}^{2+}$-exchange current ( $\mathrm{Nan}$. ) also plays a significant role in many cases (ie,

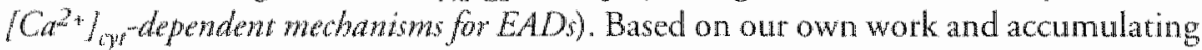
evidence in the literature, such a role is not only restricted to EADs related to $\mathrm{Ca}^{2+}$ overload and spontaneous $\mathrm{Ca}^{2+}$ release from the SR, but applies also to EADs that occur in the setting of less extreme $\mathrm{Ca}^{2}+$ loading.

Whereas numerous studies have accentuated the differences between DADs and EADs, we and other groups have often described similarities berween the rwo. In Table 1, a number of experimental conditions associated with the generation of both 
DADs and EADs in transmembrane and/or monophasic-action-potential (MAP) recordings are categorized. A first argument favoring the contribution of $\left[\mathrm{Ca}^{2+}\right]_{6 y \mathrm{r}}$-dependent mechanisms for EADs is based on the observarion that, dependent on the mode of induction, DADs and EADs can appear jointly in consecurive action potentials or even in relation to the same action potential. A second argument for $\left[\mathrm{Ca}^{2+}\right]_{\mathrm{Cy}}$-dependent mechanisms derives from the dynamic cellular responses to rate acceleration and adrenergic-receptor stimularion, known clinically to be involved in the initiation of triggered cardiac arthythmias, notably torsades de pointes. $21-25$ Several types of EADs are induced or amplified by fast pacing rates or rate acolerarions during bradycardia, just like DADs, and the infuence of increased adrenergic stimulation can become proarthythmic wia sudden changes in cellular $\mathrm{Ca}^{2+}$ homeostasis.

The importance of EADs and DADs lies in their capaciry ro provide both the substrate and the trigger for torsades de pointes. Ir is imperative to better understand the basic mechanisms in situacions that are relevant for in-vivo arrhythmia induction, because only this can improve the clinical management of life-chreatening ventricular arrhythmias on ration grounds. In this Chapter, we will discuss recent advances in cardiac arthythmology related to afterdepolarizations from cell to clinic. As a background, we will first review the literature of the 19905 on cellular $\mathrm{Ca}^{2}+$ homeostasis and its relation to DADs (sections 2.1 to 2.4 ). The reader who is familiar with these aspects can proceed with section 2.5 to learn about the new views on $\mathrm{Ca}^{2+}$-dependent mechanisms of EADs and their significance for the initiation and treatment of torsades de pointes.

\section{Cellular Mechanisms of $\mathrm{Ca}^{2+}$ Homeostasis and Their Relation to Delayed and Early Afterdepolarizations}

\subsection{Can Homeostasis in Normal Cardiac Cells}

$\mathrm{Ca}^{2}$ transients underlying excitation-contraction coupling in cardiac cells result mainly from $\mathrm{Ca}^{2}$ release from the $\mathrm{SR}$ triggered by $\mathrm{Ca}^{2}$ entry during the action potencial. Under normal circumstances, $\mathrm{Ca}^{2}$ entry into cardiac myocytes is carried primarily via $I_{C a L}$, whereas additional fractions can enter via $I_{C a}$ and on reverse-mode $\mathrm{Na}^{*} \mathrm{Ca}^{2+}$ exchange. All three parhways are capable of triggering $\mathrm{SR} \mathrm{Ca}{ }^{2+}$ release and contraction, but the relarive contribution and efficiency is largest for $\mathrm{I}_{\mathrm{Cal}}{ }^{26-31} \mathrm{Addi}-$ tional trigger mechanisms of $S R \mathrm{Ca}^{2+}$ release are currently being inwestigared. ${ }^{32-35}$ The above-described $\mathrm{Ca}^{2+}$-entry pathways serve two main purposes: (1) they constitute the external rigger for activation of the ryanodine receptors and subsequent release of $\mathrm{Ca}^{2}$. from the SR; and (2) they are largely responsible for cellular $\mathrm{Ca}^{2 *}$ gain, both at steady state and under circumstances when $\mathrm{Ca}^{2+}$ loading is required for an increased contractile performance.

Modern concepts of excitarion-contraction coupling rely on a local-control theory", which was originally developed from theoretical models to explain how global 


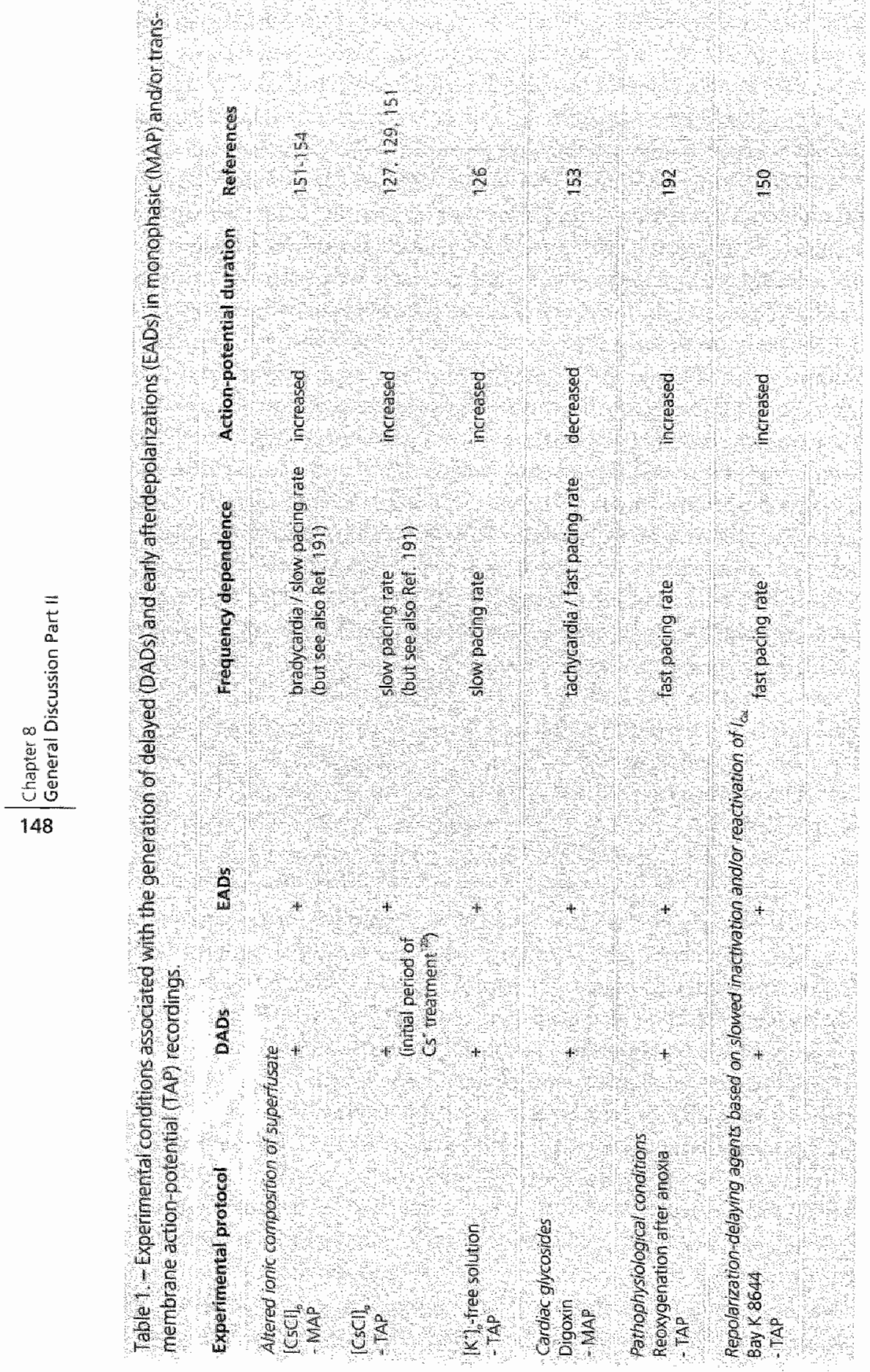




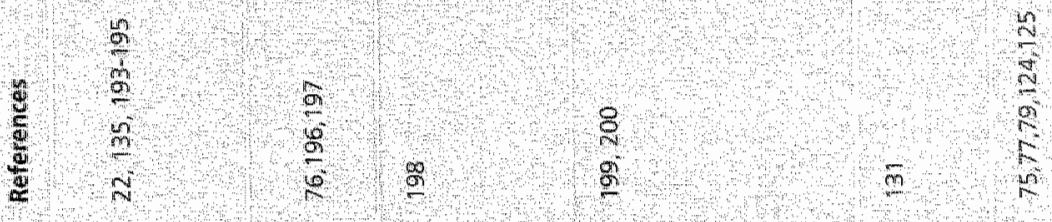
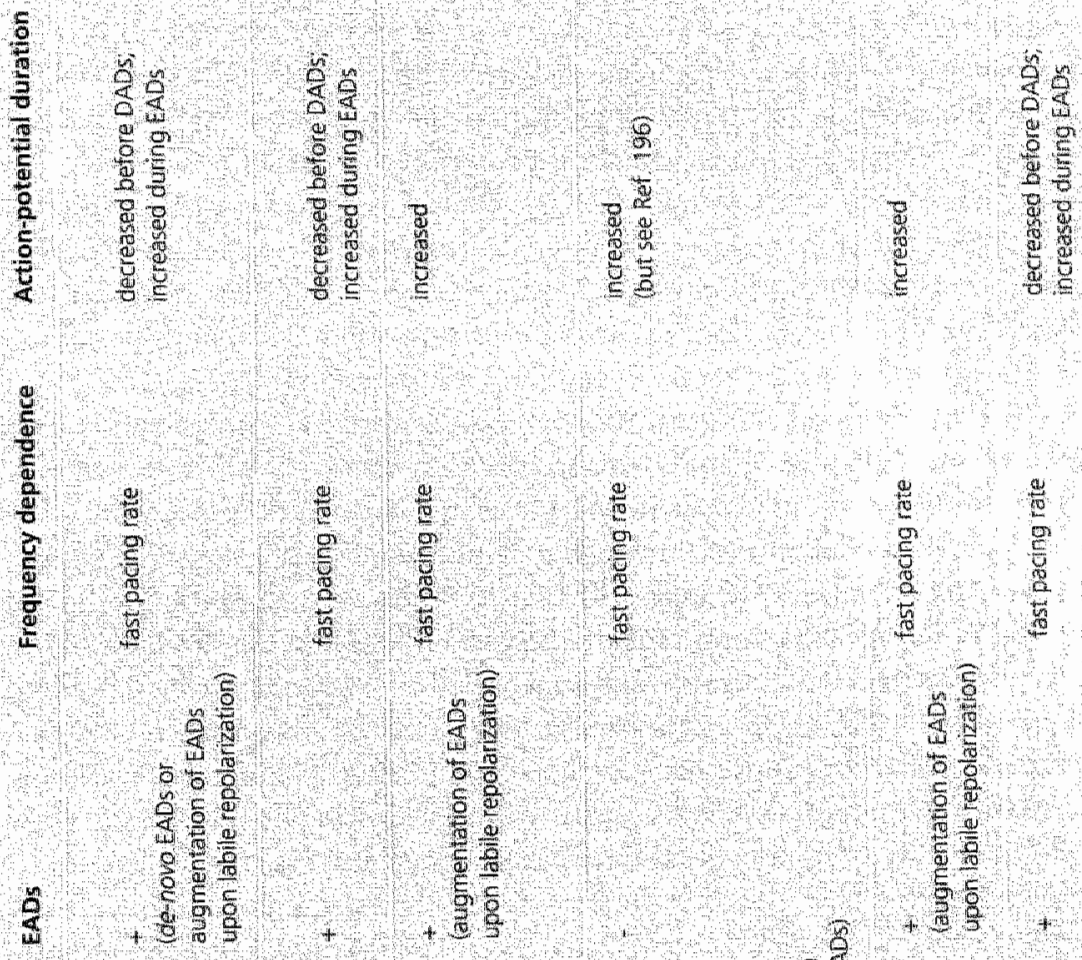

की

ats?

a d a

$\frac{1}{6} \mathrm{~g}^{\mathrm{g}}$

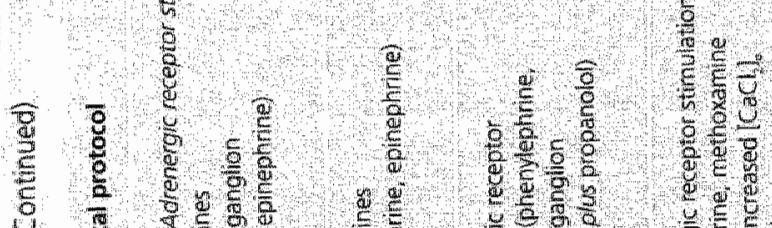

है

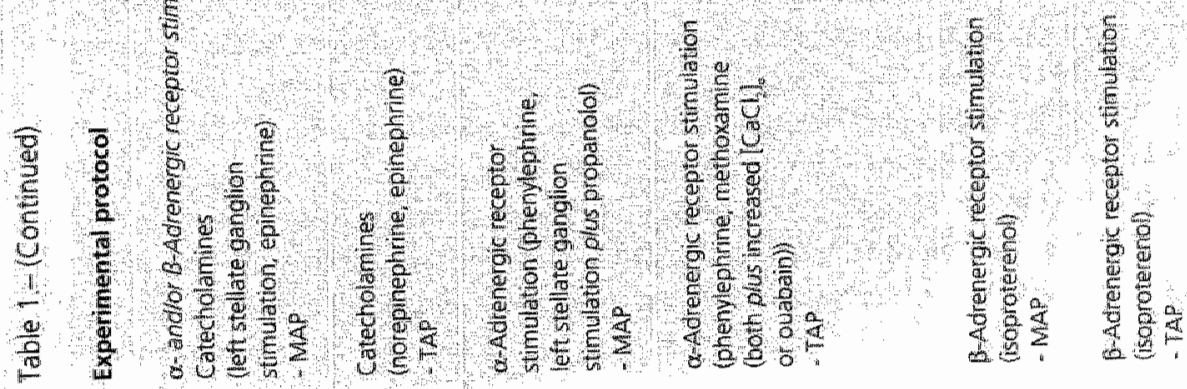


$\mathrm{Ca}^{2+}$ transients can be graded by the $\mathrm{Ca}^{2+}$ influx withour uncontrolled regenerarive release. ${ }^{36}$ This theory was supported by morphological studies on the microarchirecture showing a close association between $\mathrm{L}-\mathrm{rype} \mathrm{Ca}^{2+}$ channels and ryanodine receptors, ${ }^{37}$ and subsequently received experimental support from investigations wich high-resolution confocal microscopy documenting local functional interaction between these channels. ${ }^{38,39} \mathrm{Ir}$ is now generally thought that cell-wide $\mathrm{Ca}^{2+}$ transients result from the spatial and temporal summation of local $\mathrm{Ca}^{2+}$ transients, termed ${ }^{2} \mathrm{Ca}^{2+}$ sparks', evoked by relarively high $\left[\mathrm{Ca}^{2+}\right]$ near ryanodine receptors upon $\mathrm{Ca}^{2+}$ entry through single L-type channels. The occurrence and size of $\mathrm{Ca}^{2+}$ sparks are tightly, though not exclusively, linked to $\mathrm{Ca}^{2+}$ flux through L-type channels ${ }^{38,39}$ and this fits well with the finding in previous work thar the size of global $\mathrm{Ca}^{2+}$ transients was regulared by the magnitude of the whole-cell $\mathrm{I}_{\mathrm{CaL}}{ }^{40,41}$ In ventricular myocytes, a welldeveloped t-tubular system promotes homogeneous $\mathrm{SR} \mathrm{Ca}^{2+}$ release throughour the cell. ${ }^{42}$ The recent observation that $\mathrm{Ca}^{2 *}$ sparks occur also in cardiac trabeculae under physiological conditions $s^{43}$ indicates that the concepts obtained in studies on single myocytes are applicable to the function of ventricular tissue.

$\mathrm{Ca}^{2+}$ release from the $S R$ is controlled by ar least three regulators: (1) the size of the triggering $\mathrm{Ca}^{2+}$ influx (as mentioned above); (2) the state of the ryanodine receptors; and (3) the $\mathrm{Ca}^{2+}$ content within the SR. Recently, Eisner et al ${ }^{44}$ have convincingly argued, both experimentally and theoretically, that the state of the ryanodine receptors as a sole factor will not affect $\mathrm{Ca}^{2+}$ release from the SR. Indeed, changes in the gating of the ryanodine receptor and consequently in the size of the $\mathrm{Ca}^{2+}$ transient will feed back on transsarcollemmal $\mathrm{Ca}^{2+}$ fluxes and this feedback will adjust the $\mathrm{SR} \mathrm{Ca}{ }^{2+}$ content such that the size of the $\mathrm{Ca}^{2+}$ transient returns to its basal level. This process has been called 'autoregulation' and underscores the importance of the SR $\mathrm{Ca}^{2+}$ content. The SR $\mathrm{Ca}^{2 *}$ content, and thus the amount of $\mathrm{Ca}^{2+}$ available for release, depends on: (1) $\mathrm{Ca}^{2+}$ uptake info the SR by the $\mathrm{Ca}^{2+}$ ATPase; (2) $\mathrm{Ca}^{2+}$ efflux (leak); (3) the $\mathrm{Ca}^{2+}$-buffering capacity of the SR; and (4) the $\left[\mathrm{Ca}^{2+}\right]_{\mathrm{cyt}}{ }^{45}$ Estimates of the $\mathrm{Ca}^{2+}$ content can be made from contractures induced by rapid cooling, ${ }^{46}$ and from caffeine-induced $\mathrm{Ca}^{2+*}$ release in single cells. ${ }^{47} \mathrm{The} \mathrm{Ca}^{2+}$ content will affect release not only passively by its effect on the concentration gradient, but also by actively determining the fraction that will be released, ${ }^{48.50}$ suggesting that there may be a regulatory site for $\mathrm{Ca}^{2+}$ on the luminal (intra-SR) side of the ryanodine receptor. As mentioned above, transmembrane $\mathrm{Ca}^{2+}$ influx triggers release and serves to fill the SR with $\mathrm{Ca}^{2+}$. Equally important for the net $\mathrm{Ca}^{2+}$ flux across the sarcolemma, and thus for the $\mathrm{SR} \mathrm{Ca}^{2+}$ content, is $\mathrm{Ca}^{2+}$ removal from the cell.

$\mathrm{Na}^{+}-\mathrm{Ca}^{2+}$ exchange is the main $\mathrm{Ca}^{2+}$-extrusion mechan ism for the beat-to-beat regularion of contracrion and relaxation in cardiac myocytes. ${ }^{51,52}$ Because of a stoichiometry of $3 \mathrm{Na}^{4}$ ions: $1 \mathrm{Ca}^{2 *}$ ion, inward current is generated when $\mathrm{Ca}^{2+}$ is extruded from the cell and outward current is generated when $\mathrm{Ca}^{2+}$ enters via this transporter. The direction and magnitude of $\mathrm{Na}^{+}-\mathrm{Ca}^{2+}$ exchange are dependent on the membrane potential and on the intra- and extracellular $\left[\mathrm{Na}^{+}\right]$and $\left[\mathrm{Ca}^{2+}\right]$ in the direct vicinity of 
the exchanger protein. $53-55$ The dynamicity of the action porential and the resultant local $\mathrm{Na}^{+}$and $\mathrm{Ca}^{2+}$ signals change the reversal porential of the $\mathrm{Na}^{+}-\mathrm{Ca}^{2+}$ exchanger on a continuous basis. Under control conditions, it funccions predominandy in the inward mode during the decay phase of the $\mathrm{Ca}^{2}+$ transient generating inward curtent during most of the repolarization of the action potential. 56,57 To evaluate the importance of inward $\mathrm{I}_{\mathrm{Na}-\mathrm{Ca}}$ for the course of the action potential, Janwer et al ${ }^{58}$ examined the effects of buffering $\left[\mathrm{Ca}^{2}\right]_{c y}$ with BAPTA AM or replacing external $\mathrm{Na}^{+}$with $\mathrm{Li}^{+}$(both of which inhibit $\mathrm{Na}_{2}{ }^{+}-\mathrm{Ca}^{2+}$ exchange) in ferrer ventricular myocytes. They found a signifcant attenuation of the action-potential dome and shortening of the action-porencial duration (APD) of 19 and $20 \%$ at $A P D$ m and $A P D-65 \mathrm{mv}$, respectively, during BAPTA AM, and of 56 and $44 \%$ during $\mathrm{Li}^{*}$, indicaring a major influence of inwart $\mathrm{I}_{\mathrm{Na}-\mathrm{Ca}}$ at baseline.

\subsection{Differences of [C $\left.\mathrm{a}^{2+}\right]$ Between the Bulk Cytoplasm and the Subsarcolemmal space}

Compelling evidence has accumulated that intraceldular concentrations of $\mathrm{Na}^{*}$ and $\mathrm{Ca}^{2}$ ions can differ considerably between the bulk cyroplasm and the subsarcolemmal space. The discussion on such concentration gradients was instigated in 1990 on the basis of experiments by Leblanc and Hume, ${ }^{32}$ who showed that reverse-mode $\mathrm{Na}^{+}-\mathrm{Ca}^{2+}$ exchange was capable of triggering $\mathrm{Ca}^{2+}$ release from the SR consequent ro $\mathrm{Na}^{+}$influx through tetrodotoxin-sensitive $\mathrm{Na}$ channels. Their data were interpreted as indicative of very high $\mathrm{Na}^{*}$ concentracions acrivating reverse $\mathrm{Na}^{*}-\mathrm{Ca}^{2 *}$ exchange in a 'functionally restricted intracellular space accessible to $\mathrm{Na}^{+}$channels, the $\mathrm{Ne}$ - $\mathrm{Ca}{ }^{2+}$ exchanger, and some of the $S R$, which was termed "fuzzy space. 59 Cameliet 60 reviewed the evidence for $\mathrm{Na}^{*}$ gradients in 1992 and new supportive data have since been published. ${ }^{61-63} \mathrm{Not}$ only $\mathrm{Na}^{+}$, but also $\mathrm{Ca}^{2+}$ gradients are present in cardiac cells. The fuzzy space is associated with the subsarcolemmal space in the diadic cleft, around the feet of the ryanodine receptors, and is some $10 \mathrm{~nm}$ wide. Within this restricted space, and with free diffusion of $\mathrm{Ca}^{2}$ reduced by a lacror of 5 to $7 \mathrm{Ca}^{2+}$ - Huxes through $\mathrm{L}-\mathrm{type}$ channels and during $\mathrm{Ca}^{2+}$ release create large local gradients. ${ }^{64}, 65$ Experimental evidence for these gradients comes mostly from studies examining Ca ${ }^{2+}$-dependent menbrane currents. Given that during voltage damp $\mathrm{I}_{\mathrm{Na}} \mathrm{Ca}$ is a linear function of the intracellular $\mathrm{Ga}^{2}$ concentration, ${ }^{66}$ severall groups endeavored to simultancously measure $\mathrm{Ca}^{2+}$ signals with fuorescent $\mathrm{Ca}^{2+}$ probes and inward $\mathrm{I}_{\mathrm{Na}^{2} \mathrm{Ca}}$. Their results confirm that during $\mathrm{Ca}^{2+}$-induced $\mathrm{Ca}^{2+}$ release from the $\mathrm{SR}$ the $\mathrm{Ca}^{2+}$ concentration sensed by the membrane rises and falls more quickly, and is higher than the bulk $\left[\mathrm{Ca}^{2+}\right]_{\text {cyt }}{ }^{67,68}$ This hysteresis is further accentuated during cellular $\mathrm{Ca}{ }^{2+}$ loading and spontaneous $\mathrm{Ca}^{2+}$ release from the SR. ${ }^{68,69}$ Inactivation of $\mathrm{L}-\mathrm{type} \mathrm{Ca}^{2+}$ currert during $\mathrm{Ca}^{2+}$ rellease from the $S R$ also exceeds the inacrivation expected on the basis of cytoplasmic $\mathrm{Ca}^{2+}$ signals. ${ }^{70,71}$ More direct measurements of local $\mathrm{Ca}^{2}$ - by membrancbound $\mathrm{Ca}^{2+}$ indicators have been hampered by methodological problems, ${ }^{2}$ al hough in smooth muscle such gradients have been demonstrated.73. 
Until now, the importance of functional intracellular $\mathrm{Ca}^{2+}$ gradients for the generation of DADs and EADs has received little atrention in the literature (but see Trafford et al $\left.{ }^{69,74}\right)$. Based on the aforementioned data, however, local $\mathrm{Ca}^{2+}$ dynamics and resultant activation of $\mathrm{NaA-Ca}_{\text {and other }} \mathrm{Ca}^{2+}$-sensitive membrane currents may be of particular relevance. In the discussion on $\mathrm{EADs}$ that appear in the serting of $\mathrm{Ca}^{2+}$ overload and spontaneous release from the SR (see Figure 1A) ${ }^{75-77}$ the relative contribution of inward $\mathrm{I}_{\mathrm{Na}-\mathrm{Ca}}$ to delay repolarization during spontaneous early $\mathrm{Ca}^{2 *}$ aftertransients may be larger than previously proposed.78,79. In the case of slow-rate-dependent EADs (as during trearment with class III anriarrhythmic agents), the close functional coupling of slowly inactivating and/or reactivating $\mathrm{I}_{\mathrm{Ca}}$, and $\mathrm{Na}^{+}-\mathrm{Ca}^{2+}$ exchange could account for an appreciable inward $\mathrm{I}_{\mathrm{Na}-\mathrm{Ca}}$ contributing significantly to the primary delay of repolarization (see further section 2.6).

\subsection{Cellular $\mathrm{Ca}^{2+}\left(\right.$ Over)load and Spontaneous $\mathrm{Ca}^{2+}$ Release from the $\mathrm{SR}$}

Spontaneous $\mathrm{Ca}^{2 *}$ release is usually observed when the $\mathrm{Ca}^{2+}$ content of the cells, and of the SR, is very high, a condition often referred to as " $\mathrm{Ca}^{2+}$ overload". Experimental interventions as diverse as rapid pacing, prolonged depolarization during voltage clamp, high $\left[\mathrm{Ca}^{2+}\right]$ or low $\left[\mathrm{K}^{+}\right]$in the superfusate, cardiac glycosides, $\beta$-adrenergic receptor stimulation (and many more) produce $\mathrm{Ca}^{2+}$ loading via direct or indirect modulation of $\mathrm{I}_{\mathrm{CaL}}$ or $\mathrm{Na}^{+}-\mathrm{Ca}^{2+}$ exchange. A review of the literature shows that all these interventions have in common that the peak $\left[\mathrm{Ca}^{2+}\right]_{\mathrm{cyr}}$ and the amplitude of the $\mathrm{Ca}^{2+}$ transient are increased during subsequent action potentials or voltage clamps. Depending on the nature and the intensity of stimulation, the baseline $\left[\mathrm{Ca}^{2+}\right]_{\mathrm{cyt}}$ during rest ('diastolic $\left[\mathrm{Ca}^{2+}\right]_{c y t}$ ) may vary from virtually unaltered to significandly upregulated, as indicated in Table 2.

Based on contraction measurements in rat ventricular myocytes during a number of these interventions, Capogrossi et al ${ }^{17}$ suggested that the first occurrence of spontaneous $\mathrm{SR} \mathrm{Ca}^{2+}$ release denotes the state of maximal inotropy in the myocardium. However, in canine ventricular myocytes we found that the rwitch potentiation during administration of isoproterenol was not maximal at the first manifestation of aftercon-

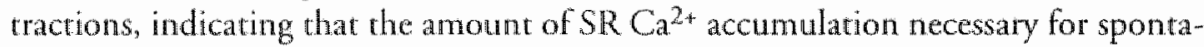
neous $\mathrm{Ca}^{2+}$ release is lower than that for maximal inotropy. ${ }^{77}$ Species-related differences in $\mathrm{SR} \mathrm{Ca}{ }^{2+}$ handling may explain these paradoxical findings: in the rat, unlike the $\mathrm{dog}$, the SR works at a near-maximal $\mathrm{Ca}^{2 *}$ sequestration, which is evident from the frequent spontaneous $\mathrm{Ca}^{2+}$ releases at rest. ${ }^{80-83}$ This spontaneous $\mathrm{SR} \mathrm{Ca}^{2+}$ release in rat ventricular myocytes at rest was recently correlated with cellular $\mathrm{Ca}^{2+}$ load. ${ }^{81}$ In myocytes oscillating at high rates the SR $\mathrm{Ca}^{2+}$ content was significantly higher than in quiescent cells. Additionally, an increase in $\left[\mathrm{Na}^{+}\right]_{\text {cyt }}$ showed a positive correlation with the frequency of spontaneous $\mathrm{Ca}^{2+}$ release, supporting a role for $\mathrm{Ca}^{2+}$ loading via modulation of $\mathrm{Na}^{*}-\mathrm{Ca}^{2+}$ exchange. ${ }^{81}$ Evidence for the crucial role of $\mathrm{SR}$ $\mathrm{Ca}^{2+}$ content for spontaneous release also comes from the studies of $\mathrm{Ca}^{2+}$ sparks. Cheng et al ${ }^{80,84}$ demonstrared that spontaneous sparks, resulting from the openings of one or a 


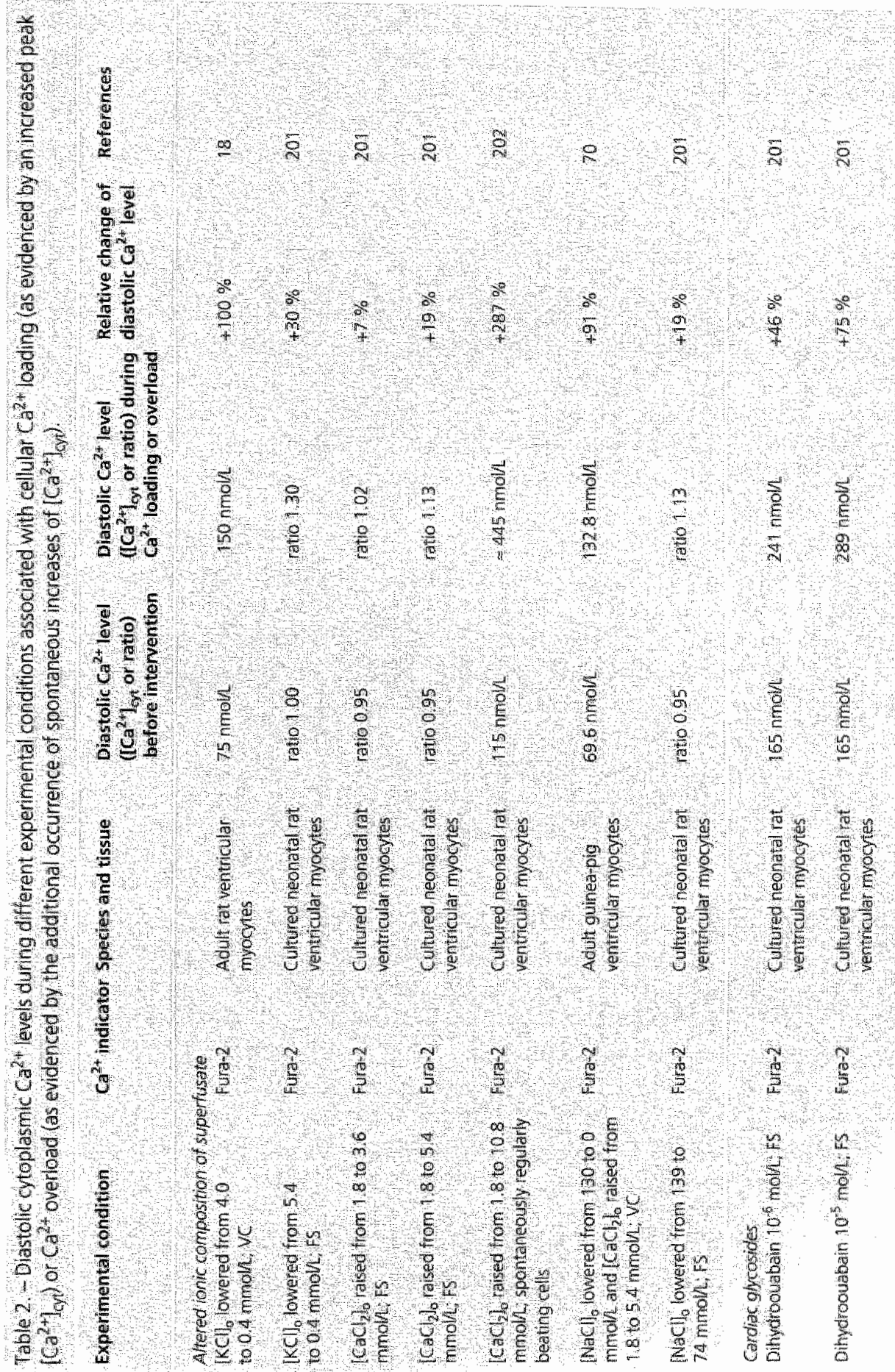




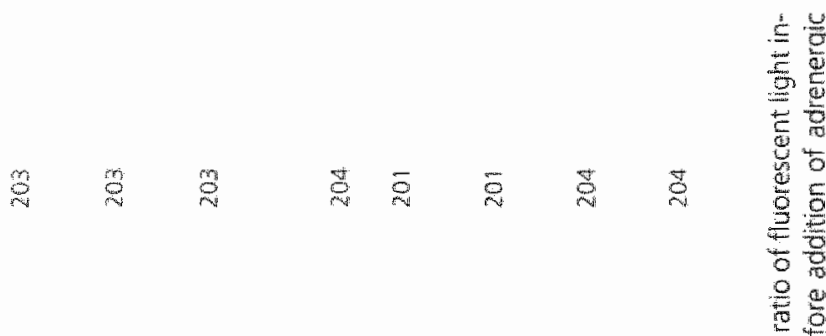

管

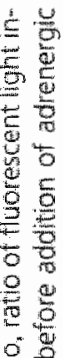

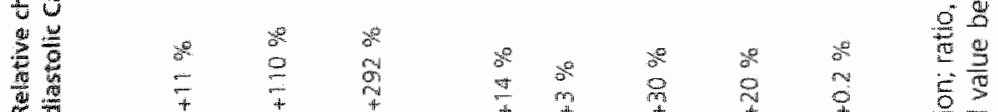

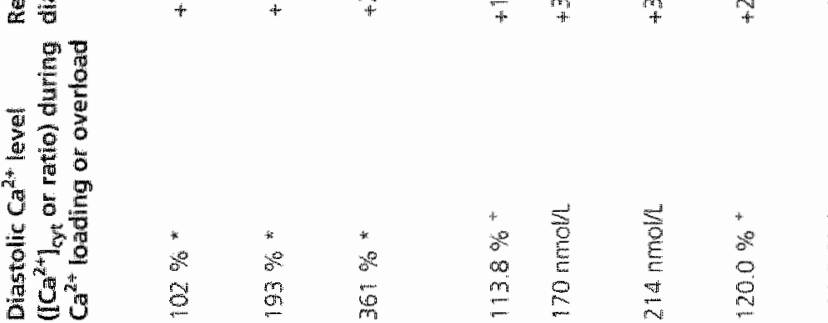

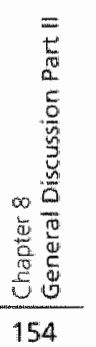

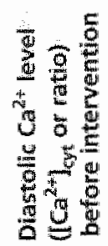

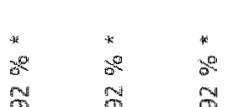

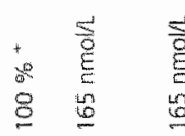

焉

$\frac{5}{10}$

E

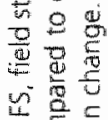

호의

응

a

y

$\stackrel{0}{0}$

$\frac{D}{g}$

을

3 두

y a

$\frac{\pi}{4}=$

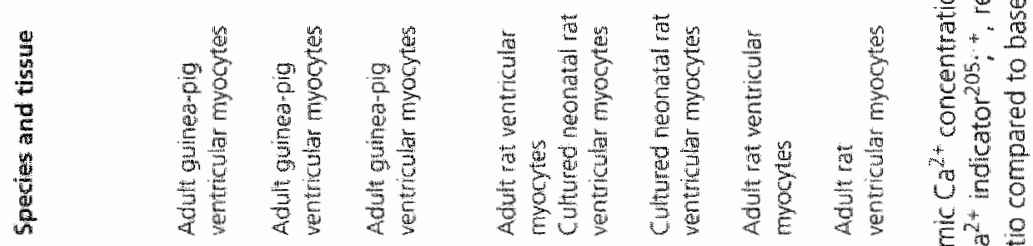

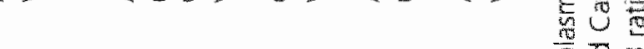

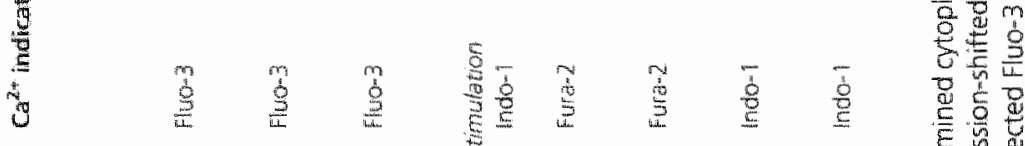

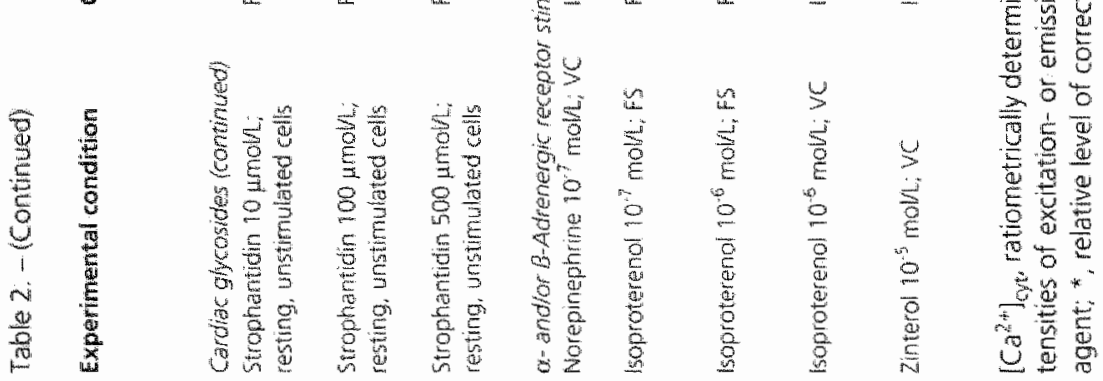


few SR Ca ${ }^{2+}$ release channels, occurred only ar low rates under normal-loading conditions (approximately 0.0001 per s). However, when $\mathrm{Ca}^{2+}$ overload was produced by high extracellular $\left[\mathrm{Ca}^{2+}\right](10 \mathrm{mmol} / \mathrm{L})$, the rates increased around $4-$ fold, whereas the sparks' amplitude and size increased 4.1-and 1.7-fold, respectively. Fusion of the local $\mathrm{Ca}^{2+}$ transients could set off global $\mathrm{Ca}^{2+}$ waves that propagated through the cell by recruiting more $\mathrm{Ca}^{2 *}$ sparks along the wave front ${ }^{80,84}$

The exact mechanisms of spontaneous $\mathrm{Ca}^{2+}$ release are srill under study. Several groups have now established that for an increase in the $\mathrm{Ca}^{2+}$ conten of the $\mathrm{SR}$, a larger fraction of the $\mathrm{Ca}^{2+}$ pool will be released, ${ }^{48-50}$ suggestive of a regulation of release by luminal $\mathrm{Ca}^{2+}$. Spontaneous release could result from an increased sensitivity of the release channel to a small increase in diastolic $\left[\mathrm{Ca}^{2+}\right]$, eirher from a small $\mathrm{Ca}^{2+}$ influx across the sarcolemma, or due to a passive leak from the $S R$, perhaps relared to saruration of the buffering capacity of the SR. Alternatively, spontancous release could be unrelated to the normal calcium-induced calcium release mechanism, as suggested by Fabiato, ${ }^{85}$ and perhaps be due to altered properties of the ryanodine receptor.

Independent of the underlying mechanism, $\mathrm{Ca}^{2+}$ imaging in cardiac myocytes has revealed two patterns of spontaneous $\mathrm{Ca}^{2+}$ release: (1) focal $\mathrm{Ca}^{2+}$ release with no or limited propagation along the SR; and (2) $\mathrm{Ca}^{2}$ trelease propagating as a wave through the entire cell (eg, see References $80,84,86$ to 90). Numerous groups have investigated the interplay between these types of $\mathrm{Ca}^{2+}$ release and arthyrhmogenic $\mathrm{I}_{\mathrm{T}}$ and $\mathrm{DADs}$ (eg, see References 18, 74-76,79,91-95). For focal release and Ca ${ }^{2+}$ waves, however, quantitative interpretation of such data remains difficult since membrane currents always represent a spatial average.

\subsection{Ionic Mechanisms of DADs}

It is generally accepted that DADs are caused by $I_{\mathrm{Tl}}$ evoked by spontaneous $\mathrm{Ca}^{2+}$ release in the serting of cellular $\mathrm{Ca}^{2+}$ overload. This sudden increase in $\left[\mathrm{Ca}^{2+}\right]_{\text {cyr }}$ modulaces $\mathrm{Ca}^{2+}$-sensitive membrane currents via channel- or transporter-specific mechanisms. Three different ionic currents, alone or in combination, have been inferred in the generation of $\mathrm{I}_{\mathrm{T}}$ since its first description in $1976 .{ }^{96}$ These are $\mathrm{I}_{\mathrm{Na}} \mathrm{Ca}$. ${ }^{74,93,95.97-102}$ non-selecive cation current $\left(\mathrm{I}_{\mathrm{NS}}\right),{ }^{97,103-106}$ and $\mathrm{Ca}^{2+}$-activated $\mathrm{Cl}^{-}$current $\left(\mathrm{I}_{\mathrm{CI}(\mathrm{Ca})}\right)^{74,93,101,102}$

Kass et al ${ }^{97}$ were among the first ro speculate on the ionic basis of $I T$ and proposed that this current, induced by strophanthidin in calf cardiac Purkinje fibers, might be carried by a leak channel or that ir reflected ' $C a^{2}+$ extrusion by an electrogentic $C a-N a$ exchange". The contribution of $\mathrm{I}_{\mathbb{N a}-C_{\mathrm{A}}}$ wo $\mathrm{I}_{\mathrm{T}}$ has been estimated by comparing the current-voltage relationships of the rwo and by determining the characteristics of $I_{\mathrm{Na}-\mathrm{Ca}}$ and $\mathrm{I}_{\mathrm{TI}}$ during spontaneous $\mathrm{Ca}^{2}$ telease from the SR. Wirt respect to the latter, Beuckelmann and $W_{i e r}^{54}$ showed that the reversal potential of the $\mathrm{Ni} \mathrm{I}^{2+}$-sensitive $\mathrm{I}_{\mathrm{Na}-\mathrm{Ca}}$ in gunea-pig ventricular myocytes increased linearly with the $\log \left[\mathrm{Ca}^{2+}\right]_{\text {eyt }}$ (see also sections 2.1. and 2.2.). The high $\left[\mathrm{Ca}^{2 *}\right]$ y during spontaneous $\mathrm{Ca}^{2+}$ release would thus shift the reversal potential of $\mathrm{I}_{\mathrm{Na}-\mathrm{Ca}}$ towards very positive membrane potentials causing 
the current to be inward at voltages relevant for the action potential. Lipp and Pot ${ }^{99}$ examined the direction of the $I_{T 1}$ during voltage clamps between -90 and $+75 \mathrm{mV}$, and found it to remain inward over the whole range. They concluded that $\mathrm{I}_{\mathrm{Na}-\mathrm{Ca}}$ was the major charge-carrying mechanism for $\mathrm{I}_{\mathrm{T} 1}$. This conclusion was also drawn by Benndorf et al ${ }^{100}$ afrer similar experiments on $\mathrm{Ca}^{2+}$-overloaded guinea-pig ventricular myocytes. Other groups investigated $\mathrm{I}_{\mathrm{T}}$ in the assumed absence of $\mathrm{I}_{\mathrm{Na}-\mathrm{Ca}}$. Sipido et al ${ }^{92}$ could nor find evidence for a significant contribution of $\mathrm{I}_{\mathrm{NS}}$ to the current oscillations during spontaneous $\mathrm{SR} \mathrm{Ca}^{2+}$ release in guinea-pig ventricular cells in such condition. In sheep cardiac Purkinje fibers, when the extracellular $\left[\mathrm{Na}^{+}\right]$was completely replaced with isotonic $\mathrm{CaCl}_{2}$, the remaining $\mathrm{I}_{\mathrm{TI}}$ had a reversal porential of $-37 \mathrm{mV}$ suggesting a channel mechanism as the charge carrier. ${ }^{103}$ Giles and Shimoni ${ }^{105}$ induced $I_{T I}$ in single rabbit ventricular myocytes by the application of low- $\left[\mathrm{K}^{+}\right]$superfusate or strophanthidin, and mentioned the possibility of $\mathrm{I}_{\mathrm{NS}}$ as an alternarive explanation for $\mathrm{I}_{\mathrm{TI}}$. Verkerk et al ${ }^{101}$ wondered wherher the controversial findings on $I_{N S}$ could be attributable to species-or cell-type-related differences and compared the $\mathrm{I}_{\mathrm{TI}}$ characteristics of Purkinje and working myocytes in sheep hearts. In neither cell type an appreciable magnitude of $I_{\mathrm{NS}}$ could be measured. ${ }^{101}$ Also in rabbit ${ }^{93}$ and canine ventricular myocytes ${ }^{102}$ the absence of $\mathbb{I}_{\mathrm{NS}}$ in $\mathbb{I}_{\mathrm{TI}}$ was reported. In summary, all experiments mentioned so far support the role of the $\mathrm{Na}^{+}-\mathrm{Ca}^{2+}$ exchange in $\mathrm{I}_{\mathrm{Tl}}$, but the exact contribution of $\mathrm{I}_{\mathrm{NS}}$ remains controversial.

A third relevant current is $\mathrm{I}_{\mathrm{CI}(\mathrm{Ca})}$, which may have been present as $\mathrm{I}_{\mathrm{NS}}$ in some of the previously mentioned studies. $\mathrm{I}_{\mathrm{C}(\mathrm{Ca})}$ requires $\mathrm{SR} \mathrm{Ca}{ }^{2+}$ release to become activated, but irs time course does not follow the time course of the $\left[\mathrm{Ca}^{2+}\right]_{\text {cyt }}$ as measured with indo-1.107 Zygmunt argued that the rapid decline of this anion current could not be explained by $\mathrm{Ca}^{2+}$-dependent inactivation. ${ }^{108}$ Rather, the transient nature could follow $\left[\mathrm{Ca}^{2+}\right]$ changes in the subsarcolemmal compartment. ${ }^{69,107} \mathbb{I}_{\mathrm{Cl}(\mathrm{Ca})}$ makes up a substantial portion of $\mathrm{I}_{\mathrm{TI}}$ in the dog: quantitative estimates in left ventricular (LV) midnyocardial (M-) cells indicate that it accounts for up to $40 \%$ of $\mathrm{I}_{\mathrm{T}}$ during $\mathrm{Ca}^{2+}$ overload, whereas $\mathrm{I}_{\mathrm{Na} \text {-Ca }}$ represents the additional $60 \%,{ }^{102}$ In ferret, ${ }^{74}$ rabbit, ${ }^{93,106,109}$ and sheep ${ }^{101} \mathrm{I}_{\mathrm{Cl}(\mathrm{Ca})}$ has also been reported. However, in guinea-pig ${ }^{92}$ and human myocytes ${ }^{95}$ the current was nor observed.

Depending on the induction protocol, DADs can appear at short or long coupling intervals after the action potential. Typical examples of short-coupled DADs are those induced by cardiac glycosides or $\left[\mathrm{K}^{*}\right]_{0}$-depleted superfusates due to inhibition of the $\mathrm{Na}^{+}-\mathrm{K}^{*}$ pump. They occur immediately after rhe action potential (often before repolarization is complete) and can exhibit an oscillatory partern with decreasing amplitudes during diastole. These membrane oscillarions reflect repetitive spontaneous $\mathrm{Ca}^{2+}$ releases from the $S R$ under circumstances when both $\left[\mathrm{Na}^{2}\right]_{c y \text { r }}$ and $\left[\mathrm{Ca}^{2+}\right]_{\mathrm{cyt}}$ are high with opposite effects on inward $\mathrm{I}_{\mathrm{Na} \text { - } \mathrm{C} \text { ( }}$ (Table 2). In the example of arrhythmogenic $\beta$-adrenergic receptor stimulation the situation is different. Although $\mathrm{Ca}^{2+}$ influxx during the action potential is greatly enhanced, the diastolic $\left[\mathrm{Ca}^{2+}\right]_{\mathrm{cyt}}$ is maintained at relatively low levels due to an increased $\mathrm{Ca}^{2+}$ uptake by the SR ATPase (Table 2). In this 
case, the $\left[\mathrm{Na}^{*}\right]_{\mathrm{Cy}}$ may be decreased. The DADs have a longer coupling interval reflecting the time needed by the SR to become overloaded.

In various pathophysiological conditions, alterations of $\mathrm{Ca}^{2+}$ homeostasis can predispose to an increased occurrence of DADs. In the dog with chronic complete atrioventricular block (AVB; see Chapter 5), the upregulation of $\mathrm{Na}^{+}-\mathrm{Ca}^{2+}$ exchange and increased $\mathrm{Ca}^{2 *}$ release from the $S R$ are associated with an enhanced propensiry to $\mathrm{Ca}^{2 *}$ overload and spontaneous $S \mathrm{RCa}^{2}$ release. In-vivo experiments in chronic $\mathrm{AVB}$, but not in acute $A V B$, demonstrate the induction of $D A D$ s and triggered ectopic bears following short pacing trains. This arthythmic activity is related to a critical increase of the $L V$ pressure rise, and can be enhanced by ouabain and suppressed by ryanodine and lidocaine.

In conclusion, the ionic mechanisms of DAD can vary according to cell rype, species and experimental condition or functional state, but cellular Ca ${ }^{2}+$ overload is the common substrare causing spontaneous $\mathrm{Ca}^{2}$ release from the $\$ \mathrm{R}$ during diastole. This primary event activates $\mathrm{Ca}^{2+}$ extrusion via the $\mathrm{Na}^{+}-\mathrm{Ca}^{2+}$ exchanger at least to some degree. Although beneficial by irself, inward $\mathrm{Na}_{\mathrm{Na}}$ can trigger premature impulses and arrhythmias.

\subsection{Ionic mechanisms of EADs}

The appearance and mechanisms of EADs are diverse as they occut' in various conditions. EADs present as transient retardations or reversals of the repolarization during phases 2 and 3 of the action potential, ofren in the setring of action porential prolongation. Although the term 'early afterdepolarization' per se would not comprise a mere retardation of the repolarization, this is actually the priming event of the EAD formation, and must be incorporated into any theoretical mechanistic framework on EADs. At the ionic level, a decrease in outward current(s), an increase in inward current(s), or combinations of the two can unbalance the repolarization such that EADs arise. However, due to the very complex dynamics and overlapping of transsarcolemmal ionic fluxes during the action potential, the impact of individual current alterations on repolarization characteristics cannot easily be estimated. In the case of the congenital long-QT syndromes, one can pinpoint single curent defects as the primary event. " 10 However, in most conditions a more complex situation exists. Experimental electrophysiological studies on EADs have often relied on pharmacological agents and slow pacing modes to cause the initial action-potential prolongation via reductions of

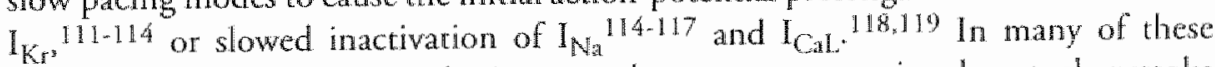
previous works, the major emphasis was on the currents generating the actual upstroke of the EAD and convincing arguments were found for the role of reactivating $I_{\mathbb{N a}}$ and

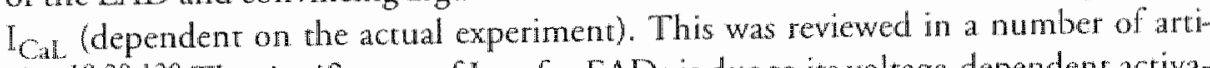
cles. $19,20,120$ The significance of CaL $_{\text {for }}$ EADs is due to its voltage-dependent activation falling in the range of membrane potentials $(-35$ to $0 \mathrm{mV})$ where repolarization is delayed and EADs arise. Based on experiments with Bay K 8644, January and coworkers $118,119,121,122$ concluded thar the induction of EADs requires: "(i) a condi- 
thoning phase controlled by the sum of membrane currents present near the action potential plateau and characterized by lengthening and flattening of the platea within a voltage rathe where, (ii) recovery from inactivation and reactivation of $\mathrm{L}-\mathrm{type} \mathrm{Ca}^{2+}$ current to cary the depolarizing charge can occur'. 19 In the presence of pharmacological agents (eg, Bay $\mathrm{K} 8644$ or $\mathrm{ATX}-\mathrm{II}$ ) or channel modifications that slow inactivation of $\mathrm{I}_{\mathrm{CaL}}$ or $\mathrm{I}_{\mathrm{Na}}$, these currents are obviously of prime importance. However, in the absence of such conditions, inward $\mathrm{I}_{\mathrm{Na}-\mathrm{Ca}}$ is likely to play a significant role in the initial delay in repolarization designated 'conditioning phase $e^{119}$ or 'conditional phase'. 77,78 The conditional phase appears as the transient delay in repolarization that can, but does not have to, be followed by an EAD upstroke or triggered action potential. Based on our own work and accumulating evidence in the literature, a primary role for $\mathrm{Na}^{+}-\mathrm{Ca}^{2+}$ exchange is not only restricted to the condirional phase of EADs related to $\mathrm{Ca}^{2+}$ overload and spontaneous $\mathrm{Ca}^{2+}$ release from the $S R$, but applies also to $E A D$ s that occur in the serting of less extreme $\mathrm{Ca}^{2+}$ loading. This is explained in the next section.

\subsection{Evidence for $\left[\mathrm{Ca}^{2 *}\right]_{\mathrm{iyt}}$-Dependent Mechanisms of EADs}

There are three major observations supporting the contribution of $\left[\mathrm{Ca}^{2+}\right]_{c y t}$-dependent mechanisms to EADs. First, dependent on the mode of induction, DADs and EADs can appear jointly in consecutive action potentials or even in relation to the same action potential (Table 1). A second argument for $\left[\mathrm{Ca}^{2+}\right]_{c y t}$-dependent mechanisms derives from the observation that several types of EADs are induced or amplified by fast pacing rates or rate acceleration during bradycardia, just like DADs. Also, the influence of increased adrenergic stimulation can induce EADs via sudden changes of cellular $\mathrm{Ca}^{2+}$ homeostasis. Clinically, increased adrenergic tone and sudden rate accelerations are often involved in the initiation of torsades de pointes. A third argument is that experimental interventions known to attenuate $\mathrm{Na}^{+}-\mathrm{Ca}^{2}+$ exchange can also inhibit EADs under certain condirions. These three arguments can be found in a number of examples on $\left[\mathrm{Ca}^{2}{ }^{2}\right]_{\text {Crt }}$-dependent $\mathrm{EAD}$ described below and illustrated in the Figures 1 to 3 .

First, we analyze the EADs induced by isoproterenol. During intense $\beta$-adrenergic receptor stimulation, arrhythmogenic responses in ventricular myocytes are accompanied by spontaneous $\mathrm{Ca}^{2+}$ release from the $\mathrm{SR}$ during borth diastole and systole (Figure 1A), often in conjuncrion with the same action potential. $75,76,123$ The systolic spontaneous releases appear as early $\mathrm{Ca}^{2+}$ aftertransients following the (twitch-related) $\mathrm{I}_{\mathrm{CaL}}$-induced $\mathrm{Ca}^{2+}$ release and they have mechanical corollaries: early aftercontractions. 7,124 . We have presented compelling evidence that the conditional phase of EADs induced by isoproterenol is generated by inward $\mathrm{I}_{\mathrm{Na}-\mathrm{Ca}}$ activared by the early $\mathrm{Ca}^{2+}$ aftertuansients. Thus, these EADs depend on a SR-dependent mechanism for their rise, ${ }^{77}$ as also suggested earlier. ${ }^{125}$ It is noteworthy to mention that the simulation. study of Zengand Rudy ${ }^{78}$ on isoproterenol-induced EADs did not incorporate a secondary systolic rise of $\left[\mathrm{Ca}^{2+}\right]_{\mathrm{Cyt}}$ and for that reason must have underestimated the contribution of inward $\mathrm{I}_{\mathrm{Na}-\mathrm{Ca}}$. We observed that DADs and EADs induced by isoproterenol 
Figure 1 (page 160$).-\left[\mathrm{Ca}^{2 *}\right]_{\mathrm{cyt}^{2}}$ dependent mechanisms of EADs in vitro.

A. Spontaneous $C a^{2+}$ release from the $S R$ underlying both $E A D$ and $D A D$ activity in a canine wentricular myocyte treated with isoproterenol. EADs and DADs appear in relation to the same action potentials during pacing at a cycle length of $1000 \mathrm{~ms}$. Arrows indicate the termination of pacing. These are whole-cell woltage recordings with the fluorescent $\mathrm{Ca}^{2+}$ indicator indo-1. The calibration bars represent 1 fluorescence ratio unit for $\left[\mathrm{Ca}^{2+}\right]_{\mathrm{Cyt}}$ activity, $50 \mathrm{~m}$ / for whole-cell vollage traces, and 2 $s$ for the time scale. Reproduced from Reference 75. B, Late EADs arising from membrane potentials more negative than $-3.5 \mathrm{mv}$ during administration of epinephrine in a cloflium-pretreated canine Purkinje fiber. In the upper panel, the action potential at baseline is depicted. In the middle panel. action-potential prolongation by clofilium is shown. No EADs or DADS are present. In the lower panel, upon the additional administration of epinephrine at low concentration, pronounced formation of EADs is present at cycle lengths greater than $1000 \mathrm{~ms}$. In these recordings the cycle length is $2000 \mathrm{~ms}$. Reproduced from Reference 140. C. Acceleration-induced EADs. in the left panel, action potentials are recorded from canine $L V M$-tisswe, treated with the $\mathrm{K}_{\mathrm{K}, \mathrm{f}}$ blocker $E-4031$, during a sudden increase of the rate from a cycle length of 2000 to $1000 \mathrm{~ms}$. The transient appearance of EADs is accompanied by action-potential prolonglation. In the right pane, the action potentials are superimposed, showing the last beat at the cycle length of $2000 \mathrm{~ms}$, and some of the first nine action potentials at $1000 \mathrm{~ms}$. Reproduced from Reterence 143.

Figure 2 (page 161). - In-vivo appearance of EADs and DADs in anesthetized dogs with chronic AVB.

In all three panels, the ECG lead II and a LV endocardial MAP recording are shown. A, DAD (closed asterisk), EADs (open asterisks), and triggered activity in conseculive MAPs after a pacing train of 8 stimuli with an interstimulus interval of 300 ms under baseline conditions. Paced beats are indicated by 5 . Just before pacing the idioventricular cycle length is $1360 \mathrm{~ms}$, increasing $101990 \mathrm{~ms}$ thereafter. The first beat postpacing shows EAD formation and a triggered action potential on the MAP signal. $B$. Induction of phase-2 and phase- 3 (tate) EADs in consecutive beats during administration of the class II antiarrhythmic agent ibutillide. The occurrence of EADs follows a MAP prolongation from 375 ms at baseline (PRE-DRUG) to $555 \mathrm{~ms}$ during ibutilide and is related to the triggering of multiple ectopic beats (as shown on the right). C. Acceleration-induced accentuation of EADs during a sudden increase in the pacing rate from a cycle length of 1500 to 1000 ms. The emergence of EAD upstrokes is a transient phenomenon upon the rate change, which fades away within 1 minute thereafter.

were completely suppressed by the cation $\mathrm{Ni}^{2+}$, whercas their accompanying delayed and early aftercontractions remained present. ${ }^{77}$ This strongly suggested the contribution of inward $\mathrm{l}_{\mathrm{Na} \text { - } \mathrm{Ca}}$ to the generation of both types of afterdepolarizations. Priori and Corr ${ }^{125}$ noted similar suppressive actions on EADs by perfusion with low- [ $\left.\mathrm{Na}^{*}\right]_{0}$ solution or treatment with the (aspecific) $\mathrm{Na}^{-4}-\mathrm{Ca}^{2+}$-exchange blocker benzamil. Using fuorescent $\mathrm{Ca}{ }^{2}+$ imaging, two groups $\mathrm{s}^{79,91,126}$ observed that the spatial fearures of $\mathrm{Ca}^{2+}$ transients associated with afterdepolarizations were different for DADs (heterogencous pattern indicating focal, spontaneous $\mathrm{SR} \mathrm{Ca}^{2+}$ release) wersus $\mathbb{E A D}$ s (homogeneous: pattern suggesting $\mathrm{I}_{\mathrm{CaL}}$-induced $\mathrm{Ca}^{2}$ release). This is in line with the concept of different ionic mechanisms underlying DADs and EADs. However, the same groups also emphasized that EADs can consisr of different types with different eriology: Miura et al ${ }^{126}$ showed that late EADs induced during perfusion with $[\mathrm{K}+]$, free solution were associated with the heterogeneous [Ca ${ }^{2} I_{\text {cr }}$ pattern akin to DADs, but much different from the homogeneous pattern accompanying EADs earlier in repolarization; and De 


\section{IN VITRO}

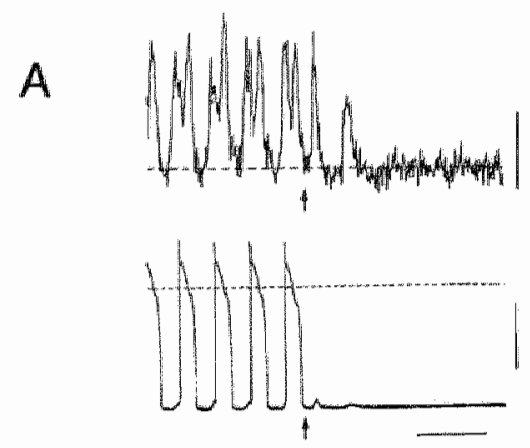

B

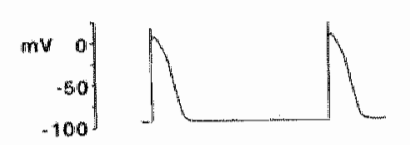

PAE-DAUT
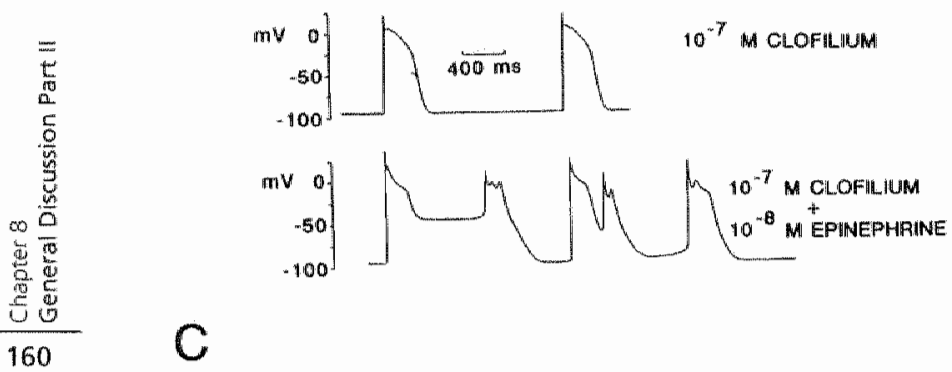

C
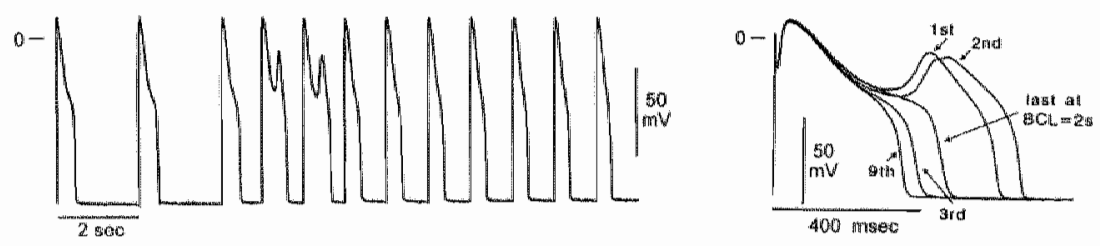


\section{IN VIVO}

A

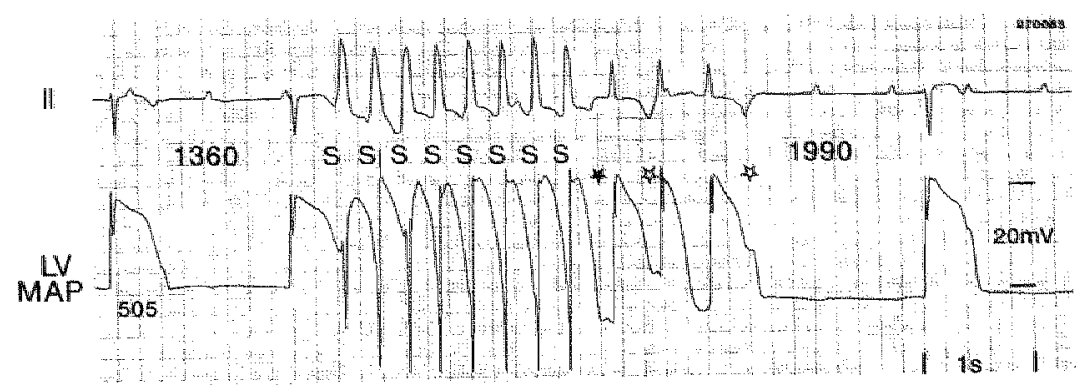

B

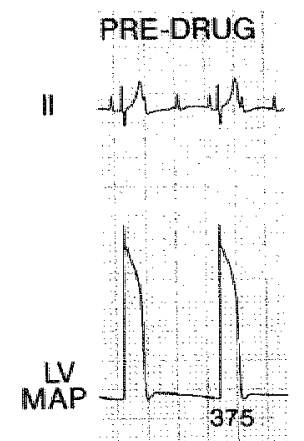

\section{$0.1 \mathrm{mg} / \mathrm{kg} / 5 \mathrm{~min}$ IBUTTLIDE}

C
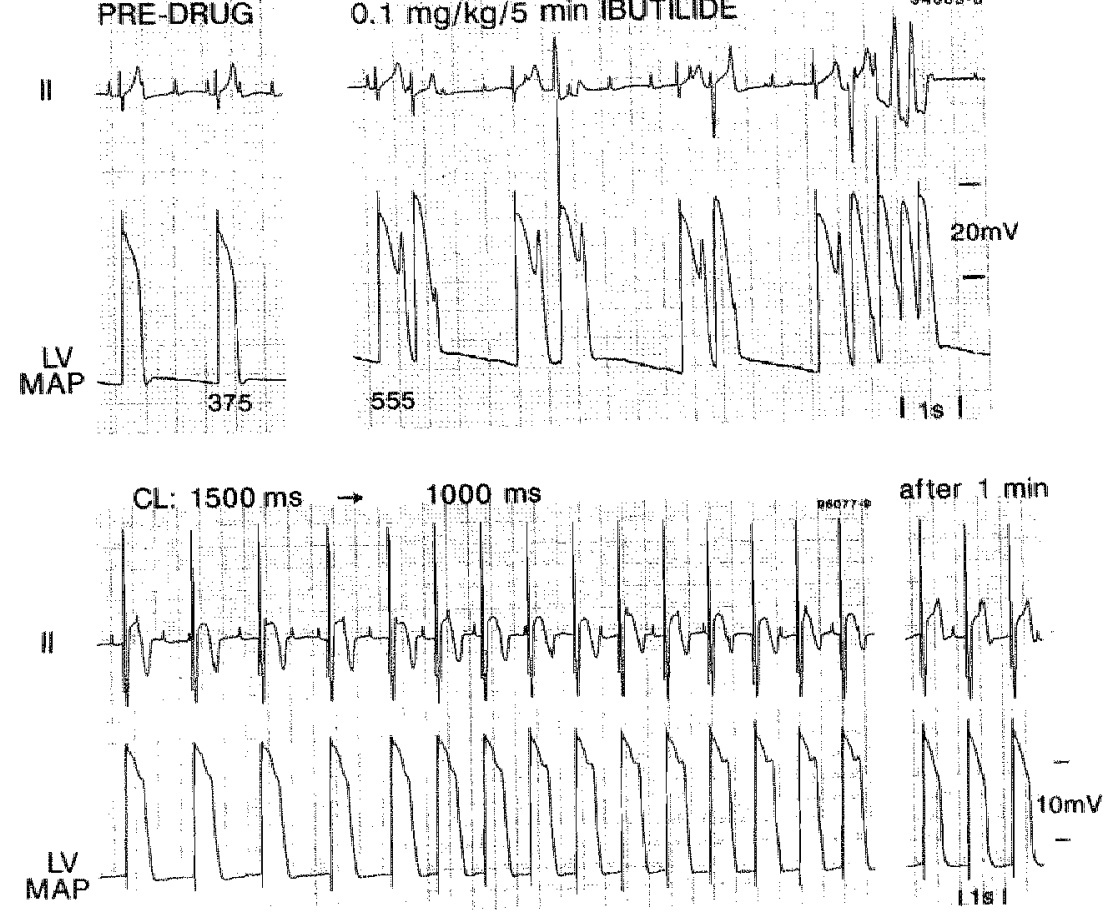
Ferrari and coworkers mentioned preliminary data on isoproterenol-induced EADs with similar characteristics. ${ }^{79}$

Next, we analyze the so-called 'late EADs' initiating at membrane potentials more negative than the range at which $\mathrm{I}_{\mathrm{CaL}}$ can be activated. ${ }^{127-129}$ Alhough conceptually $\mathrm{I}_{\mathrm{Na}}, \mathrm{I}_{\mathrm{Ca}}$ or $\mathbb{I}_{\mathrm{NS}}$ could underlie these late EADs, there is increasing evidence that inward $I_{\mathrm{Na}_{\mathrm{C}} \mathrm{C}}$ has the primary role. Ir has been shown that interventions causing cellular $\mathrm{Ca}^{2+}$ loading augment these EADs. ${ }^{128-130}$ Such an effect is produced by the application of $\mathrm{Cs}^{+}$, which inhibits $\mathrm{K}^{+}$currents, and epinephrine. In Purkinje fibers or ventricular myocytes, relatively low concentrations of these agents do not generate EADs when applied scparately. The explanation for late-EAD generation under these conditions is in increasing the $\mathrm{APD}$ by $\mathrm{Cs}^{+}$and increasing $\mathrm{Ca}^{2+}$ sequestration and release from the $\mathrm{SR}$ by epinephrine at the same time. Inward $\mathrm{I}_{\mathrm{Na}-\mathrm{Ca}}$ is the main current responsible for the iniciation of the afterdepolarizations as demonstrated by the inhibitory effects of high extracellular $\left[\mathrm{Ca}^{2 *}\right]$ and of ouabain (the latter being due to the effect of increased $\left[\mathrm{Na}^{+}\right]_{\text {cys }}$ on the exchanger).

Finally, we focus on the conditional phase of EADs induced during congenital or acquired inhibition of $\mathrm{I}_{\mathrm{Kr}_{\mathrm{r}}}$ and/or $\mathrm{I}_{\mathrm{KS}_{s}}$. We recall that the typical example of the congenital form of inhibition is the long-QT syndrome, whereas acquired forms are seen, for example, during treatment with class IA or class III antiarrhythmic agents. In the clinic, these syndromes are associated with an increased regional dispersion of ventricular repolarization, generation of EADs, premature ventricular beats and a serious risk of torsades de pointes (eg, see References 22, 131-135 and 132, 134, 136-139). Most often, torsades de pointes is precipitated by sudden accelerations or short-long-short sequences of the heart rate during bradycardia, ${ }^{21,23-25}$ whether or not under the influence of an increased sympathetic tone. ${ }^{22}$ In an attempr to comprehend the behavior and proarrhythmic potential of abnormal ventricular repolarization and EADs under these circumstances, and to appreciate the significance of inward $\mathrm{I}_{\mathrm{Na}-\mathrm{Ca}}$ herein, we must return to the cellular level. The influences of increased sympathetic tone, rate accelerations and short-longshort sequences are consecutively addressed.

Patterson et al ${ }^{140}$ evaluated the electrophysiological actions of the class 1 II antiarthythmics $d$, t-sotalol and clofilium in canine cardiac Purkinje fibers and found that acrion-potential prolongation by these agents is necessary but not sufficient to produce afterdepolarizations and triggered activity. The elicitation of slow-rate-dependent EADs was only observed after the additional administration of epinephrine ar low concentrations (10-100 nmol/L; Figure 1 B). In the case of clofilium, fast-ratedependent DADs were also seen. Epinephrine alone did not produce afterdepolarizations. The authors tested wherher inward $\mathrm{I}_{\mathrm{Na}-\mathrm{C}_{\mathrm{a}}}$ could contribute to the generation of EADs and found good arguments that this is indeed so: a temporary increase of the extracellular $\left[\mathrm{Ca}^{2+}\right]$ to $5 \mathrm{mmol} / \mathrm{L}$, which atrenuates inward $\mathrm{I}_{\mathrm{Na}^{2}-\mathrm{Ca}^{3}}{ }^{55}$ suppressed $\mathrm{EAD}$ formation. ${ }^{140}$ The same group more directly evaluated the role of $\mathrm{Na}^{+}-\mathrm{Ca}^{2+}$ exchange in class III EAD. 141. During arrhythmogenic actions of clofilium and $d, /$ sotalol in canine Purkinje fibers and subepicardial ventricular myocytes, inhibition and subse- 


\section{d-SOTALOL and PACING INDUCED EADS}

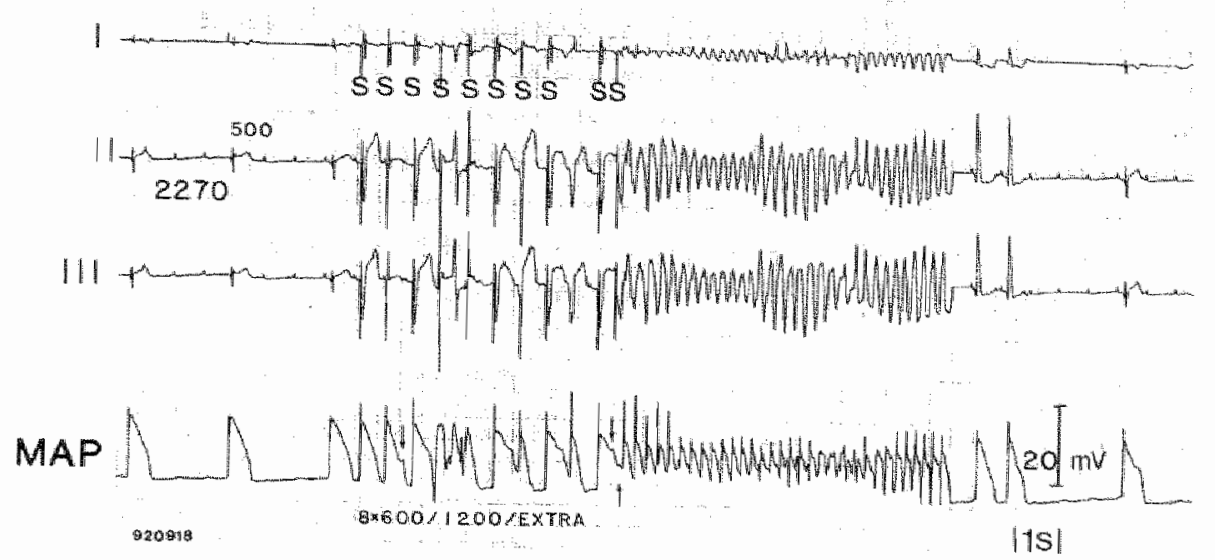

Figure 3:- Pacing-dependent torsades de pointes in the presence of d-sotalol ( $2 \mathrm{mg} / \mathrm{kg} / 5 \mathrm{~min}$ ) in an anesthetized dog with chronic AVB.

Shown are the ECG leads I, II and 1 , and a LV endocardial MAP recording. Just before pacing the idioventricular cycle length is $2270 \mathrm{~ms}$ and the QT interva! measures $500 \mathrm{~ms}$. The pacing protocol consists of 8 stimuli with $600 \mathrm{~ms}$ intervals, 1 stimuius at $1200 \mathrm{~ms}$ and a short-coupled extra beat ( $8 \times 600 / 1200 / E X T R A$; indicated by S). Pacing-induced phase-2 and phase-3 EADs, and related triggered ectopic beats precipitate torsades de pointes. In this case, the arrhythmia is self-terminating. Reproduced from Reference 190.

quent transient stimulation of inward $T_{\text {Na-Ca }}$ was obtained by substituting LiCl for $\mathrm{NaCl}$, followed by the return to normal extracellular [Na"]. Whereas EADs had been absent at baseline (class III agents only), this forth-and-back change of solutions potenriaced EAD formarion in a significant number of prepararions upon reintroduction of the normat $\left[\mathrm{Na}^{*}\right]$ with $\mathrm{EAD}$ take- off potentials being more negative than $-60 \mathrm{mV}$.

Proarhythmic effects of sudden rate acceleration have been related to the marked electrical characteristics of $\mathrm{M}$ cells in the midmyocandial layer of the ventricte. Sicouri et all/2 found that tate acceleration in the presence of $a^{\prime}$-sotalol led to a para doxical transient prolongation of the action potental and the occurrence of EADs in LV M-cells, bur not in endo-or epicardial cells. This behavior caused a temporary increase in the ransmural dispersion. Burashnikov and Antzelevitch ${ }^{143}$ investigated. the influence of rate accelerations on EADs induced by the $\mathrm{K}_{\mathrm{K}}$ blocker $\mathrm{E}-4031$ in tissue preparations from the canine LV wall and Purkinje fibers. Sudden accelerations from initially slow pacing rates aused transent EAD activity if none existed before or resulted in augmentation of preexisting EADs in the majority of M-rissues (Figure $1 \mathrm{C}$ ) and to a lesser degree in Purkinje fibers. A large transmural dispersion of repolarization resulted from the absence of such effecr in the endo-and epicardial layers. The invescigators applied ryanodine, flumarizine and low extracellular [ $\left.\mathrm{Na}^{\dagger}\right]$ to examine whether 
cellular $\mathrm{Ca}^{2+}$ loading and increased activity of the $\mathrm{Na}^{+}-\mathrm{Ca}^{2+}$ exchanger could be mechanistically involved. In support of such a role, all three interventions abolished the acceleration-induced EADs and the APD prolongation. 143 With regard to the cellular correlates of the in-wivo short-long-short sequence, the following: Burashnikov and Antzelevitch ${ }^{143}$ reported on the ability of single premarure ventricular beats to induce EADs and action-potential prolongation in M-cells. In line with an earlier study, ${ }_{2} 44$ this potentiating effect could be explained by increased $\mathrm{Ca}^{2+}$ transients accompanying the post-extrasystolic beats, which fitted well with a central role for the $\mathrm{Na}^{+}-\mathrm{Ca}^{2+}$ exchanger. Similar interpretations were made by Viswanathan and Rudy 145 for pauseinduced EADs in a simulation study on the iniriarion of torsades de pointes. Single pauses interrupting the steady-state pacing rates caused prolongation of the post-pause action potential due to a smaller $\mathrm{I}_{\mathrm{Ks}}$ (more deactivation) and an enhanced $\mathrm{I}_{\mathrm{Na} \cdot \mathrm{Ca}}$ (larger post-pause $\mathrm{Ca}^{2+}$ transient). This delayed repolarization set the stage for reactivation of $\mathbb{I}_{\text {Cai, }}$, to depolarize the membrane and generate the EAD upstroke. ${ }^{145}$

\section{Afterdepolarizations and Arrhythmogenesis in Myocardial Tissue and the Intact Animal Heart}

In this part of the review, we will focus on triggered acrivity in multicellular preparations and the intact animal heart. Because we will concentrate on the literature of the 1990s, the emphasis will be on direct evidence (microelectrodes or MAP catheters) concerning: (1) the occurrence and propagation of acquired EADs, and their consequences for arrhythmogenesis; (2) circumstances when EADs and DADs occur in the same experiment; (3) other circumstances when EADs appear to be linked to myocardial $\mathrm{Ca}^{2+}$ overload.

For an excellent recent review on the initiation and propagation of DADs in myocardial tissue we refer to ter Keurs et al. ${ }^{146}$

\subsection{EADs in Multicellular Preparations: Consequences for Arrhythmogenesis}

In Purkinje-muscle preparations, ${ }^{20,112,147}$ a number of studies demonstrated more pronounced changes of the APD in response to either bradycardia and/or repolarizarion-delaying drugs in Purkinje fibers than in ventricular muscle. Under these specific circumstances, a marked dispersion of repolarization is often observed and is an important determinant of arrhythmogenesis. Furthermore, there is an increased incidence of EADs in Purkinje fibers, which can give rise to propagated ectopic beats on the basis of: (1) direct triggering of EADs in Purkinje fibers (Figure 1B), most likely from phase-3 EADs; or (2) prolonged repolarization-dependent reexcitation. The capacity for reexcitation will depend on the difference in membrane potential between connected cells, but also on the excitability threshold of the alreadyrepolarized cells. Using canine LV-wedge preparations, Antzelevitch and coworkers $13,114,148,149$ found similar results with now the M-layer as the culprit cell 
type. The APD and EAD sensitivity of M-tissue for bradycardia and/or class III agents was significantly higher than of the surrounding endo-and epicardium. Similar observations were made for the occurrence of DADs during treatment with acetylstrophan rhidin and Bay K $8644 .{ }^{150}$ It has to be stated that, by no means, M-cells are rhe electrophysiological or pharmacological equivalent of Purkinje fibers, but their responses to bradycardia and certain drugs are quite alike. Microelectrode recordings in $\mathrm{LV}$-wedge preparations showed that transmural dispersion (developing through nonhomogeneous responses of the $\mathrm{M}$-layers to chromanol $293 \mathrm{~B}$ plw isoproterenol, ${ }^{149}$ $d$-sotalol, ${ }^{114}$ and ATX-III ${ }^{14}$ ) was the prerequisite for spontaneous or pacing-induced polymorphic arthythmias, mimicking torsades de pointes in the intact heart. The initiating beats of the spontaneous arrhythmias most frequently seemed to originate from the deep subendocardium (either in Purkinje or in M-cells).

\subsection{Simultaneous Appearance of DADs and EADs in the Intact Heart}

To the best of our knowledge, Patterson and coworkers ${ }^{15} 1$ were the first to describe that EADs and DADs could appear together in the same intact heart, albeit at different time points after the administration of intravenous Cs Cl. At first instance (2 to 5 min after the start of infusion). Cs ${ }^{*}$ caused acrion-potential prolongation with the appearance of EADs. Thereafter, the MAP duration started to decrease and at 8 to 10 min DADs appeared. Surprisingly, the coupling interval of the afterdepolarizations remained similar, indicating that depending on the APD an EAD (long APD) or a DAD (short APD) could occur. It was also the Oklahoma-City group that suggested that these EADs and DADs could be based on similar cellular mechanisms via alterations of myocardial $\mathrm{Ca}^{2+}$ homeostasis. ${ }^{151}$ Since 1990 , more publications have indicated the simultaneous appearance and common etiology of certain EADs and DADs in the intact heart. ${ }^{152,153}$ Using floating microelectrodes in cats, Xie and Xie ${ }^{154}$ again reported the occurrence of EADs and DADs at different time points after administration of CsCl. Most EADs arose during phase 3 of the transmembrane and monophasic action potential. These investigations provided evidence that the afterdepolarizations recorded in transmembrane action potentials could be visualized simultaneously by MAP recordings. In a study by Xu et al, ${ }^{153}$ it was shown in guinea pigs with the use of MAP recordings from the midmyocardium that digoxin induced DADs and phase-3 EADs, which were both suppressed by verapamil. Some types of EADs converted to DADs in the MAP after administration of the $\mathrm{K}^{+}$-channel opener pinacidil, which shortens the APD. These authors concluded that late phate 3-EADs generated under conditions of $C{ }^{2}+$ overload and DADs share similar properties'. 153

We have described that chronic AVB in the dog results in: (1) electrical remodeling (nonhomogeneous action-potential prolongation); (2) an enhanced contractile performance at the slow idioventricular heart rate; and (3) biventricular hypertrophy. 155 In some of these (anestherized) dogs, short pacing trains can induce both EADs and DADs, and relared ectopic beats under baseline condicions. A typical example is shown in Figure 2A. Ryanodine abolishes both these EADs and DADs (not 
shown), suggesting a common cellular mechanism for the two. In experiments with dass III antiarriythmic drugs at clinically relevant doses, the dogs show the appearance of EADs in MAP recordings. As illustrated in Figure 2B, these EADs can occur at the end of the plateau (phase 2) and during phase 3 of the repolarization, often in consecutive beats. More importantly, EADs and related ectopic beats can be induced by fastpacing modes leading to the induction of torsades de pointes (Figure 3 ). In correspondence with the in-vitro experiments by Burashnikov and Antzelevirch, ${ }^{143}$ we further find that sudden increases in pacing rate (eg, from a cycle length of 1500 to $1000 \mathrm{~ms}$ ) cause the emergence or accentuation of EADs, which are transient usually restricted to a period of seconds to 1 minute of the new rate (Figure 2C). These observations are not in concrast with the known APD adaptation to heart-rate increases during pacing or adrenergic acrivation, but rather uncover the delicate ballance of ventricular repolarization in this animal model, which needs time to adapr to a new steady state.

\subsection{EADs Occurring in Conditions Associated with Myocardial Ca ${ }^{2+}$ Overload}

In the dog with chronic AVB and acquired QT prolongation, a relation between myocardial $\mathrm{Ca}^{2+}$ overload and the generation of class III-dependent EADs and torsades de pointes has been suggested by the attenuating (EADs) and preventive (pacinginduced torsades de pointes) effects of the agents ryanodine and flunarizine. ${ }^{156} \mathrm{Simi-}$ larly, in a rabbit model of torsades de pointes (co-administration of methoxamine and almokalant), Carlsson et al ${ }^{157}$ showed the prevention of spontaneous torsades de pointes when the rabbits were pretreated with nisoldipine and flunarizine.

\section{Clinical Management of Arrhythmias in the Congenital and Acquired Long-QT Syndromes}

Early electrophysiological studies with recordings of endocardial electrograms and MAPs in patients with congenital and acquired long-QT syndromes implicated EADs as contributors to the T-U waves and generators of arthythmias. ${ }^{158.161}$ Later investigations with MAP recordings in humans indicated the appearance of EADs that were enhanced at longer cycle lengths and with adrenergic stimulation, and were diminished by $\beta$-adrenergic blockers, $\mathrm{Ca}^{2+}$-chamel blockers, and $\mathrm{K}^{+}$-channel openers. 22,131,133,135.137-139,162-167 Because EADs are related to the congenital and acquired long-QT syndromes, the recording of these deflections in patients is of help in the understanding of: (1) the pathogenesis; (2) the influence of EADs on the surface ECG; and (3) the effects of treatment. The inciting effects of emotion and exercise in the congenital long-QT syndrome were first recognized in the report of Jervell and Lange-Nielsen, 168 and have been reiterated in subsequent reports. ${ }^{169}$ Based on these observations, $\beta$-adrenergic blockade and left cardiac sympathectomy were empirically derived successful therapies. ${ }^{170-172}$ 
The acquired long-QT syndromes are characteristically seen during bradycardia with the surface ECG showing accentuated T-and U-wave abnormalives. Irregularities in the rhythm, such as premarure beats, as caused by ventricular ectopy or atrial fibrillation, can lead to the induction of torsades de pointes. Most drugs prolonging ventricular repolarization may cause corsades de pointes, but the arthythma is usually seen in a typical clinical context, which includes female preponderance, bradycardia, irregular rhythm, and hypopotassema and/or-magnesemia. The plasma level of the repolarization-prolonging drug is often not elevated, which suggests an idiosyncracic rather than a toxic effect. In some parients whth a (presumed) acquired long-QT syndrome, de-novo gene mutarions can be identified, which suggest the presence of a forme fruste of the congenital long-QT syndrome. ${ }^{173}$ Chinical studies on the electrophysiological characteristics of the acquired long-QT syndrome have been conducted mostly in forms induced by drugs, such as quinidine, ${ }^{137}$ procainamide, ${ }^{138}$ disopyramide, ${ }^{139}$ and the novel class III drug almokallant. ${ }^{174}$ The provocation of arrhythmias by long cycle lengths was emphasized in the acquired long QT syndromes 169 and it is operative also in the congenital long-QT syndromes. During these incerventions the behavior of the repolarization phase was often dynamic, with T-U waves showing abnormal configurations such as bifidicy, negativity, and $2: 1$ alternation. 174 The U-wave amplitude correlated strongly with the EAD amplitude, especially when the latter was recorded from a corresponding endocardial site (eg, ECG lead V 2 werwigh high right-ventriculai MAP). ${ }^{139}$

A sustained increase of the heart rate is an effective maneuver to suppress torsades de pointes acutely in the acquired long-QT syndromes, ${ }^{169}$ and isoproterenol administration and permanent pacemakers have been effective in the congenital long-QT syndromes. ${ }^{175} \mathrm{Ca}^{2+}$-channel blockers, including intravenous $\mathrm{Mg}^{2+}$, have been reported to be effective in suppressing arrhythmias. ${ }^{22,169}$ The correspondence of these clinical observations with observations of the responses of EADs in MAP recordings supports the hypothesis that EADs are a basic trigger mechanism for arrhythmogenesis in the long-QT syndromes.

The therapeuric benefir of $\beta$-adrenergic blockade, left carcliac symparhectomy, and $\mathrm{Ca}^{2+}$-channel blockers implicates $\mathrm{Ca}^{2+}$ entry and $\mathrm{Ca}{ }^{2+}$ loading in the riggering mechanism, but does not allow the identification of $\mathrm{I}_{\mathrm{CA}}$ or $\mathrm{I}_{\mathrm{Na}-\mathrm{Ca}}$ as the major current generator for EADs. Reducrion of $\mathrm{C}_{\mathrm{CaL}}$ by these therapeutic measures woutd also result in reduction of $\mathrm{Ca}^{2+}$ loading and $\mathrm{Na}^{4}-\mathrm{Ca}^{2+}$ exchange, and inhibit sponcaneous $\mathrm{SRC} \mathrm{Ca}^{2+}$ release. In all reporrs of EADs shown in MAPs in both congenital and acquired long-QT syndromes, these membrane responses occurred during phase 3 of the action potential. In some studies EAD s also appeared during phase 2, but when triggering was observed, it was observed to be cimed with phase $3.138,162,163$ While MAPs do not allow precise determination of the membrane potential ar which the EADs originate, the relative location on phase 3 strongly suggests an inirial potential that is often more negarive than $-35 \mathrm{mV}$, excluding a role for $I_{C a}$ in those cases. These observations implicate $\mathbb{I}_{\mathrm{Na}-\mathrm{Ca}}$ rather than $\mathbb{I}_{\mathrm{CaL}}$ as a common current generator for $\mathrm{EAD}$ s and triggering. 
In the congenital long-QT syndromes, strategies to abbreviate repolarization and the QT interval, thereby eliminating the basis for EAD generation, are appropriate. Recent discoveries of gene mutations and their functional consequences have presented new therapeutic options. In LQT3, various mutations of the SCN5A gene result in abnormal inactivation of the $\mathrm{Na}^{+}$channel and an excess of persistent $\mathrm{Na}^{+}$current that prolongs the plateau of repolarization. ${ }^{176}$ This abnormality is corrected by $\mathrm{Na}^{+}$-channel blocking agents of the IB class. Mexiletine has been shown to abbreviate the QT interval to normal or near normal in patients with this defect. ${ }^{177}$ However, the efficacy of class $1 \mathrm{~B}$ agents in the prevention of sudden death has not yet been demonstrated.

In LQT2, a defect in HERG causes diminished $\mathrm{I}_{\mathrm{Kr}}$ and delayed repolarization. ${ }^{178} \mathrm{I}_{\mathrm{K} .}$ is enhanced by increased extracellular $\mathrm{K}^{+},{ }^{179} \mathrm{It}$ has been shown that intravenous infusion of $\mathrm{K}^{+}$normalizes the QT in LQT2. ${ }^{180}$ The effects of long-term measures to elevate serum $\left[\mathrm{K}^{+}\right]$are sill poorly explored. Recently, $T$ an et al ${ }^{181}$ presented a female patient with $\mathrm{LQT}_{2}$, who had been treated with $\mathrm{K}^{+}$-sparing drugs and increased $\mathrm{K}^{+}$ intake to normalize her ECG and prevent torsades de pointes. The aurhors found that in the presence of a normal renal function, $\mathrm{K}^{+}$homeostasis limited a long-lasting rise of serum $\left[\mathrm{K}^{+}\right]{ }^{181}$ Enhancement of $\mathrm{I}_{\mathrm{Kr}}$ or reduction of persistent $\mathrm{I}_{\mathrm{N}_{2}}$ would tend to abbreviate repolarization not just in the defects specifically involving these currents, but the effect predictably might be less if the interwention were applied when other currents were responsible for the prolongation of repolarization. In a report comparing the effects of mexiletine in patients with LQT1, LQT2 and LQT3, the effect appeared to be greatest in LQT1, but there was a trend towards reduction in the QT interval in both LQT2 and LQT3. ${ }^{177}$

In the congenital long-QT syndromes, the commonly used therapies, $\beta$-adrenergic blockade, left cardiac sympathectomy, and pacing, developed empirically as measures for suppressing arrhythmias rather than normalizing repolarization. Because $I_{K s}$ is enhanced by $\beta$-adrenergic receptor stimulation, the deficiency of $I_{K_{s}}$ would impair action-potential shortening during adrenergic stimulation and exaggerate the disproportionarely long duration of repolarization at adrenergically-induced higher heart rates. There is an indication supported by preliminary observations that adrenergic rriggers may be most potent in mutations causing deficient $\mathrm{I}_{\mathrm{Ks}}$ LQT1, LQT5, and Jervell and Lange-Nielsen syndrome. ${ }^{182,183}$ LQT1 is the most common form of the syndrome. ${ }^{183} \beta$-Adrenergic blockade may be most effective in the varieties of the long-QT syndrome that have involved deficient $\underline{I}_{\mathrm{Ks}}$ and be less effective in the other varieties. Conversely, long cycle lengths may be more important as arrhythmia triggers in other varieties of long-QT syndromes, notably LQT3, and pacing may be more effecrive in arrhythmia suppression. Early observations indicate that LQT3 patients are more prone to sudden dearh at night or at rest than the other varieties of the syndrome.

The growing evidence for the roles of $\mathrm{Ca}^{2+}$ entry into the myocyte and $\mathrm{Ca}^{2+}$ loading in EAD generation has presented other possibilities for suppression of EADs and arrhythmias. $\mathrm{Ca}^{2+}$-channel blockers have not had widespread use in the congenital 
5yndromes, but there are reports of their efficacy ${ }^{22}$ Infusion of $\mathrm{Mg}^{2}$, a $\mathrm{Ca}^{2+}$-channel blocker, ${ }^{184}$ is accepted as first-line therapy for acute suppression of torsades de pointes. The commonly used cardioactive Cal ${ }^{2}$-channel blockers verapamil and diltazen both show use-dependent block of the L-type $\mathrm{Ca}^{2+}$ channel, 185 which might limir their effectiveness at slow heart rates.

The major drawback of the powerful anti-reentrant therapeutic action of class III agents is the induction of EADs and torsades de pointes in a small percentage of patients. A desirable strategy would be to retain, even augment, the QT prolongation, but eliminate EADs and arthythmogenesis. For this goal, interwentions directed ar $\mathrm{Ca}^{2}$ * traffic in the myocytes may be appropriate but greater understanding is required of EAD generation and ionic arrhythmia mechanisms including the putacive role of $\mathrm{M}$ cell layers and dispersion of repolarizacion in reentry mechanisms that maintain torsades de poinres. 186,187

The rrigger role of adrenergic stimulation in congenital long-QT syndromes is compatible with the hypothesis that $\mathrm{Ca}^{2+}$ entry, $\mathrm{Ca}{ }^{2+}$ loading of the $\mathrm{SR}$, and spontaneous $\mathrm{SR} \mathrm{Ca}^{2+}$ release are integral components of the mechanism of EAD generation and triggering in the long-QT syndromes. However, in the acquired long-QT syndromes, $\beta$-adrenergic receptor stimulation in the form of isoproterenol has been used therapeutically to suppress torsades de pointes. One possibility for this discorm dance is that the effect of $\beta$-adrenergic receptor stimulation on heart rate and enhancement of $\mathrm{L}_{\mathrm{Ks}}$, as well as other repolarizing currents, may override its effect to enthance $\mathrm{Ca}^{2}$ entry and $\mathrm{Ca}^{2+}$ loading. In the acquired long-QT syndromes, $I_{K r}$ may be the culprit current more commonly, allowing for action-potential shortening with adrenergic enhancement of $\mathrm{I}_{\mathrm{Ks}}$. In the case of the congenital long-QT syndromes, $\mathrm{I}_{\mathrm{Ks}}$ is more commonly reduced. ${ }^{183}$ In addition, natural adrenergic stimulation would involve stimulation of both $\beta$ and $\alpha$ receptors, $\alpha$-Adrenergic recepror stimulation may promote generation of EADs and torsades de pointes. ${ }^{188,189} \beta$-Adrenergic blockade and left cardiac sympathecromy would be expected to reduce $\mathrm{Ca}^{2+}$ entry and $\mathrm{Ca}^{2+}$ loading and, in the case of sympathecomy, ro diminish in addition $\alpha$-adrenergic receptor sumularion and its possible potentiating effect on EAD generation. The clinical observation that with these therapies the QT interval is generally not normalized indicates that their role is to suppress EADs and triggering rarher than affect the fundamental defect in repolarization. This concept fits with the generic findings as well.

\section{Conclusions}

In conclusion, the complex ionic basis of EADs and the significance of EADs for in-vivo arthythmogenesis initiating torsades de pointes are currently being unraveled at rapid pace. At the cellular level, the distinction berween the conditional phase and the upstroke of EADs is the rationale for new experiments. Whereas the upstroke may be regarded as a passive regenerative response, the conditional phase is the target for 
improved mechanistic insights and a better control. In the balance of ion fluxes creating this fundamental cvent during repolarization, the contribution of inactivating and reactivating inward currents is undisputed. Additionally, an important role is reserved for increased cytoplasmic and/or subsarcolemmal $\mathrm{Ca}^{2+}$ cycling, which may determine the 'go or no go' for EAD generarion under many circumstances by setting the magnirude of inward $\mathbb{N}_{\mathrm{Na}-\mathrm{Ca}}$. During systolic spontaneous $\mathrm{Ca}^{2+}$ rellease from the $S R$, as in some types of EADs, this magnitude is expected to be amplified. It has been demonstrated that in other types of EADs, such as those due to defective or inhibited $K^{*}$ currents, the significance of $\mathrm{I}_{\mathrm{Na}-\mathrm{C}_{\mathrm{t}}}$ is dependent on various momentary influences (eg, heart-rate changes and neurohumoral input), but can become arrhythmogenic even at relatively low amplitudes and in the absence of spontaneous $\mathrm{Ca}^{2+}$ release. It is important to recognize that the multifactorial substrate for EADs in situ is of a greater complexity than currently controllable by experimental design. In this regard, one should be very cautious to extrapolate the results on EADs induced under relatively steady-state conditions in the cellular electrophysiological laboratory to in-vivo arrhythmias.

From experimental and clinical investigations, it becomes increasingly clear that the various congenital and acquired long-QT syndromes may each have specific features in terms of electrophysiological substrate, inciting events for torsades de pointes, and responses to antiarrhythmic rherapies. The trigger roles of dynamic rate swirches and adrenergic stimulation in many of these forms are compatible with the hypothesis that $\mathrm{Ca}^{2+}$ entry, $\mathrm{Ca}^{2+}$ (over)loading of the $\mathrm{SR}$, and spontaneous $\mathrm{SR} \mathrm{Ca}{ }^{2+}$ release are integral components of the mechanisms of increased dispersion of repolarization and $\mathrm{EAD}$ iniriaring ventricular tachycardia. However, this may be more pronounced in conditions in which $\mathrm{I}_{\mathrm{Ks}}$ is the culprit current, than with downregulated $\mathrm{I}_{\mathrm{Kr}}$ or persistent late $\mathrm{I}_{\mathrm{Na}}$ when the response of a normal $\mathbb{I}_{\mathrm{KS}_{s}}$ to adrenergic stimulation and increased $\left[\mathrm{Ca}^{2+}\right]_{\mathrm{cyt}}$ is still sufficient to prevent excessive action-potential prolongation. The development of diagnostic electrophysiological protocols to recognize these phenotypes to tailor therapeutic strategies for the individual patient is obviously necessary.

\section{References}

1. Cranefield PF. Action potentialls, afterpotentials, and arrhythmias. Corc Res. $1977: 41: 415-423$

2. Hoffman BF, Rosen MR. Cellular mechanisms for cardiac arrhythmias. Cinc Res. $1981 ; 49: 1-15$.

3. Antzelevitch $\mathrm{C}$, Sicouri $\mathrm{S}$. Clinical relevance of cardiac arrhythmias generated by afterdepolarizations: role of $\mathrm{M}$ cells in the generation of $\mathrm{U}$ waves, rriggered acrivity and torsade de pointes. / Am Coll Cardiol 1994;23:259-277.

4. Wir AL, Rosen MR. Afterdepolarizations and triggered activiry: distinction from automaticity as an arrhythmogenic mechanism. In: Fozzard $H A$, Haber E, Jennings RB, Karz 
AM, Morgan HE, eds. The Hewt and Cardowdsaldar System. New York, NY: Raven Press; 1992:2113-2163.

5. Segers M. Le róle des potentels tardifs du coeur. Mén Acal Mád Belg. 1941:1:1-30.

6. Bozler E. The initiation of impulses in cardiac musce Am / Physiol 1943:138:273-282.

7. Bozler E. Tonus changes in cardiac muscle and their significance for the initarion of impulses. Am J Phyiol 1943,139:477-480.

8. Segers M. Le battement automentrecenu du coeur. Arch fht Phamarodym. 1947:75:144-156.

9. Rosen MR, Gelband H, Merker C, Hoftman BF. Mechanisms of digitalis toxicity; effects of ouabain on phase four of canine Purkinje fiber rransmembrane potentials. Circulation 1973;47:681-689.

10. Ferrier GR, Moe GK. Effect of calcium on acetylstrophanthidin-induced transient depolarizations in canime Purkinje tusste. Cir Res. 1973;33:508-515.

11. Ferrier $G R$. The effects of tension on acetylstrophanchidin-induced transient depolarizations and aftercontractions in canine myocardial and Purkinje rissues. Cin Res. 1976;38:156-162.

12. Kass RS, Lederer W], Tsien RW, Weingart R. Rale of calcium ions in transient inward currents and aftercontractions induced by strophanthidin in cardiac Purkinje fibres. J PHyiol. 1978;281:187-208.

13. Eisner DA, Lederer WJ. Inotropic and arthythmogenic effects of potassium-depleted solutions on mammalian cardiac muscle. J Pbysol. 1979;294:255-277.

14. Orchard $\mathrm{CH}$, Eisner DA, Allen DG. Oscillations of intracellular $\mathrm{Ca}^{24}$ in mammatian cardiac muscle. Nature. 1983;304:735-738.

15. Kort AA, Capogrossi MC, Lakatra EG. Frequency, amplitude, and propagation velocity of spontaneous $\mathrm{Ca}^{+-}$-dependent contractile waves in intact adule rat cardiac muscle and isolated myocytes. Circ Res. 1985;57:844-855.

16. Berlin JR, Cannell MB, Lederer WJ. Regulation of rwitch tension in sheep cardiac Purkinje fibers during calcium overload. Am J Pbysiol. 1987;253:H1540-H1547.

17. Capogrossi MC, Stern MD, Spurgeon HA, Lakarta EG. Spontaneous Cats release from the sarcoplasmic reticulum limits $\mathrm{CA}^{3+}$-dependent witch potentiation in individual cardiac myocytes: a mechanism for maximum inotropy in the myocardin. / Gen Pbysiol 1988;91:133-155.

18. Berlin JR, Cannell MB, Lederes WJ. Cellular origins of the ransient inward current in cardiac myocytes: role of fluctuations and waves of elevated intracellalar calcium. Circ Res. 1989;65:115-126.

19. January CT, Shorofsky S. Early afterdepolarizations: newer insights into cellular mechanisms. J Cardiovasc Electrophysiol. 1990;1:161-169.

20. E-Sherin. Early afterdepolarizations and arthythogenesis: experimental and clinical aspects. Arob Mal Coewr. 1991:84:227-234.

21. Kay GN. Plumb VJ, Arciniegas JG, Henthorn RW, Waldo AL. Torsade de poinres: the long short intiating sequence and oher clinical features: observations in 32 patients. I Am Coll Cardiol 1983;2:806-817. 
22. Jacknan WM, Szabo B, Friday KI, Margolis PD, Moulton $K$, Wang X. Patrerson E, Lazzara R. Ventricular tachyarhythmias related to early afre depolarizations and truggered fring: relationship to QT interval prolongarion and potential therapeutic role for calcium channel blocking agents. J Cardiovasc Electrophyiol. 1990;1:170-195.

23. Locan EH, Maison-Blanche P, Dejode P, Cauchemez B, Coumel P. Spontaneous sequences of onset of torsade de pointes in patients with acquired prolonged repolariza. tion: quantitative analysis of Holrer recordings. J Am Coll Candiol. 1995;25:1564-1575.

24. Viskin $\$$, Alla SR, Barron HV, Heller K, Saxon L, Kitzis I, van Hare GF, Wong MJ, Lesh MD, Scheinman MM. Mode of onser of torsade de pointes in congenital long QT syndrome. J Am Coll Cardiol. 1996;28:1262-1268.

25. Krishnan SC, Galvin J, McGovern B, Garan H, Ruskin JN. Reproducible induction of "atypical" torsades de pointes by programmed electrical stimulation: a novel form of soralol-induced proarthychmia? I Cardiovasi Eletrophysiol. 1997;8:1055-1061.

26. Sham JSK, Cleemann L, Morad M. Gating of the cardiac Ca ${ }^{2+}$ release channel: the role of $\mathrm{Na}^{*}$ current and $\mathrm{Na}^{+}-\mathrm{Ca}^{2 *}$ exchange. Science. 1992:255:850-853.

27. Kohmoto $O$, Levi AJ, Bridge JHB. Relation beween reverse sodium-calcium exchange and sarcoplasmic reticulum calcium release in guinea pig ventricular cells. Circ Res. $1994: 74: 550-554$.

28. Grantham CJ, Cannell MB. Ca ${ }^{2}$ influx during the cardiac action potential in guinea pig ventricular myocytes. Circ Res. 1996;79:194-200.

29. Sipido $\mathrm{KR}$, Maes $\mathrm{M}$, Van de Werf $\mathrm{F}$. Low efficiency of $\mathrm{Ca}^{2+}$ entry through the $\mathrm{Na}^{*}-\mathrm{Ca}^{2+}$ exchanger as trigger for $\mathrm{Ca}^{2 *}$ release from the sarcoplasmic reticulum: a comparison between L-type $\mathrm{Ca}^{2+}$ current and reverse-mode $\mathrm{Nat}^{2}-\mathrm{Ca}^{2+}$ exchange Circ Res. $1997 ; 81: 1034-1044$.

30. Sipido $\mathrm{KR}$, Carmelier $\mathrm{E}$, Van de Werf $\mathrm{F}$. T-type $\mathrm{Ca}^{2 *}$ current as a trigger for $\mathrm{Ca}^{2+}$ release from the sarcoplasmic reticulum in guinea-pig ventricular myocytes. $/$ Physiof. $1998 ; 508: 439-451$.

31. Zhou $Z$, January CT. Borh T- and L-type $\mathrm{Ca}^{2 *}$ channels can contribute to excitationcontraction coupling in cardiac Purkinje cells. Biophys/. 1998;44:1830-1839.

32. Leblanc $N$, Hume JR. Sodium current-induced release of calcium from cardiac sarcoplasmic reticulum. Science. 1990;248:372 376.

33. Ferrier GR, Howlet $S E$. Contractions in guinea-pigventricular myocytes triggered by a calcum-release mechanism separate from $\mathrm{Na}^{*}$ and L-currents. I Physol. $1995: 484: 107-122$.

34. Hobai LA, Howarth FC, Pabbathi VK, Dalcon GR, Hancox JC, Zhu JQ, Howlet SE, Ferrier GR, Lewi AJ. "Voltage-acivated Ca release" in rabbit, rat and guinea-pig cardiac myocytes, and modulation by internal CAMP. Pfatgers Arch. 1997:435:164-173.

35. Santana LF, Gómez AM, Lederer WJ. Ca ${ }^{2 *}$ fux through promiscuous cardiac $\mathrm{Na}^{+}$channels: slip-mode conductance. Science. 1998;279:1027 1033.

36. Stern MD. Theory of excitation-contracrion coupling in cardiac muscle. Biophys f. $1992 ; 63: 497-517$. 
37. Sun XH, Protasi F, Takahashi M, Takeshima H, Ferguson DG, Franzini-Armstrong C. Molecular architecture of membranes involved in excitarion-contracrion coupling of cardiac muscle. / Cell Biol 1995;129:659-671.

38. López-López JR, Shacklock PS, Balke CW. Wier WG. Local calcium transients triggered by single L-type calcium channel currents in cardiac cells. Science. 1995; 268: 1042-1045.

39. Santana LF, Cheng H, Gomez AM, Cannell MB, Lederer WI. Relation between the sarcolemmal $\mathrm{Ca}^{2+}$ current and $\mathrm{Ca}^{2+}$ sparks and local concrol theories for cardiac excitation-contraction coupling. Cire Res. 1996;78:166-171.

40. Callewaert G, Cleemann L, Morad M. Epinephrine enhances Ca current-regulated $\mathrm{Ca}^{2}$ release and $\mathrm{Ca}^{2+}$ reuprake in rat ventricular myocytes. Proc Nat Acad So USA. 1988:85:2009-2013.

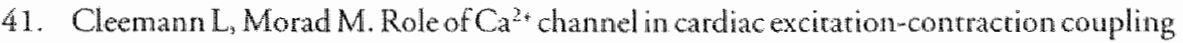
in the rat evidence from Ca ${ }^{2}$ transients and contraction. J Pbysiol 1991:432:283-312.

42. Shacklock PS, Wier WG, Balke CW. Local $\mathrm{Ca}^{*}{ }^{*}$ transients (Ca" sparks) originate at transwerse tubules in rat heart cells. / Physiol. 1995;487:601 -608.

43. Wier WG, rer Keurs HEDJ, Marban E, Gao WD, Balke CW. Ca' 'sparks' and waves in intact ventricular muscle resolved by confocal imaging. Cin Rer. 1997:81:462-469.

44. Eisner DA, Trafford AW, Dia ME, Overend CL, ONeill SC. The control of Ca release from the cardiac sarcoplasmic reticulum: regularion versus auroregulation. Cardisnasc Rer. 1998;38:589 604.

45. Shannon TR, Bers DM. Assessment of intra-SR free [Ca] and buffering in rat heart. Bioplys. 1. 1997;73:1524-1531.

46. Bers. DM. SR Ca loading in cardiac muscle preparations based on rapid-cooling contractures. Am J Pbysiol. 1989;256:C109-C120.

47. Varro A, Negretti $N$, Hester $S B$, Eisner DA. An estimate of the calcium content of the sarcoplasmic rericulum in rat ventricular myocytes. Pflighers A rds. 1993:423:158-160.

48. Han S, Schiefer A, Isenberg G. $\mathrm{Ca}^{2}$ load of guinea-pig ventricular myocytes derermines efficacy of brief $\mathrm{Ca}^{2+}$ currents as trigger for $\mathrm{Ca}^{2}$ release. J Plysial. 1994:480:411-421

49. Janczewski AM, Spurgeon HA, Stem MD, Lakarta EG. Effects of sarcoplasmic reticulum $\mathrm{Ca}^{2 *}$ load on the gain function of $\mathrm{Ca}^{2 *}$ release by $\mathrm{Ca}^{2}$ current in cardiac cells. Am J Plysiol. 1995;268:H216-H920.

50. Bassan JWM, Yuan W, Bers DM. Fractional SR Ca release is regulared by rigger Cand SR Ca content in cardiac myocytes. Am J Physiol 1995:268:C1313-C1319.

51. Barry WH, Rasmussen CAF, Jr. Ishida H. Bridge JHB. Extemal Na-independent Ca extrusion in cultured ventricular cells: magnitude and functional significance. / Gen Pbysiol. 1986;88:393411.

52. Bassani RA, Bassani JWM, Bers DM. Mitochondral and sarcolemmal Ca" transport reduce $\left[\mathrm{Ca}^{2 n}\right]_{\text {i }}$ during caffeine contractures in rabbir cardiac myocytes. I Phyriol. $1992,453: 591-608$.

53. Ehara T. Marsuoka S, Noma A. Measurement of reversal potential of Na" - Ga $^{2}$ exchange current in single guinea-pig wentricular cells. / Physiol. 1989:410:227-249. 
54. Beuckemann D], Wher WG. Sodium-calcium exchange in guinea-pig cardiac cells: exchange curren and changes in intracellular Ca". J Physiol. 1989:414:499-520.

55. Miura $Y$, Kinura J, Sodium calcium exchange current dependence on internal Cand Natand comperitive binding of external $\mathrm{Na}$ and Ca J Gem Pbysiol 1989;93:1129-1145.

56. Schouren VIA, ter Keurs HEDJ, Quaegebeur M. Influence of electrogenic Na/Ca exchange on the action potential in human lueart muscle. Cardiovess Res. $1990 ; 24: 758-767$.

57. Janvier $\mathrm{NC}$, Boyett $M R$. The role of $\mathrm{Na}$-Ca exchange current in the cardiac action porential. Cardiovase Res. 1996;32:69-84.

58. Janvier $\mathrm{NC}$, Harrison SM, Boyet MR. The role of inward $\mathrm{Na}^{+}-\mathrm{Ca}^{2+}$ exchange current in the ferret ventriculat action potential. / Phystol 1997; 498:611-625.

59. Lederer WJ, Niggli E, Hadley RW. Sodium-calcium exchange in excicable cells: fuzzy space. Science. 1990:248:283.

60. Carmeliet E. A fuzzy subsarcolemmal space for intracellular $\mathrm{Na}^{*}$ in cardiac cells? Cardiovelsc Res. 1992;26:433-442.

61. Main MJ, Grantham CJ, Cannell MB. Changes in subsarcolemmal sodium concentration measured by $\mathrm{Na}$-Ca exchanger activity during $\mathrm{Na}$-pump inhibition and $\beta$-adrenergic stimulation in guinea-pig ventricular myocytes. Pfügers Arch. 1997;435:112-11.8.

62. Fujioka $\mathrm{Y}$, Matsuoka S, Ban T, Noma A. Interaction of the $\mathrm{Na}^{+}-\mathrm{K}^{+}$pumpand $\mathrm{Na}^{*}-\mathrm{Ca}^{2}$ " exchange via $[\mathrm{Na}]_{i}$ in a restricted space of guinea-pig wentricular cells. / physiol. $1998 ; 509: 457-470$.

63. Su Z, Zou A, Nonaka A, Zubair I, Sanguinetti MC, Barry WH. Influence of prior Nat pump activity on pump and $\mathrm{Na}^{*} / \mathrm{Ca}^{2+}$ exchange currents in mouse ventricular myocyres. Am J Pbysial. 1998;275:H1808-H1817.

64. Langer GA, Peskoff A. Calcium concentration and movement in the diadic cleft space of the cardiac ventricular cell. Biophys J. 1996;70:1169-1.182.

65. Soeller $\mathrm{C}$, Cannell MB. Numerical simulation of local calcium movements during L-type calcium channel gating in the cardiac diad. Biophys J. 1997:73:97-111.

66. Barcenas-Ruiz $L$, Betckelmann DJ, Wier WG. Sodium-calcium exchange in heart: membrane currents and changes in $\left[\mathrm{Ca}^{2}{ }^{2}\right]_{i^{\circ}}$ Sctence. 1987;238:1720-1722.

67. Lipp P, Port L, Callewaer G, Carmeliet E. Simulaneous recording of Indo-1 fluoresence and $\mathrm{Nat}^{1} / \mathrm{Ca}^{2}$ exchange current reveals two components of $\mathrm{Ca}^{2}{ }^{2}$-release from sarcoplasmic reticulum of cardiac atrial myocytes. FEBS Letreys. 1990;275:181-184.

68. Hüser J, Lipsius SL. Batter LA. Calcium gradients during excitation-contraction coupling in car atrial nyocytes / Physiot 1996;494:641-651.

69. Trafford AW, Draz ME, O'Neill SC, Eisner DA. Comparison of subsarcolemmal and bulk calcium concentration during spontaneous calcium release in rat ventricular myocytes. / Phyriol 1995:488:577-586.

70. Sipido KR, Callewaer $\mathrm{G}_{\mathrm{s}}$ Carmeliet E. Inbibition and rapid recovery of Ca $\mathrm{a}^{24}$ current during $\mathrm{Ca}^{2}$ release from sarcoplasmic reticulum in guinea pig ventricular myocytes. Corc Re. 1995:76:102-109. 
71. Sham JSK, Cleemann L, Morad M. Functional coupling of Ca ${ }^{2 *}$ channels and ryanodine receptors in cardiac myocytes. Proc Nad Acad Soi U SA. 1995:92:121-125.

72. Blatter LA, Niggli $E$. Confocal near-membrane derection of calcium in cardiac myocytes. Call Calcum. 1998:23:269-279.

73. Etter EF, Minta A, Poenie M, Fay FS. Near-membrane $\left[\mathrm{Ca}^{2}\right]$ transients resolved using the Ca ${ }^{3+}$ indicator FFP18. Proc Nat Acad Sc U S A. 1996;93:5368-5373.

74. Trafford AW, DGaz ME, Eisner DA. Cal-acrivated chloride current and Na-Ca exchange have different rimecourses during sarcoplasmic reticulum Ca release in ferer ventricular myocytes. Pfuigers Arch. 1998;435:743-745.

75. Yamada KA, Corr PB. Effecrs of $\beta$-adrenergic receptor acrivarion on intracellular calcium and membrane potential in adult cardiac myocytes. J Cardiowasc Elecroplysiol. 1992;3:209-224.

76. Janiak $\mathbb{R}$, Lewartowski $B$. Early after-depolarisations induced by noradrenaline may be initiated by calcium released from sarcoplasmic reticulum. Mol Cell Biochew. $1996 ; 163 / 164: 125-130$.

77. Volders. PGA, Kulcsár A, Vos MA, Sipido KR, Wellens HJJ, Lazzara R, Szabo B. Similarities between early and delayed afterdepolarizations induced by isoproterenol in canine ventricular myocytes. Cardiovasc Res. 1997:34:348-359.

78. Zeng J, Rudy $Y$ Early afterdepolarizations in cardiac myocytes: mechanism and rate dependence. Biophys J. 1995;68:949-964.

79. De FerrariGM, Viola MC. D'Amato E, Antolini R, Fort S. Distinct patterns of calcium transients during early and delayed afterdepolarizations induced by isoproterenol in ventricular myocytes. Circulation. 1995;91:2510-2515.

80. Cheng $H$, Lederer WJ, Cannell MB. Calcium sparks: elementary events underlying excitarion-contraction coupling in heart muscle. Science. 1993;262:740-744.

81. Diaz ME, Cook S], Chamunorwa JP, Trafford AW, Lancaster MK, S.C. ON, Eisner DA. Variability of spontaneous $\mathrm{Ca}^{2+}$ release between different rat ventricular myocyres is correlared with $\mathrm{Na}^{+}-\mathrm{Ca}^{2+i}$ exchange and [ $\left.\mathrm{Na}^{*}\right]_{3}$. Circ Res 1996:78:857-862.

82. Satoh H, Blatter LA, Bers DM. Effecrs of $\left[\mathrm{Ca}^{2}\right]_{i}$, SR $\mathrm{Ca}^{2}$ load, and rest on $\mathrm{Ca}^{24}$ spark frequency in ventricular myocytes. Am y Physiot. 1997:272:H657-H668.

83. Parker 1, Wier WG. Variability in frequency and characteristics of $\mathrm{Ca}^{22}$ sparks ar different release sites in rat wentricular myocytes. J Physol. 1997:505:337 344.

84. Cheng $\mathrm{H}$, Lederer MR, Lederer WJ, Cannell MB. Calcium sparks and $\left.\mid \mathrm{Ca}^{2 n}\right]_{1}$ waves in cardiac myocyes. Am / Physiol. 1996:270:C148-C159.

85. Fabiato $\mathrm{A}$. Time and calcium dependence of acrivation and inacrivation of calciuminduced release of calcium from the sarcoplasmic reviculum of a skinned canine cardiac Purkinje cell. /Gen Physiol. 1985;85:247-289.

86. Wier WG, Cannell MB, Berlin IR, Marban E, Lederer WJ. Cellular and subcellular hererogeneity of $\left[\mathrm{Ca}^{2+}\right]_{3}$ in single heart cells revealled by fura-2. Sivence. $1987 ; 235: 325-328$.

87. Takamarsu $T$, Wher WG. Calcium waves in mammalian heart: quantification of origin, magnitude, waveform, and velociry. FASEB J 1990;4:1519-1525. 
88. Grouselle M, Srupwers B, Bonoron-Adele S, Besse P, Georgescauld D. Digital-imaging microscopy andysis of calcium release from sarcoplasmic reticulam in single rar cardiac myocytes. Pftigers Arch. 1991:418:109-119.

89. Willams DA, Delbridge LM, Cody SH, Harris PJ, Morgan TO. Sponcaneous and propagated calcium release in isolated cardiac myocytes viewed by confocal microscopy. Am J Pbysial. 1992;262:C731-C742.

90. Lipp P. Niggli E. Modulation of $\mathrm{Ca}^{2+}$ release in cultured neonatal rat cardiac myocytes: insights from subcellular release patterns revealed by confocal microscopy. Circ Res. $1994774: 979-990$.

91. Miura M, Ishide N, Oda H, Sakurai M. Shinozaki T, Takishima T. Sparial fearures of calcium transients during early and delayed afterdepolarizations. Am I Physol. $1993 ; 265 \mathrm{H} 439-\mathrm{H} 444$.

92. Sipido KR, Callewaer G, Porciani F, Vereecke J, Carmelier E. [Ca $\left.{ }^{20}\right]$-dependent membrane currents in guinea-pig ventricular cells in the absence of $\mathrm{Na} / \mathrm{Ca}$ exchange. Pfligers Axch. 1995:430:871-878.

93. Iaflamme MA, Becker PL. Ca ${ }^{2+}$ induced current oscillations in rabbit ventricular myocytes. Circ Res. 1996;78:707-716.

94. Wang YG, Huiser J, Blater LA, Lipsius SL. Withdrawal of acetylcholine elicits $\mathrm{Ca}^{2}$-induced delayed afterdepolarizations in cat arrial myocytes. Circulation. $1.997 ; 96: 1275-1281$.

95. Köster OF, Szigeri GP, Beuckelmann DI. Characterization of a $\left[\mathrm{Ca}^{2+}\right]_{i}$-dependent current in human atrial and ventricular cardiomyocytes in the absence of $\mathrm{Na}^{+}$and $\mathrm{K}^{*}$. Cardiowasc Res. 1999;41:175-187.

96. Lederer W], Tsien RW. Transient inward current underlying arrhythnogenic effects of cardiotonic steroids in Purkinje fibres. J Pbysiol. 1976;263:73-100.

97. Kass RS, Tsien RW, Weingart R. Ionic basis of transient inward current induced by strophanchidin in cardiac Purkinje fibres. J Ploysiol. 1978;281:209-226.

98. Fedida D, Noble D, Rankin AC, Spindler AJ. The arthythmogenic transient inward current $i_{1}$ and related contratrion in isolated guinea-pig ventricular myocytes. J Physiol. 1987:392:523-542.

99. Lipp P. Pon L. Transient inward current in guinea-pig atrial myocytes reflects a change of sodium-calcium exchange current. J Physiol. 1988;397:601-630.

100. Benndorf K. Biskup C, Friedrich M. Voltage-dependent kinetics of Na-Ca exchange current in Ca" ${ }^{2}$-loaded guinea pig heart cells. Am / Physiol. 1993;265:C1258-C1265.

101. Verkerk AO. Cellular mechanims of arbythmiass effects of womadrenaline, bypoxia and injwy current on the elcorophysiology of isolated ventricular and Purkinje myocytes $[\mathrm{PhD}$ thesis]. Amsterdan, Nerherlands: University of Amsterdam; 1998.

102. Zygmun AC, Goodrow RJ, Weigel CM. $I_{\mathbb{N a}}$ and $I_{\mathrm{ClC}}$ contribure ro isoproterenolinduced delayed afterdepolarizations in midnyocardial cells. Am $/$ Physiol. $1998: 275: 111979-\mathrm{H} 1992$. 
103. Cannell MB, Lederer WJ. The arthythmogenic current $I_{\mathrm{I}}$ in the absence of electogenic sodium-calcium exchange in sheep cardiac Purkinje fibres. $f$ Pbysiol. $1986 ; 374: 201-219$.

104. Ehara T, Noma A, Ono K. Calcium-activated non-selective cation channel in ventricular cells isolated from adult guinea-pig hearts. f Pbysol. 1988:403:117-133.

105. Giles W, Shimoni Y. Comparison of sodium-calcium exchanger and transient inward currents in single cells from rabbit ventricle. / Physiol 1989:417:465-481.

106. Han X, Ferrier GR. Transient inward current is conducted through wo types of channelis in cardiac Purkinje fibres. J Mol Cell Cardiol. 1996:28:2069-2084.

107. Sipido KR, Callewaert $G$, Carmeliet $\mathbb{E}$. $\left[\mathrm{Ca}^{2 *}\right]_{i}$ transients and $\left[\mathrm{Ca}{ }^{2 *}\right]_{;}$-dependent chloride current in single Purkinje cells from rabbit heart. / Physiol. 1993;468;641-667.

108. Zygmunt AC. Intracellular calcium activates a chloride current in camine ventricular myocytes. Am J Pbysiol. 1994;267:H1984-H1995.

109. Papp Z, Sipido KR, Callewaet $G$, Carmeliet E. Two components of [Can" i, actiwated $\mathrm{Cl}$ current during large $\left[\mathrm{Ca}^{2+}\right]_{i}$ transients in single rabbit heart Purkinje cells. $/ \mathrm{p}$ bysiol. $1995 ; 483: 319-330$.

110. Roden DM, Lazzara R, Rosen M, Schwartz PJ. Towbin J, Vincent GM. Multiple mechanisms in the long-QT syndrome: current knowledge, gaps, and future directions. The SADS Foundation Task Force on LQTS. Circulation. 1996:94:1996-2012.

111. Lee KS, Tsai TD, Lee EW. Membrane acrivity of class III antiarrhythmic compounds; a comparison between ibutilide, d-sotalol, E-403 i, sematilide and dofetilide. Eur / Pharwacol 1993;234:43-53.

112. Carlsson L, Abrahamsson C. Andersson B, Duker G, Schiller-Linhardt G. Proarrhythmic effects of the class III agent almokalant: importance of infusion rate, QT dispersion and early afterdepolarisarions. Cardiovasc Res. 1993;27:2186-2193.

113. Antzelevitch $C$, Sun ZQ, Zhang ZQ, Yan GX. Cellular and ionic mechanisms underlying erythromycin-induced long QT intervals and torsade de pointes. I Am Coll Candiol 1996:28:1836-1848.

114. Shimizu W, Anzelevirch C. Sodium channel block with mexilctine is sffective in reducing dispersion of repolarization and preventing rorsade de pointes in LQT2 and LQT3 models of the long-QT syndrome. Cricularion. 1997:96:2038-2047.

115. Isenberg $\mathrm{G}$, Ravens $\mathrm{U}$. The effects of the Anemonia sulata toxin (ATXII) on membrane currents of isolated mammalian myocytes. J Physiol. 1984,357:127-149.

116. Bourjdir M, El-Sherif $\mathrm{N}$. Pharmacological evaluarion of early afterdepolarisarions induced by sea anemone toxin (ATXIN) in dog heart. Cardionnasc Res. 199 1:25:815 819.

117. Bourjdir M, Restivo M, Wei Y, Stergiopoulos K, El-ShenifN. Earlyafterdepolarization formarion in cardiac myocytes: analysis of phase plane parterns, acrion potencial, and membrane currents. J Cardiovasc Electrophysiol 1994:5;609-620.

118. January CT, Riddle JM. Salata J. A model for early afterdepolarizations: induction with the $\mathrm{Ca}^{2}$ channel agonist Bay K 8644. Cir Res. 1988;62:563-571.

119. January CT, Riddle JM. Early afterdepolarizations: mechanism of inducrion and block. A role for L-type Ca ${ }^{2 *}$ current. Cin Res. 1989;64:977-990. 
120. January $C T$, Chau $V$, Makielski JC. Triggered activity in the heart cellular mechanisms of early after-depolarizations. Eur Heart) 1991;12 (suppl F):4-9.

121. Hirano $Y$, Moscucci A. January CT. Direct measurement of L-rype Ca ${ }^{2 *}$ window wurtent in heart cells. Cir Res. 1992,70:445-455.

122. Shorofsky SR, January CT.L-and T-type Ca ${ }^{2 *}$ channels in canine cardiac Purkinje cells: single-channel demonstration of L-type $\mathrm{Ca}^{2 *}$ window current Circ Res. $992 ; 70: 456-464$.

123. Sweidan R, Gesztelyi I, Fugate R, Szabo B, Lazzara R. Adrenergic receptor stimularion, intracellular $\mathrm{Ca}^{2 *}$ transienes and afterdepolarizations in canine ventricular myocytes. Crrculation. 1990;82:111-523. Abstract.

124. Tweedic D, O'Gara P, Harding SE, MacLeod KT. The effect of alterations to action potential dutation on $\beta$-adrenoceprormediated aftercontractions in human and guinea-pig ventricular myocytes. J Mol Cell Cardiol. 1997:29:1457-1467.

125. Priori $\mathrm{SG}$, Corr PB. Mechanisms underlying early and delayed aftendepolarizations induced by catecholamines. Am J Pby:sol. 1990:258:H1796-H1805.

126. Miura M, Ishide N, Numaguchi H, Takishima T. Diversity of early afterdepolarizations in guinea pig myocytes: spatial characteriscics of intracellular $\mathrm{Ca}^{2}$ " concentration. Heart Vessels. 1995:10:266-274.

127. Brachmann J, Scherlag BJ, Rosenshtraukh LV, Lazzara R. Bradycardia-dependent triggered activity: relevance to drug-induced multiform ventricular tachycardia. Circulation. 1983;68:846-856.

128. Szabo B, Sweidan R, Rajagopalan $\mathrm{CV}$, Lazzara $\mathbb{R}$. Role of $\mathrm{Na}^{*}: \mathrm{Ca}^{\text {** }}$ exchange curren in Cs'-induced early afterdepolarizations in Purkinje fibers. J Cardiovas Electrophyol. $1994 ; 5: 933-944$.

129. Szabo B, Kovacs T, Lazzara R. Role of calcium loading in early afterdepolarizations generated by $\mathrm{Cs}^{+}$in canine and guinea pig Purkinje fibers. / Cardiowase Electrophysiol. 1995;6:796-812.

130. Szabo B, Sweidan R, Patterson E, Scherlag B], Lazzara R. Increased intracellular Cat+ may be important also for early afrerdepolarizations. / Am Coll Cardiol 19879:210A. Abstract.

131. Shimizu W, Ohe T, Kurita T, Takaki H, Ahara N, Kanakura S, Matsuhisa M. Shimomura K. Early afterdepolarizations induced by isoproterenol in patients with congeniral long QT syndrome. Cinkthion. 1991;84:1915-1923.

132. Habbab MA, EL-SherifN. TU alremans, long QTU, and torsade de pointes: dinical and experimental observarions. Paong Clim Elechophysiol 1992;15:916-931.

133. Zhou IT, Zheng LR, Liu WY, Zhang GL, Zhao I, Shi IL, Wang ZY, Zhang YS. Early afterdepolarizarions in the familial long QTU syndrome. / Cardionase Electrophystol. $1992 ; 3: 431-436$.

134. Miwa S, Inoue T, Yokoyama M. Monophasic accion potentials in patients with torsades de pointes. Jph Cir J. 1994:58:248-258.

135. Shimizu W, Ohe T, Kurita T, Kawade M, Arakaki Y, Aihara N, Kamakura S, Kamiya I, Shimomura $\mathrm{K}$. Effects of verapamil and propanolol on early afterdepolarizations and 
ventricular arrhythmias induced by epinephrine in congenital long $\mathrm{QT}$ syndrome. $/ \mathrm{Am}$ Coll Cardol. 1995;26:1299-1309.

136. El-Sherif N, Zeiler RH, Craelius W, Gough WB, Henkin R. QTU prolongarion and polymorphic ventricular tachyarthythmias due to bradycardia-dependent early afterdepolarizations: afrerdepolarizations and ventricular arrhythmas. Cin Res. $1988 ; 63: 286-305$.

137. El-SherifN, Bekheit SS, Henkin R. Quinidine-induced long QTU interval and torsade de pointes: role of bradycardia-dependent early afterdepolarizations. I Am Coll Candiol. $1989 ; 14: 252-257$.

138. Habbab MA, EI-Sherif N. Drug-induced torsades de pointes: role of arly afrerdepolarizations and dispersion of repolarizanion. Am J Med. 1990;89:241-246.

139. Kurita T, Ohe T, Shimizu W, Suyama K, Ailuara N, Takaki H, Kamakura S, Shimomura K. Early afterdepolarizationlike activity in patients with class LA induced long QT syndrome and torsades de pointes. Pacing Clin Electrophysiol. 1997,20:695-705.

140. Patterson E, Scherlag BJ, Szabo B, Lazzara R. Facilitation of epineplarine-induced afterdepolarizations by class III anciarrhychmic drugs. / Electrocardiol 1997;30:217-224.

141. Patterson $\mathrm{E}_{\mathrm{x}}$ Scherlag BJ, Lazzara R. Early afterdepolarizarions produced by d,J-sotalol and dofilium. / Cardionasc Electropbysiol. 1997:8:667-678.

142. Sicouri $S$, Moro S, Elizari MV. $d$-Soralol induces marked action potential prolongarion and early afterdepolarizations in $\mathrm{M}$ but not epicardial or endocardial cells of the canine wentricle. J Cardiovasc Pharmacol Ther. 1997;2:27-38.

143. Burashnikov A, Antzelevitch C. Acceleration-induced action porenrial prolongation and early afterdepolarizations. J Cardiovocic Electropbysiol. 1998:9:934-948.

144. Zaugg CE, Wu ST, Lee RJ, Parmley WW, Buser PT, Wikman-Coffelt J. Importance of calcium for the vul nerability to ventricular fibrillation detected by premature ventricular stimularion: single pulse versus sequential pulse methods. I Mol Cell Cardiol. $1996 ; 28: 1059-1072$.

145. Viswanathan PC, Rudy Y. Pause induced early afterdepolarizations in the long QT syndrome: a simulation study. Cardiowas Res. 1999; in press.

146. ter Keurs HEDJ, Zhang YM, Miura M. Damage-induced arrtiythmias: reversal of excitation-contraction coupling. Cardiovasc Res. $1998 ; 40: 444.455$.

147. Li ZY, Maldonado C, Zee-Cheng C, Hiromasa S, Kupersmith J. Purkinje fibrepapillary muscle interaction in the genesis of triggered activity in a guinea pig model. Cardiovasc Res. 1992;26:543-548.

148. Yan $G X$, Shimizu W. Antzelevitch $C$. Characteristics and distribution of $M$ cells in arrerially perfused canine left ventricular wedge preparations. Circulation. 1998;98: 1921-1927.

149. Shimizu W, Anzzelewitch C. Cellular basis for rhe ECG features of the LQT 1 form of the long-QT syndrome: effects of $\beta$-adrenergic agonists and antagonists and sodium channel blockers on transmural dispersion of repolarization and torsade de pointes. Cinculation. 1998;98:2314-2322. 
150. Sicouri 5 , Anrzevitch $C$. Aftendepolarizations and triggered activity develop in a select population of cells (M cells) in can ine ventricular myocardium: the effeces of acerylstro. phanthidin and Bay K 8644. Pacing Clin Electrophysiol. 1991;14:1714-1720.

151. Patterson E, Szabo B, Scherlag B), Lazzara R. Early and delayed arterdepolarizations associated with cesium chloride-induced arrhythmias in the dog. J Cardiowasc Pharmarol. 1990;15:323-331.

152. Xie JT, L CL. Induction and remination of afterdepolarizations and triggered arnythmias by drugs in cat heart in wivo. Meth Find Exp Clin Phamacal 1992;144347-354.

153. Xu J, Zaim S, Pelleg A. Effects of pinacidil, verapamil, and heart rate on afterdepolarizations in the guinea-pig heart in viwo. Heart Vessels. 1996;11:289-302.

154. Xie J, Xie L. Can the MAP technique be applied to study triggered activinies of the heart? Intracellular evidence in vivo. Metb Find Exp Clin Pharmacol 1990;12:419-424.

155. Vos MA, de Groot SHM, Verduyn SC, van der Zande J, Leunissen HDM, Cleutiens IPM, van Bilsen M, Daemen MJAP, Schreuder J], Allessie MA, Wellens HJJ. Enhanced susceptibility for acquired torsade de pointes arrhyrhmias in the dog with chronic, complete AV block is related to cardiac hypertrophy and electrical remodeling. Cinculaton. 1998;98:1125-1135.

156. Verduyn $\$$ C, Vos MA, Gorgels AP, vander Zande J, Leunissen JDM, Wellens H]. The effect of flunarizine and ryanodine on acquired torsades de pointes arrhythmias in the intact canine heart. / Cardiovase Electrophysiol. 1995;6:189-200.

157. Carlsson L, Drews $L, D$, Duker $G$. Rhythm anomalies related to delayed repolarizarion in vivo: influence of sarcolemmal. Cat entry and intracellular $\mathrm{Ca}^{\text {t+ }}$ ovetload. / Pharmatol Exp Ther. 1996:279:231-239.

158. Gavrilescu S, Luca C. Righe wentricular monophasic action potentials in patients with long QT syndrome. Br Heart J. 1978;40:1014-1018.

159. Bonatti V, Finardi A, Botri G. Enregistrement des potentiels d'action monophasiques. du ventricule droit dans un cas de QT long et alternance isolée de l'onde U. Arch Mal Coen. 1979:72:1180-1186.

160. Bonatri $V$, Rolli $A_{4}$ Botti $G$. Recording of monophasic action potentals of the right ventricle in long QT syndromes complicated by severe ventricular arrhythmias. Eur Heart) 1983:4:168-179.

161. Schechter E, Freeman CC, Lazzara R. Aferdepolarizations as a mechanism for the long QT syndrome: electrophysiologic studies of a case $/$ Am Coll Cardiol 1984:3: $1556-1561$.

162. Ohe T', Kurita T, Aihara N, Kamakura S, Matsuhisa M, Shimomura K. Electrocardiographic and electrophysiologic studies in parients with totsades de pointe: role of monophasic action potentials. fpn Circ J. 1990,54:1323-1330.

163. Shimizu W, Tanaka K, Suenaga K, Wakamoto A. Bradycardia-dependenc early afterdepolarizations in a patient with QTU prolongation and rorsade de pointes in association with marked bradycardia and lyypokalemia. Pacing Cin Electrophysiol 1991;14: $1105-1111$. 
164. Kurita T, Ohe T, Shimizu W, Hotta D, Shmomura K. Early afterdepolarization in a patient with complete atrioventricular block and torsades de pointes. Pacing Clin Eloctrophystol. 1993; 16:33-38.

165. Shimizu W, Ohe T, Kurita T. Tokuda T. Shimomura K. Epinephrine-induced ventricular premature complexes due to early afterdepolarizations and affects of verapamil and propranolol in a parient with congenital long QT syndrome. I Cardiowar Electrophyiol. 1994;5:438-444.

166. Sato $T$, Hata $Y$, Yamamoto M, Morita H. Mizuo K, Yamanari H, Saito D, Ohe T. Early afrerdepolarization abolished by potassium channel opener in a patient with idtoparhic long QT syndrome. J Cardiovasc Electrophysiol 1995;6:279-282.

167. Shimizu W, Kurita T, Matsuo K, Suyama K, Ahara N, Kamakura S, Towbin JA, Shimomura K. Improvement of repolarization abnormaliries by a $K$ " channel opener in the LQT1 form of congenical long-QT syndrome. Cinculation. 1998;97:1581-1588.

168. Jervell A, Lange-Nielsen F. Congenital deaf-mutism, functional heart disease with prolongation of the Q $\mathrm{T}$ interval, and sudden death. Am Heart 1 1957:54:59-68.

169. Jackman WM, Friday KJ, Anderson JL, Aliot EM, Clark M, Lazzara R. The long QT syndromes: a cricical review, new dinical observations and a unifying hypothesis. Prog Cardiouas Dis. 1988;31:115-172.

170. Moss AJ, MCDonald J. Unilateral cervicothoracic sympatheric ganglionectomy for the treament of long QT interval syndrome. N Engl/ Med. 1971;285:903-904.

171. Schwartz PJ. Idiopathic long QT syndrome: progress and questions. Am Hear J. $1985 ; 109: 399-411$.

172. Schwartz PJ, Locati EH, Napolitano C, Priori SG. The long QT syndrone. In: Zipes DP, Jalife J, eds. Cardiac Electrophysiology: From Cell To Bedside. Philadelphia, PA: WB Saunders Co; $1995: 788-811$.

173. Donger C, Denjoy I, Berthet M, Neyroud N, Cruaud C, Bennaceur M, Chivorer G, Schwarz K, Coumel P, Guicheney P. KVLQT'1 C-terminal missense mutarion causes a forme fruste long-QT syndrome. Circulation. 1997;96:2778-2781.

174. Houlz B, Darpö B, Edvardsson N, Blomström P, Brachmann J. Crijus HJGM, Jensen SM, Svernhage E, Vallin $H$, Swedberg K. Electrocardiographic and clinical predictors of torsades de pointes induced by almokalant infusion in patients witin chronic atrial fibrillation or Alutter: a prospective study. Pacing Clin Electrophysiol. 1998;21:1044-1057.

175. Eldar M, Griffin JC, Abbor JA, Benditt D, Bhandari A, Herre JM, Benson DW. Scheinman MM. Permanent cardiac pacing in parients with the long QT syndrome. I Am Coll Cardiol 1987:10:600-607.

176. Wang Q, Shen J. Splawski I. Atkinson D, Li Z, Robinsoni JL, Moss AJ. Towbin JA. Keating MT. $\$ C N 5$ A mutations associated with an inherited cardiac arthythmia, long QT syndrome. Cell. 1995;80:805-811.

177. Schwartz PI, Priori SG, Locati EH, Napolitano C, Cantu F, Towbin IA, Kearing MT, Hammoude H, Brown AM, Chen LSK, Colatsky TJ. Long QT syndrome patients with mutations of the SCNSA and AERG genes have differential responses to Na channel 
blockade and to increases in heart rate: implications for gene-specific therapy. CirculaHork $1995 ; 92: 3381-3386$.

178. Curran ME, Splawski I, Timothy KW, Vincene GM, Green ED, Keating MT. A molecular basis for cardiac arrhythmia: HERG mutations cause long QT syndrome. Cell. 1995;80:795-803.

179. Sanguinetri $\mathrm{MC}$, Jurkiewica $\mathrm{NK}$. Role of external $\mathrm{Ca}^{2 *}$ and $\mathrm{K}^{+}$in gating of cardiac delayed rectifier $K^{*}$ currents. Pfliggers Arch. 1992;420:180-186.

180. Compron SJ, Lux RL, Ramsey MR, Strelich KR, Sanguinetti MC, Green LS, Keating MT, Mason JW. Generically defined therapy of inherited long-QT syndrome: correction of abnormal repolarization by potassium. Circulation. 1996;94:1018-1022.

181. Tan HL, Alings M, van Olden RW, Wilde AMM. Long-term (subacute) potassium creatment in congenital HERG-related long QT syndrome (LQTS2). J Cardiovasc Electroptysiol. 1999;10:229-233.

182. Zareba W, Moss AJ, Schwartz PJ, Vincent GMi, Robinson JL, Priori SG, Benhorin J, Locat EH, Towbin IA Keating MT, Lehmann MH, Hall WJ. Influence of the genotype on the clinical course of the long-QT syndrome. International Long-QT Syndrome Registry Research Group. N Engl/ Med. 1998;339:960-965.

183. Priori SG, Barhanin J, Hawer RNW, Haverkamp W, Jongsma HJ, Kleber AG, McKenna WJ, Roden DM, Rudy Y, Schwartz K, Schwarz PJ, Towbin JA, Wilde AM. Generic and molecular basis of cardiac arrhythmias: impacr on clinical management. Pars I and II. Circulation. 1999;99:518-528.

184. Fazekas T", Scherlag BJ, Vos M, Wellens H]], Lazzara R. Magnesium and the heart: anianrhythmic therapy with magnesium. Clin Cardiol 1993;16:768-774.

185. Kanaya S, Arlock P, Karzung BG, Hondeghem LM. Diltiazem and weraparnil preferentially block inactivared cardiac calcium channels.J Mol Cell Cardiol. 1983;15:145-148.

186. Verduyn SC, Vos MA, van der Zande J, van der Hulst FF, Wellens HJ. Role of interventricular dispersion of repolarization in acquired torsade-de-pointes arrhythmias: reversal by magnesium. Cardiovase Res. 1997:34:453.463.

187. El-Sherif $N$, Chinushi M, CarefEB, Restivo M. Electrophysiological mechanism of the characteristic electrocandiographic morphology of torsade de pointes tachyarrhyrhmias in the long-QT syndrome: detailed analysis of ventricular tridimensional activation parterns. Circulation. 1997;96:4392-4399.

188. Garza LA, Vick RL, Nora JJ, McNamara DG. Heritable Q-T' prolongation wichour deafness. Circulation. 1970;41:39-48.

189. Grubb BP. The use of oral labetalol in the treatment of arrhythmias associated with the long QT syndrome Chest 1991;100:1724-1725.

190. Vos MA, Verduyn SC, Gorgels APM, Lipcsei GC, Wellens HJJ. Reproducible inducrion of early afterdepolarizations and torsade de pointes arrhythmias by $d$-sotalol and pacing in dogs with chronic atrioventricular block. Circulation. 1995;91:864-872.

191. Saroh T, Zipes DP. Rapid rates during bradycardia prolong ventricular refractoriness and facilicate ventricular achycardia induction with cesium in dogs. Circulation. 1996;94:217-227. 
192. Benndorf K, friedrich M, Hirche H. Reoxygenation-induced arhythmogenic transient inward currents in isolated cells of the guinea-pig heart. Pforgers Aro 1991,418: 248-260.

193. Hanich RF, Levine JH, Spear JF, Moore EN. Auronomic modulation of ventricular arrhythmia in cesium chloride induced long. QT syndrome. Curmlation. 1988;77: 1149-1161.

194. Priori SG, Mantica M, Schwarez PJ. Delayed afterdepolarizations elicired in vivo by left stellate ganglion stimulation. Circulation. 1988;78:178-185.

195. Ben-David I, Zipes DP. Differential response to right and left ansae subclaviae stimularion of early afterdepolarizations and ventricular tachycardia induced by cesium indogs. Cinculation. 1988;78:1241-1250.

196. Marchi S, Szabo B, Lazzara R. Adrenergic induction of delayed afterdepolariations in veratricular myocardial cells: $\beta$ inducrion and $\alpha$ modulation. J Cardlowasc Elertrophysiol. $1991: 2: 476-491$.

197. Tseng $\mathrm{GN}$, Wit AL. Effects of reducing $\left[\mathrm{Na}^{+}\right]_{2}$ on catecholamine-induced delayed afrerdepolarizations in atrial cells. Am J Physiol. 1987:253:H115-H125.

198. Ben-David J, Zipes DP. $\alpha$-Adrenoceptor stimulation and blockade modulates cesiuminduced early afterdepolarizations and ventricular tachyarthythmias in dogs. Ciwatation. $1990 ; 82: 225-233$.

199. Kimura S, Cameron JS, Kozlovskis PL, Bassett AL, Myerburg RJ. Delayed afterdepolarizations and triggered activity induced in feline Purkinje fibers by $\alpha$-adrenergic stimulation in the presence of elevated calcium levels. Cinculation. 1984;70:1074-1082.

200. Lee JH, Rosen MR. Modulation of delayed afterdepolarisations by $\alpha_{1}$ adrenergic receptor subtypes. Cardiovasc Res. 1993;27:839-844.

201. Tatsukawa $Y$, Arita M, Kiyosue T, Mikuriya $X$, Nasu M. A comparative study of effects of isoproterenol and dihydroouabain on calcium transients and contraction in culcured rat ventricular cells. / Mol Cell Cardiol. 1993;25:707-720.

202. Thandroyen FT, Morris AC, Hagler HK, Ziman B, Pai L, Willerson JT, Buja LM. Intracellular calcium transients and arthychmia in isolated heart cells. Cinc Res. $1991 ; 69: 810-819$.

203. Saroh $H$, Hayashi $H$, Noda $N$, Terada $H$, Kobayashi $A$, Hirano $M$, Xamashita $Y$, Yamazaki $\mathrm{N}$. Regularion of $\left[\mathrm{Na}^{*}\right]_{i}$ and $\left[\mathrm{Ca}^{2}{ }^{2}\right]_{i}$ in guinea pig myocytes: dual loading of fluorescent indicators SBEI and fuo 3. Am / Physial. 1994;266; H568-H576.

204. Xiao RP, Lakarta EG. $\beta_{1}$-Adrenoceptor stimulation and $\beta_{x}$-adrenoceptor stimulation differ in their effects on contraction, cytosolic $\mathrm{Ca}^{2}{ }^{2}$, and $\mathrm{Ca}^{2+}$ current in single rat ventricular cells. Cime Res, 1993,73:286-300.

205. Grynkiewicz G, Poenie M, Tsien RY. A new generation of $\mathrm{Ca}^{2+}$ indicators with greatly improved Aworescence properties. J Biol Chem 1985,260:3440-3450. 


\section{Summary}

Under normal circumstances, the rhythmic activity of the heart is controlled by electrical impulses that originate in the sinus node and travel through the atria and the atrioventricular node to the ventricles. Via the specialized conduction system of the ventricles (bundle of His, left and right bundle branches, and Purkinje fibers), the impulses are transferred to the ventricular muscle cells. Every heart beat is the result of the synchronized activation and consequent contraction of these cells in the left and right wentricular wall, followed by the recovery from electrical activation and the relaxation from contraction, respectively.

At the level of the single myocyte, elecrrical stimulation during diastole initiates the action potential. Various ion fluxes crossing the membrane are responsible for the depolarization and repolarization phases of the action potential. The depolarization (phase 0 ) is generated mainly by the influx of $\mathrm{Na}^{+}$and $\mathrm{Ca}^{2+}$ ions, whereas the repolarization (phases 1 to 3 ) is determined by a large number of in-and outward currents, including inacrivating $\mathrm{Na}^{+}$and $\mathrm{Ca}^{2+}$ currents, various $\mathrm{K}^{+}$currents, $\mathrm{Na}^{+}-\mathrm{Ca}^{2+}$-exchange current, $\mathrm{Cl}$ - current and $\mathrm{Na}^{+}-\mathrm{K}^{+}$-pump current. The resting membrane potential (phase 4) is maintained by the concerted action of the so-called inward rectifier $\mathrm{K}^{+}$current, the $\mathrm{Na}^{+}-\mathrm{K}^{+}$-pump current, and (depending on the intracellular $\mathrm{Na}^{+}$and $\mathrm{Ca}^{2+}$ concentrations) the $\mathrm{Na}^{+}-\mathrm{Ca}^{2+}$-exchange current. It is likely that also other currents contribute to the resting phase.

Contraction is initiated by the influx of $\mathrm{Ca}^{2+}$ ions into the cell during the early phase of the action potential. This influx triggers the release of a much larger pool of $\mathrm{Ca}^{2+}$ stored in the sarcoplasmic reticulum. The cytoplasmic $\mathrm{Ca}^{2+}$ made available by this process (called ' $\mathrm{Ca}^{2+}$-induced $\mathrm{Ca}^{2+}$ release') serves to acrivate the myofilaments causing contraction via the 'cross-bridge cycle'. At the end of contraction, the majority of $\mathrm{Ca}^{2+}$ ions is taken up again by the sarcoplasmic reticulum, whereas a small fraction is extruded from the cell interior by the $\mathrm{Na}^{+}-\mathrm{Ca}^{2+}$ exchanger.

Under circumstances of mechanical overload, such as during hypertension, myocardial infarction, valvular disease, idiopathic hypertrophic or dilated cardiomyoparhy, and complete atrioventricular block, the heart employs a number of intrinsic and extrinsic mechanisms in an atrempt to maintain a normal cardiac output. One of the manifestations of chronic overload is ventricular hypertrophy, but many other complex responses occur. The contractile performance of the heart may initially show a compensatory adaptation, but, dependent on the degree and duration of overload, this is often followed by the development of some form of pump failure. In part, these contractilealterations are reducible to (mal) adaptive changes of the myocardial $\mathrm{Ca}^{2+}$ homeostasis.

With respect to electrophysiological alterarions, consistent features observed in numerous animal models and patients with cardiac hypentrophy or failure are the prolongation of the ventricular action potential and accentuated regional differences in 
acrion-potential durations. This may cause beat-to-beat variations of the QT interval on the electrocardiogram and latent or overt forms of acquired QT prolongation, both of which have been related to an increased risk of sudden cardiac death due to an enhanced suscepribiliry to ventricular tachyarthythmias.

In the present thesis the cellular basis of acquired QT prolongation and enhanced susceptibility to the polymorphic ventricular tachyarrhythmia "torsades de pointes" is investigated in the dog with complete atrioventricular block of chronic duration. For this purpose, adult mongrel dogs were operated and their atrioventricular node irreversibly damaged. In the ensuing condition the conduction of electrical impulses through this node is interrupted, which causes independent beating of the atria and the ventricles. Furthermore, the heart rate drops to approximately 45 beats per minute and is fully dependent on impulse generation from the ventricles, which is intrinsically slow. As a result, the stroke volume during systole and the filling of the ventricles during diastole increase. This state of increased cardiac load causes hypertrophy of both the left and right ventricle.

Chapter 1 comprises the general introduction to the thesis and a historical overview of the congenital and acquired long-QT syndromes, and torsades de pointes. It is described that the ventricular arrhythmias of cardiac hypertrophy and failure appear to be based partly on pathological action-potential prolongation and increased regional dispersion of repolarization, and thus resemble the long-QT syndromes. The dog model with complete atrioventricular block is introduced and the aims of the suidy are put forward. The meaning of 'The Substrate' and 'The Trigger' is explained.

In Chapter 2 the regional heterogeneity of the action-potential configuration and duration in the normal dog heart is described. The new finding of action-potential differences between the left and right ventricular midmyocardium is further investigated in voltage-cllamp studies, and appears to be attributable to differences in $\mathrm{K}^{+}$currents. This means that electrical remodeling of the ventricles during cardiac overload starts from uneven action-potential characteristics, which must be taken into account to explain arthythmogenesis under these circumstances.

In Chapter 3 the cellular basis of biventricular hypertrophy and arrhythmogenesis in the dog with chronic complete atrioventricular block is examined. Ventricular enlargement is the result of cellular hypertrophy of both the left and right ventricular myocytes. In this animal model the interventricular differences of actionpotential duration (known from control hearts) are exaggerated, predominantly by a pronounced prolongation of the left ventricular action potential. Midmyocardial myocytes from both ventricles exhibit an abnormal response to dlass III antiarrhythmic agents with much larger increases of the acrion-potential duration and a higher incidence of early afterdepolarizations than control cells. The data indicate that ventricular repolarization in chronic complete atrioven tricular block is intrinsically weak and may predispose to class III-dependent torsades de pointes in vivo.

It is outlined in Chapter 4 thar downregulation of certain $\mathrm{K}^{+}$currents contributes to the repolarization abnormalities in these dogs. In left and right midmyocar- 
dial myocytes, the slowly activaring component of the delayed rectifier $\mathrm{K}^{*}$ current; which constitutes a significant fraction of the outward current underlying normal ventricular repolarization, shows markedly lower amplitudes. Furthemote, in the right ventricular cells the rapidly activating component of the delayed tectifer $K^{+}$current is also decreased. Unlike other animal models and patients with cardiac hypertrophy or failure the transient outward $K^{*}$ current is not altered. Thus, the ionic basis of acquired QT prolongarion in dogs with chronic complete atroventricular block resembles to some extent the $\mathrm{K}^{*}$-current defects known for some of the human congenital long $\mathrm{QT}$ syndromes.

A detailed description of the cardiac contractile performance and cellular $\mathrm{Ca}^{2+}$ handling in chronic complete atrioventricular block is given in Chapter 5 . Conrractile function in vivo is enhanced, in particular at the slow idioventricular rate. Likewise, cell. contraction and $\mathrm{Ca}^{2+}$ release from the sarcoplasmic reviculum in single left and right midmyocardial myocytes are enhanced ar slow stimulation frequencies. Whereas $\mathrm{Ca}^{2 *}$ influx through $\mathrm{L}$-type $\mathrm{Ca}^{2+}$ channels is unchanged, $\mathrm{Ca}^{2}$ influx via reverse-mode $\mathrm{Na}^{+}-\mathrm{Ca}^{2+}$ exchange is significantly increased and contributes to cellular $\mathrm{Ca}{ }^{2}$ loading, but also to $\mathrm{Ca}^{2 *}$ overload. Inward-mode $\mathrm{Na}^{+}-\mathrm{Ca}^{2+}$-exchange currents are increased in left (but not right) ventricular cells, which, in response to the larger $\mathrm{Ca}^{2+}$ transients, may cause sufficient inward current to impain a fast repolarization. Therefore, the upregulation of $\mathrm{Na}^{+}-\mathrm{Ca}^{2+}$ exchange may improve contractile adaptation to chronic complete arrioventricular block, but at the same time promote proarthythmia by increasing regional dispersion of repolarization and increasing the propensity to $\mathrm{Ca}^{2}$. overload and spontaneous $\mathrm{Ca}^{2+}$ release from the sarcoplasmic reticulum.

In Chapter 6 the cellular arrhythmogenic consequences of spontaneous $\mathrm{Ca}^{2+}$ release from the sarcoplasmic reticulum are investigated in normal canine ventricular myocytes. $\mathrm{Ca}^{2+}$ overload is induced by low concentrations of isoproterenol, which stimulates the $\beta 1$ - and $\beta 2$-adrenergic receptors and theit intracellular cascades leading to enhanced L-type $\mathrm{Ca}^{2+}$ currents and enhanced $\mathrm{Ca}^{2+}$ uptake into the sarcoplasmic reticulum. Based on contraction measurements it is concluded that spontancous $\mathrm{Ca}^{2+} \mathrm{re}-$ lease can occur during the action potential and after completion of the repolatization, corresponding with carly and delayed afterdepolarizations, respectively. These membrane responses can trigger new action potentials via various mechanisms. "The results indicate that a $\mathrm{Cat}^{2+}$-activated membrane cument is necessary for both types of afterdepolarizations. The importance of these mechanisms lies in their capacity to generate the extrasystolic activity that may initiate torsades de pointes under circumstances of increased sympathetic activation.

Chapter 7 contains a discussion of the specific electrical alterations in the dog with chronic complete atrioventricular block and how these alterarions could lead to arrhythmias. The possible pathogenetic stimuli for electrical remodeling are ourlined in a schematic diagram.

Finally, in Chapter 8 the results of these studies are discussed in broader perspective, from cell to clinic. A review is given on recent advances in cardiac 
arhythmology related to afterdepolarixations. Subsequently, the emergence of new views on $\mathrm{Ca}^{2+}$-dependent mechanisms of abnormall impulse generation, and their significance for the initiation and treatment of torsades de pointes are contemplated. 


\section{Samenvatting}

Onder normale omstandigheden wordt de ritmische aktiviteit van het hart gecontroleerd door elektrische impulsen die ontstaan in de sinusknoop en die vervolgens door de boezems en de arrioventrikulaire knoop naar de kamers bewegen. Via het gespecialiseerde geleidingssysteem van de kamers (bundel van His, linker en rechter bundeltakken, en Purkinje vezels), worden deze impulsen naar de hartspiercellen van de kamers (ofwel de ventrikels) voortgeleid. Elke hartslag is het resultaat van de gesynchroniseerde aktivatie en de daardoor geïnduceerde contractie van de hartspiercellen in de linker en rechter kamerwand, gevolgd door een herstelfase van de elektrische aktivatie en de relaxatie van de contractie.

In de individuele hartcel initieert elektrische srimulatie tijdens diastole de aktiepotentiaal. Multipele ionenstromen die de celmembraan passeren, zijn verantwoordelijk woor de depolarisatie- en repolarisatie-fasen van de akriepotentiaal. De depolarisatie (fase 0) gebeurt voornamelijk door de influx van $\mathrm{Na}^{+}$- en $\mathrm{Ca}^{2+}$-ionen. De repolarisarie (fasen 1 tot 3) wordr bepaald door vele in- en uitwaartse stromen, waaronder inaktiverende $\mathrm{Na}^{+}$- en $\mathrm{Ca}^{2+}$-stromen, verschillende $\mathrm{K}^{+}$-stromen, $\mathrm{Cl}^{-}$-stroom, en de stromen gegenereerd door de $\mathrm{Na}^{+}-\mathrm{Ca}^{2+}$-uirwisselaar en de $\mathrm{Na}^{+}-\mathrm{K}^{+}$-pomp. De rust-membraanpotentiaal (fase 4) wordt in stand gehouden doot de zogenaamde inwaarts-rectificerende $\mathrm{K}^{+}$-stroom, de $\mathrm{Na}^{+}-\mathrm{K}^{+}$-pomp-stroom, en (afhankelijk van de intracellulaire $\mathrm{Na}^{+}{ }^{+}$en $\mathrm{Ca}^{2+}$-concentraties) de $\mathrm{Na}^{+}-\mathrm{Ca}^{2+}$-uitwisselaar-stroom. Her is waarschijnlijk dat ook andere stromen bijdragen aan de rustfase.

De contractie wordt geïnitieerd door de influx van $\mathrm{Ca}^{2+}$-ionen in de cel tijdens de vroege fase van de aktie-potentiaal. Deze influx veroorzaakt de vrijstelling van een veel grotere hoeveelheid $\mathrm{Ca}^{2+}$ opgeslagen in het sarcoplasmic rericulum. Her cytoplasmatische $\mathrm{Ca}^{2+}$ dat door dit proces (genaamd ' $\mathrm{Ca}^{2+}$-geinduceerde- $\mathrm{Ca}^{24}-$ tritjstelling') wordt vrijgemaakt, aktiveert de myofilamenten, hetgeen de contractie veroorzaakt. Aan het einde van de contractie wordt de meerderheid van de $\mathrm{Ca}^{2+}$-ionen weer opgenomen door het sarcoplasmatisch reticulum, terwijl een klein deel via de $\mathrm{Na}^{+}-\mathrm{Ca}^{2+}$-uirwisselaar uit de cel verdwijnt.

Onder omstandigheden van mechanische overbelasting van her hart, zoals tijdens hyperrensie, hartinfarct, kleplijden, idiopathische hypertrofische en gedilateerde cardiomyopathie, en compleet atrioventrikulair geleidingsblok, gebruikt het hart een aantal intrinsieke en extrinsieke mechanismen om te proberen de normale cardiale output te handhaven. Eén van de veranderingen tijdens chronische overbelasting is ventrikulaire hypertrofie, maar vele andere complexe responsen treden ook op. De contractiele eigenschappen van het hart kunnen in her begin een compensatoire adaptatie ronen, maar, afhankelijk van de mate en de duur van de overbelasting, wordt dit vaak gevolgd door de ontwikkeling van hartfalen. Deze contractiele veranderingen 
zijn deels gebaseerd op (mal)adaptieveveranderingen wan de myocardiale $\mathrm{Ca}^{2}+$ homeostase.

Ten anzien wan de elektrofysiologische veranderingen wijdens chronische overbelasting van de harspier zijn er twee consistente bevindingen die in talloze diermodellen en patienten met ardiale hypertrofie of falen opvallen: verlenging van de ventrikulaire aktiepotential en toegenomen regionale verschillen in de aktiepotentiaal-duur. Dit kan geaccentucerde QT-variabiliteit op het elektrocardiogram veroorzaken en latente of owerte vormen van verworven QT-prolongatie. Beide zijn geassocieerd met een verhoogd risico op plotse hardood als gevolg van een toegenomen gevoeligheid woor kamertachycardieèn.

In dit proefschrift wordt de cellulaite basis van verworven QT-verlenging en verhoogde gevoeligheid voor polymorfe ventrikulaire tachycardieën, de zogenaamde 'rorades de pointes', in honden met chronisch compleet atrioventrikulair geleidingsblok onderzocht. Hiervoor werden volwassen honden geopereerd en hun atrioventrikulaire geleiding onherstelbat geblokkeerd. In deze toestand kloppen de boezems en de kamers wan het hart onafluakelijk van elkaar. De harrslag claalt naat ongeveer 45 slagen per minuut en is volledig afhankelijk van impulsworming in de kamers, welke intrinsiek traag is. Dientengevolge stijgen het slagvolume tijdens systole en de vulling van de kamers tijdens diastole. Deze staat van verhoogde cardiale belasting veroorzakt hypertrofie van zowel de linker- als de rechrerventrikel.

Hoofdstuk 1 bevat de algemene introduktie van her proefschrift en een historisch overzicht van de congenitale en verworven lange-QT-syndromen, en torsades de pointes. Er wordt in beschreven dat de ventrikulaire ritmestoornissen van cardiale hypertrofie en falen, tenminste gedeeltelijk, gebaseerd lijken te zijn op pathologische akriepotentiaal-werlenging en verhoogde regionale dispersie van cle repolarisatie, en zo een gelijkenis vertonen met de lange-QT-syndromen. Her hondenmodel met compleet atrioventrikulair blok wordt geintroduceerd en de doelstellingen van de studie geformuleend. De betekenis van 'The Substrate' en 'The Trigger' wordt uitgelegd.

In Hoofdstulk 2 wordr de regionale heterogeniteit in de vorm en de duurvan de aktiepotentiall in het normale hondenhart beschreven. De nieuwe bevinding van akriepotential-verschillen tussen her linker-en rechrerwentrikel midmyocard wordt verder onderzochr in voltage-clamp-experimenten warmee de diverse ionenstromen aftzonderlijk bestudeend kunnen worden. Verschillen in $K^{+}$-stromen lijken bij te dragen aan de aktieporentiaal-verschillen. Dit betekent dat de elektrische veranderingen van het kamermyocand tijdens cardiale overbelasting reeds beginnen met regional ongelijke aktiepotential-kenmerken, hergeen in acht moet worden genomen om de aritmogenese onder zulke omstandigheden te verklaren.

In Hoofdstuk 3 word de cellulaire basis van biventrikulaire hypertrofie en aritmogenese in de hond met chronisch compleet atrioventrilkulair geleidingsblok onderzocht. Ventrikulaire vergroting is her gevolg wan cellulaire hypertrofie wan zowel de linker-als de rechterkamercellen. In dir diermodel zijn de (nomaal reeds aanwezige) interventrikulaire verschillen van de aktiepotential-duur vergroot, hoofdzakelijk door 
een forse verlenging van de aktiepotentiaal van de linkerventrikel. Midmyocardiale cellen van beide kamers vertonen een abnormale respons op klasse-III-antiaritmica met een veel grotere verlenging van de aktiepotentialen en een frequenter voorkomen van wroege nadepolarisaties dan controlecellen. De resultaten geven aan dar de ventrikulaire repolarisatie in chronisch compleet atrioventrikulair blok intrinsiek verzwakt is en kan predisponeren voor klasse-III-afhankelijke torsades de pointes in vivo.

In Hoofdstuk 4 wordt ingegaan op een verklaring voor de repolarisatie-afwijkingen in de hond met chronisch compleet atrioventrikulair geleidingsblok. Het blijkt dat een afname van bepaalde $\mathrm{K}^{*}$-stromen hieraan bijdraagt. In linker en rechter midmyocardiale cellen, vertoont de traag-akriverende component van de zogenaamde dellayed rectifier $\mathrm{K}^{+}$stroom (die een significante bijdrage in de normale ventrikulaire repolarisatie heeft) opmerkelijk lagere amplitudes. Verder is in de rechterkamercellen de snel-aktiverende component van de delayed rectifier $\mathrm{K}^{+}$stroom ook verlaagd. In regenstelling tor andere diermodellen en patiënten met cardiale hypertrofie of falen is de zogenaamde transiënte uitwaartse $\mathrm{K}^{+}$stroom niet verlaagd. Zo lijkt de ionische basis wan verworven QT verlenging in honden met chronisch compleet arrioventrikulair blok op de bekende $\mathrm{K}^{*}$-stroom-afwijkingen van sommige van de humane congenitale lange-QT syndromen.

Een gedetailleerde beschrijving van de cardiale contractiele eigenschappen en de cellulaire $\mathrm{Ca}^{2+}$ homeostase in honden met chronisch compleet atrioventrikulair geleidingsblok wordt gegeven in Hoofdstuk 5. De contractiele funktie in vivo is verhoogd, mer name tijdens het trage idioventrikulaire ritme. De cellulaire contractie en $\mathrm{Ca}^{2+\pi}$-vrijstelling uit het sarcoplasmatisch reticulum in individuele linker en rechter midmyocardiale myocyten zijn eveneens verhoogd tijdens trage stimulatie-frequenties.

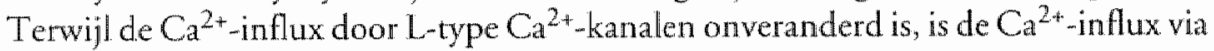
uitwaartse $\mathrm{Na}^{+}-\mathrm{Ca}^{2+}$-uitwisseling significant verhoogd en draagt dit bij tot cellulaire $\mathrm{Ca}^{2+}$ lading, maar ook tot overlading. De inwaartse $\mathrm{Na}^{+}-\mathrm{Ca}^{2+}$-uitwisselaarstroom is verhoogd in linker-, maar niet in rechterventrikelcellen en in respons op de grotere $\mathrm{Ca}^{2+}$ transienten kunnen deze voldoende inwaartse stromen genereren om de repolarisatie te verzwalken. Om deze redenen kan een toegenomen $\mathrm{Na}^{+}-\mathrm{Ca}^{2+}$-uitwisseling de contractiele adaptatie tijdens chronisch compleet atrioventrikulair blok verbeteren, maar op herzelfde moment de kans op ritmestoornissen vergroten door een toename van de regionale dispersie van de repolarisatie en de neiging tot $\mathrm{Ca}^{2+}$ overlading en spontane vrijstelling van $\mathrm{Ca}^{2+}$ uit het sarcoplasmatisch reticulum.

In Hoofdstuk 6 worden de aritmogene consequenties van spontane $\mathrm{Ca}^{2+}$ vrijstelling uit het sarcoplasmatisch reticulum in normale myocyten van het hondenhart besproken. $\mathrm{Ca}^{2+}$ overlading wordr geïnduceerd door lage concentraties isoproterenol. Isoproterenol stimuleert de $\beta 1$ - en $\beta 2$-adrenerge receptoren en hun intracellulaire second messengers, hergeen leidt tot vergrote $\mathrm{L}$-type $\mathrm{Ca}^{2+}$-stromen en verhoogde $\mathrm{Ca}^{2+}$ opname in het sarcoplasmatisch reticulum. Op basis van contractie-metingen kan geconcludeerd worden dat spontane $\mathrm{Ca}^{2+}$ vrijstelling tijdens en na de aktiepotentiaal kan optreden, en gepaard kan gaan met vroege en late nadepolarisaties. Deze 
membraan-responsen kunnen via verschillende mechanismen nieuwe aktiepotentialen veroorzaken. De resultaten geven aan dar een $\mathrm{Ca}^{2+}$-geakriveerde membraan-stroom noodzakelijk is woor beide typen van nadepolarisaties. Het belang van deze mechanismen ligt in hun capaciteit de extrasystolische aktiviteit te genereren die torsades de pointes kan initièren onder omstandigheden van verhoogde symparhische aktivatie.

Hoofdstuk 7 bestaat uit een discussie van de specifieke elektrische veranderingen in de hond met chronisch compleet atrioventrikulair geleidingsblok en hoe ze tot ritmestoornissen kunnen leiden. De mogelijke pathogenetische stimuli voor elektrofysiologische weranderingen worden in een schematisch diagram weergegeven.

Als laatste worden in Hoofdstuk 8 de resultaten van deze studies in breder perspectief bediscussieerd, van cel tot kliniek. Een overzicht van de recente vooruitgangen op her gebied van de cardiale aritmologie gerelateerd aan nadepolarisaties wordt gegeven. Vervolgens worden nieuwe inzichten over $\mathrm{Ca}^{2+}$-afhankelijke mechanismen van abnormale impulsworming, en hun belang woor de initiatie en behandeling van torsades de pointes besproken. 


\section{Dankwoord}

Onderzoek naar het hoe en waarom van hartritmestoornissen is een uitdagende bezigheid. Het vereist een fundamentele kennis van de electrofysiologie from cell to bedside. Alleen zo kan de chaos van gebeurtenissen die de hartslag ontregelen, ontrafeld worden. Ik had her geluk mijn promotie-onderzoek te mogen uitvoeren bij de vakgroep Cardiologie van het Academisch Ziekenhuis Maastricht met een wereldfaam op dit gebied. Daarnaast kon ik gebruik maken wan de uitstekende faciliteiten en organisatie van het Cardiovascular Research Institute Madstricht van de Universiteit Maastricht.

Veel mensen hebben bijgedragen tor het welslagen van dit werk en het is haast ondoenlijk ze allemaal te danken. Hier volgt een poging ...

Prof. Hein Wellens is mijn grote inspirator, iemand mer een fenomenale kennis van het electrocardiogram, de hartritmestoornissen en de Cardiologie in het algemeen, een klinicus pur sang, een man met een goed richtingsgevoel woor relevante ontwikkelingen op ons vakgebied. Hij zag perspectief in het opstarten van een laboratorium voor cellulaire electrofysiologie, en heeft deze en verwante basale disciplines in hun opbouw gesteund. Prof. Wellens, bedankt dat U mijn promotor wilt zijn, ik ben er trots op!

Dr. Marc Vos is de initiator en motor van mijn AlO-project. Beste Marc, vanaf het eerste moment, in 1.992, heb jii je vollop ingespannen voor een goede organisatie, een stimulerende begeleiding, en een nauwe betrokkenheid bij mijn dagelijkse werkzaamheden. Je reisde de halve wereld rond om te volgen waar ik mee bezig was en je moest op de koop toe met een knorrende maag naar het famous Spaghetti Warehouse bij ons om de hoek in Norman ... Onder jouw leiding heeft de Experimentele Electrofysiologie wan onze vakgroep zich verder gevestigd en is er differentiatie opgetreden in cellulaire en moleculaire richting. Telkens zocht je naar een acceptabele balans tussen de belangen van het individu en de groep. Wat er nu staat, daar hebben we samen voor geknokt en dat geft een goed gevoel. Echter, de ontwikkelingen gaan verder en her moment is gekomen om nieuwe functies te creëren en taken te delegeren. Bedankt dat je mijn co-promotor wilt zijn en voor je steun door de jaren heen.

Mijn andere co-promotor Dr. Karin Sipido is bij her AlO-project betrokken sinds eind 1994. Karin, ik heb bewondering voor de wijze waarop je de rollen van onderzoeker, arts, echtgenote en moeder van twee kinderen kunt combineren. Met veel roewijding en succes heb je verantwoordelijkheid genomen voor de cellulaire onderzoekslijnen binnen het Laboratorium voor Experimentele Cardiologie in Leuven. Je internationale aanzien op het gebied van de cardiale excitatie-contractie koppeling is tor grote hoogte gestegen. Bij dit alles heb je tijd weten te vinden om mij te begeleiden. Ik heb goede herinneringen aan onze eerste ontmoetingen in het Laboratorium voor Fysiologie in Leuven (mede dankzij Dr. Geert Callewaert), en ik wil je bedanken woor jc kritische blik op de experimenten en je inhoudelijke bijdragen aan mijn proefschrift. Ik 
hoop dat we in de roekomst nog veel nieuwe studies zullen uitwoeren. Bedankt dat je mijn co-promotor wilt zijn.

Het was cen eer dat ik mocht samenwerken met Prof. Edward Carmeliet en ik ben hem zeer erkentelijk voor zijn, haast vaderlijke, betrokkenheid bij mijn onderzoekingen en de opbouw van het proefschrift. In de periode december 1994 tot maart 1995 onderwees hij mij de praktische beginselen van het voltage clampen in Leuven (mer dank. aan Jean Prenen) en de biofysische betekenis van ionenstromen in hartcellen. Ik had. geen betere leermeester kunnen treffen. Prof. Carmeliet, tijdens onze frequente contacten in Leuven en Maastricht, en in andere plaatsen van de wereld, heb ik niet alleen veel van U geleerd, maar hebben we ook alrijd plezier gehad (vaak bij een heerlijke dis en een goed glas wiin). Daarbij heeft $U$ telkens ook belangstelling getoond voor zaken die buiten het werk liggen. Hartelijk dank voor al die momenten.

I am most grateful to Dr. Bela Sxabo and Prof. Ralph Lazzara for inviting me to their laboratories at the University of Oklahoma Health Sciences Center of Oklahoma City in 1993 and 1994. My first acquaintance with the complex matters of cellular electrophysiology was under their guidance. Patience, a challenging attitude, and an endless support characterize their teaching during the $11 / 2$ years of my stay and thereafter. Ilja and Ihad a splendid time in Oklahoma. The warm whearher, the beautiful lakes and the red earth are engraved in our memories. A special word of thank goes to you, Bela and Eva, for your hospitality during a couple of visits in the last years. I wish you all the luck and health for the future. Beware of the tornados.

Deleden van de beoordelingscommissie Prof. Mat Daemen, Prof. Maurits Allessie en Prof. Marcel Borgers wil ik bedanken voor hun bereidheid her manuscript kritisch door te lezen en tijdens de verdediging te opponeren. In the same manner, I thank Prof. Charles Antzelevitch and Prof. Dirk Beuckelmann for reviewing the thesis manuscript and for making the long trip to Mastricht to attend the defense.

Mijn paranimfen Marieke de Groot en Henny Leerssen hebben me bijgestaan bij de organisatie van deze promotie. Gelukkig maar, want alleen was dat nooit gelukr. Marieke, jij gaf vorig jaar her goede voorbeeld met je eigen promotie en vanuit die ervaring konden we het draaiboek voor mijn promotie vlot samenstelien. Ondanks de drukke voorbereidingen van je huwelijk heb je tijd gevonden om me op vele punten te helpen. En erbleef ook nog ruimte om samen mer de partners een heleboel leuke dingen te ondernemen. Als je dit leest hebben Maurits en jij elkaar het Ja-woord gegeven en dat geeft me de gelegenheid jullie nogmaals alle geluk toe te wensen. Ik hoop dar we als collega's en echre vrienden nog veel bijzondere momenten mogen meemaken. Henny, net als Marieke was jij een van de collega's van het eerste uur. I $\mathrm{k}$ was en ben nog steeds gefascineerd door het antitachyardia-pacing onderzoek wat je je mee bezig hebr gehouden. Het leek me een goede zaak de fakkel door te geven nu jouw eigen promotie aanstaande is. Onze rollen zijn dan omgedraaid en ik ben vereerd dat ikje als paranimf mag helpen. We gaan er een mooie dag van maken! Je was niet alleen een fijne collega, maar ook een goeie kameraad (met uitzondering van het moment van je medeplichtigheid aan her rode-kart incident ...). Tijdens de keren dat Mlja en ik bij jullie thuis waren, leerden we je 
kennen als een echte familie-man, pas echt compleer met Marlie, Casper en Eeke inde buurt. Je relativerende blik op her werk in relatie tor gezin heeft altijd indruk gemakkt. Henny en Marieke, bedankt dat jullie mijn paramimfen willen zijn.

Dr. Attilla Kulcsár, you were my colleague for almost three years boch in Oklahoma City and in Maastricht, and we took some big hurdles on our way to learn about the interior of the heart. I thank you for all your efforts in the cellular laboracory in Maastrichr. Wealso had a lot of fun outside the working places. The drive to Tulsa, the SMALL steaks in my apartment, the rear lock of your big brown Oldsmobile, the socer games on the Norman campus and in Houthem (you even made it to the first ream of IASON and they still call your name there), your fully-understandable conversations in Hungarian, or was it Slovak? These are just a few of the many good memories! I still hope to get an opportunity to visit Bratislava.

Graag wil ik Prof. Fons Verdonck (Katholieke Universiteit Leuven, Campus Kortrijk) bedanken voor zijn inspanningen in het onderzock naar de rol van de $\mathrm{Na}^{+}-\mathrm{K}^{+}$-pomp en de intracellulaire $\mathrm{Na}^{+}$-concentratie van de AV-blok-cellen. Ik ben zeer benieuwd naar de uiteindelijke bevindingen.

Mijn collega's van de Experimentele-Cardiologie-groep hebben in belangrijke mate bijgedragen tot een plezierige werksfeer. Het zijn er nogal wat geweest in de afgelopen jaren: Roel, Jet, Jérôme, Jurren, Dirk, Xander, Marieke Schoenmakers, Cora, Ferenc, Evgeny, Tamas, Mirella, Stephan, Johannes en Jolanda. Roel, jouw betrokkenheid bij her reilen en zeilen van het cel-lab is groot. Je hebt je ontwikkeld to een vaste waarde die zich de electrofysiologische technieken swel eigen maakre. Ik kan me niet herinneren dar ik je ooit én keer tevergeefs om hulp hebr gevraagd. Geweldig! Jet, dank voor je enthousiaste samenwerking en de goede verzorging van de honden in en buiten de OK. En voor je organisatie van de korte wandelingerjes. Jéròme, veel succes mer je eigen promotie-onderzoek! Met plezier denk ik terug aan de heerlijke dinertjes samen met Ilja en Belinda. En we hebben met volle teugen genoten van een glaasje whiskey, single blend of double malt of was het nou andersom? Jurren, amite, over jou kan ik een boek schrijven en menig boekje open doen. $1 \mathrm{k} \mathrm{denk}$ dar je het meest in je element bent als je in driedeligkostuum, in een chique et-tent, met net iets teveel wijn op, en een wilde Havana in de hand, blakend van zelfyert rowwen, ongenuanceer de uitspraken makkt in een discussie met een gewichtig persoon. Op de werkvloer ben je een prima collega, altijd goed gehumeurd en de joker van het ream. Veel succes met de adrenerge studies en je eigen promocie. Dirk, de goede vragen zin vaak her moeilijkst te stellen, maar met zoveel Deutsche Gründlichkeit zal het probleem wan hibernatie spowedigzijn opgelost. Bedankr voor je enchousiasme. Xander, we zullen clkar nog wel wak tegen komen op het raakvlak van de Moleculare en de Cellulaire Cardiologie. Ik kijk zeer thit naar je resultaten in New York. Succes daar!

In de Yruimte heb ik verder altijd prettig kunnen samenwerken met Domien Engelen (succes mer de afronding van jouw promotie!), and also I wish to thank Ashish Nabar and Ravinder Batra for being good colleagues. When are we going for a beer? 
Gragg wil ik de stafleden wan de vakgroep Cardiologie bedanken en met name Dr. Anton Gorgels die nauw betrokken was bij de opzet wan dit AIO-project, bij de eerste contacten met Oklahoma City en bij her schrijven van de Review.

De dames van het secretariaar wilik hartelijk danken voor hun dagelijkse hulp in tal wan zaken. Met name Vivian S., Birgit, Lenny, Viviane L., Monique, Margriet en Marion. Voor de ondersteuning van computer-zaken en het netwerk-beheer waren Berto en Rob van wezenlijke betekenis, en dit geldt ook voor Léon Dohmen aan de universitaire zijde.

Ik ben Maaike Peschar (Fysiologie) en Bart Stubenitsky (Algemene Heelkunde) erkentelijk voor her beschikbaar stellen van de honden. Verder dank ik de collega's van de vakgroep Fysiologie (onder leiding van Prof. Maurits Allessie) voor hun gewaardeerde samenwerking.

De kundige heren van de Instrumentele Dienst (afdeling FMT onder leiding van Jan Aerts) verdienen een woord van dank voor hun adequate en snelle hulp bij tal van technusche vragen en problemen. De Centrale Proefdier Voorzieningen (onder leiding van Ton van den Boogaard) voor de goede verzorging van de honden.

In de spaarzame vrije tijd konden we altijd terecht bij onze familie, vrienden, en kennissen voor een kop koffie of een etentje. In het bijzonder wil ik bedanken: Jo Simons, mijn schoonouders, Maarten en Oswin, mijn eigen familie, de familie van Ilja, Esther, Pascal en Emma, Tanja en Frank (zet 'm op 10 julit), Bart en Dorothee, Marieke en Maurits, Henny en Marlie, de buren van de Prinses Irenelaan en al onze overige kemnissen.

De artistieke impressie van torsades de pointes op de omslag is van de hand van mijn inmiddels beroemde zus. Claudia, ik wil je bedanken voor dit en al de andere prachrige werken die je vervaardigt. Je bereikt er veel mensen mee. Succes op de aankomende tentoonstellingen. Claudia en Sven, bedankt voor de gezellige momenten die we meemaken. Het wordt tijd dat we weer eens een caravan-tocht plannen. Wellicht dat jullie dan het woord kunnen nemen.

Mam, ons ritje naar Groningen is al menig maal de moeite waard gebleken. Dit proefschrift is een nieuw hoogtepunt. Er is zoveel waar ik jou en pappa voor moer bedanken. Van kinds af aan hebben jullie me in alles geholpen en gesteund. Me geleerd wat doorzettingsvermogen is. Zaken re kunnen relativeren. En ook: oog te hebben voor de estherische dingen van het leven. Het is heel wonderlijk hoe de wetenschap en de kunst zijn samengevloeid in ons gezin. Bedankt voor alles! Met een knipoog naar boven.

Lieve Ilja, het boekje is eindelijk af. Al die avonden en nachten achter de computer zijn niet voor niets geweest. Je was er altijd voor mij en ik nier altijd voor jou. "Nog even iets afmaken.... Morgen isereen deadline ..., Ik kam zo naar bed.... Ik moet dat artikel nog lezen ..., Is het al zo laatt? Nu kunnen we de tijd gaan inhalen. Ik ben intens gelukkig mer elke dag van ons huwelijk. En het mooiste staat ons nog te wachren! De harttonen die we recent gehoord hebben, klonken als muziek in de oren. Ik kan er geen genoeg van krijgen. Snel en regelmatig, geheel anders dan het onderwerp van dit proefschrift. De geboorte van ons kindje is nabij en maakt alle andere dingen eigenlijk totaal onbelangrijk. 


\section{Curriculum vitae}

Name: Volders, Paul Gertrudis Alphonsus

Date of Birth: July 31, 1968

Place of Birth: Heerlen, Netherlands

Marital Status: Married

Edtacation: Gymnasium $\beta$, Stella Maris College, Meerssen, Netherlands, graduated in 1988.

Medicine, Maastricht University, Maastricht, Netherlands.

M.D. degree in 1997.

Ph.D. student at the Department of Cardiology, Cardiovascular Research Institute Maastricht, Netherlands under the guidance of Prof. dr. H.J.J. Wellens, Dr. M.A. Vos and Dr. K.R. Sipido (Laboratory of Experimental Cardiology, University of Leuven, Belgium).

Project: "Cellular Medanisms of Ventricular Arrhythmins in Cardiac Hypertrophy and Failure?. Period: 1993 to 1999.

Resident in Cardiology at the Academic Hospital Maastricht, Netherlands. Period 1999-2006.

External Stays: Département de Parhologie, Centre Médicale Universitaire, Geneva, Switzerland under the guidance of Prof. dr. $\mathrm{G}$. Gabbiani. Period: June to July 1991.

Department of Medicine, Cardiovascular Section, University of Oklahoma Health Sciences Center and Department of Vererans Affairs Medical Center, Oklahoma Ciry, OK, USA under the guidance of Prof. dr. R. Lazzara and Dr. B. Szabo. Period: June 1993 to December 1994

Laboratory of Physiology. University of Leuven, Belgium, under the guidance of Prof. dr. E. Carmeliet. Period: December 1994 to March 1995 



\section{Publications}

\section{Abstracts}

1. Volders PGA, Havenith MG, Cleurens JPM, Daemen MIAP. Changes in interstital collagen in the human myocardium after myocardial infarction (abstract). $/$ Mol Coll Cardiol. 1991;23(suppl V):S.61.

2. Cleurjens JPM, Volders PGA, Smits JFM, Havenith MG, Daemen MJA. Toename van de extracellulaire matrix in het niet-geinfarceerde deel van het hart na een nyocardinfarce (abstraco). Nod Tijdschr Geneeskd. 1992;136:400.

3. Volders PGA, Vork MM, Glarz JFC, Smits JFM. Rapid release of heart farry acidbinding protein into plasma and myocardial infarct size after coronary ligation in the rat (abstract). Procedings of the Second International Workihop on Farty Acid-Binding Proteins (Masitricht, the Netherlands), P38, 1992.

4. Bär FW, Volders PG, Hoppener PJ, Vermeer F. QRS Changes are completed within 10 hours after onset of myocardial infarction (abstract). Circulation. 1992;86(suppl 1): I-858.

5. Bär FWHM, Volders PGA, Höppener PJ, Vermeer IF, Wellens HJJ. In acute myocardial infarction QRS changes are completed within 10 hours after onset of chest pain (abstract). Neth J Catiol. 1992;5:300.

6. Volders PG, Höppener PJ, Bär FW, Vermeer F. Early reperfusion in acute myocardial infarction diminishes changes in the QRS complex (abstract). I Am Coll Cardiol. 1993:21:273A.

7. Volders P, Szabo B, Kulcsar A, Lazzara R. Flunarinine antagonizes triggered activity but not the positive inotropic effect of isoproterenol in canine ventricular myocytes (abstract). Eur Heart J. 1994;15(suppl):192.

8. Bär FW, Volders P, Vermeer F, Hoppener P. ECG changes during the first 48 hours of myocardial infarction are similar in pts with TTMI 2 and TIMI 3 and differ from $p$ s with TIMJ 0/1 (abstract). J Am Coll Cardiol 1995;(suppl February 1995):342A.

9. Szabo B, Kulcsar A, Volders P, Lazara R. The role of $\left[\mathrm{Ca}^{2}\right]_{i}$ and $\mathrm{Na}: \mathrm{Ca}^{2}$ exchange in the "spike and dome" configuration of the action potential in caninc ventricular myocardium (abstract). Biopbys. 1995:68:A412.

10. Volders PGA, Szabo B, Kulcsar A, Lazzara R. Early aftercontractions precede canly afterdepolarizarions induced by isoproterenol in canine ventricular myocytes (abstrace). Pacing Cin Electropbysol 1995;18:831. 
11. Volders P, Kulcsár A, Sipido K, Verduyn C, Vos M, Wellens H. Proarrhythmia in dogs with chronic $\mathrm{AV}$ block is associated with biventricular hypertrophy and actionpotential prolongation (abstract). J Mol Cell Cardiol 1996;28:A228.

12. Volders PGA, Kulcsút A, Vos MA, Szabo B, Sipido KR, Wellens H. Differential rate dependence of early afterdepolarizations induced by isoproterenol versus almokalant (abstract). European Working Group on Cardiac Cellutar Electrophysiology (Ensen. Germaryy): C20, 1996.

13. Volders PGA, Kulcsár A, Sipido KR, Venduyn SC, Vos MA, Wellens HIJ. Cellular basis of biventricular hypertrophy and acrion-potential prolongation in dogs with chronic complete AV block and proarthythmia (abstract). Cardiologie. 1996;3:375.

14. Volders PGA, Kulcsár A, Vos MA, Sipido KR, Wellens HJ]. Characteristics of class-III dependent early afterdepolarizations in ventricular myocytes from dogs with chronic complete atrioventricular block and torsade de pointes (abstract). Circulation. 1996,94(suppl 1):1-744.

15. Volders PGA, Sipido KR, Kulcsár A, Vos MA, Wellens HJJ. Cellular basis of proarrhythmia in dogs with chronic complete atrioventricular block (abstract). Bioplyss). 1997;72:A47.

16. Volders PGA, Kulcsár A, Vos MA, Szabo B, Sipido KR, Wellens HJJ. Early afterdepolarizations and aftercontractions induced by isoproterenol in canine ventricular myocyces are fast-pacing dependent (abstract). I Am Coll Cadiol 1997; (suppl A):329A.

17. Sipido KR, Volders PGA, Vos MA. With reverse mode Na/Ca exchange as rrigger, Ca release from the sarcoplasmic reticulum (SR) and acrivation of the $\mathrm{Ca}$-dependent $\mathrm{Cl}$ current, are delayed, in normal as well as in hypertrophied dog ventricular myocytes (abstract). Biophys J. 1998;74:A54.

18. Volders P, Sipido K, Vos M, Carmeliet E, Wellens H. Phenotypic alterations of repolarizing $\mathrm{K}^{*}$ currents in a dog model of biventricular hypertrophy and acquired torsade de pointes (abstract) Earopean Working Group on Cardiac Cellular Electrophysiology (Milano, Itaby), O17, 1998.

19. Sipido KR, Volders PGA, de Groot SHMA, Vos MA. Enhanced cardiac contractile performance and sarcoplasmic reticulum $\mathrm{Ca}^{2}$ release in dogs with chronic complete atrioventricular block (abstract). Circulation. 1998;98(suppI I):I-141-I-142.

20. Volders PGA, Sipido KR, Carmeliet E, Spärjens RLHMG, Vos MA. Repolarizing K* currents $\mathrm{I}_{\mathrm{To}}$ and $\mathrm{I}_{\mathrm{k}, \mathrm{are}}$ larger in the right than the left ventricular midmyocardium of the dog (abstracr). Corculation. 1998;98(suppl 1):1-610-1-611.

21. Volders PGA, Sipido KR, Carmelier E, Wellens HIJ, Vos MA. Properties of $I_{K r}$ and $I_{K i s}$ in midmyocardial cells from the canine right versus left ventricle (abstract). Biopbys $\int$. 1999;76:A89.

22. wan der Huist FF, Vos MA, Leunissen HDM, Volders PGA, Wellens HIJ. Regional heterogeneiry of action potential duration in the intact hypertrophied canine heart: difference berween the septum and the left ventricular free wall (abstract). Biophys $f$. 1999:76:A365. 


\section{Journal Articles}

1. Volders PGA, Willems IEMG, Clewtens JPM, Arends JW, Havenith MG, Daemen MIAP. Interstitial collagen is increased in the non-infarcted human myocardium after myocardial infarction. J Mol Cell Cardiol 1993;25:1317-1323.

2. Volders PGA, Vork MM, Glatz JFC, Smirs JFM. Faty acid-binding proteinuria diag. noses myocardial infarction in the rat. Mol Cell Biochew. 1993; 123:185-190.

3. Bär FW, Volders PGA, Höppener P, Vermeer $\mathbb{E}$, Meyer J, Wellens HJ]. Development of ST-segment elevation and $\mathrm{Q}$ - and $\mathrm{R}$-weve changes in acure myocardial infarction and the infuence of thrombolytic therapy. Am/ Cardiol 1996;77:337-343.

4. Volders PGA, Kulcsár A, Vos MA, Sipido KR, Wellens H]J, Lazzana R, Szabo B. Similarities berween early and delayed afterdepolarizations induced by isoproterenol in canine ventricular myocytes. Condiowac Ros 1997,34:348-359.

5. Volders PGA, Sipido KR, Vos MA, Kulcsír A, Verduyn SC, Wellens HIJ Cellular basis of biventricular hypertrophy and arthychmogenesis in dogs with chronic complete acrioventricular block and acquired rorsade de pointes. Crovation. 1998;98:11361147 .

6. Volders PGA, Sipido KR, Carmeliet E, Spätjens RLHMG, Wellen HJ], Vos MA. Repolarizing $\mathrm{K}$ * currents $\mathrm{I}_{\mathrm{I} o \text { a }}$ and $\mathrm{I}_{\mathrm{K} \text { s }}$ are larger in right than left camine ventricular midmyocardium. Cinculation. 1999;99:206-210.

\section{Book Chapters}

1. Volders PGA, Sipido KR. Outward currents during depolarizing voltage-clamp steps in rabbit ventricular myocytes. In: Vereeke J, van Bogaert PP, Verdonck F, eds. Poths simm? Channels in Nomal and Pathological Condinons. Lenven: University Press: 1995:231-234.

\section{Letters to the Editor}

1. Volders PGA, Daemen MJAP. Interstitial fibrosis and angiotensin-converting enzyme inhibition in patienrs with end-stage myocardial infarction. I Am Coll Cardiol. 1998:32:552-553. 